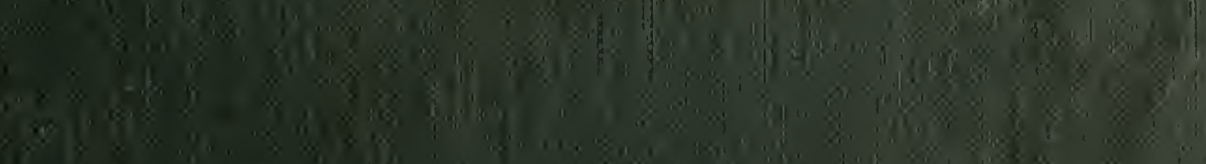

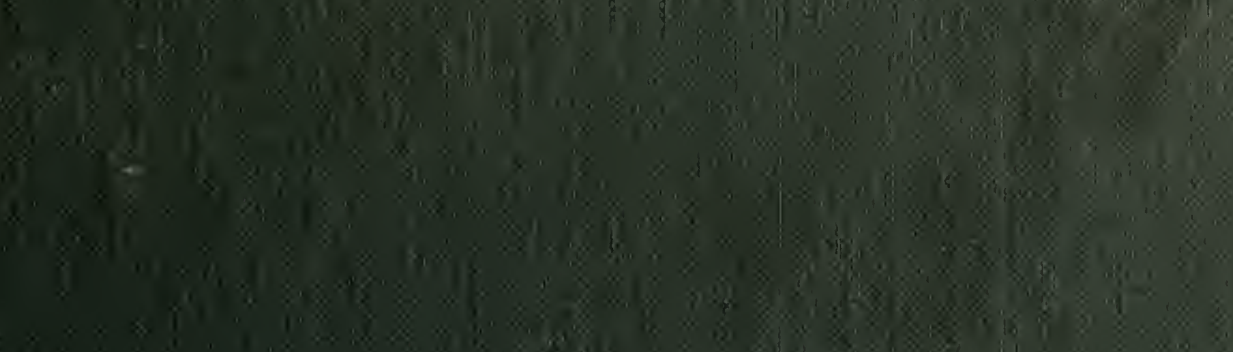

1

1.8<smiles></smiles>

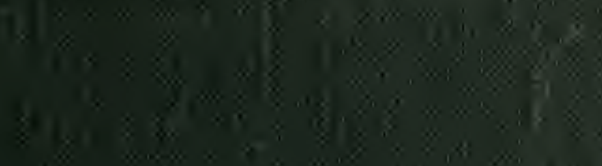

(ii)<smiles>C1CC([As]C2CC[As]2)C1</smiles>

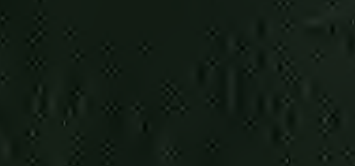

$(-9)$

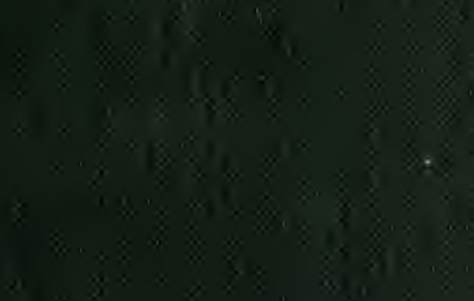

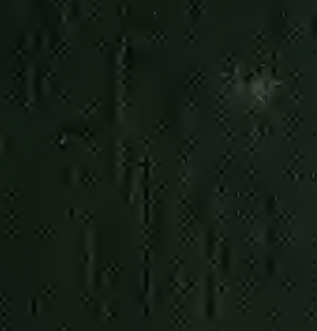

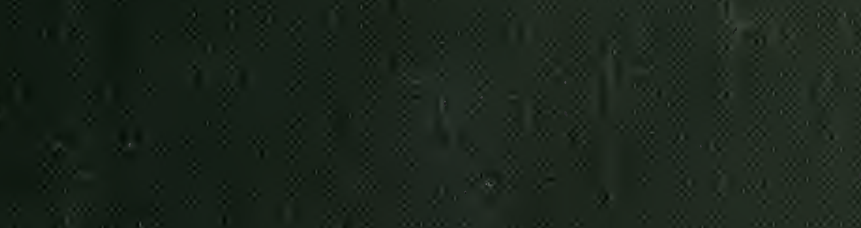




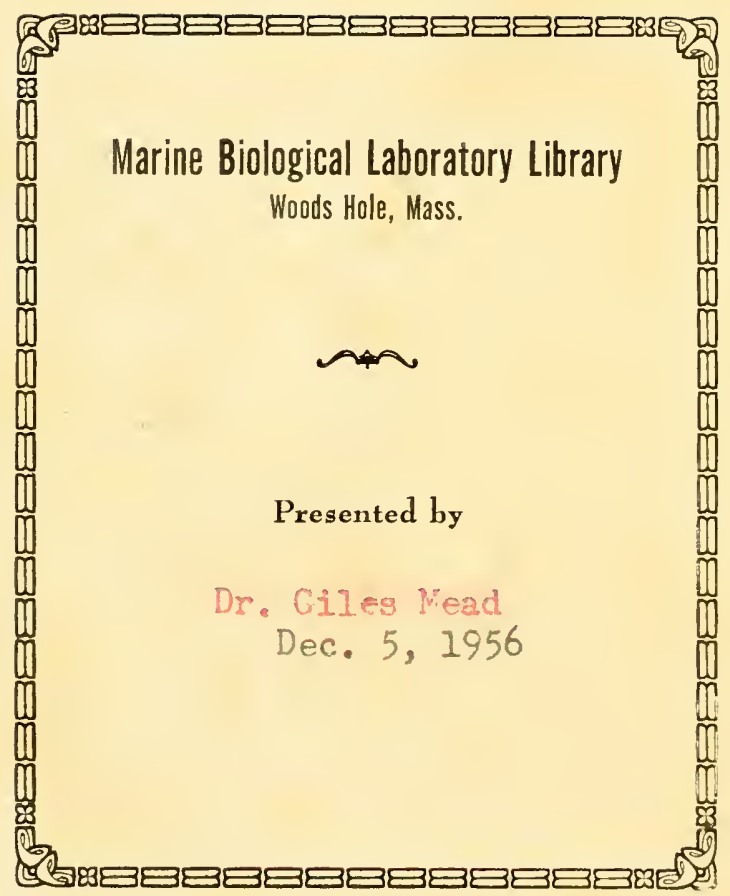



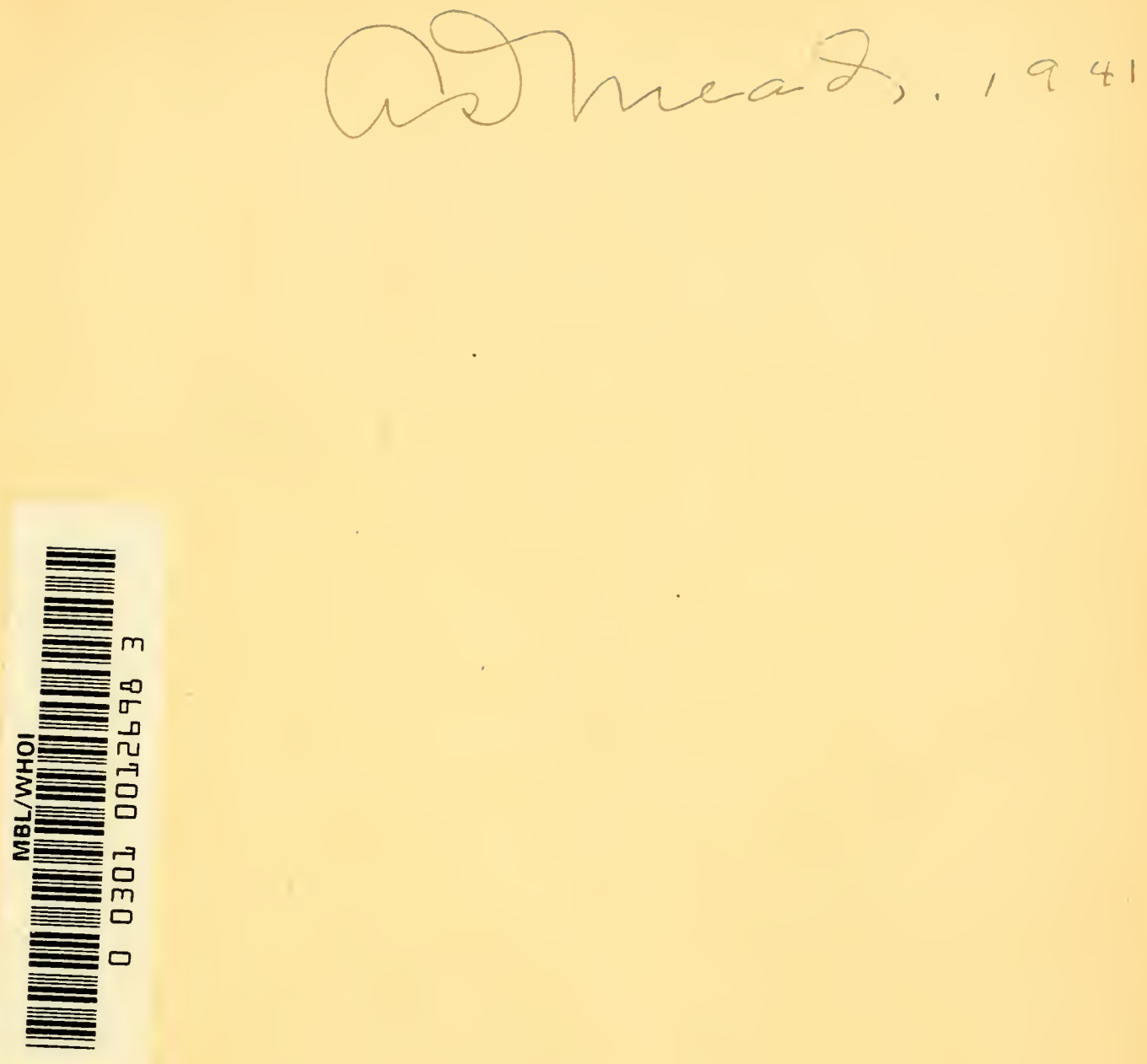



\title{
THE CELL AND PROTOPLASM
}

\author{
Publication of the American Association \\ for the Advancement of Science \\ No. 14
}

\author{
Publication Committee \\ C. V. TAYLOR, Chairman \\ Alva R. Davis \\ J. Murray Luck \\ C. B.' van NIEL \\ Albert Tyler
}

Edited by

Forest Ray Moulton

Published for the American Association for the Advancement of Science Smithsonian Institution Building, Washington, D. C., by

The Science Press 
Copyright, 1940 , by

THE AMERICAN ASSOCIATION FOR

THE ADVANCEMENT OF SCIENCE

THE SCIENCE PRESS PRINTING COMPANY LANCASTER, PENNSYLVANIA 


\section{FOREWORD}

This volume on The Cell and Protoplasm is the tenth symposium published by the American Association for the Advancement of Science in the three years that have elapsed since it began such publications in 1938. Like the earlier volumes in this series, this one is a systematic and authoritative treatment by eminent specialists of an important field of science.

In a sense the Cell Theory is not new, for the long history of its development includes dim foreshadowings by Greek naturalists of Aristotle's time and approaches to it by Robert Hooke in 1665, nearly two centuries in advance of the important papers of Schleiden and Schwann, in commemoration of the centennial of which this symposium was organized. In another sense the Cell Theory is always new, for every discovery respecting this primary and essential unit of living organisms, both plant and animal, has raised more questions than it has answered and has always widened the fields of inquiry.

The fact that there are many possible approaches to an understanding of the nature of the living cell is indicated by the variety of chief scientific interests of the seventeen contributors to this symposium. In biographical directories five of them are classed as zoologists, four as chemists, three as botanists, two as anatomists, and one each as a biologist, a geneticist and a biochemist. Specialists in seven fairly distinct branches of science have participated in a survey of what has been established regarding living cells and protoplasm, often indicating what is only probable or conjectural and sometimes pointing out what is quite unknown.

From the Table of Contents it will be found that this volume contains discussions of such various biological entities as cell walls, chromosomes, genes, viruses, enzymes, hormones and vitamins; and of such various questions of mutual relationships as nucleus and cytoplasm, chromosomes and genes, cell differentiation and external environment, cell differentiation and internal environment, and the cell and the organism. It will be found that there are reports on such various basic investigations as the bridge between the living and the lifeless, the biochemistry of micro-organisms, the physical and chemical properties of protoplasm and colloids, and the nature and mode of action of structural units in cellular physiology. Finally, illustrations will be found of the use of such technical means as the compound microscope and a discussion of the micromanipulation of living cells.

Previous symposia published by the Association were presented at its meetings. This one was held during five days immediately following the meeting of the Pacific Division at Stanford University in June, 1939. It was not, however, local in its organization nor participated in only by local scientists. Of the seventeen contributors, seven were from the Pacific Slope, one from the Middle West, six from the East and three from Europe. Thus to the variety of chief interests of the participants is added the wide diversity of their environment and immediate scientific associations.

It would be difficult to name a more important and interesting subject for a joint discussion by biologists, biochemists and chemists than that treated in this symposium, for protoplasm is the material basis of life and the cell is the fundamental unit involved in the vital processes of all the myriads of kinds of living organisms that inhabit the earth. The fact that this unit is common not only to all species of plants and animals but also to all their parts enormously multiplies the opportunities for investigating its properties and the modes of its functioning. Its universal presence implies its importance in all problems of growth, maturity and senescence, of health and disease, of heredity and variation.

As its name indicates, the primary purpose of the Association is to contribute to the advancement of science. It is fulfilling this purpose in various ways, one of which is by publishing the best of the symposia that are presented at its meetings. In making available in this volume a clear, comprehensive and documented summary of what is now known concerning living cells and protoplasm the Association makes a substantial contribution to progress in
biology.
F. R. Moulton 


\section{LIST OF CONTRIBUTORS}

Irving W. BaIley, M.F., Sc.D.

Professor of Plant Anatomy, Harvard University, Cambridge, Mass.

J. D. Bernal, M.A.

University Professor of Physics, Birkbeck College, University of London, London, England.

Robert Chambers, M.A., Ph.D.

Department of Biology, New York University, New York, N. Y.

C. M. Child, M.S., Ph.D., Sc.D.

Emeritus Professor of Zoology, The University of Chicago, Chicago, Ill.; Stanford University, Calif.

Edwin G. Conklin, A.M., Рн.D., Sc.D., LL.D.

Emeritus Professor of Biology, Princeton University, Princeton, N. J.; Executive Vice-president, American Philosophical Society, Philadelphia, Pa.

Richard B. Goldschmidt, Рh.D., M.D., Sc.D.

Professor of Zoology, University of California, Berkeley, Calif.

Ross G. Harrison, Ph.D., M.D., Sc.D.

Osborn Zoological Laboratory, Yale University, New Haven, Conn.; Chairman of the National Research Council, Washington, D. C.

L. V. Heilbrunn, Ph.D.

Associate Professor of Zoology, University of Pennsylvania, Philadelphia, $\mathrm{Pa}$.
H. S. Jennings, Sc.D., Ph.D., LL.D.

Professor Emeritus, Johns Hopkins University, Baltimore, Md.; Research Associate, Department of Zoology, University of California, Los Angeles, Calif.

Charles A. Kofoid, A.M., Ph.D., Sc.D., LL.D.

Emeritus Professor of Zoology, University of California, Berkeley, Calif.

O. L. Sponsler, A.M., PH.D.

Professor of Botany, University of California, Los Angeles, Calif.

W. M. Stanley, M.S., Ph.D., Sc.D.

Member, The Rockefeller Institute for Medical Research, Princeton, N. J.

Albert Szent-Györgyi, M.D., Ph.D.

Professor of Medical and Organic Chemistry, Department of Medical Chemistry, University of Szeged, Szeged, Hungary

C. V. Taylor, A.M., Ph.D.

Herzstein Professor of Biology, Stanford University, Calif.

\section{Hugo Theorell}

Director, Biochemical Division, The Nobel Institute for Medicine, Stockholm, Sweden

C. B. van Niel, Chem.E., D.Sc.

Professor of Microbiology, Hopkins Marine Station of Stanford University, Pacific Grove, Calif.

F. W. Went, M.S., Ph.D.

Professor of Plant Physiology, California Institute of Technology, Pasadena, Calif. 


\section{TABLE OF CONTENTS}

The Cell and Protoplasm. C. V. TAYLOR

Cell and Protoplasm Concepts : Historical Account. Edwin G. ConkLin

The Micromanipulation of Living. Cells. Robert Chambers

The Walls of Plant Cells. Irving W. BaIley

Chromosomes and Cytoplasm in Protozoa. H. S. Jennings

Chromosomes and Genes. Richard B. GoldschmidT

Cellular Differentiation and External Environment.

C. M. CHILD

Cellular Differentiation and Internal Environment. Ross G. HARRISON ...
Cell and Organism. Chardes A. KoFoID

The Biochemistry of Micro-organisms; an Approach to General and Comparative Biochemistry. C. B. VAN NieL

20 The Structure of Viruses. W. M STTANLEY 120

31 Structure and Function of Some Enzymes. Hugo TheorelL 136

44 Plant Hormones. F. W. WeNT 147

Vitamins. ALbert Szent-Györgi ......... 159

56 Molecular Structure in Protoplasm. O. L. SponsLer 166 67 Protoplasm and Colloids. L. V. HeILBRUnN 188

Structural Units in Cellular Physiol77 ogy. J. D. BERNAL 199 



\title{
THE CELL AND PROTOPLASM
}

\author{
By C. V. TAYLOR
}

SCHOOL OF BIOLOGICAL SCIENCES, STANFORD UNIVERSITY, CALIF.

THE sixteen papers comprised in this volume were presented in a Symposium on The Cell and Protoplasm at Stanford University, June 30-July 5, 1939. The oceasion commemorated the one hundred years of advancement in knowledge of the protoplasmic unit of living things after Schleiden and Schwann's formulation of the Cell Theory.

The participants were men of merited eminence, including several distinguished biologists whose names have been familiar in biological science for more than a quarter of a century, along with others whose more recent analyses of the cell and its constituents have greatly extended the confines of biological knowledge and have doubtless pointed the way for further studies of fundamental importance.

The first three papers have to do primarily with early and moderu concepts of the cell and protoplasm. The initial article by Professor Conklin on "An Historical Account of Cell and Protoplasm Concepts", reviews the results of investigations on the cell previous to the work of Schleiden and Schwann. The accurate descriptive accounts of these earlier investigators have evidently not been adequately recognized. Thus the degree of credit commonly accorded Schleiden and Schwamn appears to be unwarranted because their accounts were antedated many years by the published findings of various, even superior, workers beginning notably with Robert Hooke (1665). This well illustrates the social nature of scientific discovery and rightly emphasizes that the end results of the successive achievements of many minds may come to have rather exclusive, and so undue, recognition.

The second paper, by Professor Chambers, on "The Micromanipulation of Living Cells," helps to resolve our modern concepts of these living protoplasmic units to the essential nature and properties of their molecular constitution. As can be strikingly illustrated by motion pictures, the protein constituents of the protoplasm tend to retain their inherent state in the presence of an engulfed droplet of oil. Upon cytolysis, however, as induced through mechanical rupture of the nucleus or otherwise, a protein "skin" forms and becomes wrinkled around the droplet, much as also happens when such a droplet is added to a protein solution on a microscope slide. 'This unique behavior of the protein constituents of the protoplasm would seem to indicate a coherent property of proteins in the living cell which may be irreversibly changed if the characteristic structure of its protoplasm is disrupted.

Another modern aspect of the cell and protoplasm, gained chiefly from studies on protoplasmic elaborations, is presented in Professor Bailey's article on "'The Walls of Plant Cells." The structural pattern of the cellulose wall laid down by the protoplast evidently should offer invaluable clues to the nature and interaction of the protoplasmic constituents. Thus, the regularity of a specific pattern-whether concentric, radial, ramifying, or radiocentric -of a given cell wall would seem to reflect a predisposed regularity in the arrangements and orientations of constituents at the interface where the cell wall is derived. All evidence thus far indicates that the cellulose matrix of the cell walls of higher plants is a contimuons, rather than a discontinuous, system of anastomosed chainmolecules whose long axis is oriented parallel to the long axis of the cellulose fibril. They exhibit positive anisotropy and sharply defined extinction angles in monochromatic polarized light. At present, there is no reliable evidence that the struc- 
tural framework of the cell wall is ever composed of any randomly oriented chainmolecules.

Complementing these three papers on "The Cell and Protoplasm" are the two that follow on "The Cell and Chromosomes." The first of these is by Jennings on "Chromosomes and Cytoplasm in Protozoa" and the seeond by Goldsehmidt on "Genes and Chromosomes."

The well-known nuelear eycle that recurs with each cell division during the ontogeny of a multicellular organism is eited by Jenning's as crucial evidence of material exchanges between the nueleus and the eytoplasm. Aecordingly, eaeh condensed chromosome enlarges during the later phases of mitosis to beeome vesicular, from material taken up from the eytoplasm. Within the resulting eontiguous chromosome vesicles which constitute the reformed nucleus, the newly acquired cytoplasmie material is altered and, as sueh, is returned again to the surrounding cytoplasm upon the subsequent breakdown of the vesieular wall of each chromosome, whose residue again condenses for the following mitosis. These cyclic interchanges and transformations apparently provide the essential mechanisms of cellular differentiations both in the ontogeny of multicellular organisms and in the raeial variations of unicellular organisms. As illustrative of the latter, De Garis' recent results from crossing large and small raees of Paramecium are discussed. These results show that the ex-conjugants having unlike eytoplasms but like nuelei retain their size differences for about 22 generations, whereupon these differences gradually disappear. Evidently, therefore, the two different cytoplasms are finally transformed by the like nuclei so that the two races of unequal size come to have the same size.

By what mechanism of the nucleus the cyelic modifications, and so racial differences, may be effected is discussed in the suceeeding paper by Goldschmidt. His thesis tends to discount the commonly aceepted gene theory of Mendelian heredity and proposes instead a chromosome theory in which the oceurrence of genes as diserete entities, arranged bead-like in a definite order, need not be assumed. From the similarities in chromosome form and structure in the eells of all organisms, wherein a visible fibril-like core may represent a single protein unit of definite stoichiometric properties along its axis, it would be more in aceord with recent X-ray, chemical, and polarimetrie analyses to identify the chromosome as a chemical unit. Such a unit might show any amount of differential chemical complexity in different chain molecules of similar length. This coneept would aseribe to the chromosome a linear pattern and would account for mutational changes (the Bar-effect, mosaicism, position-effeet, ete.) as due to changes in the chromosomal pattern (inversions, transloeations, duplieation of parts, etc.) rather than to changes within diserete partieles, or genes, of molecular order.

The demonstrable interrelations between eytoplasm and nueleus which would aecount for differentiation in both the individual and the race obviously represent but one of the two major components in the fundamental phenomena of living things. The other essential component is, of course, the environment. The role of environmental factors is well exemplified in the three papers that follow on developmental aspects of the cell and its relation to the organism. These include "Cellular Differentiation and External Environment" by Child, "Cellular Differentiation and Internal Environment" by Harrison, and "Cell and Organism" by Kofoid.

The external environment of the primordial cell, aceording to Child, is a determining factor in its differentiation at the very onset of develcpment. The cell's primordial pattern is essentially a surface-interior pattern which reflects an intimate relationship with its enviromment. Also, by action of a suitable differential in its external enviromment, its polar or axiate differentiation is duly determined. Any one or more of various environmental differentials may induee this superimposed axiate pattern, as demonstrated in numerous experiments by Child and by others. Accordingly, the axiate pattern arises as a gradient which is 
initially quantitative in nature and which, once established, constitutes a gradient in rate of metabolic activity. Moreover, this environmentally induced axial or metabolic gradient then subtends the production and transfer of active constituents (chemical substances) in differentiating cells and so predetermines the course of later development.

Factors of differentiation in later stages of early development are discussed by Harrison as factors of the internal environment. These are illustrated especially from his extensive transplantation experiments on amphibian larvae. Here the developmental pattern, which has progressed well beyond the initial axiate stage of Child's account, has demonstrably a primary cellular locus (organizer) in the region of the dorsal lip of the blastopore, and later, various secondary loci, which determine organ differentiation throughout ensuing development. Depending upon the age of donor and of host as well as on the piece removed and its disposition where transplanted, the fate of the transplant and its effect upon the organogeny of the host are strikingly illustrated. From this it seems evident that the fate and effect of a developing part are functions of its relation to other parts. This fundamental relationship obviously marks the internal environment of cellular differentiation.

In the succeeding paper presented by Kofoid, it is emphasized, however, that even were the roles of both genetic and environmental factors of ontogenetic development well understood, that knowledge, essential as it must be, could constitute only part of any adequate understanding of the cell and organism. For the organism, beginning its individuality as a primordial cell, represents in its complete life history not only the ontogeny that follows its unicellular stage but also the phylogeny preceding that stage. And all organisms exhibit in this fundamental respect comparable life histories which may include, even for numerous so-called unicellular forms, a multicellular as well as a unicellular phase. Accordingly, it is only in terms of their total life history as an expression of their evolutionary, developmental, and environmental history that the cellular organization of living things can have basic significance and the results of fundamental investigations a satisfactory basis of interpretation.

The two papers that follow, one on "Chemical Aspects of Microorganisms" by van Niel, and the other on "The Structure of Viruses" by Stanley, mark a transition from consideration of the cell and protoplasm of the more conspicuously cellular organisms to a discussion of the subcellular bacteria and of those ultramicroscopic, reproducing entities, the viruses, whose systematic status, whether animate or inanimate, apparently remains a problem of great moment.

Recognizing Schwann's important contribution not only to the formulation of the Cell Theory but also to the concept of yeast cells as vital agents of alcoholic fermentation, van Niel recounts the later developments of that concept, beginning especially with Pasteur, which have now led to a distinctly basic and far-reaching generalization. This generalization affirms that all chemical activities of living organisms are fundamentally hydrogen transfer reactions. Postulated first by Wieland for respiration, as essentially a dehydrogenation of the respiratory substrate with oxygen or some other agent as the final hydrogen acceptor, this concept has become expanded by Kluyver and others to its present broadest generalization. Thus all enzyme activity in metabolic processes serves primarily to facilitiate hydrogen transfer reactions. And it now appears that in the catabolic process this leads to the formation of products from which the building stones of cell growth and differentiation are directly synthesized by means of thermodynamically spontaneous reactions. This comprehensive generalization re-emphasizes the processes common to living things as the fundamental processes, whose elucidation provides our point of departure for an adequate understanding of the more complex vital phenomena.

In this respect the succeeding discussion on the viruses by Stanley is distinctly of 
fundamental significance. It now appears that these entities represent a margin of animate nature beyond the limits of cellular organization as commonly understood, yet they exhibit properties of organic synthesis and reproduction characteristic of the living cell. Evidently their size relations alone are not definitive since they are larger than some well-known microbes but several times smaller than some protein molecules. Their apparently complete dependence on a living cell for their reproduction would place them among obligate parasites whose nutrient requirements are highly specific and, at present, beyond experimental duplication. Their essential nature, however, may have a counterpart in the chromosomal genes of the cell nucleus or in other known protoplasmic constituents such as the enzymes-a relationship which would obviously carry fundamental implications.

Some of the major advances in modern researches on the cell have had to do with its active protoplasmic constituents. Resumes of some recent results are presented in the three articles that follow on "Enzymes" by Theorell, on "Plant Hormones", by Went, and on "Vitamins" by SzentGyörgyi.

The common theme of these discussions demonstrates the essential relations between these several active constituents. The common role of enzymes in the formation or release of linkages within the carbon chain is referable initially to the prosthetic groups. And for a number of well-known enzymes, the ritamin nature of their active groups is now established. Thus, Theorell has isolated the prosthetic groups of the "yellow enzymes" from the protein component by means of electrophoresis and lias identified this active group with Vitamin $\mathbf{B}_{2}$. It is now known also that Vitamin $B_{1}$, including its pyrophosphate derivative, is identical with the prosthetic group of the enzyme carboxylase, and that the antipellagric vitamin is identical with the nicotinic acid amide which is the essential part of the prosthetic group of the dehydrogenases.

Enzyme specificity, however, is evidently not due to the prosthetic group but to its associated protein molecule, thus denoting a relationship between activating and reacting components of the cell which may come to account fundamentally for all biological specificity. According to Went, therefore, the more generalized activity of the growth hormones can be attributed to their identity with prosthetic groups. This was well illustrated by the multiple effects of auxin in cell elongation, bud inhibition, root formation, and probably other functions inside the plant. The initiation of these growth processes, or their inhibition, is traceable to the effect of diffusing or freemoving auxin on the translocation of other essential growth factors. But the specificity of this effect inheres in the co-growth factors of the reacting tissues. The production of these essential active groups by some cells, such as those of the growing tip of a coleoptile, and the transport of these groups to other cells of the plant, which through cellular differentiation have lost this producing capacity, afford an excellent illustration of the interdependence of cells and the functional integration of the various differentiated organs. These relationships obviously underlie a unity in the plant organism that is entirely comparable with that in the animal.

These considerations of enzymes and growth hormones clearly indicate the essential nature of the vitamins. As re-emphasized by Szent-Györgyi, a vitamin is to be identified with the prosthetic group of enzymes and it differs from a hormone, chiefly through the accident of nomenclature, according to the source of its production. Thus for rats or plants, ascorbic acid is not a vitamin since they themselves are able to synthesize it. In the same sense, thiamin is a vitamin for animals, a hormone in some plants, and a vitamin for other plants, depending only on their powers of synthesis. Obviously these relationships give further evidence of the fundamental unity in the plant and animal kingdoms, and in terms of the enzyme concept noted above, the vitamins constitute an important key to a better understanding of the essential nature of protoplasm and the cell. 
The three concluding papers effectively linked this Symposium with the National Colloid Symposium which directly followed. These include: "The Molecular Structure of Protoplasm" by Sponsler, "Protoplasm and Colloids" by Heilbrumn, and "Structural Units"' by Bernal.

The g'eneral concept of the living' cell as an organized protoplasmic unit, which is stressed in foregoing papers, evidently presupposes for its protoplasm a fundamental architecture, i.e., an integrated spatial arrangement of the protoplasmic constituents.

An analysis of this architecture is presented by Sponsler as based on the known molecular constitution of protoplasm and computed from fairly well-established dimensions of its protein chains and their linkages through hydrogen bouds. Assuming a degree of protoplasmic homogeneity, it is concluded that the protoplasm comprises parallel protein chains, of dimensions about $1000 \AA$ by $10 \AA$ by $4.5 \AA$, which are laterally united by water hydration centers, and which in turn compose a sponge-like framework intercalated with water containing the various solutes. From this elementary protoplasmic architecture is derived the fundamental patter'n of the primordial cell which, through developmental differentiation, gives rise to the tissue cells and organs of the adult organisin, as recounted in the earlier discussions.

The colloidal properties of protoplasm and its cellular differentiation are variously exemplified in the paper by Heilbrunn. His recent investigations have demonstrated especially a localization of calcium in the cortex of the cell which, upon appropriate stimulus, is released within and so effects a gelation of the pro- toplasm involving contraction. Further evidences of this gelating effect were found upon exposing cut surfaces of cells to various concentrations of calcium salts. Thereupon a reversible limiting membrane was formed on the cut surface, or a bulb-like contraction was locally induced, due to the penetrated calcium. Thus the age-old problem of contractility, a common property of protoplasm, may find its solution normally in the localization and release of calcium in the cell's cortex.

Recalling the emphasis given throughont the Symposium to the structural aspects of protoplasm, Bernal in the final paper urges that consideration of the energy relations is equally important since not only do the energies involved determine the sort of structure possible, but also their nature must be known in order to account for that structure. These energies relate primarily to the protein constituents of the protoplasm, a model for which may be found in the tobacco mosaic virus when contained in known salt solutions. Here the virus entities, which are long protein molecules, become oriented in striking spindle-like patterns, or tactoids, and their regular distances apart vary directly with the concentration of the salt solution. Evidently long-range forces between the virus entities are operative through the ionic atmosphere of the surrounding medium with which the former are in equilibrium. The magnitude and direction of forces inside the tactoid pattern are different from those on the outside. These differences, in fact, acconnt for the pattern formation. Apparently analogous forces may similarly account for the formation of the mitotic figure and the ensuing phenomena during the mitosis of the living cell. 


\title{
CELL AND PROTOPLASM CONCEPTS: HISTORICAL ACCOUNT
}

\author{
By EDWIN G. CONKLIN
}

DEPARTMENT OF BIOLOGY, PRINCETON UNIVERSITY, PRINCETON, N. J.

\section{INTRODUCTION}

IN preparing this historical account of the cell and protoplasm concepts I have had occasion to note how much less interesting such work is, based as it must be on the publications of others, than that which is first-hand observation. Indeed the latter is so much more agreeable that I suspect all historians must be tempted to mix their own thoughts and fancies with the actual records which they consult. The burden of looking up literature is one of the unpleasant features of modern research, and I quite sympathize with Jacques Loeb who used to say that he had no time or inclination for it. Some one lias said that the ancient Greeks werc able to accomplish so much because they had no ancient languages and literatures to master.

I suspect I was selected to give this historical review because I am probably the oldest living cytologist in America, now that our beloved master and foremost student of the cell, Professor Edmund B. Wilson, has passed away. But in spite of my age, which may seem venerable to some of you, I was not in at the birth of the cell theory and I have had to rely largely on literature in preparing the earlier part of this address. That portion of it which concerns the last half century falls within my own period of research work and with this account I have mingled some of my own observations, thoughts and fancies. Some of the earlier portions of this review repeat in part a paper entitled "Predecessors of Schleiden and Schwann" (1939) which I gave in a symposium on the centenary of the cell theory at the Richmond, Virginia, mecting of the American Association for the Advancement of Science on Deccmber 27, 1938.

In the history of science, no less than in that of the material universe, it is difficult if not impossible to find the real beginning of anything, for every event is the result of many preceding ones. In short there is no creation de novo in either the material or the intellectual universe. In an interesting article in the Scientific Monthly for December 1937 entitled "Who Invented It?" S. C. Gilfillan lists the numerous reputed inventors of the telegraph, the friction match, the barometer, the telephone, the airplane, steam boat, wireless and many other modern inventions, and as to the ancient inventors of the wheel, the pulley, the boat, the sail, history is silent. And yet in each and all of these inventions we may be sure that there were many cooperators. The fact is that all discovery and all science are social phenomena and their progress is possible only by the conscious or unconscious cooperation of many minds.

But it is difficult for human beings to keep in mind a multitude of persons or a multiplicity of causes. Consequently, even in science we find discoveries attributed to some one person, or phenomena ascribed to some one cause, whereas a more accurate account would recognize that they are the results of many persons and many causes. This difficulty of keeping in mind the many, joined with a common human tendency to make and worship heroes, leads to a great deal of historic error and injustice. We pick out some one per'son as the discoverer or inventor or leader or soldier and build monuments to him, forgetting all his collaborators; we concentrate our devotions on the tomb of one unknown soldier, rather than on the armies of the fallenwe celebrate anniversarics of births, decades of science, jubilees of men and institutions, ccnturies of progress, millennia of world history, as if these periods were independent of all others. We pick out some 
event of 1839 and celebrate its centenary in 1939, as if it had no antecedents-as if it were a creation rather than an evolution.

These remarks apply with especial force to the origin of the cell theory. This symposium was designed in part to celebrate the centenary of the cell theory of Schleiden and Schwann, but the cell theory in all its fundamental features is older than either Schleiden or Schwann. Their cell theory was a special and, in important respects, an erroneous one. Since there is no present biological interest in their particular theory, it is amazing that we still continue to call the great conception that the cell is the universal unit of organic structure and function after them, as if they were its sole discoverers, thus embalming the names of two scientists, distinguished for other discoveries, with one of their most serious blunders.

Greek philosophers and naturalists, and especially Aristotle, are said to have reached the conclusion "that animals and plants, complex as they may appear, are yet composed of comparatively few elementary parts frequently repeated" (Locy 1908). But there is no doubt that these elementary parts were the roots, stems, nodes and internodes, the leaves and flowers of plants and the segments, organs and other parts of animals that were visible to the unaided eye. The discovery of the fundamental elementary parts, the cells, was not possible before the invention of magnifying lenses. It is probable that the use of simple lenses was known to the ancients. Pliny the Elder says that crystal globes filled with water were used as burning glasses. Seneca remarks that small letters are enlarged when seen through such glass globes. Nero, who was near-sighted, is said to have used a large emerald as a distance glass. Coming to more recent times, spectacles for far or near sight were invented by d'Armato of Florence about 1300. Roger Bacon is said to have invented biconvex reading glasses in 1270 , but apparently his invention remained unknown to the world for nearly 500 years. It has also been claimed that he invented the compound microscope, but if this be true it also remained unknown until William Romaine Newbold deciphered the Voynich manuscript (1921).

The invention of the compound microscope is generally attributed to Hans and Zacharias Jaussen, father and son, grinders of spectacles in Middleburg, Netherlands, between 1590 and 1609. In 1610 Galileo made a microscope which he called Occhiale, "that made a fly look as big as a hen" ; and, as is well known, he also invented the telescope. The names microscope and telescope originated with Giovanni Faber of the Academia de Lincei about 1625 (Carpenter 1891).

\section{Oriain and Development of the Cell THEORY}

Cells were first seen, named, described and figured by Robert Hooke ${ }^{1}$ (1635-1703), an English scientist and architect, 170 years before the work of Schleiden and Schwann. Hooke had been a student at Christ Church, Oxford, and assistant to Robert Boyle, author of "The Sceptical Chymist," 1661. In the year that the Royal Society received its charter, 1662, he was appointed curator of experiments and his duty was to furnish the Society at their weekly meetings with three or four considerable experiments. This he did satisfactorily for forty years in spite of the fact that most of the instruments for experiments had to be made by himself. His experiments covered the whole range of the science of that time and led to a great

1 Hooke was a man of amazing versatility, one of the best mechanics and inventors of his age, a good mathematician and physicist and for thirtyeight years professor of geometry in Gresham College. After the great fire of London in 1666 he drew plans for the reconstruction of the burned over area which were approved by the Royal Society and the Common Council of London. He was appointed surveyor of the City and was responsible for widening the streets, and the building of the Monument, Bedlam Hospital, Montague House, College of Physicians et al. "His active, jealous mind conceived that almost every discovery of his time had been initiated by himself and this anxiety to claim priority induced Newton to suppress his treatise on optics until after Hooke's death in 1703." (A. E. Shipley in Cambridge History of English Literature, vol. 14, 1916.) 
many discoveries of a fundamental nature. Unfortunately the very abundance of his experiments precluded a proper publication of them. His experiments and discussions at the meetings of the Royal Society kept it alive and active during its formative period, and "it is scarcely an exaggeration to say that he was, historically, the Creator of the Royal Society" (Robinson 1935).

In 1665, Hooke published a remarkable book entitled "Micrographia or Some Physiological Descriptions of Minute Bodies made by Magnifying Glasses.' Using a compound microscope of excellent form which he had made himself, he described and figured sixty different types of microscopical objects. The section of the book of especial interest to us is entitled "Observ. XVIII. Of the Schematisme or Texture of Cork, and of the Cells and Pores of some other such frothy Bodies," which begins thus: "I took a good clear piece of cork and with a penknife sharpened as keen as a razor, I cut a piece of it off, and thereby left the surface of it exceedingly smooth, then examining it very diligently with a Microscope, methought I could perceive it to appear a little porous." Further study of thin sections showed that it was "all perforated and porous, much like a honeycombe ... in that these pores, or cells, were not very deep, but consisted of a great many little boxes, separated out of one continued long pore by certain diaphragms." That he realized the importance of this observation is shown by the following: "I no sooner discerned these (which were indeed the first microscopical pores I ever saw, and perhaps, that were ever seen, for I had not met with any writer or person that had made any mention of them before this) but methought I liad with the discovery of them presently hinted to me the true and intelligible reason of all the phenomena of cork" (i.e., its lightness, imperviousness and compressibility). Of course he knew nothing of the way in which these cells were formed nor of the substance which had filled them in life, though he says of the cells of other plants, "In sev- eral of those vegetables, whilst green, I have with my microscope plainly enough discovered these cells or pores filled with juices." Hooke counted three score of these cells of cork placed end ways in the eighteenth part of an inch and he calculated that there were $1,166,400$ in a square inch, or "above 12 hundred million in a cubic inch, a thing almost incredible." He showed that this cellular structure was not peculiar to cork for he subsequently found it in many other plant tissues.

Nehemiah Grew (1628-1711), English botanist and Secretary of the Royal Society (1677-1679), published numerous treatises on vegetable structures and functions. In his "Anatomy of Plants," published in 1672, he slowed that the parenchyma of plants is composed of vesicles or closed spaces in a homogeneous ground mass. In 1675 and again in 1679, Marcello Malpighi (1628-1694), an Italian anatomist, pliysiologist and physician, published two folio volumes which justify his being called "creator of scientific botany." He distinguished different plant tissues and called the cells of the parenchyma "utricles." His figures also indicated that even plant vessels are composed of series of utricles joined end to end.

The Dutch microscopist, Antony van Leeuwenhoek (1632-1723), was one of the most colorful and indefatigable students of microscopical objects during the late 17 th and early 18th centuries. He used only simple lenses and it is amazing what he could see with them. In 1673 he sent his first paper to the Royal Society, and from that year until his death in 1723 the Roval Society received 375 letters and papers from him, while 27 more were sent to the French Academy of Sciences. In addition to his studies on numerous protozoa and protophyta and on the microscopic anatomy of plants and animals, he discovered bacteria and spermatozoa and with his simple lenses he thought he saw in the human spermatozoon the homunculus, or little man, postulated by the preformationists.

During the next hundred years several botanists and anatomists saw and figured the utricles or vesicles in plants and ani- 
mals. The most notable of these was Caspar Frederich Wolff (1733-1794). His thesis for the M.D. degree, published in 1759 when he was only 26 years old, was entitled Theoria Generationis and it marks an epoch in the study of the development of plants and animals. Wolff showed that in their development animals and plants are composed of "globules or utricles which may always be distinguished under a microscope of moderate magnification." He supposed that utricles arise as vacuoles in a homogeneous jelly. According to von Sachs, his was the most important work of the period between Grew, 1672, and Mirbel, 1808. "It was Wolff's doctrine of the formation of cellular structures in plants which was adopted in the main, by Mirbel" (v. Sachs, History of Botany).

For more than one hundred year's the words "utricles," "vesicles" or "globules" were used to designate these constituent parts of animals and plants, and only in the begimning of the 19th century did Hooke's term "cell" again come into use. In 1808 and 1809, Brisseau de Mirbel (1776-1854), professor of botany in the Musée d'Historie Naturelle in Paris, published a notable work on his theory of plant organization ("Théorie de l'organization végétale"). The general conclusions of this work were that "the plant is wholly formed of a continuous cellular membranous tissue." In a set of "Aphorisms" that he had prepared to accompany a large plate illustrating the finer structure of plants he wrote, "Plants are made up of cells, all parts of which are in continuity and form one and the same membranous tissue." It is apparent from this that while Mirbel recognized the miversal presence of cells in plants, he also regarded them as bound together in a membranous tissue.

Professor John H. Gerould (1922), in an important paper entitled "The Dawn of the Cell Theory," has shown that the great French naturalist, Lamarek (1744-1829), deserves to rank as one of the founders of the cell theory. In his Philosophie Zoologique published in 1809 he says: "No body can possess life if its containing parts are not a cellular tissue, or formed by cellular tissue." Again :

Thus every living body is essentially a mass of cellular tissue in which more or less complex fluids move more or less rapidly; so that if this body is very simple, that is without special organs, it appears homogeneous and presents nothing but cellular tissue containing fluids which move within it slowly; but if its organization is complex all its organs without exception, as well as their most minute parts, are enveloped in cellular tissue, and even are essentially formed of it.

In the second volume of his great work Lamarck devotes an entire chapter to cellular tissues, in which he says:

It has been recognized for a long time that the membranes that form the envelopes of the brain, of nerves, of ressels of all kinds, of glands, of viscera, of museles and their fibers, and even the skin of the body are in general the productions of cellular tissue. However, it does not appear that anyone has seen in this multitude of harmonizing facts anything but the facts themselves; and no one, so far as I know, has yet perceived that cellular tissue is the general matrix of all organization, and that without this tissue no living body would be able to exist nor could have been formed. Since the year $1796 \mathrm{I}$ have been accustomed to set forth these principles in the first lessons of my course.

Everywhere Lamarck speaks of cellular tissue and apparently neither he nor Mirbel thought of the cell as an independent unit. This idea was more clearly expressed in 1824 by Dutrochet, a French physiologist and physicist, in the following words:

All the organic tissues of animals are actually globular cells of exceeding smallness, which appear to be united only by a simple adhesive force; thus all tissues, all animal organs, are actually only a cellular tissue variously modified. This uniformity of finer strueture proves that organs actually differ among themselves merely in the nature of the substances contained in the vesicular cells, of which they are entirely composed.

Another French naturalist who seems to have escaped recent notice was J. P. F. Turpin (1775-1810), who published in 1826 a remarkable memoir with a title so complete that it forms an abstract of the contents :

Organographie microscopique élémentaire et comparée des végétaux. Observations sur l'origine et la formation primitive du tissue cellulaire, sur chacune des vésicules composantes de ce tissu, considérées comme autant d'individualités distinctes ayant leur centre vital particulier de végétation et 
de propagation, et destinées à former par agglomération l'individualité composée de tous les végétaux dont l'organization de la masse comiporte plus d'une vésicule.

Here is clearly expressed the fact that plant tissues are composed of cells, that these cells are distinct individualities having their own vital center of vegetation and propagation and destined to form by agglomeration the composite individuality of all those plants whose organization is composed of more than one cell-and all of this twelve years before the publication of "the epoch-making theory of Schleiden and Schwann."

In 1830, eight years before Schleiden's Beiträge, the German botanist, Meyen (1804-1840), in his Phytotomie wrote:

Plant cells appear either singly so that each one forms a single individual, as in some algae and fungi, or they are united together in greater or smaller masses, to constitute a more highly organized plant. Even in this case each cell forms an independent isolated whole; it nourishes itself, builds itself up, and elaborates raw nutrient materials, which it takes up, into very different substances and structures.

He even spoke of such cells as "little plants inside larger ones." Meyen also described the circulating movement of cell contents which had previously been observed by Corti in 1774 and by Treviranus in 1811. In his three-volume work on Pflanzen-physiologie, published in 1837, Meyen described cells as the "essential elementary organs of assimilation and construction."

Hugo von Mohl (1805-1872) is one of the most important figures in the early development of the cell theory. Like so many of his contemporary biologists, he was a doctor of medicine, a physiologist, and a botanist, but his cell studies were chiefly on plants. In 1831, seven years before Schleiden, he announced that the cell is the individual elementary unit of structure in plants and that vessels and secreting tubes are formed by end-to-end union of elongated cells. His subsequent work on cell division and on protoplasm is particularly important and will be referred to later.

The English botanist, Robert Brown
(1773-1858), in 1831, discovered that clear round bodies, which he called "areolae" or "nuclei," are present very generally in plant cells. He called attention to the fact that nuclei had previously been seen and figured in cells by Meyen, Purkinje, Brogniart, Braur, et al., but they had been regarded as unimportant. Brown recognized nuclei as important organs of the cell and his work marks a major stage in the development of the cell theory. This discovery is the more remarkable in that Brown worked only with simple lenses and without the aid of stains. About the same time that Brown discovered and named the nucleus, others, particularly Mirbel, saw it in other objects. In 1836 Valentin (18101883) observed it in the epithelial cells of the conjunctiva and found a round corpuscle within it which he called the "nucleolus, a kind of second nucleus within the nucleus."

Cell division had been seen in filamentous algae by Turpin in 1826 and by Dumortier in 1832. In 1835 Hugo von Mohl described very exactly the manner of division of the cells of the filamentous alga, Cladophora; he found that a circular constriction appears around the middle of the cell and this gradually deepens to form division walls by which the cell is divided into two daughter cells. Four years later he figured and described the division of spore mother cells in the scale moss, Anthosceros, some of his figures (1839, Figs. 21-23) suggesting that he had seen mitosis. Meyen in his Neues Systems der Pflanzen-physiologie, published in 1838, said that cell division is everywhere easily and plainly seen in Confervae, Chara, mycelia, and also in terminal buds and root tips of $\mathrm{Ph}$ anerogams.

All of this significant work on cells preceded the famous publication one hundred years ago by Matthias Schleiden (18041881), Professor of Botany at Jena, entitled Beiträge zur Phytogenesis, which is generally credited with being the origin of the cell theory. There is no doubt that Schleiden was a stimulating figure and that his polemics attracted more attention than the modest research of some of his predecessors, but so far from his being the 
founder of the cell theory it can be truly said that his contributions to this great theory were inferior to those of many of his predecessors. It is one of the amazing facts of scientific history that in many biological textbooks Schleiden is called the founder of the cell theory, as if he had first discovered that all tissues of plants are composed of cells, or that the cell is the universal unit of organic function as well as of structure. His own particular contribution was in his opinion the discovery of the way in which new cells arise, and yet this has been known for a hundred years to be not only fundamentally wrong but even fantastic. It is still supposed by some biologists that he first set forth the conclusion that the cell leads an independent life. In the beginning of his famous Beiträge he says :

Each cell leads a double life: an independent one pertaining to its own development alone, and another incidental in so far as it has become an integral part of a plant. It is, however, apparent that the vital process of the individual cell must form the very first, absolutely indispensable basis of vegetable physiology and comparative physiology. (English translation, The Sydenham Society, 1847.)

But thirty years earlier Mirbel had expressed this thought and twelve years before Turpin had stated it with great clarity, while eight years earlier it had been set forth by the famous German botanist, Meyen, in a still clearer and more accurate manner.

It was the method of origin of new cells which Schleiden regarded as his most important contribution. In his Grundzüge der wissenschaftichen Botanik, translated by Ray Lankester and published by the Sydenham Society in 1849, he says (p. 31):

Only in a fluid (cytoblastema) containing sugar, dextrine and mucus (protein) can cells be formed. The particles of mucus are drawn together into a cell kernel (cytoblastus) into which penetrates external fluid so that the eytoblast is attached on one side and free on the other.

And again he says (p. 102):

Filial cells (blastidia) are formed within mother cells (matrix).... The process of the reproduction of eells by the formation of new cells in their interior is a general law in the vegetable kingdom and is the foundation of the production of celltissue.

So far as the genesis of new cells is concerned, Schleiden's fantastic views, as expressed, in 1838, in his Beiträge, that granules (nucleoli) within cells become eytoblasts (nuclei) and that on one side of these a membrane arises "like a watch crystal on a watch" to form new cells within the old ones-all this could be charitably set down to that liability to error which we all experience if it were not for the fact that he is so lacking in charity toward his predecessors, some of whom happened to be right where he was wrong. For example, he says :

Sprengel's pretended primitive cells have long since been shown to be solid granules of amylum. To enter upon Raspail's work appears to me incompatible with the dignity of science. Mirbel does not make any allusion to the process of cell formation.

After describing von Mohl's account of the origin of new cells by the process of division, Schleiden says :

After Mohl, Meyen has been the principal advocate of this view, believing that he has in numerous instances recognized this process of spontaneous scission and regarding it as almost a general law in plants. In most of the cases adduced by him the fact has simply been invented, not observed. In the instance in which he refers to direct observation on the origin of four pollen cells in the matrix the fact is exactly the reverse. Unger also has again propounded the multiplication of cells by scission as a general law in plants (1840) but with as little truth as Meyen. (Sydenham Society translation, p. 104.)

Of much of Meyen's great work he says, "I still have many doubts, the solution of which I had hoped to have found in his Physiology but hoped in vain." He either underestimated or ignored all the careful work which had been done by previous students of cells showing that cells arise by division.

On the whole one gets a very unpleasant picture of Schleiden's relations to his predecessors and contemporaries, and the question forces itself upon us, how did he come to be recognized as the founder of the cell theory? I once heard a distinguished physiologist say pessimistically 
that there are two ways to gain recognition, either brag or fight. It seems to me that Schleiden did both.

It appears from many accounts that he loved a fight and it is certain that he had plenty of them. Some of his observations and generalizations were absurdly wrong and he was unsparing in his criticisms of those who criticized them. For example, in $\mathbf{1 8 3 9}$ he proclaimed that the embryo plant forms in the pollen tube which is therefore female and that the ovule is really the male element. In his textbook, Grundzüge der wissenschaftlichen Botanit, it is said that he was so vehement in his criticisms and poured forth such a flood of botanical satire and personal antipathies that the book was considered libelous in France. (Matthias Schleiden, Pop. Sci. Monthly, Dec., 1882.)

\section{Karl Müller said of him :}

He has given us in his works a diversified mixture of philosophical prepossessions, jejune observations and fanciful descriptions. Nevertheless, despite his peculiar weaknesses, his followers recognize him as a reformer in botany, and allot him a permanent and eminent place in the history of that science.

Nevertheless it is still a mystery how it has happened that he occupies so high a place in the annals of science since his cell theory had no great significance for botany; it met with immediate and open opposition by all those who had championed cell division as the method of cell genesis, and especially by Meyen who, in 1839, stoutly maintained that cells arise by self-division.

Julius von Sachs, in his celebrated History of Botany, says of Schleiden and his work (p. 188):

Endowed with too great love of combat, and armed with a pen regardless of the wounds it inflicted, ready to strike at any moment, and very prone to exaggeration, Sehleiden was just the man needed in the state in which botany then was. His first appearance on the scene was greeted with joy by the most eminent among tliose who afterwards, contributed to the real advance of the science, though their paths it is true diverged considerably at a later period, when the time of reconstruction was come. If we were to estimate Sehleiden's merit only by the facts which he discovered, we should scarcely place him above the level of ordinarily good botanists; we should have to reckon up a list of good monographs, numerous refutations of ancient errors and the like; the most important of the theories which he proposed, and over which vigorous war was waged among botanists during many years, have long since been set aside. His true historical importance has been already inti- mated; his great merit as a botanist is due not to what he did as an original investigator, but to the impulse be gave to investigation, to the aim and object he set up for himself and others, and opposed in its greatness to the petty character of the text-books. He smoothed the way for those who could and would do great service.

Again, after sketching the earlier work on the cell theory, von Sachs says:

Schleiden's behavior was different. After having somewhat hastily observed the free cell formation in the embryo sac of phanerogams in 1838, he proceeded at once to frame a theory upon it which was to apply to all cases of cell formation, and especially to that in growing organs. The very positive way in which he announced this theory and set aside every objection which was made to it combined with his great reputation at the time, at once procured for it the consideration of botanists generally. (p. 311.)

Schleiden's theory of cell formation arose out of a curious mixing together of obscure observations and preconceived opinions . . . did not rest on any thorough course of observation. (p. 323.)

We make acquaintance with Schleiden's theory of cell-formation in its original form, if we turn to his treatise, "Beiträge zur Phytogenesis", (1838). The work begins with some remarks on the general and fundamental laws of human reason, etc., discusses the literature of cell-formation in a few lines without mentioning von Mohl's numerous observation, goes on to mention the general occurrence of the nucleus ... then occupies itself with gum, sugar and starch, and at last comes to the main subject. (p. 323.)

Then follows his erroneous description of new cell formation and the contradictions which it aroused by Unger, von Mohl and finally Nägeli.

The first result was that Schleiden found himself obliged to accept the cell-division established by Nägeli in algae and the motlier cells of pollen as a second kind of cell-formation; thus began the movement in retreat which, in 1846, ended with the overthrow of Schleiden's theory. ${ }^{3}$

\footnotetext{
3 Discussion of his erroneous theories raged for twenty years and then they were abandoned and forgotten. Schleiden, discouraged, withdrew from botany and turned to anthropology for a brief period and then to retirement where he wrote popular articles on the three kingdoms of nature, on materialism in German philosophy, "The signifieance of the jews in the conservation and revival of science in the middle Ages," and "The Romance of the Jewish Martyrology of the middle Ages." He died in Frankfurt in 1881. (Pop. Sci. Monthly, Dec., 1882.)
} 
Theodore Schwann (1810-1882), the associate of Johamnes Müller at Würzburg and Berlin and later Professor of Anatomy at Louvain and Liège, took over the erroneous views of Schleiden as to cell genesis and proceeded to apply these to animal cells. Lamarck (1809), Dutrochet (1824), Turpin (1826), Henle (1838), Purkinje (1833) and Valentin (1836) had observed and described animal cells and compared them with plant cells, but only Dutrochet before Schwann had taught that all the many kinds of animal tissues are everywhere derived from cells which are the elementary type of organism. Schwann held that all the different kinds of cells are morphologically related beause they all arise by the same process, namely, as he mistakenly supposed, from granules (nucleoli) which become nuclei and which in turn give rise to the cell body. Unlike Schleiden, he heid that this genesis could take place in a formless ground substance, the "cytoblastem," in spaces between cells, as well as within mother cells "by a kind of crystallization in a mother liquor." These erroneous views persisted in botany for a long time under the caption of "free cell formation." Fifty years ago I heard this idea presented in lectures on g'eneral biology.

The extra-cellular formation of cells was opposed by many botanists and zoologists soon after its proposal by Schwann. ${ }^{4}$ Remak held that such a mode of origin of cells was as improbable as generatio aequivoca of organisms and he proved in the case of many animal tissues that new cells arise only by division of preceding cells. In 1852 , he extended this conclusion to pathological tissues and tumors. Finally Vir-

4 Schwann's more enduring work was in physiology rather than cell-studies. He made valuable contributions on gastric digestion (he first named pepsin) and on the function of gall. His study of the anatomy of nerve fibers is still recognized in the "sheath of Schwann," and his work on the contractility of arteries and on muscular contractility in general are worthy of mention. He furnished evidence against the occurrence of spontaneous generation and in favor of the bacterial cause of putrefaction; also that alcoholic fermentation is caused by yeast, all of this some twenty years before Pasteur's work on these subjects. chow (1859) is given the eredit of forever disposing of Schwann's hypothesis of free cell formation, summing up this conclusion in his dictum, "Omnis cellula e cellula."

Schwann was the first to undertake a comprehensive investigation of the general tissues of the animal body and their development out of cells. He first used the term "cell theory" for this conception:

The development of the proposition that there exists one general priuciple for the formation of all organic productions, and that this principle is the formation of cells, as well as the conclusions which may be drawn from this proposition, may be comprised under the term Cell Theory. (Sydenham Society translation, p. 166.)

The work of Schwann formed the basis of the theory of the "cell state," which maintained that "cells are organisms and that entire animals and plants are agroregates of these organisms arranged according to definite laws." This theory had a long life and is still probably true in part, but in its extreme form its inadequacies were pointed out, in 1893, by Whitman and by many experimental embryologists who have called attention to the fact that both in structure and function "the organism as a whole," is more than the sum of its cells and that organization precedes cell formation and is not its product.

In view of the fact that all discoveries are based upon previous ones and that science is possible only by such cooperation, I suggest that it would be more accurate, as well as more becoming, to strike out of our literature these personal possession tags attached to important discoveries in which many persons have participated. And in the case of the great generalization that the bodies of animals and plants are composed of cells and that these have all come by division from preceding cells, it is absurd to still speak of this as "the cell theory of Schleiden and Schwann."

\section{Origin and Development of the Protoplasir Concept}

In its beginning the cell theory paid little attention to the cell contents and attributed chief importance to the cell walls; the cell 
space or chamber was regarded as the essential feature. Many of the early students of cells recognized that they contained or were embedded in a semi-fluid or gelatinous substance. Wolff, in 1759, said:

Every organ is composed at first of a little mass of elear, viscous, nutritive fluid, which possesses no organizatiou of any kind but is at most eomposed of globules. In this semi-fluid mass cavities are developed; these, if they remain round or polygonal, become utricles (cells); if they elongate, vessels.

\section{In 1809, Oken wrote:}

Organic nature has for its basis an infinity of small vesicles. These little bladders arise from original, semi-fluid globules of "Urschleim."'5

Many botanists of that period, including Schleiden, described the cell contents as "plant slime," "mucus," or "mucilage" ; Mirbel called it "cambium"; Nägeli, in 1844 , considered it a mixture of gum, sugar and proteid.

In 1835, Felix Dujardin (1801-1860) proposed the name "Sarcode" for the semifluid material of the bodies of Foramenifera, which other observers of Protozoa had called "living jelly." Dujardin described Sarcode as a "substance glutinous, perfectly homogeneous, elastic, contractile, diaphanous, without any trace of organization, fibers, membranes, or appearance of cellulosity."

In 1840, Purkinje (1787-1869) used the name "protoplasm" to designate the formative material of embryos of animals, and, in 1846, von Mohl applied this word to the living substance in the embryonic cells of plants. From this supposedly primordial and undifferentiated protoplasm of embryonic cells he derived the thin pellicle of protoplasm which lines the cell membrane and surrounds the cell sap in adult plant cells; this layer he called the "primordial utricle," a name which has persisted in botany until the present.

The streaming of protoplasm which was first seen and deseribed in plant cells, in 1772, by Bonaventura Corti and then by Treviranus, in 1807, was found by von Mohl to be located in this primordial 5 Quoted from Haeckel's History of Creation. utricle. As early as 1830 Meyen attributed this circulation within the cell to the power of the fluid itself since it is moved by no organs. He thought the circulation of the cell contents in plants was suggestive of the revolution of the planets around the sun and he spoke of its being caused by "a gravitation of plants." Cohn in 1848 showed that plant protoplasm is similar to animal sarcode, and in 1859 DeBary proved that the sarcode of protozoa and the protoplasm of plants are essentially similar. Finally, Max Schultze in 1861 established the essential resemblance of sarcode with the protoplasm of all animals and plants. Thus was established what $\mathrm{O}$. Hertwig, in 1892, called the "protoplasm theory," which is a much more fundamental generalization than the cell theory. In 1874, the English histologist, Lionel Beale, called living matter "bioplasm," and this name was regarded by some persons with vitalist leanings as less objectionable than protoplasm, since it included life as a characteristic part of the substance.

As is often the case when some great theory is first proposed, this protoplasm theory was at first earried too far. By some persons it was supposed that protoplasm was a definite ehemical compound, a life substance, and that the solution of all the problems of all life was to be found in the structure and functions of this one compound; but soon it was realized that protoplasm is no single chemical substance but a combination of many chemical compounds and that it differs in every species of animal or plant and, indeed, in every different kind of cell.

Gradually the view developed that protoplasm is not merely a combination of many of the most complex chemical compounds that are known, but that it is a complicated organization, or organism, and that to identify life with protoplasm is no more revolutionary than to identify it with plant or animal. In this protoplasmic organization the constituent parts that were first recognized were the nucleus and its surrounding material; the latter was named "cytoplasm" by Kölliker, in 1862, and "plasson" by Van Beneden, in 1871. The 
work of biologists during the past fifty years has revealed a further complicated organization of both nucleus and cytoplasm that would have greatly astonished earlier students of the cell.

It was early shown that many animal cells have no such membranes as plant cells have. Brücke, Beale and Max Schultze at nearly the same time, 1861, reached the conclusion that a structural cell membrane is not a necessary part of a cell. With the development of the protoplasm concept it became evident that the name "cell" was a misnomer and many attempts were made to supplant it. Beale (1870) proposed the name "bioplast," Sachs (1892) the term "energid," Hanstein (1880) the name "protoplast" as more truly descriptive of what the cell really is. Fortunately, none of these terms has been generally accepted. Scientific names should be first of all permanent, and should not be changed every time new or contradictory qualities are found in the objects named.

\section{The Organization of Protoplasm}

Nothing else has so fully revealed the complex organization of protoplasm as have the detailed and long-continued studies on nuclear and cell division. In 1835, von Mohl described cell division in a filamentous alga, Cladophora, in which a cireular constriction around the middle of the cell deepened until the cell was cut in two. In 1841, Remak described the division of red blood corpuscles of the embryo chick in which the nucleolus first divided by constriction, then the nucleus and finally the cell body. For a long time it was supposed that this "type of Remak" was a common form of cell division, but Wilson, in 1924, rightly says that it is one of the rarest. It does occur in certain cases of direct division (amitosis) as in the follicle cells surrounding the eggs of certain insects, but in most cases of direct division the nucleolus does not divide and frequently the cell body does not. Direct division, segmentation or fragmentation of the nucleus have been described by many students of the cell but such forms of nuclear division probably occur only in fully differentiated tissue cells, e.g., in functional muscle or gland cells, in the trophic nuclei of certain protozoa, or in senescent and degenerating cells. Many so-called cases of direct nuclear division are really stages of incomplete union of chromosomal vesicles following indirect nuclear division (mitosis).

Star-shaped figures had been seen by C. G. Carus in the eggs of Unio as far back as 1832 , and by Grube in the cleavage cells of Clepsine in 1844; a double star or diaster was seen by Krohn in the eggs of the ascidian Phallusia in 1852 ( $c f$. Mark 1881). In 1873, Anton Schneider observed in the eggs of certain flatworms that the vesicular nucleus is transformed during division into a mass of filaments (named chromosomes by Waldeyer in 1890); he saw these filaments separate toward two asters in the cell and then disappear, after which new vesicular nuclei appear in their places.

Many investigators saw the nucleus disappear and two new ones appear later, but Strasburger, in 1875 , was probably the first to trace the continuity between the disappearing mother nucleus and the two daughter nuclei, through the formation, division and separation of nuclear filaments (chromosomes). In 1879, Schleicher observed in living cartilage cells of the frog that rods appear in the nucleus, the nuclear membrane and nucleoli disappear, the nuclear rods become arranged in a starshaped figure on a spindle, and then divide and move to the two poles. Owing to the movements of the nucleus in this process he called it karyokinesis.

In a series of important papers beginning in 1878 and culminating in 1882, Flemming added enormously to our knowledge of nuclear division. The various stages of this process were accurately traced in epithelial cells of the salamander, and many of the names introduced by him, including the term mitosis for this form of nuclear division, are still in current use. In 1884, Flemming, Strasburger, Van Beneden and Rabl found that the nuclear filaments (chromosomes) double in number by longitudinal division and Strasburger saw the two halves of each migrate to opposite poles. They also found that the numbers of 
ehromosomes differ in different species of animals and plants but are constant for each species.

The mitotic figure (amphiaster, Fol 1887 ) is a marvellous apparatus for the exact division of each individual chromosome. The vesicular nucleus is plainly a compound structure, in some cases composed of chromosomal vesicles each containing one chromosome and it could not be divided with exact equality in any other way. The chromosomes are thus persistent cell organs, and all parts of chromosomes, such as chromomeres, chromioles and genes, are self-perpetuating by individual growth and division.

At the poles of the amphiaster, Van Beneden described polar corpuscles, in 1874, and attraction spheres, in 1883. Both Van Beneden and Boveri found, in 1887, that these central corpuscles or centrosomes are persistent, self-perpetuating cell organs. In 1895 Boveri and others found that the centriole within the centrosome is a persistent organ. In 1894, Heidenhain, and, in 1896, Kostanecki regarded polar rays and spindle fibers as persistent organs, but sufficient evidence of this is lacking. Altmann maintained, in 1890, that certain granules in the cytoplasm (his bioblasts), which are now called mitochondria, are "elementary organisms" comparable to bacteria and capable of growth and division, but this view is not generally held at present.

Every persistent part of the cell is selfperpetuating by the process of growth and division. This is known as the principle of "Panmerism", (O. Hertwig). The long disputes regarding the origin of cells was finally concluded with the establishment of the fact that all cells eome by division from preceding ones, as was neatly expressed, in 1859 , in the dictum of Virchow, "Omnis cellula e cellula." In 1884, Strasburger's demonstration of this principle of panmerism in the case of the nucleus led to the dictum, "Omnis nucleus e nucleo." The work of Rabl, in 1885, of Boveri, in 1887, and of Van Beneden, in 1887, proved its truth in the case of chromosomes, "Omnis chromosoma e chromosoma," and the work of the last two named authors extended it to centrosomes, "Omnis centrosoma e centrosoma," and to central bodies, later named by Boveri, in 1895, centrioles, "Omnis centriola e centriola." In 1890, Altmann claimed that his granules or bioblasts were panmeristic, and, in 1894, Heidenhain held a similar view regarding spindle fibers, but probably these are not self-pcrpetuating. There are undoubtedly still others, not included in this list, which are self-perpetuating units of protoplasm. This applies particularly to the ultramicroscopic units of life and heredity, which have been postulated by many students.

Long ago, in 1861, Brücke maintained that because of its growth by intussusception protoplasm must be composed of ultramicroscopic units capable of assimilation, growth and division, and he called these units "the smallest living parts." Supposed logical necessity led Herbert Spencer, in 1866, to postulate his "physiological units," each endowed with all the essential properties of life. As is well known, in 1868 Darwin assumed the existence of different kinds of "gemmules" in his "provisional hypothesis of pangenesis" to account for phenomena of heredity. A somewhat similar process of reasoning led, in 1876 , to the proposal of the "plastidules" of Haeckel; in 1889, to the "pangenes" of de Vries and the "plasomes" of Wiesner; in 1892, to the "ideoblasts" of $\mathrm{O}$. Hertwig and to the "biophores" and "determinants" of Weismann. These units were postulated as logically necessary, but had little other basis.

A great advance was made in 1910 and later when Morgan and his foliowers furnished experimental evidence of the existence of self-perpetuating "genes" arranged in linear order in the chromosomes, and in 1934 when Painter and in 1935 when Bridges furnished visible evidence of their locations in the giant chromosomes of the salivary gland cells of Diptera. Whether or not these are units of heredity, as many have held, there are certainly differential factors in these loci which appear to have the properties of panmerism, that is, individual assimilation, growth and division, 
and they raise the question whether "filterable viruses" and "bacteriophage," which seem to be panmeristic, are also vital units. Furthermore, in what respect do such elementary vital units differ fundamentally from the colloidal aggregates and enormous protein molecules of chemistry? If there is no really essential difference, these panmeristic units would appear to bridge the g'ulf between the living and the non-living.

Biologists generally hold that the simplest and most fundamental properties of life are (1) assimilation, (2) growth and (3) reproduction by division; to these are usually added (4) sensitivity, or the capacity of responding to stimuli, and (5) adaptability, or the capacity of responding to stimuli in a selective or differential manner.

"Nothing that lives is alive in every part." In every organism and every cell there are living and not-living portions, formative and formed materials, or protoplasm and metaplasm. It is not always possible to sharply distinguish these, but panmerism or the ability to assimilate, grow and divide is the general test of living. Even in the protoplasm itself some parts are more alive than others, if measured by their viability. The hyaloplasm or ground substance remains alive even after it has lost almost all of its fluid content or eytolymple, as is seen in dry seeds and some desiccated animals. The same is true of the nuclear contents; condensed chromosomes have lost most of their fluid content but not their ability to assimilate, grow and divide. But it has not been demonstrated that any of the visible parts of cells, much less these ultra-microscopic parts, are eapable of showing these properties of life when they are completely isolated from all other parts. In short the entire cell is still the ultimate vital unit capable of showing all these properties of life. It seems highly probable that these vital properties are the results of the complicated interactions of different parts of the cell, or, in other words, of cellular organization.

In physics and chemistry new atoms with new properties are formed by new com- binations of protons and electrons, new molecules by new combinations of atoms. Perhaps in similar manner the distinctive properties of life arise or "emerge" from the interactions of parts which by themselves do not show these properties. This principle of "emergence" is seen everywhere in ontogeny and phylogeny. New structures and functions appear at every stage in development as the result of "creative synthesis." It seems to me highly probable that this same great principle is operative in the transition from the nonliving to the living. If so the fundamental properties of life are not found in any separate individual units of protoplasm but in the complicated interrelations of many parts, and such individual units are not independent units of life or heredity though they may be factors in such complex processes. Life is the product of organization and the fundamental problems of biology are the organization of cells and protoplasm and the interrelation of the parts of this organization.

The method of scientific analysis which has been so fruitful in our study of natural phenomena has led many scientists to forget or neglect the importance of organic synthesis. Not infrequently they have sought the properties of the whole in the individual parts of which it is composed. Colloidal particles and protein molecules have been held to bridge the gap between the living and the non-living. Chromatin granules, or chromioles, have been regarded as the ultimate units of life (Minchin 1915). Crystallizable viruses are supposed by some to be on the border line between the living and the lifeless. At present the gene is regarded by many as the ultimate living unit from which all other parts of the protoplasm have been derived.

This tendency to locate all the properties of such a complex phenomenon as life in some one or a few of its constituents is a very common error. It is suggestive of the ancient views as to the localization of certain emotions in the heart, others in the kidneys or bowels, or Descartes' proposal that the pineal gland is the seat of the soul. 
With increasing knowledge of the finer organization of living matter it is only natural, but probably futile, to look for the vital properties in these smaller and smaller parts. Haeckel assigned the peculiar properties of life to the carbon atom; Buchner's famous dictum, "Ohne Phosphor kein Gedanke," seems to identify mental phenomena with phosphorus. I once heard the physicist, A. E. Dolbear (1895), suggest that the immortal soul could be safely lodged in an immortal atom. ${ }^{6}$ Unfortunately for this idea the atoms are no longer immortal, even if one were large enough to furnish a home for the soul. Recently several physicists and biologists have suggested that phenomena of automatism, freedom, and creativity, so characteristic of many living beings, may be derived from the uncertainty principle of Heisenberg as found in electrons. All such proposals involve the error that the properties of the whole are to be found in its constituent parts, or that the whole is no greater than the sum of its parts. Whitman pointed out this error as regards the totipotence of cells in his thoughtful paper on "The Inadequacy of the Cell Theory of Development"' (1893), and it could now be extended to the inadequacy of the independent gene theory of heredity or the more extreme view which regards genes as "units of life," or to the atomic or electronic theories of life.

Attempts have been made to explain the constitution of cells and protoplasm as a symbiotic union of a swarm of the smallest living things. In 1890, Altmann maintained that the granules which we now call mitochondria are elementary organisms like bacteria. Wallin maintained a similar view, in 1930, in his book on "Symbionticism." The sharp distinction between nucleus and cytoplasm led certain cytologists, among them Boveri and Watase, to suggest that nucleus and cytoplasm may be symbionts in the cell. Others, recognizing that nuclei are built up from self-perpetuating chromosomes, chromomeres and chromioles,

6"If mind itself requires a material habitat then it has in an atom an imperishable living home." have regarded these as the elementary organisms or symbionts (Minchin 1915). Unfortunately for all such speculations there is no evidence that any of these cell constituents are capable of independent existence. So far as now known some of the micrococei are the smallest living things capable of cultivation as independent organisms. It is probable that they, like larger bacteria, contain chromatin granules (chromioles) and plasma, or elements of both nucleus and cytoplasm, and that they have the properties of assimilation, growth and division. But there is no evidence that these functions are located in either chromioles or plasma separately. Rather, these vital functions appear to be the results of the coordination and cooperation of these constituents, and when other vital functions appear in higher organisms they are not to be regarded as the distinctive contribution of some particular substance or unit that has been added to the complex, but rather as the results of the organization and cooperation of all the constituent parts. Life is not found in atoms or molecules or genes as such, but in organization; not in symbiosis but in synthesis.

The origin of cellular and protoplasmic organization is a vast problem upon which science has scarcely made a beginning, but once this organization or combination of constituent parts has been achieved, the fundamental properties of life emerge. Once the organization of the germ cells is established and is brought into proper relation with the environment, development results. Here in mere outline is a possible mechanism for the origin of life, for the increasing complexities of structures and functions in development, for the evolution of the million species of living things.

The mystery of mysteries is not the mechanism of evolution, but the evolution of the mechanism by which cells and protoplasm came to have the organization that has resulted in "the promise and potency of all life." This is the great problcm which is sure to occupy increasingly the attention of biologists in the future. From our mere beginnings in the study of cells and protoplasm we confidently look for- 
ward to the epoch-making work of the future on the origin and nature of life. "Morituri salutamus!"

\section{References Cited}

Brown, RoBert. 1831. Observations on the Organs and Mode of Fecundation in Orchideae, etc., Trans. Linn. Soc. London.

Carpenter, W. B. 1891. The Microscope and Its Revelations. 7th Ed. Blakiston, Philadelphia.

Conklin, E. G. 1939. Predecessors of Schleiden and Schwann. Am. Naturalist, 73: 538-546.

Dolbear, A. E. 1895. Woods Hole Biol. Lect. 1895: 21.

Dutrochet, H. J. 1824. Recherches sur la structure intine des animaux et des végétaux. Paris.

Gerould, J. H. 1922. The Dawn of the Cell Theory. The Seientific Monthly, 14: 267-276.

Hooke, RoBertr. 1665. Micrographia or Some Physiological Descriptions of Minute Bodies Made by Magnifying Glasses. London.

LamarcK, J. B. P. A. 1809. Philosophie Zoologique. Paris.

LocY, W. A. 1908. Biology and Its Makers. Henry Holt \& Co., New York.

MARK, E. L. 1881. Maturation, Fecundation and
Segmentation of Limax campestris. Bull. Museum Comp. Zool. Harvard, 6: 245.

Meren, J. 1830. Phytotomie. Berlin.

Minchin, F. A. 1915. The Evolution of the Cell. Report of the British Assn. Adv. Sci. Section D, pp. 1-28.

Mirbel, Brisseau De. 1808, 1809. Theorie de l'organization végétal, ete. Paris.

Newbold, W. R. 1921. Unpublished paper read before American Philosophical Society, April 21.

Robinson, H. W. 1935. The Diary of Robert Hooke. Taylor \& Francis, London.

Shipley, A. F. 1916. "Biology" in Cambridge History of English Literature, vol. 14.

TurPin, J. P. F. 1826. Organographie microscopique élémentaire et comparée des végétaux, etc. Paris.

Von Morr, Hugo. 1837. Ueber die Vermehrung der Pflanzenzellen durch Theilung, Dissert. Tübingen 1835. Flora, 1837.

VoN SACHS, Julius. 1890. History of Botany, English translation. Oxford Univ. Press.

WolfF, C. F. 1759. Theoria Generationis, Uebersetzt und Herausgegeben von Paul Samassa. Ostwald's Klassiker der exacten Wissenschaften. W. Engelmann. Leipzig, 1896. 


\section{THE MICROMANIPIJLATION OF LIVING CELLS}

\section{By ROBERT CHAMBERS}

DEPARTMENT OF BIOLOGY, NEW YORK UNIVERSITY, NEW YORK, N. Y.

THE micromanipulative or micrurgical technique owes its inception in large measure to the natural urge of the investigator to handle the object of his scientific interest.

Minute dissections, performed centuries ago by men like Grew, Malpighi, and Swammerdam with the use of magnifying lenses or perspicilla, revealed delicately small anatomical structures. These investigators, and others throughout the 17th and 18th centuries, actually depicted cells, but they did not realize the significance of what they were looking at. They might be likened to Tom in Kingsley's Water Babies who, when he arrived at the sea, mistook the water-babies for seashells and pebbles and their laughter for ripples on the sand. It was not till the tur'n of the 19 th century that the cellular constitution of living organisms began to be appreciated. The diminutive size of the cells precluded the possibility of dissecting them, so that of necessity the attention was focussed mainly on observational studies. However, some investigators who were more experimentally minded found means of testing the material composing the cells. An early method, occasionally in use today, was to exert gentle pressure on a cellular tissue placed between a slide and coverslip and to note the effect of partially erushing the cells. It seems fitting that such experiments should have first been done on freeliving cells or Protozoa. By this means Dujardin determined the fluid nature of protoplasm which he termed sarcode. He also observed that when the cell wall was ruptured the interior would exude without being destroyed. In one of his observations he took advantage of a chance cotton fiber which lay across a Paramecium, and by compressing the preparation he caused a bulging mass of the protoplasm to be completely pinched off. The result- ing fragment rounded up and the beating cilia on its surface carried it away. Another investigator, Carl Nägeli, a botanist, crushed plant cells, such as Vaucheria, and found that the interior of the cell could be extruded and separated off as viable masses or bodies.

Three important deductions can be drawn from these early experiments: (a) a bit of protoplasm isolated from the mass of a cell may still exhibit properties of life; (b) the way in which the internal material flows out of the cell and rounds up indicates the fluid nature of protoplasm; and $(c)$ the persistence of a sharply defined boundary between the exuding protoplasm and the surrounding medium shows that the protoplasm must either be non-miscible in water, or be able to reconstitute a membrane about itself. Pfeffer, to whom we owe the term plasma membrane, was convinced that the exuding material maintains its integrity by the formation of a precipitation membrane about it. He noted that when such a membrane did not form, the exposed material became dissipated. Pfeffer was interested in the osmotic phenomena of the plasma membrane and attempted to determine its physical nature. In one of his papers he actually proposed the possibility of building a mechanical contrivance for moving minute glass needles and pipettes to permit operations on living cells.

The nucleus was also the object of early experimental study. W. H. Ransom, who apparently has been overlooked by historians, ${ }^{1}$ published an article on the isolation of the nucleus of the eggs of certain fish in the Philosophical Transactions of London in 1867. He crushed the egg's in water and in various salt solutions and observed the effect on the extruded nuclei. His con-

1 I am indebted to W. R. Duryee for having brought this article to my attention. 
tribution was the observation that the nucleus need not lose its structural integrity when removed from the cell.

Nuclei of ovarian eggs of fish and of Amphibia are proving to be excellent material for micromanipulation. W. R. Duryee (1937) is studying the effect of chemicals on the isolated nuclei of the frog and of Triturus. Chambers and Sands (1923) had shown that the chromosomes of spermatocytes of the grasshopper are highly tenacious and elastic. Duryee's dissections confirm this conclusion on isolated amphibian chromosomes, which are tenuous filaments, often as long as $500 \mu$.

The incentive for the micromanipulative technique we owe to bacteriologists. TVe are indebted to George Lester Kite for the adaptation of the bacteriological technique to the microdissection of living cells.

Kite was an enthusiastic pioneer inspired by A. P. Nathews who was at that time at the University of Chicago. Kite's graphic account of his first attempts at micromanipulation was given in a lecture at Woods Hole during the summer of 1911 (never published). One of the operations which astonished his hearers was the interposition of the tip of a microneedle between the male and female pronuclei of a recently fertilized Toxopneustes egg. He stated that he could push one of the nuclei about but that it would persist in slipping off the needle to advance toward its mate. ${ }^{2}$

Kite used exclusively the so-called Barber Pipette Holder. At that time, 1911 and 1912, there were two instruments used to isolate bacteria in the field of the oil-immersion objective, one devised by S. L. Schouten, in Holland, and the other by M. A. Barber', in America. Two features made it possible to extend the technique to cellular research. They are the use of glass needles with microscopically fine tips on relatively rigid shafts, and the bending of the shaft to permit the tips to be operated in a hanging drop. This arrangement allows the use of the highest available magnifications during the operations since there is no obstacle between the lens of the ob-

2 Kite's early death was a tragic loss but the work he initiated is still being carried on. jective and the coverslip from which the hanging drop is suspended. The instruments of Schouten and Barber had eomparatively good vertical movements, which are essential for picking up bacteria, but the lateral movements left much to be desired. A mechanical device for more adequate control was necessary. Such a device and the development of a micro-injection apparatus have made possible astonishingly delicate operations on cells. With the years the technique has been progressively so improved that now the investigator's ingenuity is no longer being expended on the technique of performance but rather on the problems involved.

Micromanipulation, exclusive of the isolation technique, has been devoted to three general forms of procedure: the dissection of cells and cell aggregates, the removal of materials from within cells, and the injection of solutions into cells.

An outstanding dissection experiment was that performed by C. V. Taylor (1920) to ascertain the significance of certain fibrils in the ciliate, Euplotes. Deep cuts were made into the cortex of various regions of the Euplotes. It was found that recovery of normal coordination of the locomotor organellae occurred in all cases except those in which certain internal fibers had been cut through or in which a granular body, the so-called motorium, where the fibers converge, had been injured.

Many of the considerable number of structural components of cells have since been investigated. A striking feature is the difference in the degree of their stability. Fibrous strands, vesicles, and rod-shaped mitochondria may be moved about and distorted with no apparent loss of their integrity. On the other hand, other structures, such as the aster, readily disappear.

The physical state of much of the protoplasm resembles that of reversible sol-gel colloidal systems. The reversibility from the gel to the sol state, with a subsequent disappearance of structural characteristics, can be induced by various experimental methods, particularly those which involve the use of pressure or sudden mechanical agitation. By mechanical means, it has 
been possible in some cases to induce the reverse change, i.e., from the sol to the gel (Chambers 1938a). Fragments of protoplasm which are pinched off from an unfertilized sea-urchin egg may act, at one moment, as if solid, maintaining deformed shapes; while at another moment, they act as if liquid, rounding up into spheres. Hence, to speak of protoplasm as a liquid or as a solid has little meaning.

The relation of the nucleus to the cytoplasm of the cell has always claimed the attention of cytologists. Experimental evidence has indicated that the nucleus is essential not only genetically but also for the continued existence of the cell. In certain ciliates the control of these two functions, the so-called kinetic and trophic, has been ascribed to the micro- and macro-nuclei, respectively. Taylor and Farber (1924) showed that the micro-nucleus alone may bear both functions. By means of a micropipette they removed the micro-nucleus of over seventy individual Euplotes and found this operation was lethal. The importance of the nucleus has also been shown by noting the effect of puncturing one of the nuclei of a binucleated fibroblast in tissue eulture (Chambers and Fell 1931). The injury irreversibly coagulated the nucleus and spread into the eytoplasm, producing a granular precipitate and a disruption of the mitochondria in the vicinity. In mononucleated fibroblasts puncture of the nucleus resulted in complete disintegration of the cell. On the other hand, in the case of the binucleated cell, the disintegrative changes were temporary and occurred only in the vicinity of the injured nucleus. Complete recovery soon followed, evidently because of the presence of the other nucleus.

The micro-injection technique has afforded a most fertile field for investigation. A difficulty, which at present has been only partially overcome, is to gauge the precise quantity injected. The amount of solution drawn into a pipette for subsequent injection can rarely be injected completely into the cell. Moreover, except for relatively large cells it is difficult to judge whether the attempted injection of the aqueous solution is successful. A positive reaction is generally the only criterion for a successful injection. It is necessary to inject substances gradually, for even minute amounts may result in cytolysis when suddenly introduced. On the other hand, the protoplasm of many cells permits the gradual introduction of surprisingly large amounts, even of water, without destruction.

It is not possible to deal in detail with the results of micro-injecting indicators which are used for colorimetric determinations of the reducing intensity and the hydrogen-ion concentration of protoplasm. Cohen and Chen (1933), using indicators not available in the earlier injection experiments on the reducing intensity of various cells under anoxybiosis, have stated that the value for Amoeba dubia is in the neighborhood of -0.260 and -0.289 volts at $\mathrm{pH}$ 7.0. They drew this conclusion from their observations that dimethylphenosafranine and safranine $\mathrm{T}$ (whose reduction potentials are -0.260 and $-0.289 \mathrm{v}$. respectively) are only partly reduced in the cell, while sulfonated rosindone with a potential of -0.380 is not.

The fact that there was even a partial reduction of the two first mentioned indicators is significant because basic dyes tend to be strongly adsorbed. This not only increases the capacity factor a great deal, but probably renders the indicator less soluble and, hence, less available for reduction. On the other hand, acid dyes at the $\mathrm{pH}$ of protoplasm tend to be very diffusible and more susceptible to the reducing intensity of the protoplasmic system. Hence the non-reducibility of sulfonated rosindone is also significant. Evidently the reducing intensity of protoplasm of the amoeba under nitrogen (approx. -0.275 v.) lies roughly midway between the potential of the hydrogen electrode (viz., -0.421 v.) and the aerobic reducing intensity of the cell, which has been found to be centered at about $-0.07 \mathrm{v}$.

With regard to the protoplasmic $\mathrm{pH}$, the variable values reported by many investigators may be explained, at least in part, by the extraordinary ability of many cells to segregate introduced materials into vacuoles where the color of the indicator tends 
to be at variance with that of the indicator in the eytoplasmic matrix. Least open to criticism are the results obtained with the salts of the highly dissociated acid compounds, such as the sulfonated indicators of Clark and Lubs. Living cells are relatively impermeable to these substances. Moreover, they are highly diffusible within the protoplasm and they can be injected in minute quantities with a minimum danger of upsetting the buffering system within the cell. A considerable variety of cells have been injected and, with due precautions being taken, the colorimetric $\mathrm{pH}$ values, of the watery phase in protoplasm at least, appear to be as follows: for the interior of the nucleus, a $\mathrm{pH}$ of 7.6 to 7.8 ; for the cytoplasmic matrix, a $\mathrm{pH}$ of 6.7 to 6.9 and for the interior of cytoplasmic vacuoles, a variable $\mathrm{pH}$ of 5.0 or greater. When cytolysis occurs the cytoplasmic $\mathrm{pH}$ drops to about 5.4, while that of the nucleus tends to persist.

Of considerable interest is the surface boundary of protoplasm, a subject which has been recently reviewed (Chambers 1938b). Probably the strongest argument for the existence of a differentiated layer on the surface of protoplasm is the fact that a colored solution which cannot enter from without will, when micro-injected, spread through the interior but will not pass out of the cell. The surface layer can be torn with a microneedle and may or may not be repaired, depending upon the suddenness of the tear. The maintenance or repair of this surface layer does not necessarily depend upon the presence of specific electrolytes in the environment. This is indicated in the so-called "churning" experiment on unfertilized sea-urchin eg'gs. The extraneous coats of the eggs were removed by several washings in a solution of potassium chloride isotonic with sea water. The eggs were then passed through several changes of any of the experimental solutions, viz., sodium chloride, potassium chloride, calcium chloride or magnesium chloride. It was found that the churning effect, that is, a central or axial streaming away from the needle tip and an over-all superficial streaming toward it, could be induced in solutions of any one of the several salts just mentioned.

A main difficulty in studying the physical properties of the protoplasmic surface lies in the failure to differentiate it from extraneous coatings which normally surround the eg'g and serve to give it mechanical support. Recently, considerable attention has been given to ways and means for distinguishing and establishing the existence of such coatings. An extremely delicate and objective one is the oil coalescency method. Oil drops exuding from the tip of a micropipette are brought into contact with the surface of a cell. Under certain' conditions the cell and oil coalesce in such a way that the oil is engulfed by the cell (Chambers 1938b; Chambers and Kopac 1937).

The method used up to the present is as follows: The tip of a micropipette previously filled with oil is placed a short distance from the surface of the eell which is suspended in a hanging drop in view under the microscope. In the case of the unfertilized mature Arbacia ovum, which averages 70 to $75 \mu$ in diameter, the tip of the micropipette is usually placed 4 to $5 \mu$ from the cell surface. Pressure is then exerted by means of the injection apparatus so that the oil exudes to form a drop which enlarges until its surface touches the cell surface. Usually the diameter of such a formed droplet will be about $10 \mu$. The contact with the cell, occurring while the oil drop is expanding, ensures the presentation of an uncontaminated surface of the oil to the cell. This is essential since most oils develop an adsorption film from impurities usually present in the sea water, which prevents the occurrence of coalescence. An oil drop first allowed to exude from a pipette and then brought into contact, even with denuded sea-urchin eggs, rarely exhibits the coalescency reaction.

In the coalescency experiments, quantitative results have been obtained by driving the oil out of the pipette under constant and known pressures. For this purpose M. J. Kopac has developed a special device as an accessory to the usual micro-injection apparatus. A driving pressure is built up 
with a motor, and the degree of the pressure is determined by a manometer.

The cell and the oil drop behave in a manner similar to two liquid drops in contact. Such a system may or may not be stable, depending, among other things, on the magnitude of the tension and the diameter of the oil drop. If the system is unstable, the two drops will spontaneously coalesce and produce a stable equilibrium. In the case of the Arbacia egg, if coalescency occurs at all, it has been found that the cell always incorporates the oil. This reaction is rapid, taking less time than the interval between two successive frames of a motion picture film at sixteen frames per second.

The tendencies toward coalescency are proportional to the tension at the interface of the oil-aqueous phase and to the diameter of the freshly applied oil drop. The importance of tension and the size of oil drop (i.e., surface area) suggest reactions involving changes in surface energies. Coalescence is therefore thermodynamically possible since the potential energy of the cell with the oil drop inside is lower than with the oil drop outside.

The level of potential energy of the cell and the oil drop in contact with it may be regulated either by selecting an oil having a high interfacial tension against the aqueous phase or by increasing the size of the applied drop.

Frequently the potential energy of the oil in contact with the cell has to be very high before the oil will be engulfed by the cell. This would not be so if the cell were an ideal liquid drop, since liquid drops coalesce spontaneously with only infinitesimal differences in the potential energies of the two. The relative pronounced differences indicate the presence of a potential hill at the cell surface. The magnitude of this potential hill may be calculated by determining the critical diameter of the oil drop at the moment of coalescence. A determination of the relative differences of coalescency is of considerable value for ascertaining the nature of the surfaces of different cells and of cells under experimental treatment. Kopac has made a eare- ful quantitative study of this problem and has compared the potential hill of the experimental cells with that of normal cells, selected as control cells.

These data may be represented as useful ratios as follows:

$\frac{\text { Potential energy (control) }}{\text { Potential energy (experimental) }}=$

relative coalescency.

Thus, ratios greater than 1 indicate that potential hills of the experimentally treated cells are lower than those of the control cells.

A high value of the potential hill at the cell surface may be due to a tangential rigidity at the cell surface, or to the existence of a third phase between the cell surface and the oil drop, which is either tangentially rigid or possesses surface activity.

The coalescency method has been very useful in studying the problem of extraneous coats in cells. Kopac and Chambers (1938) have made a series of determinations on the effect of removing the vitelline membrane of the Arbacia egg by various means.

The control egg was the unfertilized egg, washed and centrifuged several times in isosmotic sodium chloride to remove the jelly but not its vitelline membrane. The relative coalescency value for these control eggs was taken as 1 . A relatively high coalescency value of 7 to 15 was obtained on egg' within three minutes after fertilization, the fertilization membranes having been removed by shaking immediately after insemination. This indicates that the process of fertilization has definitely lowered the potential hill, presumably by removing the vitelline membrane during the formation of the fertilization membrane. The coalescency value of fertilized eggs remaining in sea water progressively drops, because, as will be shown later, a hyaline layer begins to be excreted on the surface of the eg' which attains pronounced proportions six to eight minutes after fertilization. However, if the fertilized eggs are placed in a solution of potassium chloride isosmotic with sea water, the presence of 
this layer becomes negligible and the coaIescency rises to a value actually onehundredfold that of the unfertilized exros possessing a vitelline membrane.

Unfertilized eggs also give relatively high values when they have been immersed for about two minutes in a $1 M$ urea solution, which dissolves the investing vitelline membrane, or when the eggs are churned with microneedles. The churning process ruptures the vitelline membrane and makes it discontinuous.

Aging also has a decided effect; the coalescency value of egres, standing in sea water for 8 to 12 hours, rises to 2.5 and 5 . For eggs remaining in sea water for 20 hours the value obtained has been as high as 100 , which is equal to that of eggs within two minutes after insemination and with their fertilization membranes removed (in solutions of potassium chloride). Increaśing coalescency with age suggests that the vitelline membrane gradually disintegrates with time.

Interesting data have also been obtained on the development of the hyaline layer in Arbacia eggs after fertilization. As shown above, freshly fertilized eggs (in sea water) with their fertilization membranes removed have more than a tenfold greater coalescency than unfertilized eggs which still possess vitelline membranes. However, the coalescencies of the fertilized eggs (in sea water) decrease steadily and become zero after 15 or more minutes. The increased magnitude of the potential hill, as calculated from the size of the coalescing drops, corresponds elosely with the formation and gradual thickening of the hyaline layer on the surface of the egg. Such data suggest that the presence of a hyaline layer increases the tangential rigidity at the cell surface.

This hyaline layer is unstable in the absence of calcium in the external medium and is readily dispersed in isosmotic solutions of acidified potassium chloride. Even when the layer is fully formed a sojourn of the fertilized eggs in potassium chloride causes the layer to become dissipated. The coalescency value may rise one-hundredfold over that of the unfertilized egg in sea water.
A reasonable interpretation of these $\mathrm{ob}$ servations is that the eggrs with the lowest potential hills (namely, highest coalescencies) are eggs which have the minimum of extraneous coatings. It is entirely probable that fertilized Arbacia eggs immersed in potassium chloride offer the closest approach thus far to exposing the actual protoplasmic surface layer or plasma membrane of the eggs.

It was of interest to find whether gelation phenomena within the Echinoderm egg may also serve as a barrier to the coalescence reaction. The conclusion has been verified after much experimentation that the naked surface of the egg consists of material which can be made to flow without losing its integrity. Normally, there is an underlying and appreciably thick gelated cortex. Moreover, in the dividing egg it has been found that the consistency of the cortex in the furrow region of a dividing egg is greater than that of the poles.

The degree of coalescency in regions of varying cortical consistency was determined on Lytechinus egg's after the fertilization membranes had been removed and the hyaline layer dispersed by immersing the eggs from 10 to 20 minutes in isosmotic potassium chloride solution (Chambers and Kopac 1937). In these experiments two oils were used, mineral oil and oleic acid. The sample of mineral oil used here had an interfacial tension of 40 dynes per $\mathrm{cm}$ against sea water, while the oleic acid under similar conditions had an interfacial tension of 10 dynes per $\mathrm{cm}$. The experiments were done with oil drops of different sizes, and mostly on eggs with the cleavage furrow differentiated. No difference in the size of the oil drop at the time of coalescence was found between the polar and equatorial regions of the egg. If increased consistency lowered the coalescency, one would expect larger drops to coalesce at the furrow zone. This we did not find. These results indicate that the consistency of the eytoplasm is of minor importance in inhibiting coalescence. The tangential rigidity or lack of it in the cell surface appears to be the prime factor in controlling coalescence.

An interesting object is the aplanospore 
of Valonia ventricosa, a coenocytic, marine alga. Aplanospores are obtained by puncturing a turgid coenocyte. The nulti-nucleate protoplast separates into numerous mono- or poly-nucleated amoeboid bodies which become spheroidal about 10 to 15 minutes later. The amoeboid fragments show a high coalescency (Kopac 1937). Within half an hour of their formation, the aplanospores, now spheroids, develop a potential barrier at their surface which is no greater than that of the assumed naked Echinoderm eggs. With each succeeding half-hour the barrier increases in its effectiveness, indicating the gradual development of an extraneous coat. About four hours later, these spheroidal aplanospores are invested in a definite cell wall and no coalescency occurs.

All oil-protoplasm interfacial tensions so far measured are of a low order of magnitude. For the naturally occurring oil drops in the mackerel and Daphnia egg, Harvey and his coworkers (Harvey and Shapiro 1934; Harvey and Schoepfle 1939) have found values of the order of .1 to 2.6 dynes per $\mathrm{cm}$. Their method was to calculate the interfacial tension from the degree of flattening of an oil drop inside the eggs under a given centrifugal acceleration. Kopac (unpublished) obtained values of $10^{-1}$ dyne per $\mathrm{cm}$ for various oils against Arbacia egg protoplasin by using a microadaptation of the maximum bubble pressure method.

Living cells (aging Arbacia eggrs, for example) will coalesce with oil drops having an interfacial tension against sea water of 2.5 dynes per cm. Therefore the oil-protoplasm interfacial tension must be lower than 2.5 dynes per cm. Coalescence is thermodynamically impossible if the oilprotoplasm interfacial tension is higher than the oil-aqueous phase interface.

The oil capping reaction which was first observed for fresli-water amoebas by Dawson and Belkin (1929), can also be made to occur on protoplasmic exovates of starfish eggs and naked sea-urchin eggs. The oil drop comes to equilibrium by partially flattening against the cell surface. Such flattened drops ean be released only after cytolysis is induced, whereupon the oil drop assumes a spherical shape. With the Echinoderm egg, it has been found that the oil cap can be made to slip over the surface of the egg in a way similar to the slippage of an oil cap on the surface of water. A spontaneous capping involves a reduction in potential energy of the applied oil drop, since the flattened drop now possesses greater surface area than the original spheroidal drop (Chambers and Kopac 1937). The following conditions must exist in the capping reaction: (a) tangential rigidity at the cell surface must be sufficient to prevent coalescence, and (b) the tension at the oilcell surface interface must be lower than at the oil-aqueous phase interface in order to compensate for the increase in area of the oil cap over that of the applied spheroidal oil drop.

The interfacial tensions between oil and internal protoplasm, ${ }^{3}$ although low, are nevertheless always positive. This conclusion is to be inferred from the following facts :

(a) All natural oil drops, namely, those occurring normally in cells, are spherical.

(b) Experimentally introduced oil drops are also spherical whether the oil be polar (plant and animal) or apolar (mineral). Any deformation can be accounted for by the presence of some meclianical obstruction. An interesting case is the ovoid shape of an oil drop introduced into the radially gelated aster of a fertilized seaurchin egg. The drop maintains its distorted shape as long as the aster is present. When the gel reverts to the sol state either by agitation of the aster with a needle or in the natural succession of events in the cell, the oil drop reverts to a spherical shape.

(c) Spherical oil drops deformed in the cell by centrifuging return to the spherical shape when the centrifugal force is removed.

(d) An oil drop constricted in the equa-

3 The foregoing diseussion is based on some published data and also on various unpublished data accumulated in this laboratory on oil-protoplasm interfacial phenomena. Detailed accounts are in preparation for early publication. 
tor of the eleavage furrow will become more nearly spherieal when the pressure exerted hy the cleavage furrow is relaxed, in case eleavage has been mosncessful. When the oil (rop) is pinched in two by the completion of the constricting furpow, the succeeding portions of the oil (leol) become spherieal, to be deformed anain during the following deavage (chambers and Kopace 1937 ).

(c) Finally, we lave the observation mentioned by costello (1938) that naturally ocentring oil dopos in Noreis egers will toalesee on contact following sperm-atetivation of the exy.

The low value of the positive interfacial tension between oil and internal protoplasm may be astribed to the hydrated protein molecules which are assimned to be the chief components of the protoplasm. It is well known that native proteins are extremely surface active at oil-water interfaces. For this reason, proteins are commonly user as emulsifying agents. Since the oil-protoplasm interfacial tensions are of the same oreler of matrinitude as those of oil-water (protein) interfaces, the conclusion that protein molernles are responsible for the low oil-protoplasm interfacial tensions seoms justifiahle. It might be added here that the oil-protoplasm interfacial tensions are many times lower than would be expected on the basis of $\mathrm{pH}$ and salt content of of the cytoplasm alone.

When protoplasm is eansed to mulergo artolysis, the interfacial tension becomes zero and spontaneons deformation of the oil drop ensues. An ingenions method dereloped by Kopac (1938) to show this is the drop-retraction method, in which the injeeted oil drop, after being allowed to reach a given size, is gradually diminished in rolume by withdrawal of some of the oil into a pipette whose tip has been kept in contact with the drop. If adsorption of substances, for example, proteins, has oecurred only partially on the drop, the drop may be decreased in size withont becoming deformed mutil a critical diameter is reached. Diminishing the drop correspondingly rednces the interfacial area and a enterntration of arlsolbed molecules takes places. The rondition is analogous to that which ocents in the reduction ol allea on a langmuir trough by moving a barriele aleross the surface. When proteins ale aldsorlhed at oil-water introfaldes, the Devalu effecet (arinkling) appeals's when the interface is coverest with more than enongh protein to form at least one momolayer. Accordingly, at the threshold of the Devalux effect the critical diameter indicates that the oil drop is coated by at least one layer of protein.

Striking oil-potoplasmic interfaral effects are produced by using eertain fishliver oils, also certain plant oils, against the protoplasm of Asterias eges. In the intart cytoplasm, the drops remain spherieal and clear-cut as long as the oil causes no pereptible injury to the cytoplasm. However, a prononnced reaction oecurs when the oil is introduced into a cell and cytolysis is indneed inmediately therealter. Within 30 secombls aftel the cell has eytolyzed, the Devanx "rinkling effect appear's spontaneonsty on the oil drop (Kopac 1938).

The contrast between the lack of a visible reaction of adsorption to the ahove oils in liring protoplasm, and the prononnced reaction oceming on death or shortly thereafter. is rery significant. Since proteins constitute the oreater part of protoplasm, it is to be ancluded that the state of the proteins in the living cell is very ditferent from that of the proteins in the lead and disintegrated cell.

For these experiments, the immature oöcrtes of Asterius are particularly useful. Crtolysis or disintegration of the egg occurs merely hy puncturing the germinal vesicle with a microneedle. Hence, following the cytoplasmie injection of a suitable oil, cytolysis can be leadily induced at will. and the effect on the oil may be instantly ohserved. Tunler such conditions, the crinkling and subsequent distortion of the oil drop is spontaneons, denoting a spontaneons increase in the interfacial area between the oil and cytolyzed residne. Such spontaneons increase in interfacial area is obrionsly possible if the interfacial tension 
should fall to zero. Apparently such a change from a low positive value to zero does oecur.

If the injected oil drop has been in contact with the extoplasm for a protracted period, induced eytolysis will have no effert. Neither is it possible to obtain the crinkling effect when the oil drops are introdnced into the cytolytic debris later than a few minntes after ytolysis has occurred.

Since the Devanx crinkling effect of the oil drop with the oil-retraction method is not noticeable in the living eytoplasm, it is concluded that the proteins in the living cell do not accummlate on experimentally introduced surfaces while the protoplasm is intact. This smgerests that the proteins are not freely difinsible and adsorbable in protoplasm, and that, therefore, these proteins may be bound together to form some kind of continuous phase.

The fact that spontaneons erinkling occurs only when the oil is introduced almost at the instant of eytolysis and not later suggests that the protoplasmic proteins initially break down into unstable, highmolecular-weight complexes which, as they are adsorbed, break further into low-molecular-weight derivatives. These molecules spread at the interface to prodnce the (rinkling efteret.

The high-molecular-weight complexes producer at the onset of cytolysis must be unstable and have a short life, since heavy protein molecrules are rarely isolated from protoplasm. Introduction of an oil surface into protoplasm just prior to eytolysis makes possible their adsorption at the moment of "ytolysis and before further dissociation oceun's. It is known that highmolecular-weight proteins will not spread until dissociation to units of low molecular weiglit is completed. From these facts we may infer the following about the eytolysing protoplasmir proteins at oil surfares: first, their adsorption, followed by dissociation into smaller units; ancl then, a globular to a laninar transformation. Spontaneous increase ol interlacial area follows such change in confignration of the protein molecules.
We therefore have two factors which induce the spontaneons crinkling effect: $(a)$ the adsorption of sufficient protein to cause the entire interface to be covered with at least a monolarer, and $(b)$ a conversion of a globular to a laminar confignation of the protein molecule, promoted by the tension and other characteristius of the interface.

There is other experimental evidence for a peculiar state of the proteins in living cells. One is from the injection into protoplasm of solutions of colorimetric indicators for measming intra-cellular pH. The large variety of indicators used, including the sulphone-phthalein indicators, give consistent results irrespective of their chemical constitution, and there seems to be no protein error such as occurs in solutions of non-living proteins. A striking example is bromthymol blue, which gives an inconsistent color with ordinary protein solutions when compared with phenol red; the color it gives when injected into a living cell agrees with the color virage presented by both brom cresol purple and phenol red.

Moreover, the acid of injury which has always been found to be associated with "ytolysis may be explained on the basis of an irreversible dissociation of protein macromolecules to low molecular weight proteins, which releases increased numbers of ionizable carboxyl groups.

Finally, there is the work of Vlès and Gex (1934) on the ultra-riolet absorption spectrmm of sea-urchin egrs. They detected different absorption curves in the living cells from those of cytolyzed cells; the latter had absorption curves resembling isolated albumin.

One of the most striking characteristics of protoplasm is that mechanical emshimg destrors it. This holds not only for the integrated cell but also for any viable farament of protoplasm which may be spontaneonsly or experimentally separated from the cell. The implication has long been recognized by cytologists that the property of life depends upon a definite architertme of structural nature. Verworn and E. B. Wilson have defined protoplasm as a morphological concept. Hypothetical mits of 
phussiological structure have been variously termed micellae by Nägeli, plasomes by Wiesner, bioblasts by (O. Hertwig, etc. An attempt to give a chemical simificance to the nltimate mit of living matter was made by Pflïger (1875). Pflüger postulated a living protein (lebrmdiges Einerss) moleenle with a emstitution based on a cranogen radical. Its stability and lability were supposed to depent mpon interchanges of atom groups in the molecule, induced by the eonsumption of oxyoren and the liberation of earbonic aeirl.

Mnch earlior than Pflitger is the almost forgotten alcount of Fletcher of the Enirersity of Edimburoh in 1835. In his "Rudiments of Physiology" Fletuher attacked the old hypothesis of a vital spirit. As an altermative he suggested that the elements romposing living matter are in a peculiar state of combination. "That, in fact, no albumen, fibrin, myosin, protagon, or fats exist as such in the living matter, but that the sum of the elements of all these is united into a compound, for which we have no chemical name, and of the complex mode in which the atoms are combined we can form no idea; and it is only at the moment of death that those chemical compomks with which we are familiar, take their origin. In fact, that death neans simply the resolution of this complex combination into the simpler ampounds, albumen, fibrin and the rest which we find on analysis., "4

The newer derelopments in the extraction of proteins, e.g. by ultracentrifuging at very low temperatures, have made possible the isolation of certain viruses hitherto unobtainable by the usual chemieal means. May not this be a first step toward isolating the extremely unstable complex which at present can be termed only as protoplasmic protein?

In regard to the morphology of protoplasm, mention should be mate of the intimate relation between the eytoplasm and the investing plasma membrane. Thus far it has been impossible to separate the two.

4 Quoted from "The Protoplasmic Theory of Life" by John Drysdale, London, 1874.
The disintegration of the one has alwars aceompanied the disintegration of the other. ('an it be that the stability of the protein eomplex of protoplasm depends upon the presence of a plasma membrane whose selective permealility preserves the proper environment within the cell? A seamohin ege torn open in a solution of potassium dhloride reacts very differently from one torn in a solution of calcium chloride (Chambers 1924). The exposed crtoplasm disperses in potassium chloride while it coagnlates in calcinm ahloride. A medium which will keep the artoplasm from destruction must be between these two opposite effects. The discovery of a suitable medium having a proper mixture of chemical substances and the right physical conclitions of density, pH, ete., may eventually be made. In such a medinm the disruption of the plasma membrane might be indured so as to set free, maltered, the protein complexes from the confines of the microscopic cell.

\section{References Cited}

Chambers, R. and SAxds, H. C. 1928. A Dissection of the Chromosomes in the Pollen Mother Cells of Tradescentia virginiea L. J. Gen. Physinl., 5: 815 .

CrIAdrbers, R. 1924. Mierodissection and Injection Sturties on the Antagonistic Action of Salts upon Protoplasm. Am. J. Physiol., 72: 210.

Chanbers, R. and Feld, I1. P. 1931. Mierooperations on Cells in Tissne Cultures. Proc. Roy. Soc. Lond., 109: 381.

Chambers, R. and Kopac, M. J. 1937. The Coalescence of Sea Crehin Eggs with Oil Drops. Ann. Rept. Carnegie Inst. Wash. Fr. Bki.. 36: 88. -. 1937. The Coaleseence of Living Cells with Oil Drops. I. Arladeia Fggs Immersed in Sea Water. J. Cellulur Comp. Physiol., 9: 331.

Chambers, R. 1938a. Cytoplasmic Inclusions and Matrix of the Arbacia Egg. Biol. Bull., 75: 350. - 1938b. The Physical State of Protoplasm with Special Reference to Its Surface. Am. Naturatist, $72: 141$.

Cones, B. and ('Hex, T. T. 1933. Reduction Intensity in Anaerolic Amoeba dubia. Proc. Soc. Exptl. Biol. Het., 31 : 115.

Costello, D. P. 1938. Beharior of Oil Drops in the Centrifuged Egg of Nereis limbata. Anat. Record, 72: 72.

DAwson, J. A. and BeLkix, M. 1929. The Digestion of Oils by Amoelsa proteus. Biol. Bull., 56: 80 . 
Duryee, II. R. 1937. Isolation of Nuclei and Non-Mitotic Chromosome Pairs from Frog Eggs. Arch. Exp. Zellforsch Gruebezïcht, 19: 171.

Harver, F. N. and Shapiro, H. 1934. The Interfacial Tension between Oil and Protoplasm within Living Cells. J. Cellular Comp. Physiol., 5: 255.

Harvey, E. N. and S'Hoepfle, G. 1939. The Interfacial Tension of Intracellular Oil Drops in the Eggs of Daphnia pulex and in Amoeha plotens. J. Cellular Comp. Physiol., 13: 383.

KopAc, M. J. 1937. The Coalescence of a Plant Cell with Oil Drops. Ann. Rept. Carnegie Inst. Wash. Fr. Bk., 36: 68.

- 1938. The Micro-estimation of Protein Adsorption at Oil-protoplasm luterfaces. Biol. Bull., 75: 372.

- 1938. The Devaux Effect at Oil-protoplasm Interfaces. Biol. Bull., 75: 351.

KOPAC, M. J. and ('HAMBERs, R. 1937. The Coalescence of Living Cells with Oil Drops. I1. Arhacia liggs fmmersed in Acid or Alkaline
Caleinm Solutions. J. Cellular Comp. Physiol., 9: 331.

- 1938. Effect of the Vitelline Membrane on Coalescence of Arbacia Eggs with Oil [)rops. Biol. Bull., 75: 372.

Marshand, D. A. 1938. The Effects of High Hydrostatic Pressure upon Cell Division in Arbacia Eggs. J. Cellular and Comp. Physiol., 12: 57.

Pflïger, E. 1875. Ueber die physiologische Verbrennung in den lebendigen Organismen. Arch. Ges. Physiol. (Pflugers), 10.

Taylor, C. V. 1920. Demonstration of the Funetion of the Neuromotor Apparatus in Euplotes ly the Method of Microdissection. Univ. Calif. Pub. Zool., 19: 403.

TAymor, C. V. and FArber, W. 1'. 1924. Fatal Effects of the Removal of the Micronncleus in Euplotes. Tnix. Calif. Pub. Zool., 26: 131.

VLès, F. et GEX, M. 1934. Sur la structure des spectres nltraviolets de l'oent' d'Oursin. Arch. de Ply.s. Biol., 11: 15i. 


\title{
THE WALLS OF PLANT CELLS
}

\author{
By IRVING W. BAILEY
}

DEPARTMENT OF BIOLOGY, HARVARD TNIVERSITY, CAMBRIDGL, MASS,

In any disemssion of the eell walls of plants, it is essential to differentiate botween two distinct "ategorles of structures. Mreristematic rells and such of their derivatives as retain a capacity for wowth and for inarease in volume are provided with a wall capable of expansion and of increase in smifare area. This wall is also capable of undergong varions reversible rhanges, for example, in thickness. Many tissme cells, particularly those in which the mechanieal fometions are emplasized, form a supplementary wall that is incapable of surface expansion. Such rells are mable to grow or to increase in volume mless the protoplast can escape from its indurated enrelope. A wall of the former category will arbitrarily be designated as a primary wall ; the latter type of wall will be referred to as a secondury wall. The serondary wall of plant cells provides a more farorable medium for phrsical, rhemical, and mirroseopic investigations; and. becanse of its eoomomic and industrial importance in textile fibers and pulp and as a somree of celluluse and its derivatives, it has been intensively stutied during the past one hundred years. Tn other words. murd more is known about the chemieal romposition, the microseopic structure, and the optical behavion and other phrsieal properties of secondary walls than is known abont primary walls.

Inder high magnification the seromelary wall of plant hairs, of fibers, and of sclecenchyma in general, exhibits many diverse strurtmal patterns; these range from ronrentric to radial patterns, or to varions complex "ombinations of such simpler pattems. Fig. 1 illustrates a transverse seftion of a thick secomdary wall at a mannifi"ation of two thomsand diameters. By transverse, I mean a section ent at right angles to the long axis of the cell. The wall

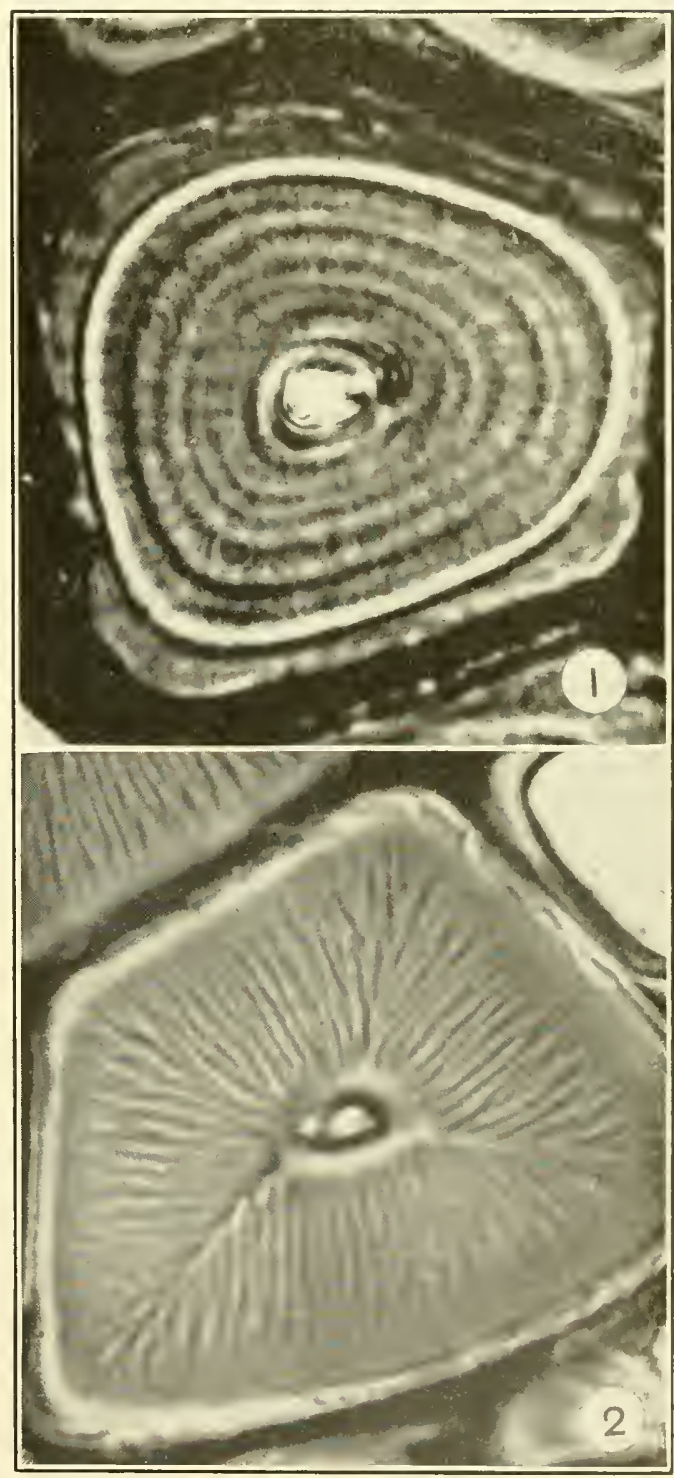

Fig. 1. Transverse section of a thick, unswollen secondary wall, slowing dominantly concentric pattern $(\times 2000)$.

Fig. 2. Transverse section of at thick, unswollen secondary wall, showing radial and ramifying pat tern $(\times 2000)$. 


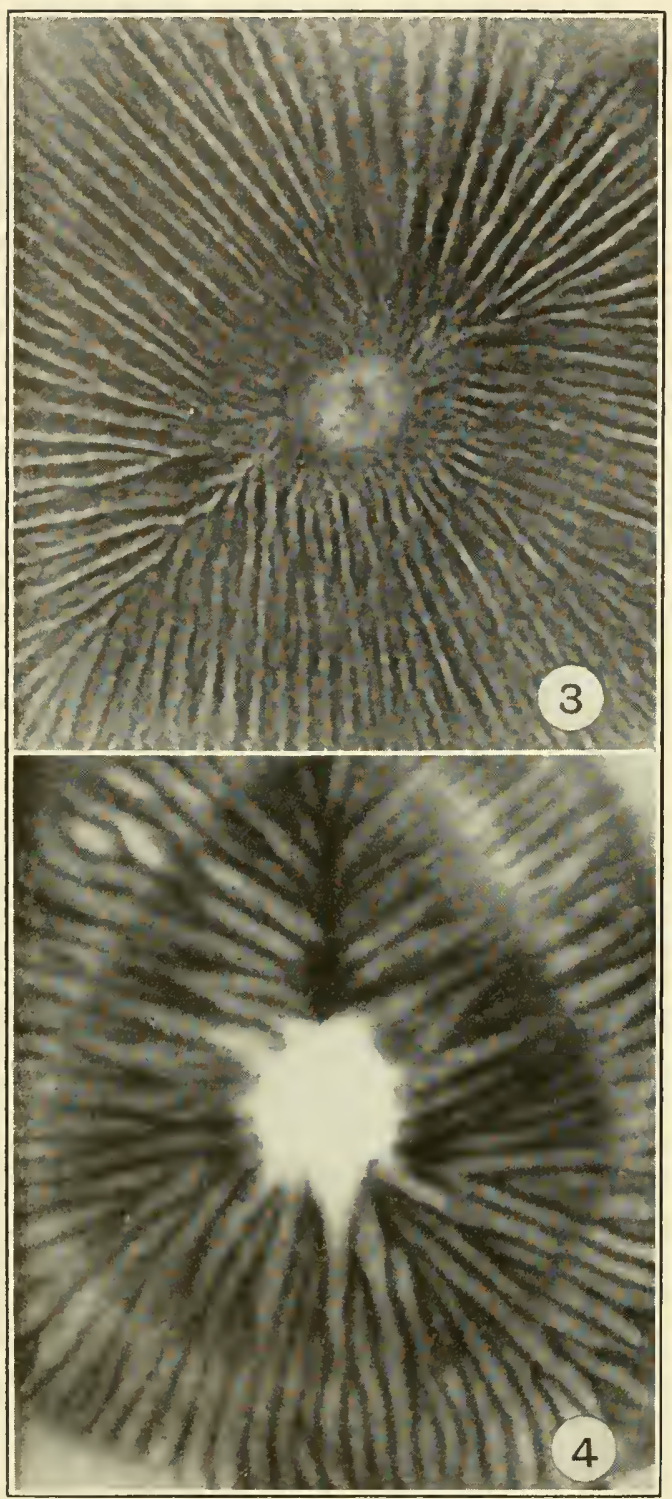

Fic. 3. Purified and expanded cellulosic matrix from section similar to Fig. "2. Total enlargement, $\times 3600$.

FIg. 4. Lignin residue of section similar to Fig. 2. Total enlargement, $\times 3000$.

shows conspicnons concentricites or lamellations, and, in addition, a finer radial pattem that apporaches the limits of microseopic visibility. Fig. 2, on the contraly, exhibits a dominantly palial and ramifying patterm. When surch sections of the seeondary wall are adrefully and grablually expanded by the use of suitable swelling reagents, finer and finer details of the characteristic structural patterns become successively visible under the mir roscope (Figs. 3 to 6 ). In all eases the secondary wall resolves itself ultimately into a system of fine threads, or microfibrils, which are variously aggregated and more or less extemsively coalesced. Where the microfibrits are oriented approximately paralled to the long axis of a cell, they appear in expanded transverse sections of such a rell as more or less circular specks or granulations (Fig. 5). The eoncentric, radial, ramifying, and other structural patterus of the secondary wall are dne, therefore, to varying densities or porosities in different parts of the wall. In the denser (darker) parts, the microfibrils are more numerous per unit area and are more extensively roalescer, whereas in the more porons (lighter) parts they are less closely agroregated and the area of interfibrillar capillary spaces is larerer.

In the case of a heavily lignified secondary wall, it is possible to remove the cellulose and leave a firmly coherent residue of lignin; and, conversely, it is possible to remove the lignin and leave the colerent matrix of cellulose. The cellulosic matrix (Fig. 3) and the limin residne (Fig. 4) exhibit positive and negative images of the same original, unswollen structural pattern (Fig. 2). It is evident that the lignin residne may be interpolated within the porosities of the cellulosic matrix. Such facts as these indicate not only that lignin ocenrs within the elongated porosities of the rellulosic matrix, but also that the microcapillary spaces in rellulose are intercommunicating. It is evident, aceordingly, that in dealing with the secondary wall of plant rells we are concelned with two continnous interpenetrating systems, (11) a matrix that is composed of coalesced miconofibrils and (b) a șstem of elongated microcapillaries that are intereommected.

The microfibrils of the secomblary wall ale (ommonly eomposed laroely of "ellulose, but

1 The term mierofibrils is msed not mecessarily to designate actual discrete entities, lut rather as a convenient expression for describing the alongated parts of a contimuous, porous matrix. 


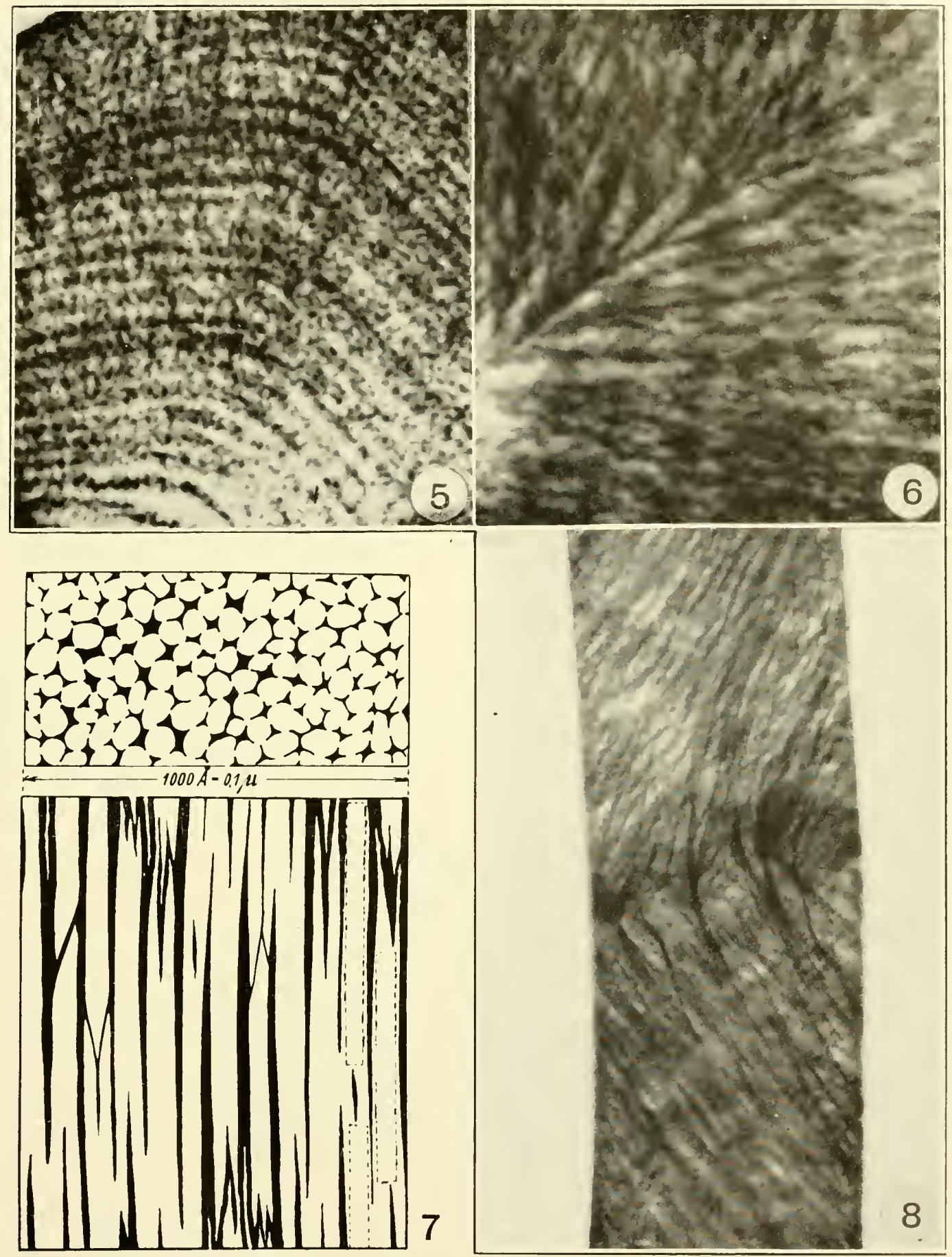

Fig. 5. Expanded transserse section of a eoncentrically lamellated secondary wall. Total magnifieation, $\times 11,000$.

Fig. 6. Expanded transverse section of wall having a ramifying structural pattern. Total magnification, $\times 7150$.

Fig. 7. Frey-Wyssling's eonception of the submieroseopie structure in transrerse and longitndinal sections of cellulose. Micelles are light, intermicellar spaces are dark.

Fig. 8. Surface view of an early stage in the formation of the secondary wall of cotton, slowing coalesced fibrils and a "reversal", in their orientation $(\times 1100)$. After Kerr. 
in certain types of plants may be formed of other substances (e.g., of chitin, as in Phycomyees, whose structure has been carefully investigated by E. S. Castle). The micocapillaries of the secomdary wall may be filled with liquid, or with lignin, cutin, suberin, liemieelluloses, ${ }^{2}$ or a rreat rariety of other organic compounds, and even at times with rystals, such as silica.

It is adrisable to raise the question, how may one be certain that the structural patterms visible under the microscope are not artifacts, produced for example by stresses and strains in an expanding disk-shaped section? There are fom lines of evinlence which shomld be emphasized in this ennection :

(1) Sperific, complex structural patterns whose coarser details are (learly visible in unswollen material are characteristic of particular types of cells and of specific types of plants.

(2) Framents of the secondary wall, whatever their shapes and sizss, exhibit. when swollen, their own particular part of the general structural pattern form which they were removed.

(3) During the earlier stages of formation of the secomdany wall, it may be observed that the cellulose is deposited in the form of coalesced fibrils (Fig. 8).

(4) In the case of cotton, the hairs elonarate for a rertain number of days; then the serondary wall is formed during a period of from twenty to forty days. By collecting material carch sucessive ilay after a known date of flowering. Kem has shown that two lamellae of raryong porosity are formed doring earle 24 hours, a denser lamella being deposited during the day and a more porous one during the night. The wirth and the porosity of these lamellae fluctuate more or less with rariations in enviponmental omelitions. In the cotton fields neall Raleigh, Nonth Carolina, chalancteristice patterms of lamellate are liequently formed

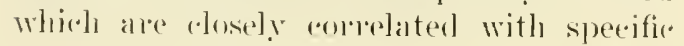

2 A. (1) Norman la:as suggested that in the case of

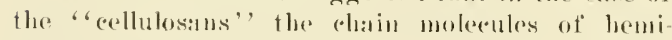
rellulose maty he associated with ehain molecules of rellulose within the mieclles. variations in temperature (Figs. 9 and 10). Thus, the hairs of different cotton plants which have grown during the same period of valying envirommental influences exhibit identiral patterns of lamellae, and it is possible to cross-date daily growth rings, much as the annual rings in the stems of western yellow pine may be cross-dated. In addition, Anderson and Kerr have shown that lamellation of the secomclary wall of the cotton hair may be eliminated by growing plants under constant light and temperature (Fim. 11). By varying these envirommental factors, lamellate may be induced to form as desired (Fig. 12).

Since the roncentricities of secondary walls are not artifacts, they provide a conrenient means of determining the approximate diameter's of the microfibrils. If the diameter of the unswollen wall is earefully measmed and the number of constituent lamellae in a swollen section is comnted, a fainy close approximation of the diameter of the lamellae in their nuswollen state ean be obtained by dividing the diameter of the unswollen wall by the number of constituent lamellae. The finer types of lamellae crate down to $500 \mathrm{~A}$ or less in diameter. Sinee such lamellat are (omposed of a single hayer of roalesced microfibrils, these threads, in their mswollen eondition must likewise approach 500 i or less in diameter.

The evidence presented thus far indicates that in the fiedd of microscopically risible structures, the secomdary wall of plant cells is composed of a continuons sustem of coalesced micomibrils which is perforated by a continnous srstem of intereommunicating mierocapillaries. The eollulosic matrix is an extraordinarily porous structure, yet it exhibits a very ligh tensile strength. It is of interest to ampare the visible strueture of cellulose witlu pictmes of its structme whirh have heen postulated in the truly submicroseropic field. For many rears following the publication of Nïgeli's micellal hypothesis, the micelles or elystallites of rellulose were considered to be discrete entities separated on all sides by intermicellar spaces. Subsequently, evirlence obtained lamely by x-lay analyses was interpmeted 
as inclicating that these mirelles ale commposed of chain molecules which are or.ented parallel to one another, with specific ant chanacteristic spacings between the indiridual chains of the agregeration.

AUGUST

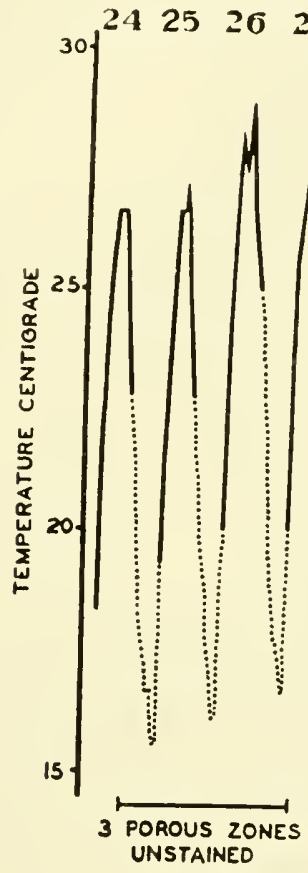

lose as a contimous matrix of oferlapplume rlatin molecules, which is perforater by al (ontimuons system of intemicellal (aipillaries (Fig. 7). In other wolels, micelles are no lomgel" to be regarded as discrede

\section{SEPTFMBER}
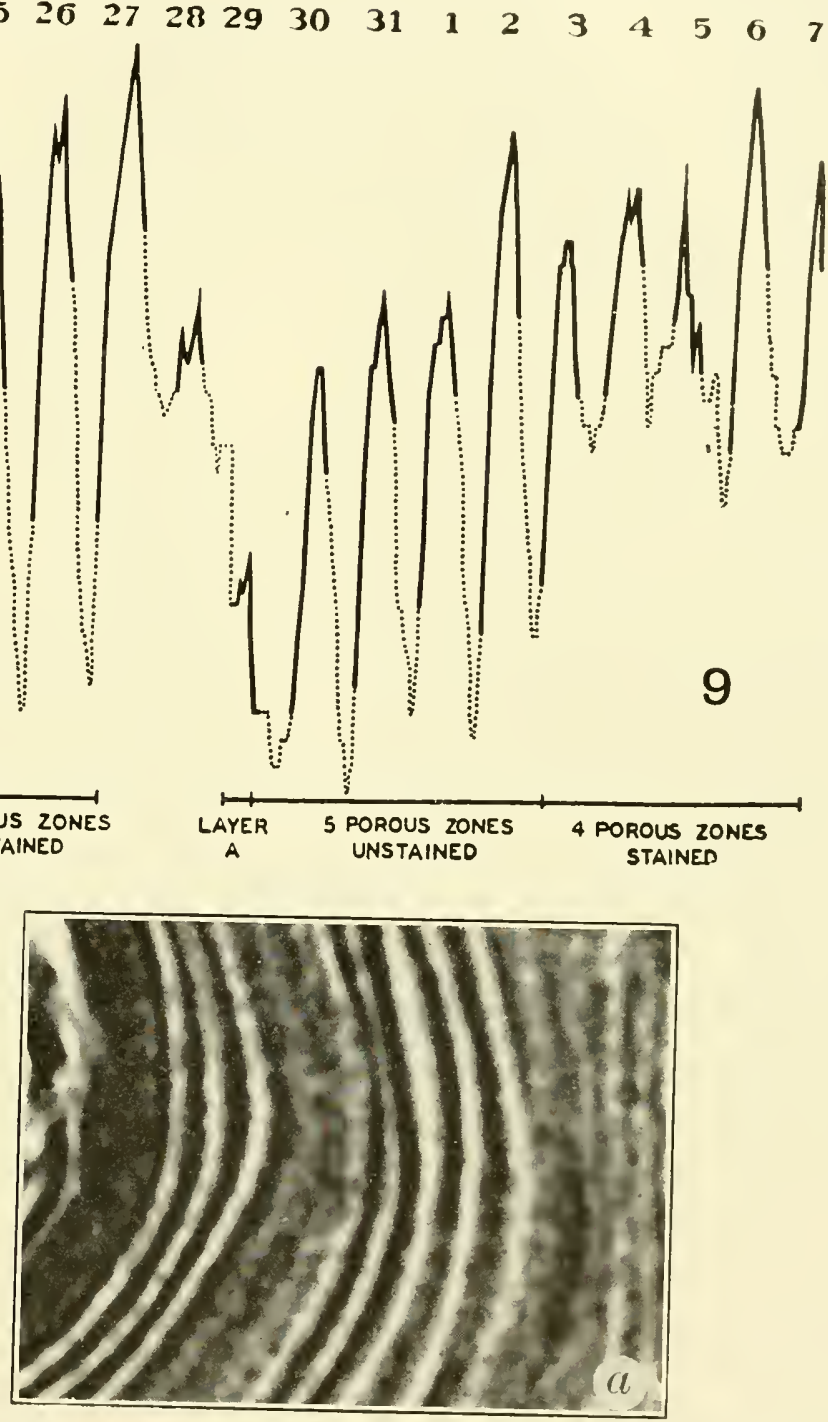

Fro. \%. Fluctuations in temperature during the development of the cotton hair illustrated in (a). Dotter parts of the curve 8 P.M. to 8 A.M. (a) Part of Fig. 10 more highly magnified $(\times 11,400)$,

Recently, Frey- Tyrsting has profommlly modified this cassical conception, in oreler to harmonize the onflicting evilence from various fields of physical. chemical. and hiological research. He now regards celhn- "ristallites, but merely as anastomosing" parts of a coherent polons matrix. There is murh that "an be said in faror of such a view, since it allows for chain molecules of greater length, for the coherence of puri- 
fied cellulose, and for rarious optical, physical, and chemical properties of cell walls in general. It should be recognized, lowever, that according to such a molification
(Fig. 7) resembles so (closely the finer visible structure of swollen secondary walls that a question arises whether there are two distinct sizes of fibrils, or rather a series of

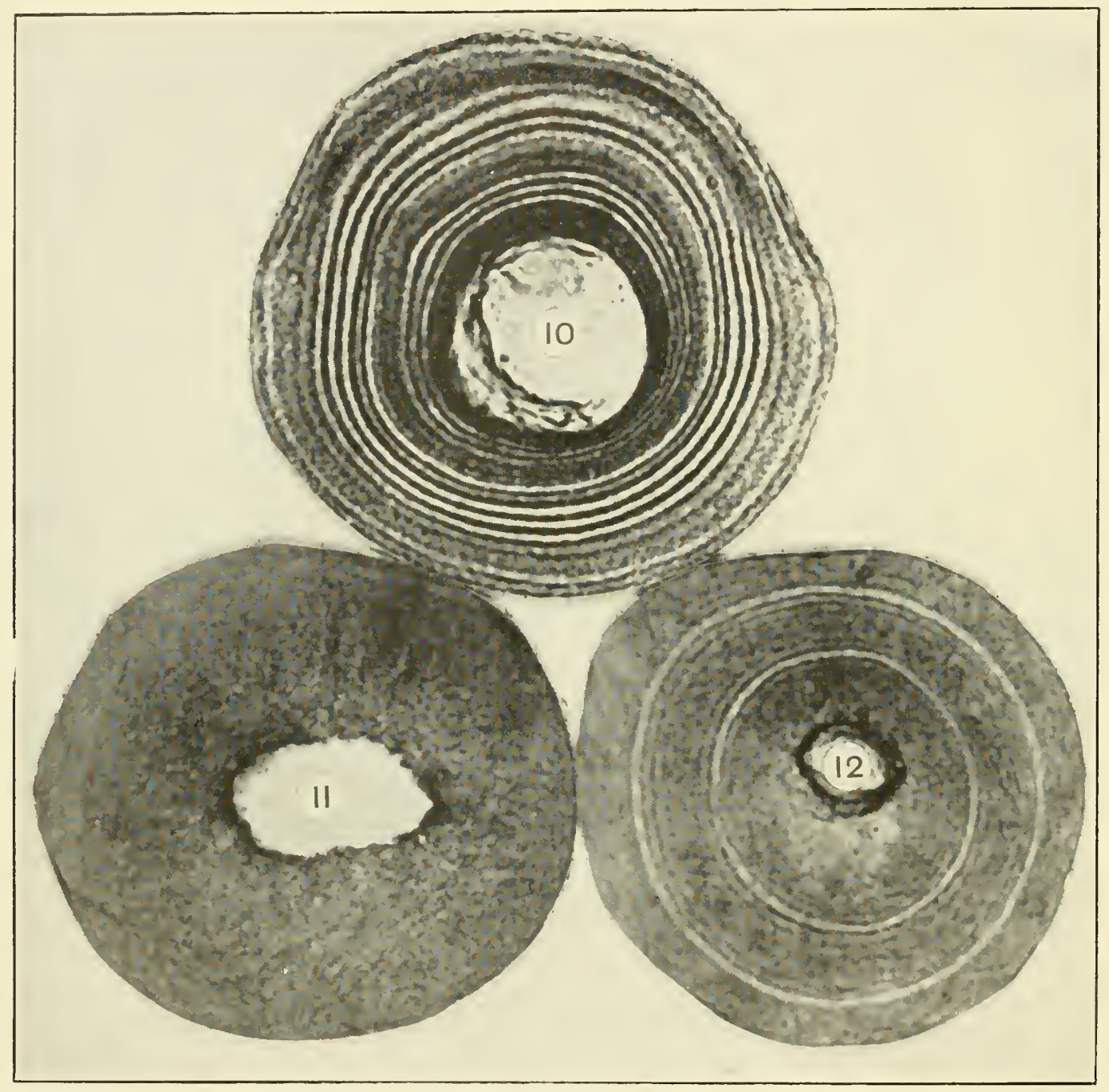

FIg. 10. Swollen transverse section of a cotton hair grown during the period of temperature fluctuations shown in Fig. 9. Total enlargement, $\times 5130$. After Kerr.

Fig. 11. Transwerse seetion of the ringless secomdary wall of a cotton hair, grown under eomstant illuminstion and temperature. Total enlargement, approximately $\times 5250$. After Anderson and Kerr. Fif. 12. Transverse section of the secomdary wall of a cotton hatir, showing experimentally induced lamellae. Total enlargement, appoximately $x 5250$. Plotographed from one of Korr's preparations.

of Nägeli's luypothesis, the crọtallite or micelle loses its imlividuality.

Frey- Wyssling's modified (onneption of the subminoseopie structure of cellulose these structures which grate down in size from macrofibrils to microfibrils and to micelles $60 \mathrm{i}$ or less in diancer. Althomgl reliable factual data for conclusively an- 
swering these questions are not available at present, it seems likely that the latter alternative may ultimately prove to be the colrect one.

It should be noted in passing that in rases where the orientation of the macrofibrils or microfibrils, and of the chain molecules, has been ac*ulately determined ${ }^{3}$ in the same material, the chain molecules are oriented apploximately parallel to the long axis of the fibrils. Apparent reviations in the orientation of chain molecules $n 1^{*}$ of micelles within the secondary wall are rommonly due to fluctuations in the orientation of fibrits, rather than to aberrations in the aligmment of chain molecules or.of micelles within the fibrils.

Not all of the risible concentricities of the secondary wall are due, necessarily, to fluctuations in density or porosity of the cellulosic matrix. Thus, the broader concentrieities that are of in tracheary and solerenchymatous cells are due largely to: (a) rarying amounts of lignin, polyuronide hemicelluloses, or otler organic substances that are deposited within the porosities of successively formed parts of the secondary wall; $(b)$ the ocenrence of non-cellulosic layers in certain specific types of cells (Figs. 16, 20) and (c) variations in different layers of the secondary wall, in the orientation of the microfibrils and pari passu of the chain molectules of cellulose (Figs. 14 and 18).

In many cases fluctuations in the porrosity of the cellulosic matrix, in the amounts of organic substances that are deposited or formed within the capillary spaces, and in the orientation of the chain molecules and mierofibrils, occur simultaneously within the limits of a single secondary wall. Much of the controversy in recent years and many of the existing discrepancies in the literature about the physico-chemical structure of plant eell walls, and particularly that concerning the orientation of chain molecules

3 For example, in the case of Falonia, compare the work of Correns and others with that of Astbury and his coworkers; or in the case of cotton, compare that of Anderson and Kerr with that of Berkley. and of micelles within them, might have been aroided if the signifirance of the mumerous biological valuables in the material murler investigation bard been alearly vismalized and alcomately interpreted. Where a wall is omposed of layers which differ markedly in thickness (Fig. 14), or of multiple layer's of more neary miform thickness but of widely fluctuating fibrillat orientations (surh as certain types of sclemenclurma), it is fresprently difficoult to obtain an acourate picture of its strncture br examining the wall in surfalce view witl polarized light, or by x-lay analyses of entire cells. Thin transverse, lomitudinal, and diagonal sertions provide the most farolable material for preliminary investigations. Not only may such sections be examined muler a polarizing microscope both before and after extraction of noncellulose constituents with suitable solvents, but they may also be swollen, in order to reveal variations in density or porosity of the cellulosic matrix and in the swelling anisotropy of successive lavers. Furthermore, arstals of iodine may be indureed to form in the elongated porosities of the cellulosic matrix (Fig. 22). Since these crystal agregates are oriented approximately parallel to the long axis of the fibrils, ther provide a convenient means of studying variations in the orientation of cellulose in different parts of a secondary wall. Additional evidence may be obtained ly olsserving changes in the orientation of "slip planes" and of predetermined planes of hydrolysis (Fig. 21). The orientation of pit apertures and of planes of mechanical clearage (Fig. 23) must be utilized with extreme caution, particularly in dealing with thimmer types of secondary walls.

In the four types of rells illustrated in Figs. 14, 16, 18, and 20, the evidence which may be obtained from these raried lines of investigation is in close agreement, and clearly indicates that the secondary walls have the general troes of structure that are shown in Fios. 13, 15, 17, and 19. The central layes of Fig. 16 and the dark layers of Fig. 20 are isotropic in longitudinal and diagonal sections of the cells, as well as in 

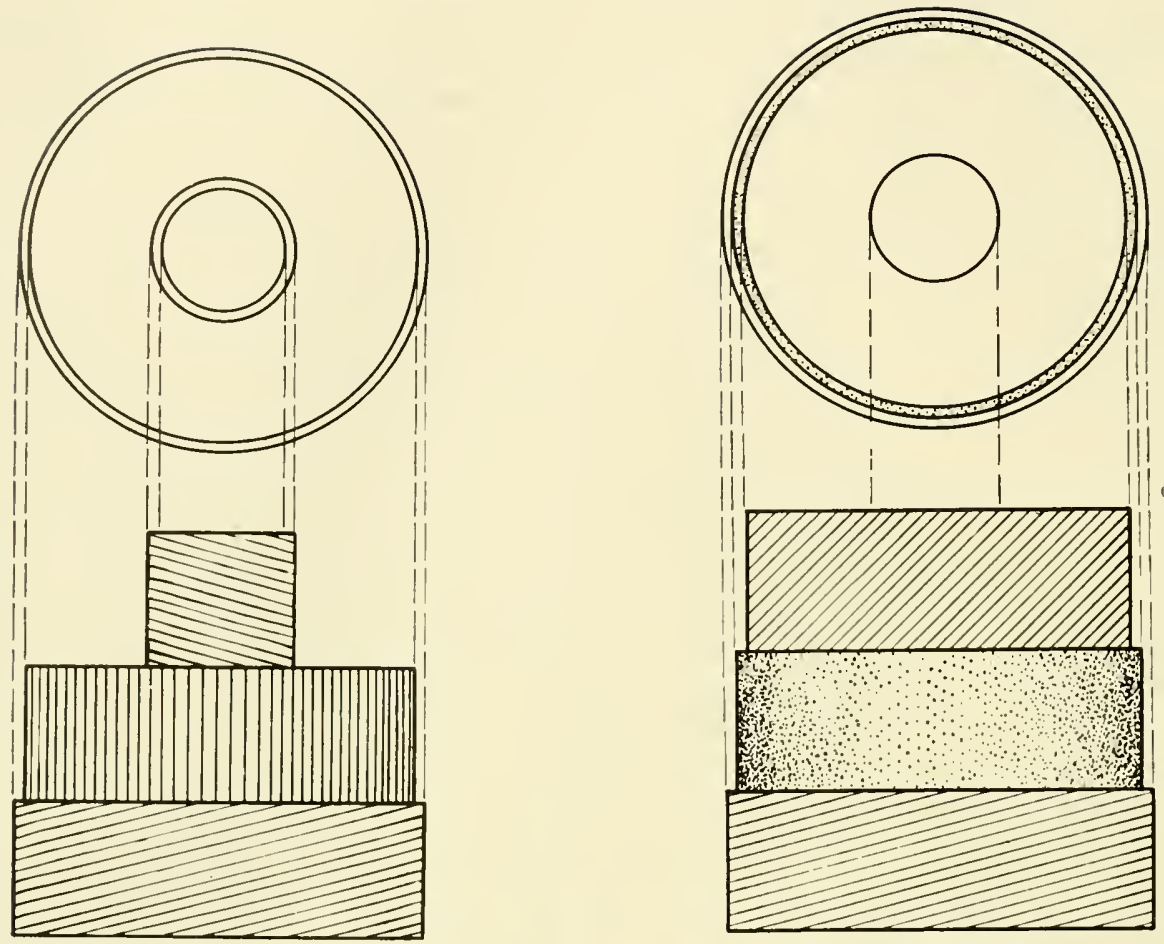

13

15

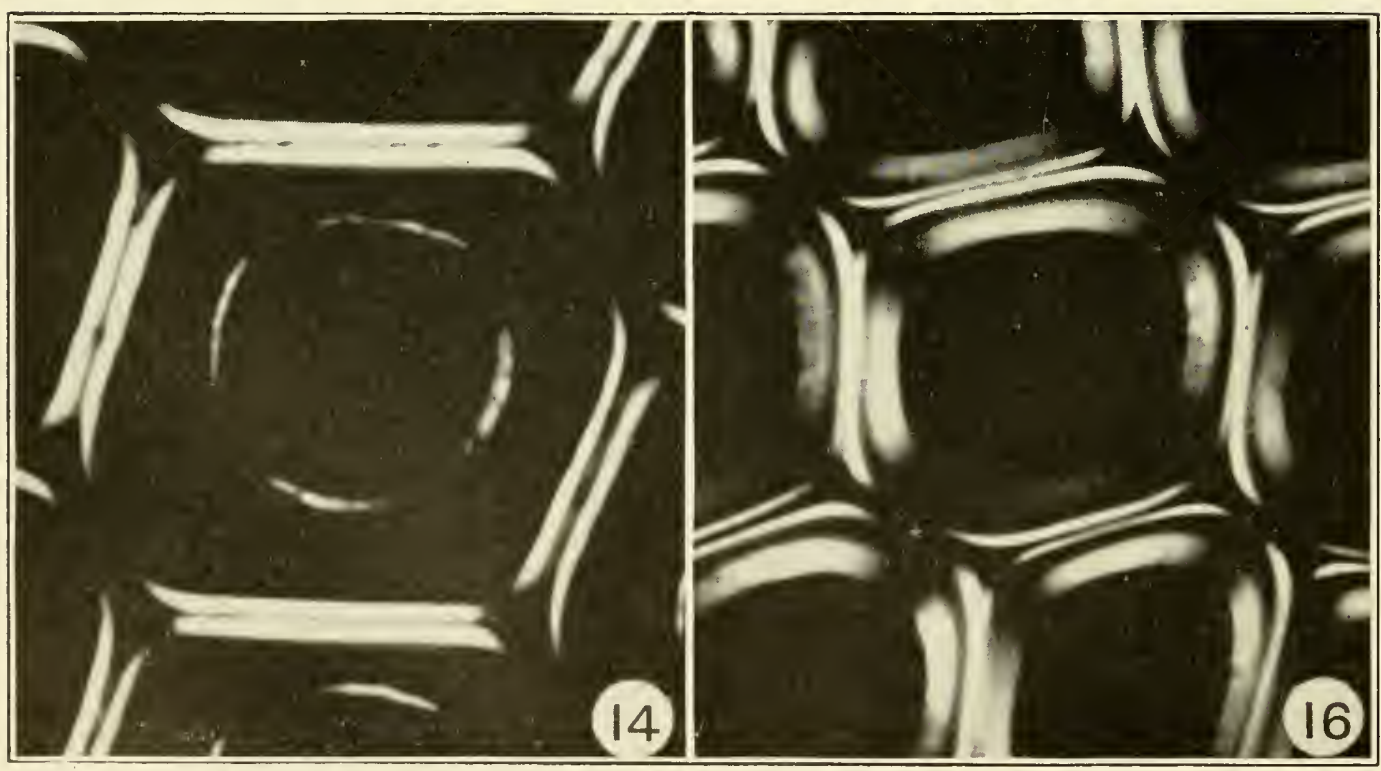

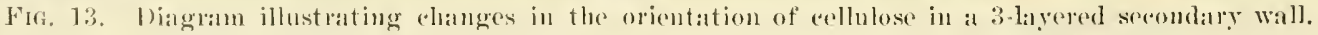
Fia. 14. Transverse seetion of wall photographed in polarized light between eressed Nirols $(\times 1340)$.

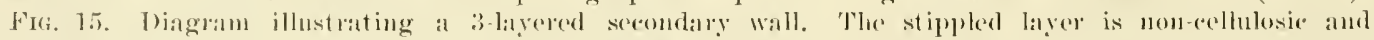
truly isotropice.

Fic. 16. Transverse seetion of wall photographed in polarized light between erosserl Nicols $(\times 1280)$. 
transvelse sections, and are soluble in leagents which do not dissolverollulose. On

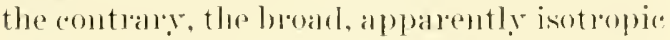
larels of Figs. 14 and 18 an strikingly birefoingeret in lomeritulinal seotions, and the temuons layers that are hireforingent in transielse sertions become isotropic ol feebly anisotropic. The infensity of birefingence fluctuates in liagomal sortions with ehanges in the angle of ohlignity. This is true resaldess of whether the sertions axe axamined moler the polatizing microsene before or after treating the sertions, with solvents for nom-cellulosic comstituents. It may be detemmined by direot observation, and loy the valious lines of colpobolative eridence ontlined in the precerling paragraph, that the microfibrils ant microcapillaries of the tenuons lavers an oriented transversely or in helices of relatively low slope, whereas those of the broal hayels are ar'anged longitudinally or in lelices of vely steep slopes. In mative cellulose, the majol axes of swelling anisotropy are oriented at right angles to the lomg axis of the micelles and microfibrils. In other works, a layer of the secondary wall expands comsiderably in planes at right angles to the long axis of the microfibrils, but only slightly in planes parallel to this axis. Thus, in walls having the trpe of stmucture illustrated in Figs. 14 ant 18, the bloat central lavers expand latelally. The temuons layers, which envelop these layers externally, have a nealy transverse orientation of microfibrils and are unable to increase malketly in cilcoumference. Therefore, they tend to rupture during swelling of the secondary wall, as shown in Fig. 24.

Although the cellulosic matrix of the seconclaly wall appears to be a continums rather than a discontinuous system, it exhibits predetermined planes of hydrolysis and of eleavare. The enzymatic hydrolysis of celltulcsic walls (Fin. 21) which is cansed by the activity of reltain remalkable mooddestroying fungi, propresses along two predetermined planes, as does the acetylation of rellulose and its hydrolysis by mineral acids. One of these sets of planes is oriented parallel to the long axis of the mirrofibrils and, mari passu, of the micon-

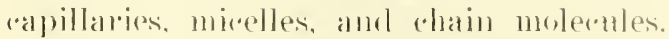
The other is or.iented at all anderle ol 20 to 25) to this axis. The latter set of planes of Jychospsis and of eheminal reatcon is

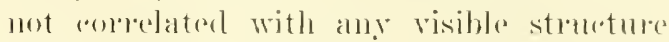

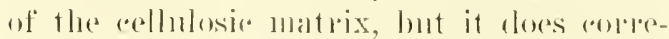
sponel lather asely with certain sparings within the arytal-latticest' rellulose. These sparoings are between the asily hyoloolyzable ether-linkagas of the (onbe-rentel and enheside chains. They fluctuate aromma $14 \mathrm{~A}$. and form planes which intersect the lone axis of the chain molecules at angles of Prom 2020 $40^{\prime}$ to $25^{\circ} 04^{\prime}$. Althomeh the submirroscopic and the visible planes are oriented at similar angles, it is not evident why the chemiral reartions shombl proness alomer these specific planes. If it bo assinned that the spacing between the ether-linkages is of most favorable manitude for the insertion and arotivities of enzyme molecules, it is not rlear why the reactions clue to acotyla-

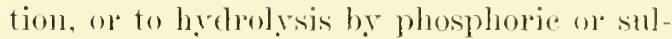
phuric arids - where smaller molecules ale concerned-shomld prouress along the same planes. Nor is it eviclent why the enzymatic hycloolysis should progress so commonly along a single plane rather than in a ziozad mammer, since at any specific ether-linkage it mould seem that hydrolysis might progress in varions directions, either mpward or lownwarl at angles of form 22 to $25^{\circ}$. Therefore, the most that may be conclucled at present is that there are predetermined planes of rhemical reaction in mative rellulose, certain of which are rosely (orrelated with visible orientations in the cellnhosic matrix and otluers which must be cansed solely hy molecolar configmations. Similarly, in mechanically-indnced colncking of the cell wall, there are predetermined planes of (leavage, some of whith may be correlated with visible weaknesses in the cellulosic matrix, and others which are cattsed hy submicoscopic factors. One of these sets of planes of structural weakness is oriented parallel to the lome axis of the mierocapillaries and microfilorils and is muth areentuated in rell walls having concentric (Fig. 5) or radial lamellae (Figr. 2) of strikingly 

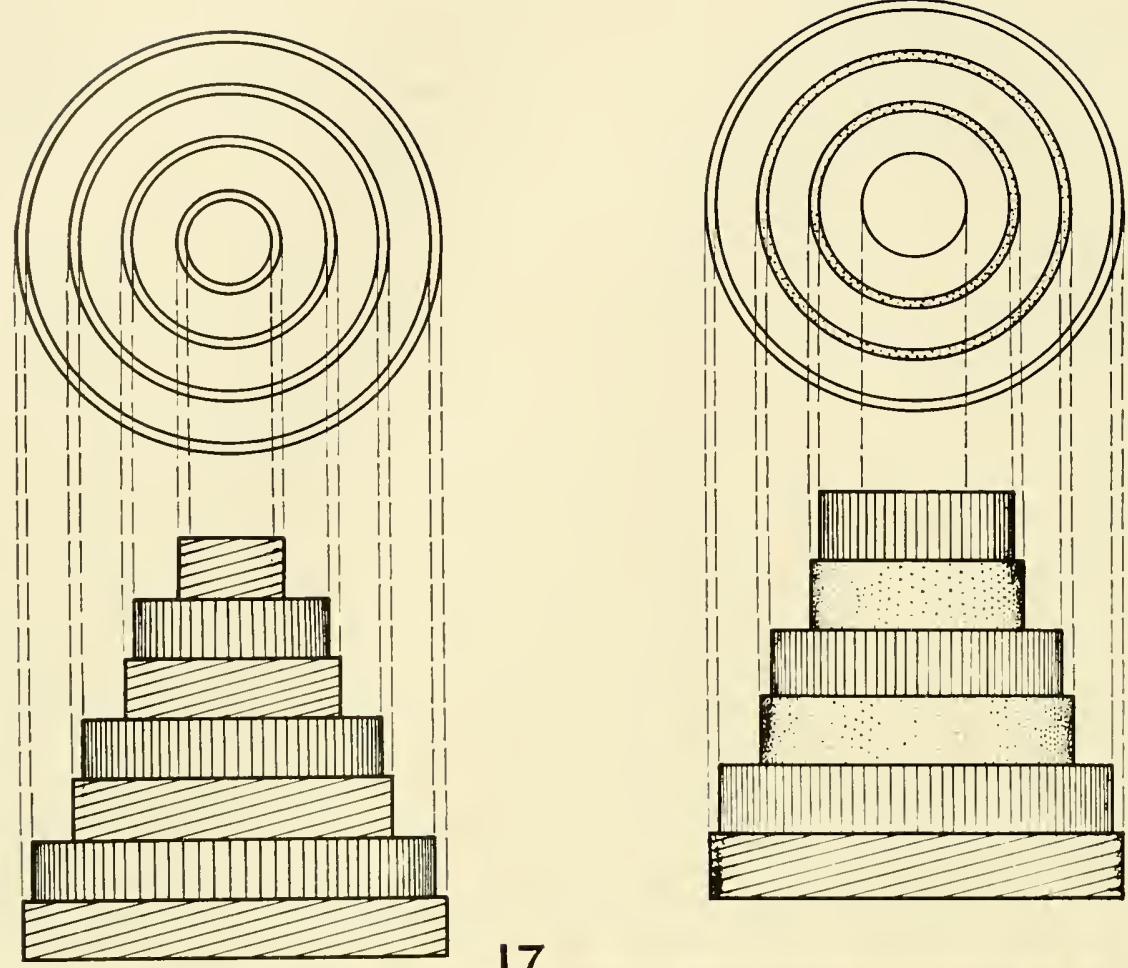

17

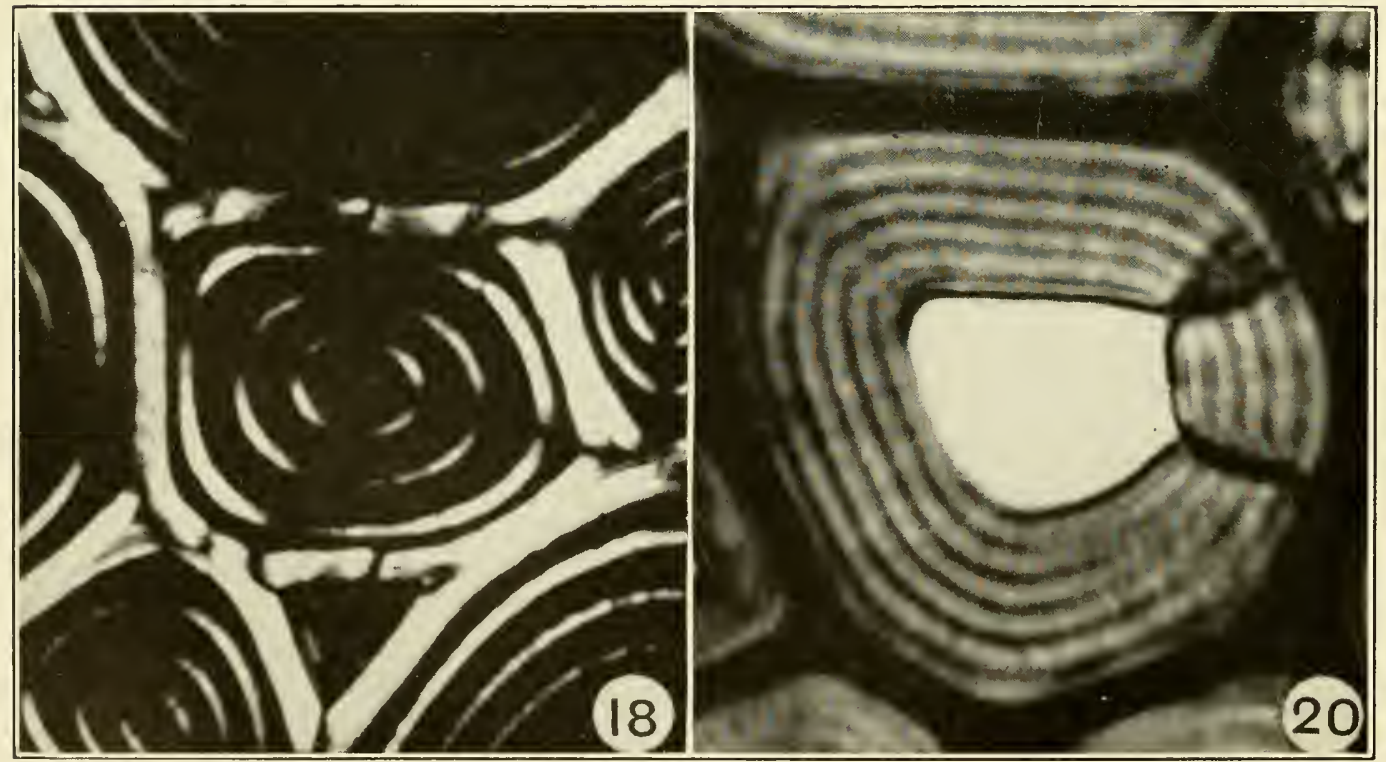

Fif, 17. Tiagram illustrating changes in the orientation of eellulose in a many-lilyered secondary wall. Fif. 18. 'Transwerse section of wall, plotographed in polarized light hetween erossed Nieols $(\times 1400)$. Fig. 19. Diagram illustrating a many-layered secondary wall. The stipled layers are non-eellulosic and truly isotropic.

Fug. 20. Differentially stained, transwerse section of such a wall, photographed in ordinary light. The dark layers ale nou-cellulosic $(\times 1830)$. 
different porosities. Such walls tend to split concentrically, radio-longitudinally or radio-helically (Fig. 23) even in ordinary drying; walls of more miform texture or of ranifying patterns do not.
By more or less drastiv "henival and mechanical treatments, the secondary wall may be dissected alome these predetermined planes of reavage and hydrolysis into fragments of varying shapes and sizes

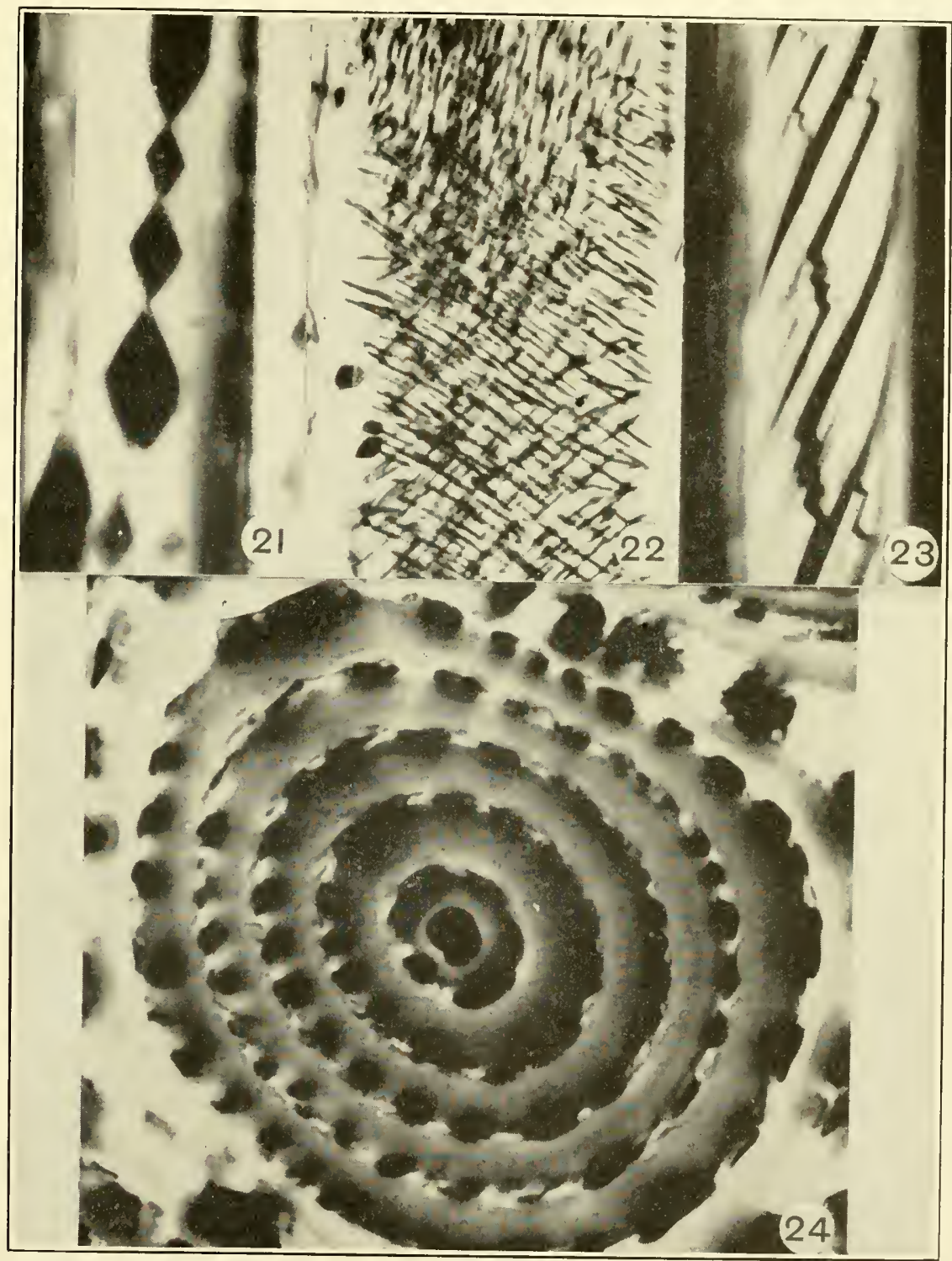

FIg. 21. Longitudinal section of a secondary wall, showing eavities produced by woor-destroying

fungus. There are two sets of planes of exzymatic hydrolysis, one oriented parallel to the long axis of the microfibrils of cellulose and the other at an angle of 20 to 25 to this axis $(\times 990)$.

FIG. 22. Longitudinal section through parts of the secondary walls of two adjacent cells, showing three orientation of the visible crystals of iodine $(x 900)$.

FIG. 23. Longitudinal section of a secondary wall showing planes of mechanical cleavage $(\times 700)$.

Fig. 24. Swollen transverse section of a secondary wall of the type illustrated in Fig. $18(\times 1300)$. 
-dermatosomes, ellipsoid particles, fusiform bodies, elongated shreds or fibrils, ete. During the last 100 years a sucession of investigator's have hypothesized that certain of these fragments are the elementary mits from which the cell wall is construrted. That such fragments are heterogeneons is indicated by their particle domble refraction, by their dichroism, and by other physical evidence. Furthermore, it should be clearly recognized that many cell walls and wall layers are much less than one micron in diameter and that the narrower types of lamellae grade down to 500 i $\mathrm{or}^{\circ}$ less in diameter. Obriously, these structures caunot be constituted of units 10,000 i or more in diameter.

As previously stated, much less is known about the primary wall of plant cells than abont the secondary. Evidence is accumulating, however, which indicates that the primary wall has a fumclamentally similar physical structure. Statements in the literature that the primary wall is amorphons or isotropic, that it is not composed of typical cellulose, that it is eonstituted of unoriented cellulose, or that it is composed of cellulose which is invariably oriented at right angles to the long axis of the cell or to the direction of major expansion are incorrect and based upon errors of observation or of interpretation.

The primary wall, like the secondary one, is composed of a continnous system of more or less extensivety coalesced microfibrils of anisotropic cellulose, or at times of chitin, mamman, etc. The elongated porosities of the cellulosic matrix commonly contain pectic compounds and hemicellukses, and not infrequently lignin, cutin, suberin, waxes, and many other orqunic substances. The primary wall frequently is lamellated, and, as in the case of the secondary wall, the orientation of the microfibrils, micelles, and chain molecules varies meatly in different trpes of cells and in clifferent lamellae or parts of the same wall. Growth and expansion of the primaly wall appear, in many cases at least, to involve the pulling apart of the fibrils in the previously formed lamellae and the deposition of new layers of coalesced fibrils. In fact, I suspect that the dissical controversy regarding growth by intussusception versus growth by apposition will ultimately be settled largely in favor of apposition.

Although we are gradually obtaining a much rearer picture of the complex structures of the walls of plant rells, we have learned very little during the last 100 years abont the actual processes by which these remarkable structures are formed by the protoplast. In this direction lies an mmexplored field for future research.

\section{References Cited}

ANDERson, D. B. and KerR, T. 1938. Growtl and strmeture of Cotton Filur. Ind. Eng. Chem. Ind. Eil., 30: 48.

Astrury, W. T., MarwIGK, T. C. and Bernal, J. D. 1932. X-ray Analysis of the Structure of the Wall of Valonia rentricosa. Proc. Roy. Soc. Lomdon, 109: 443.

Astbery, W. T., l'Reston, R. D. and Normax, A. G. 1935. X-ray examination of the Effects of Removing Non-cellulosic Constitnents from Vegetable Fibers. Nature, 84: 391.

BAILEY, 1. W. and KerR, T. 1935. The Visible Structure of the Secondary Wall and Its Significance in Physical and (hemieal Inrestigations of Tracheary Cells and Fibers. J. Amold Arboretum, $16: 273$.

—_- 1937. The Structural Variability of the Secondary Wall as Revealed by "Lignin" Residues. $J$. Arnold Arboretum, 18: 261.

Baney, I. W. and Vestal, M. R. 1937. The Orientation of Cellulose in the Secondary Wall of Tracheary Cells. J. Arnold Arborctiom, 18 : 185.

1937. The Rignifieance of Certain Wood-destroying Fungi in the Study of the Enzymatic IIydrolysis of Cellulose. J. Anold Arboretum, 18: 196.

Berkefy, F. F. 1939. Collulose Orientation. Strengtle and Cell Wall Development of Cotton Fibers. Textile Resenteh, 9: 355.

Bonser, J. 1935. Zum Merhanismus der Zellstreckung anf Grund der Micellarlehre. Jahrb. H'iss. Botan., 82: 377 .

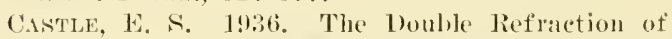
('hitin. J. Gen. Physiol., 19: 797.

1937. Membrane T'onsion and Orientation of Strueture in the 1'lant cell Wall. $J$. Cellular Comp. Ihysiol., 10: 113.

- 1938. Orientation of Structure in the Cell Wall of Plyeomyers. Proloplasma, $31: 331$. ('orrans, C. 1893. Zur Kenntnis der inneren Struktur ciniger Algemmenliranen. Beitr. Horphol. Physiol. Pflanzenz (Zimmerman), 1: 260 . 
Freudenberg, K. 1932. The Relation of Cellulose to Lignin in Wood. J. Chem. Ed., 9: 1171.

Freudenberg, K., Zocher, H. and Durr, W. 1929. Weitere Versuche mit Lignin. Ber, Deut. Chem. Gcs., 62: 1814.

Frey, A. 1928. Die Micellartheorie von Carl Nägeli. Leipzig.

Frey-Wyssling, A. 1935. Die Stoffausscheidung der höheren Pflanzen. Berlin.

Zellwäinde. Protoplasma, 25: 261.

—. 1937. Röntgenometrische Vermessung der submikroskopischen Räume in Gerūstsubstanzen. Protoplasma, 27: 372 .

. 1937. Ultramikroskopische Untersuchung der submikroskopische Räume in Gerüstsubstanzen. Protoplasma, 27: 563.

KERR, T. 1937. The Structure of the Growth Rings in the Secondary Wall of the Cotton Hair. Protoplasma, $27: 229$.

KERR, T. and BAILEY, I. W. 1934. Structure, Optical Properties and Chemical Composition of the So-called Middle Lamella. J. Arnold Arboretum, $15: 327$.

Meyer, K. H. and Mark, H. 1930. Der Aufbau der hochpolymeren organischen Naturstoffe. Leipzig.

Norman, A. G. 1937. The Biochemistry of Cellulose, the Polyuronides, Lignin, etc. Oxford.

Preston, R. D. and Astbury, W. T. 1937. The Structure of the Wall of the Alga, Valonia ventricosa. Proc. Roy. Soc. London, B, 122: 76.

Sisson, W. A. 1938. X-ray Diffraction Analysis and Its Application to the Study of Plant Constituents, Contrib. Boyce Thompson Inst., 9: 381.

Sponsler, O. L. 1933. The Molecule in Biological Structures as Determined by X-ray Methods. Quart. Rev. Biol., 8: 1.

Sponsler, O. L. and Dore, W. H. 1926. The Structure of Ramie Cellulose as Derived from X-ray Data. Colloid Symposium Monograph, 4: 174.

Stamm, A. J. 1936. Colloid Chemistry of Cellulosic Materials. U. S. Dept. Agr., Misc. Pub., 240.

VAN ITERSON, G. 1927. Die wording van den plantaardigen celwand. Chem. Weekblad, 24: 166. cellulose symposium. Chem. Weekblad, 30:2. 


\title{
CHROMOSOMES AND CYTOPLASM IN PROTOZOA
}

\author{
By H. S. JENNINGS
}

DEPARTMENT OF ZOOLOGY, THE UNIVERSITY OF CALIFORNIA AT LOS ANGELES, LOS ANGELES, CALIF.

Mr subject is the interaction of chromosomes and cytoplasm in genetics and in development, with special emphasis on the role of cytoplasm. I shall first treat this subject generally. Then I hope to illustrate, and perhaps to illuminate, some of these relations-particularly those concerned with genetics-from experimental observations on some of the more complex Protozoa.

Many years ago a well-known investigator whose devotion was all to biological chemistry ridiculed the notion, then coming into prominence, that chromosomes have an important role in inheritance and development, characterizing them in their supposed fixity and inertness as "bullets." Possibly some recent theories of the unitary nature of genes might, for the genes, offer temptation to such a gibe.

But chromosomes as perceptual objects in space show none of the fixity and inertness of bullets. The pictures that we see of the condensed stages of chromosomes, at the time when they are undergoing division, are most misleading if they are assumed to show the distinctive characteristics of chromosomes. The chromosomes are active and changeable; they continually operate on the remainder of the cell (which we lump together as cytoplasm), visibly interchanging materials with the cytoplasm, altering it, differentiating it. Recall a few of the fundamental features of such interaction of chromosomes and cytoplasm.

In the egg of Fundulus, according to the work of Richards (1917), the changes in the chromosomes, though visible in normal development, are rendered more conspicuous by brief exposure to radiation. Then the following changes are secn clcarly. The condensed chromosomes begin to enlarge and to take in material from the cytoplasm, so becoming vesicular. The vesicles in- crease in size; they take in so much cytoplasmic material that each chromosome forms a vesicle hundreds of times the volume of the same chromosome in the condensed condition. The chromosomal vesicles become so large that their boundaries touch and they are pressed together. The whole group of vesicles now constitutes the nucleus.

The chromosomes then are not merely the minute dense structures ordinarily called chromosomes. For the greater part of their lives they are large vesicles enclosing much cytoplasmic material. Such chromosomal vesicles may be seen and counted in the so-called resting nucleus of many cells; they are described under the name of prochromosomes.

These vesicles are active; they are conltinually changing. At their maximum size they contain a large quantity of material absorbed from the cytoplasm. What are they doing with this material?

What they are doing with it is learned partly from cytological observations and partly from our knowledge of the activities of chromosomes, acquired in the study of genetics. Direct observation shows that after the vesicles have become very large by absorbing much cytoplasmic material, they discharge that material back into the cytoplasm. The membranes of the vesicles fade away. The contained materials pass out into the cell body, where they are again classified as cytoplasm. The condensed chromosomes for the next cell division are formed from minute reserve parts of the large vesicles.

Direct observation shows further that the materials thus returned to the cytoplasm have been greatly altered while in the chromosomal vesicles. They carry with them great numbers of chromatin particles, detectable by cytological methods. 
Cytoplasm and chromosomes thus are not separate in fact and in substance, though they are often kept isolated in concept-to the great detriment of sound understanding. There is a continual cycle of interchange between them, a transformation of material from one to the other. Such a eycle recurs at every cell generation. As Conklin (1902) remarks in summarizing his illuminating observations on these phenomena in Crepidula, "One might speak of these changes in the nucleus as systole and diastole, by means of which an exchange of nuclear and cytoplasmic materials is brought about."

The observations made with the microscope must be supplemented by considerations drawn from the discoveries of genetics and of experimental embryology. We know from genetics that the chromosomes are effective in determining the characteristics of organisms. We know that they cannot determine the developed characteristics without influencing, altering, determining, the processes of development by which the characteristics arise. We see them doing this in the processes that have just been illustrated. Bodies as demonstrably active as the chromosomes, and effective in such diversified ways, must greatly alter the materials that they absorb from the cytoplasm; they must give off greatly changed materials into the cytoplasm. Observation in favorable organisms of what occurs in the earliest stages of development is strongly in agreement with this conclusion. Let us recall a few such cases.

The absorption of eytoplasmic materials into the nuclear vesicles is most conspicuous in the egg at the very beginning of development, just before cell division begins. So much material is absorbed that the nucleus becomes enormously enlarged, forming the great "germinal vesicle," which may have half or more the diameter of the entire egg. Then by the solution of the nuclear membrane all this absorbed and altered material is cast back into the cytoplasm. And thereupon occur revolutionary changes in the egg cytoplasm. Its materials rearrange themselves, become stratified, and take on an organization which forms the basis for the organization of the young animal. These changes have been vividly presented in the sea urchin by Boveri, and in the ascidian by Conklin. In this fundamental organization, those materials which have been elaborated in the chromosomal vesicles visibly play a conspicuous and important role.

The further course of development, after this fundamental organization has been laid down in the undivided egg, is such as to suggest-nay, perhaps to disclose-an outline schema of the role of chromosomes and cytoplasm in the origin of bodily differentiations. The organization of the ovum shows itself in the stratification of different materials in the so-called "ego pattern": a stratification which shows that there must have been some fundamental axial differentiations in the cytoplasm, handed on from the parental cytoplasm before the stratification took place. By cell divisions the different formative materials of the diverse layers are separated into different cells. And these cells containing diverse cytoplasmic materials develop differently, to produce different parts of the young individual. And differentiation in accordance with this schema is progressive. Parts that at first form a homogeneous unity later become differentiated into diverse structures by an extension of these processes.

In bringing about these differentiations, there is repeated in every cell the "systole and diastole" of chromosomal and cytoplasmic interchange. But by the earlier steps of this interchange, the cytoplasms of the different cells have already become diverse. Therefore the reactions with the chromosomes must now give different products in the different cells.

Further, the chromosomes, as we know, are not homogeneous; each single chromosome is composed of many different materials commonly known as genes, and these materials have very diverse effects in development. The different cytoplasmic materials in the different cells must react in different cases with different chromosomal materials, yielding diverse products in the 
different cells. What chromosomal materials shall come iuto action in any cell must depend on what cytoplasmic materials are already in the cell. Thus the cytoplasm is not merely passive; it actively determines what shall happen in the chromosomes, as was demonstrated in a striking case long ago by Boveri. Every cell retains all the chromosomal materials, but which of these materials comes into action in each cell depends on what cytoplasm is there present, as well as upon the conditions under which the reactions occur, a matter with which we are not here concerned.

This process of diversification of parts continues, by the methods already set forth. It is not my province to follow in detail the infinitely varied phenomena of development. But the fundamental phenomena, for our purposes, are those just indicated: interaction of chromosomes and cytoplasm to produce new materials that are incorporated into the cytoplasm; localization of these diverse materials in definite patterns and in different cells; repeated interaction of these diverse materials with each other and with the chromosomes, yielding additional differentiations, until at the end the many diverse tissues and organs of the developed body have been formed. Every cell, at least for the greater part of development, contains the whole set of chromosomes with their genes. The differentiations of the cells are not in their chromosomes, but in their cytoplasm, produced through reaction with the chromosomes.

Such, then, appears the nature of chromosomal and eytoplasmic interaction in producing one kind of differentiation-the differentiation of the single individual into diverse tissues, organs, and functions, during ontogenetic development.

But there is another type of differentiation, quite diverse from that so far sketched. A species is not uniform; its individuals are diverse. They develop differently, yielding diversities of form, structure, and function -diversities in what we call their hereditary characteristies. It is this diversity among individuals, along with the complementary similarity of some individuals, that presents the great problem of genetics. The differentiations within the single body form the problem of experimental embryology. It is the province of genetics to inquire as to the origin of the differences and similarities among different individuals. Ontogenetic differentiation and genetic differentiation are two diverse problems.

The studies of genetics show that differences among the chromosomes play a very great role in the production of diversities among individuals. Individuals are diverse in their hereditary characters because they begin life with diverse chromosomal materials. The chromosomes present in the collective members of a given species are highly diversified; they differ greatly in the different individuals. When these individuals unite in pairs for reproduction, great numbers of diverse combinations of chromosomal materials are produced; and these diverse combinations yield individuals differing in their characteristics-in form, colors, structure, chemical properties, and functions. The system according to which these diversities are produced through the distribution of chromosomal materials constitutes Mendelian heredity.

Has the cytoplasm a role in producing these hereditary differences? Are some of the hereditary differences between individuals due to the fact that the different individuals begin life with different types of cytoplasm? May differences in cytoplasm at the beginning of development produce diverse characteristics in different individuals, just as differences in chromosomal materials may do? And may such cytoplasmic diversities be transmitted from generation to generation, as chromosomal diversities are transmitted? These are the fundamental questions as to the role of cytoplasm in geneties.

In a series of articles a few years ago, East (1934) summarized the evidence on these questions drawn from the study of genetics in multicellular organisms. I will not attempt to summarize the summary of East, but will present certain phenomena in the geneties of some of the higher Protozoa that appear to illuminate some of 
these matters and to extend our knowledge in these directions.

To present these things effectively I must recall important features in the relations of nucleus and cytoplasm in these organisms, as well as certain striking features in their biology. The organisms with which we are concerned are the ciliate infusoria, familiar to all of us in the school example Paramecium, or in other species.

These organisms begin their life cycle inmediately after conjugation with a single diploid nucleus; half of its chromosomes are derived from one of the two parents that have united in conjugation and half from the other. This single nucleus is in the midst of a complex body, the varied substances of which are known collectively as the cytoplasm. This eytoplasmic body is a highly organized structure, with protective parts, contractile fibers, transmissory fibers that tempt one to speak of a nervous system, motile organs (or organelles if you prefer), a partially differentiated alimentary canal (often with a complex armored pharynx), and other structures, as definite and as functionally arranged and operative as the organ systems of some of the multicellular creatures. To think of the eytoplasm in these organisms as an undifferentiated mass of material is to totally misconceive the situation; it has an extraordinarily complex organization.

In the infusorian there is interaction between the nucleus and the cytoplasmic parts comparable to what I have sketched in the ovum of multicellular organisms. But in the Ciliate, this interaction is highly developed, involving differentiated parts not seen in most cells.

The single diploid nucleus that is present after conjugation soon gives off a portion of itself which is destined for interaction with the cytoplasm. The details differ in different species, but the essential feature is that the nucleus divides into two parts. One of these absorbs much material from the cytoplasm, becomes greatly enlarged, loses its sharply defined chromosomal structure, and eventually becomes completely absorbed into the eytoplasm. This part, commonly known as the macronucleus, corresponds in function to the chromatin granules and so-called "nuclear sap" that in the ovum of multicellular organisms are given off to the cytoplasm by the nucleus. But in the infusorian this mass of nuclear material for a long time persists as a definite body. It is only after a number of vegetative generations-few or many-that it is absorbed into the cytoplasm. In many species this oceurs just before or during conjugation; in others, such as Paramecium aurelia and Paramecium caudatum, it occurs during vegetative life at fairly regular intervals of 20 to 60 generations. The dissolution of this great mass of nuclear material into the cytoplasm is a particularly striking example of the fact that nucleus and cytoplasm are not wholly separate, but that material continually transforms from one to the other. The transfer of so great a quantity of nuclear material into the cytoplasm must greatly affect the nature and physiological activity of the cytoplasm; some of its presumable results we shall see later in the genetics of these organisms.

The production of the highly differentiated organization of the cytoplasmic body in these animals presents a problem for experimental embryology that appears more difficult even than does differentiation in multicellular organisms. The schema which I outlined for the interaction of nucleus and cytoplasm in producing the bodily differentiations in multicellular organisms appears to break down in its application to the development of complex Protozoa. That schema included differentiations of the cytoplasm produced by interaction with the nucleus; the segregation of the diverse cytoplasmic materials in different cells, each with its nucleus; the further interaction of the diverse cytoplasms of the different cells each with its own nucleus, yielding diverse products in the different cells; and further segregation by cell division. But here in the infusorian the multifarious differentiations all occur in a single minute mass of cytoplasm in the presence of but a single nucleus. When experimental embryology has satisfied itself on the 
problem of differentiation in multicellular development, it may tackle the puzzles of differentiation, localization, and functional organization in these enormously complex single cells. [See an interesting attempt in this direction in the case of the giant algal cell of Acetabularia (Hämmerling 1934).]

But it is not problems of development, but of genetics, that I wish to call to your attention in these organisms.

The "doctrine of the inheritance of acquired characteristics" finds its last refuge in the genetics of Protozoa. It is a fact that Protozoa are modified in many ways by the action of environmental conditions, and it is known that the modified characteristics so induced are inherited for long periods in vegetative reproduction-for hundreds of generations. By some investigators, notably by Jollos and his followers, it is maintained that these inherited environmental modifications affect the cytoplasm only. From this, if correct, it follows that diverse conditions of the cytoplasm are transmitted to different offspring and that these diverse cytoplasmic conditions produce diverse inherited characteristics in the descendants. The eytoplasm, if this be true, shares with the chromosomes the function of producing inherited differentiations between individuals, so that it must be accounted a part of the genetic material.

To appreciate the genetic situation, a brief review of some of the phenomena must be presented. The heritable modifications induced by environmental conditions in Protozoa may be classified in three groups. First, there are degenerative changes induced by unfavorable conditions acting for many generations. When ciliate infusoria are bred for hundreds of vegetative generations under conditions to which they are not entirely adapted, they gradually "run down"; their vital processes become depressed, slow, inefficient. In time the animals become distinctly degenerate, abnormal in form and structure, and reduced in size. As an index of this decrease in vitality the changes in the rate of multiplication are useful. The frequency of cell division becomes reduced, and this is accompanied by a lowering of vitality in all functions. These changes are shown in the familiar graphs which register the gradual slowing up of the rate of multiplication. In the later generations this rate is very low. Now if individuals of these later generations are cultivated under conditions identical with those of the same stock which have not lived for a long time under unfavorable conditions, it is found that the depression and degeneracy are inherited. Under the same conditions, one of the two sets multiplies rapidly and at a high level of vitality; the other slowly and at a low level of vitality, and in a degenerate condition. These differences continue for generation after generation, for a great number of generations. An immense amount of work with these results has been carried on by many investigators. In these Protozoa, therefore, we find realized what some have held must occur in mankind: the production of inherited degeneracy by long-continued bad living conditions.

The second type of inherited change induced by environmental conditions is acclimatization, or the acquirement of immunity. The Protozoa share with higher animals the power of developing immunity to certain injurious agents-the power of becoming acclimatized to high and low temperatures or to injurious concentrations of chemicals. To produce these results in the Protozoa, they are subjected for many generations to gradually increasing intensities of the injurious agent. And after removal from the injurious conditions the acquired acclimatization or immunity is inherited in vegetative reproduction for many generations. Cases are on record in which such inheritance continued for many months, including some hundreds of generations.

But in the course of these many generations under favorable conditions, that is, with the injurious agent no longer present, the acquired immunity gradnally becomes weaker and less marked; it slowly decreases and finally is lost. But this may not occur till months have passed after removal from the immunizing agent; during this time the 
acquired immunity has been inherited for many vegetative generations.

Such acquirement of inherited immunity is most extensively known in parasitic Protozoa and in pathogenic bacteria, because in these it is of practical importance. But it occurs, also, according to the investigation of Jollos, Neuschloss, Dallinger, and others, in free-living Protozoa. Such freeliving Protozoa have been acclimatized to injurious intensities of temperature, and of solutions of arsenic, antimony, quinine, methyline blue, and various organic chemicals. In these matters we are obviously dealing with adaptive changes, as compared with the degenerative changes which were discussed first.

The third eategory of inherited changes produced by environmental conditions consists of alterations of form and structure which are not clearly matters either of. degeneracy or of adaptation. In some Protozoa individuals that have lived for many generations under special conditions have peculiarities of form and structure. When they are removed from these special conditions they retain for many generations - often for hundreds of generationsthese peculiarities of form and structure. But gradually in the course of long periods under the new conditions, they lose the special peculiarities resulting from the former conditions, and take on characteristics such as are shown by those stocks that have always lived under the later conditions. Many remarkable instances of such inherited environmental effects have bcen described in flagellates recently by Moewus (1934).

In attempting to interpret these inherited environmental modifications, and particularly in trying to discover their seat in the cell, much significance has been attached to certain peculiarities which some or all of them show. First, as before mentioned, after a great number of generations have passed under conditions that are free from the agents that produced them, the acquired modifications gradually fade away. This is known to be true for acquired immunity and for structural modifications induced by special conditions. It is not known to be true for degenerative changes induced by unfavorable conditions.

Second, the inherited environmental modifications very commonly disappear when sexual reproduction occurs. The descendants of individuals that have conjugated may not show the depression and degeneration seen in their ancestors. They often lose at the occurrence of conjugation the immunity or acclimatization that has been acquired and inherited by their forbears. It is a peculiar and striking fact, however, that conjugation does not always bring about these results. After conjugation many of the depressed individuals show a renewal of vitality, an increase in rate of multiplication. But some of the descendants from the conjugated individuals do not. Some are left still depressed in vitality, or are indeed in a worse condition after conjugation than before. The renewal of vitality in depressed stocks through conjugation is famous under the name of rejuvenescense.

A similar situation exists with relation to inherited acclimatization or immunity. It commonly disappears at conjugation; the descendants of the individuals that have conjugated no longer show the greater resistance to injurious conditions. But, as in the case of inherited degeneration, in some cases this does not occur. In some cases the descendants of the individuals that have conjugated continue to manifest the acquired immunity.

These two peculiarities-the gradual disappearance of the inherited modifications when removed from the agents that induced them, and their frequent disappearance after conjugation has occurred-have led certain investigators to place them in a different category from inherited characters determined by peculiarities of the chromosomal materials. Jollos, who has worked and theorized much on these matters, led by these considerations, has assigned these inherited modifications to the cytoplasm instead of to the nuclear constituents. A change in the genes, a mutation, he urges, is a permanent change; 
it would not disappear after many generations in an altered environment. But a change in the cytoplasm wouid in the course of time be overcome and dominated by the unchanged nucleus, bringing about a return to the original characteristics. The environmental modifications-which Jollos calls Dauermodifikationen-according to this view are essentially transitory conditions, forming no part of the system of genuinely inherited characters, which are dependent on diversities of chromosomal materials. A school of followers has accepted and expounded the views of Jollos on these phenomena (see the summary and exposition by Hämmerling 1929).

The usual disappearance of the inherited modification after conjugation is by this school seemingly attributed to the profound working over of the eytoplasm that has been believed to accompany conjugation and to produce rejuvenescense. The long continued inheritance of these modifications during vegetative reproduction is held to be an example of cytoplasmic inheritance.

Does eytoplasmic inheritance indeed occur in these organisms? And if so, what are its conditions and manifestations? What light do the phenomena in Protozoa throw on the role of the eytoplasm in genetic processes? The conditions in the normal sexual reproduction of the ciliate infusoria are such as to give a clear answer to these questions, when appropriate crosses of stocks with diverse characteristics are made. To bring this out I must remind you of conditions which may be familiar to you. In the ciliate infusoria sexual reproduction takes the form of conjugation. In conjugation two individuals place themselves side by side, and through small openings in the body wall they exchange parts of their nuclei; then they separate, and each continues to reproduce by division as before.

The essential fact here, for our present purposes, is that each of the two individuals retains its own cytoplasm unmixed, but each rcceives a half nucleus from the other individual. After conjugation, when the two individuals separate, therefore, each has a nucleus that is half from one of the two individuals, half from the other; but each has cytoplasm that is unmixed. The relations of cytoplasm and nucleus in the two may be expressed as follows: The two individuals that conjugate commonly belong to two different races, differing in characteristics. Call one race $A$, the other $B, A$ differing from $B$ in both nucleus and cytoplasm. Before conjugation one individual has nucleus and cytoplasm of race $A$; the other has nucleus and cytoplasm of race $B$. After conjugation both individuals have nuclei that are constituted half from race $A$, half from race $B$. But one of the two individuals still has the pure cytoplasm of race $A$, the other the pure cytoplasm of race $B$. The two are now alike in the constitution of their nuclei, but they differ in their cytoplasm. Will the difference in their cytoplasm make differences in the inherited characters of the two individuals and their descendants? We have here, placed squarely before us in comparative and experimental form, the question whether differences in cytoplasm result in diversities of inherited characters. Nowhere else, I believe, is there so favorable an opportunity for testing the relative genetic roles of nucleus and cytoplasm.

The results of such breeding experiments demonstrate that the difference in cytoplasm does indeed make a difference in the inherited characters of the descendants. And it shows the conditions and limitations of this cytoplasnic inheritance and its relation to nuclear inheritance. Such results have already been reached with relation to a number of different types of characteristics. They are shown most vividly in crosses between large and small races of these animals. Such crosses between large and small races of Paramecium have been extensively made by De Garis (1935) working at Johns Hopkins University. The nature of the phenomena will best be seen from typical examples.

In a certain race, which we may call $A$, the individuals are large; the mean length is 198 microns. Individuals of this large race were induced to conjugate with indi- 
viduals of a very small race $B$, in which the mean length of the individuals is but 73 microns. The relative sizes of the two are shown in their correct proportions at the upper left in Fig. 1. The large individual has about 20 times the bulk of the smaller one. The large and small sizes are hereditary in the two races, so long as they multiply separately. All individuals of race $A$ are large; all those of race $B$ are small. Two individuals of these races, differing greatly in hereditary size, conjugate and exchange halves of their nuclei. Then they separate. Each retains its own cytoplasm. They are now alike as to nuclei and diverse as to their cytoplasm. They are still very diverse in the sizes of their cytoplasmic bodies.

After separation the two individuals divide in the usual way. The large individual $\boldsymbol{A}$ divides into two which are of course at first small, having but half the volume of the parent. But these two grow, becoming practically as large as their parent $A$. Similarly, the small individual $B$ divides into two, which grow only to the small size of their parent $B$. The two offspring produced by each of course divide again, and such divisions continue daily for generation after generation, each of the two ex-conjugants producing a great number of descendants.

At first, as we have seen, the offspring of the large individual are large, and the offspring of the small individual are small. This difference lies entirely in the cytoplasmic bodies of the two, since after conjugation the two are alike in nuclei. Now, as we follow successive generations of descendants of the two, we find that a difference in size continues for many generations, but that the differences slowly become less (Fig. 1). The descendants of the small individual $B$ increase in size as generations pass; the descendants of the large individual $A$ decrease in size. Fig. 1, drawn to scale, represents the average sizes of the descendants at intervals of two or three generations. At the end of about 22 generations, requiring 22 days, the descendants of the large and the small parents have reached about the same size. All the descendants are now intermediate in size, between the two original parents. At this size they remain until there is another conjugation.

The results can be due only to the fact that after conjugation the two sets are alike in their nuclei. The nuclear con-

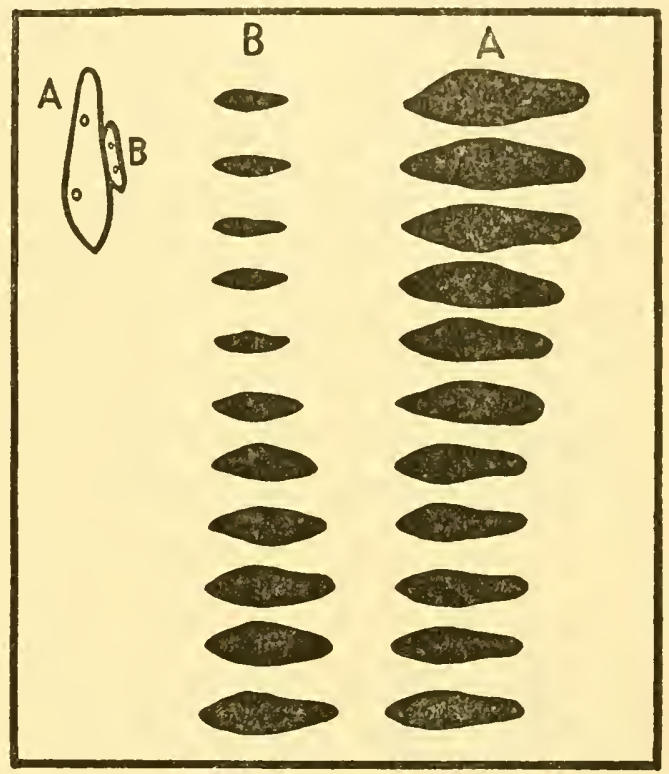

FIG. 1. Paramecium caudatum. Changes in size in consequence of the erossing of a large race $A$ and a small race $B$. At the upper left are shown in their correct proportional sizes the two individuals $A$ and $B$ united in conjugation. In the column headed $A$ are seen (following downward) the successive different sizes, at intervals of two days, in the clone descended from the ex-conjugant $A$. In the column headed $B$ are shown at the same intervals (following downward) the successive sizes in the clone descended from the ex-conjugant $B$. Figures drawn to scale from the dimensions and curres of De Garis (1935).

stitution gradually alters the cytoplasm, bringing the size in both sets ultimately to that which is characteristic for the nuclear constitution. The nuclear constitution finally dominates completely. But for 22 generations the cytoplasmic differences affect the characteristics.

Many such crosses between large and small races were made by De Garis (1935). In every case the cytoplasm affects the size 
for many generations, but finally the descendants of the two parents come to a common size, corresponding to the properties of the common nuclear constitution. The final size is, however, not always midway between the sizes of the two parents. Such a case is illustrated in Fig. 2; in which the final size reached by both sets

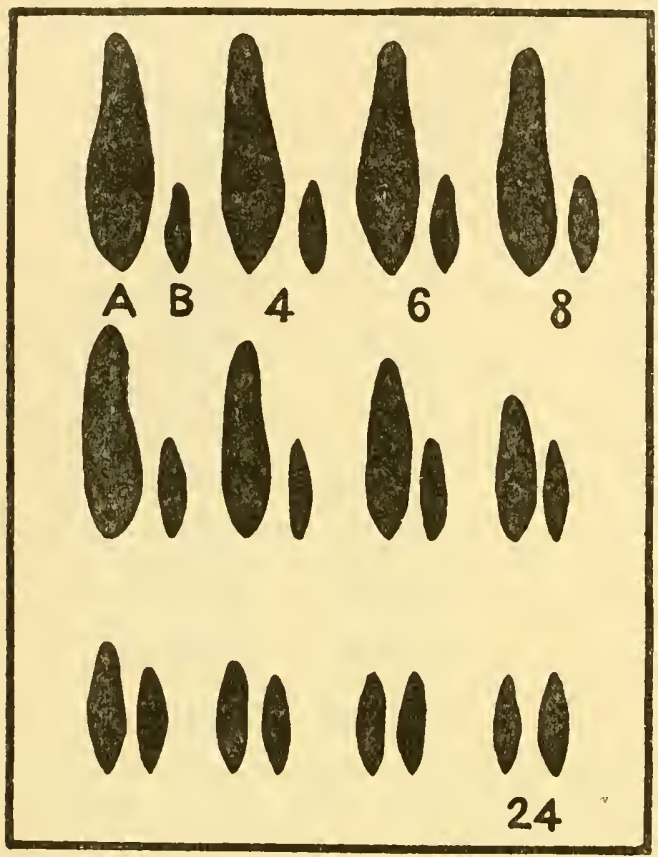

Frg. 2. Paramecium caudatum. Changes in size resulting from the crossing of two other races differing in size (these races are again designated $A$ and $B$ ). At the upper left are shown the relative sizes of $A$ and $B$ immediately after conjugation. The sizes of the two clones at the end of successive two-day periods are shown, reading from left to right in the three rows, beginning with the top row. Finally (lower right) the descendants of the two ex-conjugants reach a common size which is near to that of the parent $B$. Drawn to scale from the dimensions and curves given by De Garis (1935).

of descendants is near that of the smaller parent. What the ultimate size shall be obviously depends on what nuclear combination is present in the two parents after conjugation.

One other set of facts may be mentioned briefly. When many crosses are made between the same two clones or races, the final size reached by the descendants is not neces- sarily the same in different cases. Different pairs of the same cross-the two parents having the same genetic constitution in each case-yield descendants of very different final sizes. These relations are illustrated in Fig. 3, which represents to scale the results of several different crosses made by De Garis. It is clear that in dif-

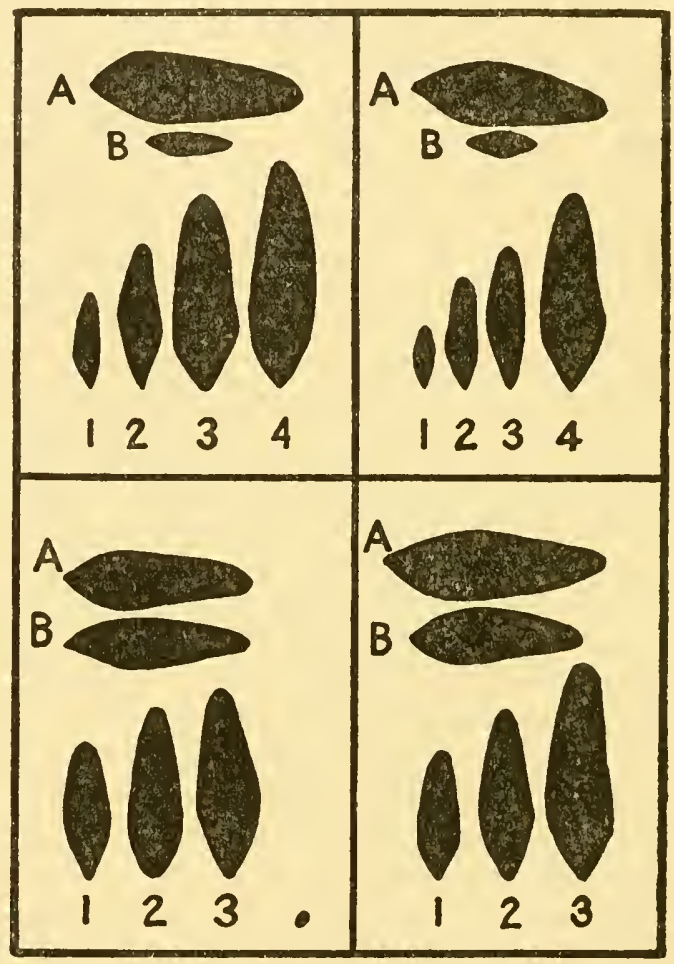

FIG. 3. Diverse final sizes resulting from different pairs in crosses of particular races. The results of four diverse crosses are shown (in each cross the parent races are designated $A$ and $B$ ). In the first two crosses the final sizes are shown for four different pairs: they are designated $1,2,3$, and 4 . In the third and fourth crosses the final size is shown for but ihree pairs $(1,2,3)$. Drawn to scale from the dimensions and curves given by $\mathrm{De}$ Garis (1935).

ferent crosses of the two races, different combinations of chromosomal materials are made, resulting in descendants of different final sizes. The phenomena are of the same kind as those seen in the fact that children of the same human family differ in their inherited characteristics.

Return now to the relations of nucleus 
and cytoplasm in producing these results. The final size is in each case determined by the nuclear constitution, since in every pair the final sizes are the same for the descendants of the two ex-conjugants. The nuclear constitution, so far as it affects size, is the same in the two ex-conjugants of any pair-a fact which reveals to us at what point in maturation the reduction division for size genes occurs. It shows that reduction does not occur at the third maturation division; otherwise in half the eases the ultimate sizes would be different in the descendants of the two ex-conjugants.

But for a long time-for 22 generations in the case illustrated in Fig. 1 and for some 36 generations in the extreme case observed-the cytoplasm affects the size of the individuals. The two individuals began life after conjugation with cytoplasm of different constitution, and the difference in cytoplasm results in a difference in size.

A similar differential effect of the cytoplasm is seen in the inheritance of other characters. Sonneborn and Lynch (1934) in the laboratory at the Johns Hopkins University found such a cytoplasmic effect in crosses of two races that differed much in rate of multiplication. This work was done before the work of De Garis; I employed the results of De Garis in introducing the matter because of the advantages in presentation of such a character as size diversity. In the cases described by Sonneborn and Lynch, one of the two races reproduced by fission frequently and rapidly, while in the other reproduction was slow, occurring only at long intervals. After two such races have united in conjugation and exchanged halves of their nuclei, the one that retains the cytoplasm of the slow race continues to divide slowly, while the other, having the eytoplasm of the rapid race, continues to divide rapidly. This effect of the cytoplasm continues for about ten generations. But during that time the difference in fission rate for the two sets becomes gradually less, until after a certain number of generations the rate of reproduction is the same in the two-a rate determined by the nuclear constitution.

A similar effect of the cytoplasm in delaying the change of characters induced by the nuclear constitution is at times seen in the inheritance of differing sex types (Kimball 1939). This matter is complex and I shall not present it. The effect of the cytoplasm in delaying the assumption of the final characteristics resulting from the nuclear constitution has come to be spoken of by the workers in this field as the "cytoplasmic lag."

Analysis of these phenomena yields some insight into the method of action of the cytoplasm, and the relative role of nucleus and cytoplasm in inheritance. The influence of the cytoplasm on inheritance must be considered in connection with what happens to the cytoplasm at vegetative reproduction. At every fission the volume of cytoplasm present is reduced one half; then the original volume is restored by growth, that is, by production of an equal volume of new cytoplasm. In the case of the large race $A$ which is gradually diminished in size after conjugation (Fig. 1) the size is reduced at the first division after conjugation to one half the original size, so that if growth did not occur, the body would in one or two generations be reduced to the final size. But owing to the properties of the cytoplasm of that race $A$, growth occurs after the first division to practically the original racial size. At every succeeding fission the original cytoplasm is diluted to one half, so that after ten generations it is diluted to less than 1/1000 part, the remainder being new cytoplasm produced by growth. Yet after ten generations the nature of the original cytoplasm still has a marked effect on size. The original cytoplasm seemingly must therefore have to some extent the power of reproducing itself in its distinctive nature, at the time that growth occurs. In this respect it partakes of the character of a gene or genetic material, in that it affects the characteristics of the individuals and reproduces itself in some degree true to type. But in time it is made over by the nucleus. 
These facts as to the differential effect of the cytoplasm on inherited characteristics in crosses furnish a basis from normal genetics for Jollos' idea that inherited environmental modifications may have their seat in the cytoplasm. These environmental modifications, like the size due to the nature of the cytoplasm in De Garis' crosses, are inherited for a number of generations, but finally fade away. But there is so great a difference in the time (in the number of generations) that the inheritance continues, in the two cases, as to raise doubts as to the fundamental similarity of the two. In the established cases which I have described, the inherited cytoplasmic effect continues in different cases 10, 20, 30 generations ; the extreme limit observed was 36 generations. By the end of such a period the cytoplasm has been made over by the nucleus, and it is thereafter the constitution of the nucleus that determines the characteristics. But such environmental modifications as acclimatization are inherited for hundreds of generations-in some of Jollos' experiments for as much as 800 generations. If they are merely modifications of the cytoplasm one might anticipate that long before so many generations had passed the cytoplasm would have been made over by the nucleus, and its modifications would have disappeared. Yet we do not know that the time required for the nucleus to dominate the cytoplasm would be subject to the same limits in all cases. The question whether inherited environmental modifications are exclusively cytoplasmic, or whether they affect the nucleus, the chromosomes, must be left open for the present. Decision of this question now appears practicable by the methods of experimental breeding. What is required is to induce environmental modifications-acclimatization or the likein a certain race, then to cross this race with another which lacks the modification. In the conjugation of the two races only nuclei with their chromosomes are transferred from one race to the other. If the modifications have affected the nuclei they should be transferred by conjugation from one race to the other. But if they affect only the cytoplasm they will not be thus transferred. The prospects for successfully carrying through such experiments have been greatly increased by the recent discovery of diverse mating types in these organisms: types which play the role of different sexes. This discovery makes it possible to make any desired crosses as readily in these organisms as in fruit-flies or in rats.

Returning to the relative role of ehromosomes and cytoplasm in determining inherited characters in these organisms, we have seen that different individuals may begin life with diverse cytoplasm, though with identical nuclei; and that the difference in cytoplasm produces differences in inherited characters which are inherited for 20 to 40 generations or possibly more. We have also seen that the length of time that this differential cytoplasmic inheritance continues makes it probable-perhaps certain-that the different kinds of cytoplasm reproduce to some extent true to type.

But further, we have seen that while this is occurring the nucleus is slowly influencing the cytoplasm, so that the characteristics influenced by the cytoplasmic constitution are slowly changing toward the condition that corresponds to the nuclear constitution. After some time the cytoplasm is fully dominated by the nuclear constitution, as is shown by the fact that the two ex-conjugants, differing greatly in their original cytoplasmic characters, finally come to identical characteristics. The characters induced by the cytoplasm are henceforth the nuclear characters.

These phenomena appear to be typical for the relations of nucleus and cytoplasm in genetic differentiations-the differentiations of diverse individuals. The primary source of such differentiations is the nucleus. But the nucleus impresses its constitution on the cytoplasm, doubtless through the material interchanges described in our earlier paragraphs. The eytoplasm retains the constitution so impressed for a considerable time, during which it assimilates and multiplies true to its impressed character. It may do this after removal from actual contact with the nucleus to 
which its present constitution is due, and even in the presence of another nucleus of different constitution. During this period eytoplasmic inheritance may occur; the new cells produced show the characteristics due to this cytoplasmic constitution impressed on it by a nucleus that is no longer present. But in time the new nucleus asserts itself, impressing its own constitution on the cytoplasm.

\section{References Cited}

Boveri, J. 1901. Die Polarität von Orocyte, Ei und Larve des Strongylocentrotus lividus. Zoöl. Jahrb. Abt. Anat., 14: 630 .

Conklin, E. G. 1902. Karyokinesis and Cytokinesis in the Maturation, Fertilization and Cleavage of Crepidula and other Gastropods. $J$. Acad. Nat. Sci. Phila., 12: 1.

Dallinger, W. H. 1887. The President's Address. J. Roy. Microscop. Soc., 1: 185.

De Garis, G. F. 1935. Heritable Effects of Conjugation between Free Individuals and Double Monsters in Diverse Races of Paramecium caudatum. J. Exp. Zoöl., 71: 209.

East, E. M. 1934. The Nucleus-plasma Problem. Am. Naturalist, $63: 289,402$.
HÄMMERLING, J. 1929. Dauermodifikationen. Handbuch der Vererbungswissenschaft, Bd. 1, Lieferung II : 1 ,

- 1934. Über formbildende Substanzen bei Acetabularia mediterranea, ihre räumliche und zcitliche Verteilung und ihre Herkunft. Arch. Entwicklungsmech. Organ., 131: 1.

Jennings, H. S. 1929. Geneties of the Protozoa. Bibliographia Genetica, 5: 105.

Jollos, V. 1921. Experimentelle Protistenstudien I. Arch. Prot., 43: 1 .

- 1934. Dauermodifikationen und Mutationen bei Protozoen. Arch. Prot., 83: 197.

Kimball, R. F. 1939. A Delayed Change of Phenotype Following a Change of Genotype in Paramecium aurelia. Genetics, 24: 49.

Moewus, F. 1934. Über Dauermodifikationen bei Chlamydomonaden. Arch. Prot., 83: 220.

Neuschloss, S. 1920. Untersuchungen über die Gewöhnung an Gifte. Arch. Ges. Physiol. (Pflügers), 176: 223; 178: 61 .

RichaRds, A. 1917. The History of the Chromosomal Vesicles in Fundulus and the Theory of Genetic Continuity of the Chromosomes. Biol. Bull., 32 : 249.

Sonneborn, T. M. and Lynch, R. S. 1934. Hybridization and Segregation in Paramecium aurelia. J. Exptl. Zoöl., 67: 1. 


\title{
CHROMOSOMES AND GENES
}

\author{
By RICHARD B. GOLDSCHMIDT \\ DEPARTMENT OF ZOOLOGY, UNIVERSITY OF CALIFORNIA, BERKELEY, CALIF.
}

Cytological work during the first decades of the cell theory up to about 1875 was mostly concerned with establishing the general ideas regarding the cell and its role in the organization of living beings. Modern cytology begins with the discovery of cell division, fertilization, and the chromosomes and their role in cell division and fertilization (Bütschli, Strasburger, O. Hertwig, Flemming, Van Beneden, 1875-81). These basic discoveries led immediately to the theory, most ingeniously derived by Roux (1883) and elaborated in detail by Weismann (1886), that the chromosomes are the bearers of the materials which are responsible for the transmission of hereditary traits and that these materials, or determiners, are arranged in the chromosomes in linear order. Though 30 more years were needed for the experimental proof of these conceptions, they have ever since been foremost in the minds of cytologists, who actually worked mostly with the purpose of elucidating the role of the chromosomes in heredity. This work culminated in Boveri's first experimental demonstration of the correctness of the chromosome theory of heredity through his brilliant analysis of the fate of dispermic sea-urchin eggs. With the beginning of the century the period of Mendelian heredity set in. It is true that the first development of Mendelism after its rediscovery was almost completely influenced by geneticists who were opposed to the chromosome-theory (Bateson, Johannsen). But those investigators who had a proper cytological background remained true to the Roux-Weismann theory, as they had every reason for doing after Sutton had shown the completc parallelism between Mendelian bchavior and chromosomal distribution; and still more so, when the discovery of the sex-chromosomes and the correct understanding of their behavior had shown that the genetic behavior of sexdistribution which follows the type of a Mendelian backcross, as first derived by Bateson and Castle, is paralleled by the special behavior of definite chromosomes. Thus the idea of determiners, or genes, as Johannsen proposed to call them, arranged in linear order in the chromosomes and responsible for mendelizing traits, became firmly established during the first years of this century (except for the resistance of Bateson and Johannsen, which broke down only later under the pressure of the discoveries of the Morgan school). It was even discussed (Boveri, Goldschmidt) under which conditions a larger number of genes than the haploid number of chromosomes might mendelize, the solution being an exchange between homologous chromosomes. It is generally known that the modern experimental foundation for Roux and Weismann's classic theory of chromosomes and genes was finally added by Morgan and his group after the discovery of crossing over and the consequent brilliant analysis (since 1910). The final proof of the chromosome theory of Mendelian inheritance was furnished (Bridges), the classic idea of the linear order of the determiners in the chromosome was put upon an experimental basis (Morgan, Bridges, Muller, Sturtevant), and a definite locus in the chromosome was assigned to the genes on the basis of their cross-over values. Combining the genetical facts with those found by the cytologists regarding the structure of the chromosome (Eisen, Montgomery, v. Winiwarter, McClung, and many others), the chromosome was conceived as a string of corpuscular genes, arranged bead-like in a definite order. It is this concept which we shall call here the classic theory as developed from Roux and Weismann to Morgan. If we look for a comparable stage in the development of 
physics, we might say that the theory of the chromosome had reached a stage represented in the history of physics by the theory of the indivisible atom of my youth, before Thompson, Rutherford, Planck, and Bohr.

After this short introduction, the first problem under the heading of our paper is this : During the development of the classic theory ehromosomes were practically identified with chromatin, i.e., nucleic acid, though different structural elements within the ehromosome were already known partly since the earliest eytological work ("Pfitzner's Körner," chromomeres, chromioles, spiral thread). Boveri, for example, thought of genes always in terms of chromatin, and Baur used the term chromomere as late as 1929 as an equivalent of gene. Our first problem, then, is to discover the relation of the chromatin to the hereditary material or genes. To be sure, cytologists working without special application to genetics had long since distinguished between a chromatin of a general function in nuclear and cellular affairs and the hereditary chromatin, trophochromatin and idiochromatin (Rückert, Lubosch, Goldschmidt). I am sure that the facts underlying this distinction (especially those taken from oögenesis) will receive new significance when they shall be reattacked with present day chemical methods. The same applies to a set of facts of greatest importance which eytogeneticists of today have completely forgotten: namely, chromatindiminution in nematodes and cecidomyids, the sloughing off of chromatin in the maturation divisions of lepidopteran eggs, the unequal distribution of chromatin in the oögonial divisions of Dytiscus, the formation of the odd nuclear vesicles in the eggs of ants, and also the existence of the macronucleus in Infusoria. The sheer mention of such facts involves a whole program.

Returning now to the problem of the chemical constituents of the chromosome, there has been considerable theorizing in face of the fact that exact tools for an attack have become available only recently. But it seems as if some of the views derived from theoretical consideration did not fall far off the mark. As long as 25 years ago I pointed out that the always chemically identic nucleic acid must play some general physico-chemical role in regard to the genic substance. My idea was that the chromatin is a kind of ground-substance which is able to adsorb definite numbers of gene molecules, thus keeping these constant and simultaneously accounting for the equal division of the gene. Though the details of this hypothesis are certainly wrong, the general trend of ideas has recently taken the same direction (see below, Caspersson and Schultz). It was Koltzoff who first assumed that the chromosome contains a genomatic protein-core surrounded by chromatin or nucleic acid. When Meyer and Mark discovered that fibers are made up of micellar aggregates of long chain molecules, I pointed out that such a structure would also furnish a good model for the genic substance, an idea which soon was taken up also by Koltzoff. This assumption appears again in the first strictly chemical theory of chromosome structure developed by Wrinch, who assumes a core of micellar bundles of different polypeptide chains, attached serially to each other and held together by bouds to the free valencies of nucleic acid. The molecules of thymonucleic acid are thus assumed to be arranged, in regard to the core, as the warp in a tissue to the woof. This latter conception has meanwhile turned out to be erroneous. Signer, Caspersson, and Hammarsten showed that thymo-nucleic acid (chromatin) is a highly polymerized compound with long molecular chains. Astbury and Bell found, by $\mathrm{X}$-ray analysis, that long chains with a period similar to that of polypeptids are involved, and W. J. Schmidt found also by polarimetric methods an arrangement parallel to the long axis of the chromosome. There is further the information gained by Caspersson that the nucleic acid is found only in the chromomeres and that it seems to be synthesized there in the prophases of mitosis. The actual chemical relation between the nucleic acids and the protein-core, which latter is assumed to be the actual 
hereditary substance, has only recently been attacked by Caspersson and Schultz. They find significant changes in the quantity of nucleic acid paralleling certain genetic and cytological facts. They conclude therefore that the nucleic acid is concerned with the function and the reproduction of the gene, the latter process being a polymerization followed by depolymerization. (The value of these conclusions is unfortunately impaired by the unproved and improbable assumption that the mottling effect of the eyes, which furnishes the genetic material, is the result of a loss of genes in development.)

The most important problem, however, has not yet been attacked by direct chemical methods, namely, that of the constitution of the gene-string. The classic theory requires a string of many hundreds of different units, each of which is at least of the order of one molecule, and of a substance different from that of all the others; these molecules must be held in place by some structure. It ought to be possible to prove or disprove such an assumption. An old and recently revived modification of the classic theory assumes that the gene-string, or chromonema, is a single giant chain molecule to which all the genes are attached as sidechains (Castle, Renner, Koltzoff, Demerec). Improbable as such an idea is, as well from a genetical as from the chemical point of view, it might be possible to test it. But it is also possible, as we shall see later on, that the chemical constitution of the proteinic core may be considered as a single unit of definite stoechiometric properties along its axis, i.e., a giant chain molecule or a micellar bundle of such molecules with no room left for individual genes. All these and eventually other possibilities ought to become accessible sooner or later to an attack with the ingenious methods now available, and cytologists and geneticists will have to adapt their ideas eventually to the findings of the physicist and chemist. Personally I am convinced that the solution of this all-important problem will be hastened if the physicists and chemists working in this field will stop looking for particulate genes, of molecular (or even submolecular) order, the very existence of which is becoming more doubtful daily, as we shall see further on.

In this connection, I should like to draw the attention of those who wield the physicochemical tools for an attack upon our problem to a remarkable cytological fact which is generally disregarded in the discussion of our problem. At the time when I was myself a staunch adherent of the classical theory of the gene, I was always puzzled by the fact that the chromosomes of all animals and plants, including Protozoa and Protophyta, which show clearly visible chromosomes, are very much alike. Whatever small differences exist, in all decisive points the completely stretched chromosomes are alike in structure as well as in the order of magnitude of their dimensions. I might put a slide of the chromosomes of the protozoan Monocystis (Gregarina) side by side with slides of some animals and plants and no one could point out any essential difference. Since the days of Roux it is assumed that this type of threadlike chromosomes takes its raison d'être from the necessity of exact division of the material of heredity. The theory of the gene is based upon exactly the same point of view. Therefore, there would not be any sense to the fiberlike form of the chromosome if its length were not roughly proportional to the number of genes therein. Actually the wellknown maps of the Drosophila chromosomes bear wituess to this conclusion. From this we must conclude that the number of genes is approximately equal, as far as order of magnitude is concerned, in some chromosomes all over the animate world. This puzzle disappears completely if the chromosome itself is a chemical unit which may show any amount of differential chemical complexity in different chain molecules of similar length.

These last remarks lead to the next chapter of our discussion. If chemical investigation has not yet furnished any information regarding the so-called gene-string, what other information can we derive from experimental facts? As everybody knows- 
though it is frequently forgotten-the classical conception of the gene is an extrapolation from three main facts: (1) mutation, (2) the localization of mutation at a definite locus in the chromosome, and (3) the possibility of reshuffling these loci. From these facts the inference is drawn that a particle, located at the normal locus, plays a major role in the control of normal development of the traits which are affected by mutation. The process of mutation, then, is assumed to change chemically this particle, the gene, and the normal gene becomes a mutant gene. Mutation, therefore, might furnish information regarding the nature of the gene. Actually the solution of this great problem is already claimed in certain quarters: it is claimed that the facts relating to the effect of radiation upon mutation-rate have already solved the problem. Timofeeff-Ressowsky, Stubbe, and the physicist Jordan repeat over and over again, even in semipopular books, that it has been proved that the gene is a single molecule, and Kühn has gone so far in a recent presidential address as to say that one of the great results of collaboration between biologists and physicists is the proof that the gene is a single molecule. Such statements, backed by the reputation of well-known scholars, are most regrettable, as they can be made only if the entire development of genetics during the past seven years is neglected. The situation is this: When Muller discovered the production of mutations by X-rays, and measured the quantity of the effect by his ingenious CLBmethod (lethal mutations in the X-chromosome are recognized by their effect upon the sex-ratio) he was perfectly entitled to assume that he measured the rate of genemutations. Then came Hanson and Heys' discovery that the rate of $\mathrm{X}$-ray induced mutation is independent of the wave-length but directly proportional to the amount of ionization produced by the dosage. This fact, confirmed by many others, together with a few measurements made by TimofeeffRessowsky of the temperature coefficients of the rate of mutation furnished the physicist Delbrück with the material for a theoreti- cal analysis. The result was that it must be assumed that a single electronic hit produced the effect, the mutation. It was further concluded that this hit produces, in a single elementary process, a definite rearrangement within a molecule if a point is acted upon which is capable of such a rearrangement. Therefore the proper model for a gene would be a stable compound of atoms, i.e., a single molecule. (At the end of the paper, however, a little loophole is left, saying that maybe the whole chromosome is a big atomic compound with many rather autonomous subgroups.) It is evident that Delbrück, who himself spoke always of a model and never claimed to have proved that the grene is a molecule, based his analysis upon the assumption that the basic data furnished him by geneticists were concerned with gene-mutations. But already this assumption had begun to crumble. Muller, himself, soon followed by many others, found that X-rays produce also chromatin-rearrangements. Since then it has become more and more elear by the work of Muller, Prokofiewa, Demerec, Sokolow, and many others that the majority of X-chromosome lethals produced by $\mathrm{X}$-rays are chromatin rearrangements and, therefore, that conclusions based upon the quantitative material mentioned above applied to chromosome-breaks and not genes. But not enough with that. It was also shown that the rule of proportion to dosage is true also for actual chromatin rearrangements (Belgowsky, Muller). Finally, it appeared as well in genetic experiments with special methods (Muller, Bauer) as in purely cytological X-ray work (Sax, Catcheside, et $a l$.) that the rate of translocations produced is such a one that the maximum rate of genuine gene mutations which could possibly be claimed after $\mathrm{X}$-radiation (i.e., mutations for which a chromatin rearrangement can not yet be demonstrated by cytological methods) shrinks into utter insignificance. Today it is safe to say that the predominant, if not the only, action of $\mathrm{X}$-rays upon the hereditary material is to produce breaks in the chromosomes, with consequent rearrangements of the chromo- 
some material. How a hit produces a break and how the two breaks necessary for a rearrangement are produced are much mooted questions of great theoretical importance. There are also additional details and some discrepancies regarding the relation of dosage to breaks. But for the point under discussion the all-important fact is that $\mathrm{X}$-raying seems, as some authors put it, a specific for production of chromosome breaks. I should go even as far as to say that a discovery of these facts prior to the discovery of mutation would have strangled the particulate gene concept before it was born. There is no question about the immense importance of the facts revealed by X-ray work. But if we are asked what information they have furnished regarding the nature of the gene (in the classical sense of a discrete body of at least molecular constitution as well as in the sense of a specific sidechain), the only objective answer which can be given is: nothing whatsoever. Nay, it may be said even that the $\mathrm{X}$-ray work has furnished some of the most powerful arguments against the actual existence of the gene as a discrete body.

Mutations may be also induced by ultraviolet rays and by chemicals (Altenburg, Stadler and Uber, Noethling and Stubbe, Muller and Mackenzie, Sakharoff, et al.). Authors who studied these mutants cytologically (or genetically) found that here chromatin-rearrangements are very rare and that the mutants must be classified mainly as point mutations (point mutations meaning that no rearrangements are visible with present-day methods, wherefore they are assumed to be the real gene mutations). This fact has now received a significance which points to important future developments. Knapp, Reuss, Risse, and Schreiber, working with monochromatic ultraviolet rays of different wave-lengths, made use of Warburg's famous method of concluding upon the chemical nature of a substance from its spectrum of action. It turned out that in the liverwort Sphaerocarpus the rate of mutations produced by ultraviolet light is different for different wave-lengths, the maximum being at $265 \mathrm{~m} \mu$. But this is the point of maximal absorption for thymomucleic acid, which substance again is supposed to be contained in the chromomeres. What conclusions may be drawn from this important fact will depend upon further work. But I am sure that decisive insight will be gained from it.

Still more important is Stadler's recent work, which includes also the same discoveries for maize as just mentioned for Sphaerocarpus. He found a surprisingly high frequency of terminal deficiencies in addition to the point mutations. This means production of single breaks by the less crude action of ultra-violet radiation as compared with $\mathrm{X}$-rays. One might use this result in favor of Stadler's and Serebrovsky's former view that all point-mutants are small deficiencies. But the facts might also suggest that point mutations are in fact breaks which result in a pattern change, in this case a subdivision of a longer chain into two smaller ones. We shall mention below facts which point in the same direction. It is certainly too early for definite conclusions, but such facts and their possible meaning have to be kept in mind.

When it was found that most of the $\mathrm{X}$-ray induced lethals are chromatin rearrangements (deficiencies, inversions, translocations), it was stated simultaneously by the same authors that most of the natural (spontaneous) lethal mutations, as well as visible ones, did not show any detectable chromosomal rearrangement. This, then, turns our attention to the much-neglected topic of spontaneous mutation in its bearing upon our problem, chromosome and gene. To be sure, there is among the natural mutants of Drosophila quite a number which turned out to be the effect of chromatin rearrangements, and with improved technique their number is constantly increasing. But it is safe to say that the majority of recessive mutants do not exhibit recognizable chromosome rearrangements, though it must be kept in mind that some types of very small rearrangements may be invisible in the salivary chromosomes of Drosophila or in the chromosomes of maize on account of 
normal pairing. (These are thus far the only objects in which such a study can be made.) But there have come to light some new facts regarding mutation which are bidding fair to throw light upon the nature of those mutations which are called point mutations because no chromosome break has been discovered, as yet, at their locus. Mutation was always assumed to be a rare haphazard process, occurring at random in one or another chromosome at different times of the developmental cycle. During the past ten years, however, a series of eases of mass mutation, closely paralleling each other in their details, have been found. The first case found by myself was unfortunately not recognized as such, as it happened in a temperature-experiment and was attributed to the action of heat, but wrongly so, as ean be shown from the pedigrees. But two more parallel cases have since been found in the same Drosophila line (Plough and Holthausen, Demerec), two more by the present author in different lines and one by Valadares, again in a different line. In addition, a statistical study of mutation in Drosophila on a large scale (Spencer) has revealed that mutation occurs not at random but in clusters. Looking for some feature in common to all these cases we realize that in three of the cases the line which produced mass mutation contained major chromatin rearrangements, translocations, and inversions. The three other cases are derived from Florida stock which since was found to contain a large inversion. In one of my cases the complete history is known and the analysis (not yet finished) shows that with the process of mass-mutation the previously present chromatin rearrangements (very small ones, but detectable in the salivary glands) had changed. Though the analysis is not yet completed, everything points to very small translocations, inversions, duplications as the actual nature of some recessive mutants. As translocations are generally considered to arise through illegitimate erossing-over, one might assume that the rearrangements which prevent legitimate crossing-over (inversions, translocations) tend to increase the tendency for illegitimate ones. I am fully aware that this statement is not as concrete as it ought to be, but I hope that the time is not too distant when it will be specified in detail. (Since this was written another case of high mutability accompanied by the presence of rearrangements in the mutable stock has been described by Tiniakov.)

There is an additional very interesting fact which strongly suggests the correctness of this interpretation. Beadle described in maize a mutant locus, sticky, which causes some physical condition in the cell which results in a tendency of the chromosomes to stick together and to break irregularly. Therefore in the presence of this mutant locus, also, the number of translocations increases immensely and simultaneously the number of regular mutants. Interpreting: this fact from the standpoint of the classic theory of the gene, one has to assume that one of the functions of the mutant locus, sticky, is to make other genes mutate. Actually this (to my mind erroneous) conclusion was drawn and the same was also done for some of the other cases of mass-mutation (Demerec), though without any proof. (I wonder what the function of the normal allele of the mutant gene for mutation would be. The normal allele of white eyes is supposed to control normal eye color or take part in its control, as evidenced by deficiencies at all so-called hypomorphic loci, if I accept the explanation in terms of the classic theory for argument's sake. Logically, then, the allele of the gene for mutation would prevent mutation.) But it seems rather obvious in the "sticky" case, that the same stickiness which produced the translocations also produced the mutations. In other words, the mutations were not chemical events within genes but mechanical changes in the chromosomes, i.e., changes of pattern alone. Facts are indeed beginning to accumulate which strongly support such an interpretation. I mention the claim that induced chromosome breaks are most frequently located in sections of the chromosomes, which are also known for a high frequency of point mutations (Timo- 
feeff). Further the reciprocal experiments of Sitko might be quoted, showing that the frequency of induced point mutations is higher near preexisting breaks. In passing I might point out that one of the methods of increasing the rate of mutation, namely aging of seed (Nawashin) fits much better into such a viewpoint than into any other. Finishing this ehapter we might say that, although this line of work is still in its infancy, it points in the same direction as the results of the foregoing chapter did: namely, that a mutated locus (acting in the overwhelming majority of cases as a disturber of normal development with the resulting monstrosity called a mutant) is in fact a change in the minute patterns of the parts of a chromosome, a rearrangement or pattern-change, and not a change within a discrete particle of molecular order. The same applies, of course, to submolecular units such as sidechains.

We come now to another group of facts, almost exclusively analyzed in Drosophila, which strongly point in the same direction, facts usually described under the term position effect. One of the standard dominant loci, in Drosophila, used in all elementary class work is Bar-eye, the prototype of a dominant "gene." A considerable time ago Sturtevant found by an admirable genetic analysis that one of the alleles of Bar, ultrabar, is in fact a so-called Bargene, represented twice in the same chromosome, and so a double-Bar. This made it possible to compare two so-called Bar-genes located in the same chromosome side by side with the same two opposite each other in different chromosomes. The effect of the two constellations was a different one, and this was called a position effect. The term has since been used for all cases in which a change in the chromosomal pattern without a change within an individual gene produces some visible effect. In order to make these cases conform to the conception of position effect and to explain them in terms of genes, it was assumed that the gene interacts with its direct neighborhood in funetioning and therefore functions differently in a new neighborhood (Muller, Offerman).
Aside from the difficulties which this idea would encounter if worked out in conerete chemical terms, it actually does not work in the majority of cases which were found since, including the Bar-case itself. I must confess that I was very skeptical towards the actual existence of the position-effect, when it first became known. The reason was that, being a convinced supporter of the classic theory of the particulate gene, I could not believe in a phenomenon which would force us to change or even abandon this theory, a necessary consequence which I realized from the beginning. But since that time numerous such pattern-effects, inexplicable in terms of genes have been found. Let us select a few cases of different types from the almost weekly increasing list of pertinent facts, and state in advance that no type of so-called genic action is known which does not also occur in the form of position effect.

There is first the Bar-case, representing the type of action which is usually ascribed to dominant genes. It is known to-day (Bridges, Muller) that Bar is actually a duplication of a small section of the chromosome and its multiple allele ultrabar a triplication of that section. Then it was found (Dobzhansky) that a translocation of a piece of another chromosome into the Bar region also produces the effect Bar-eye. Finally, the school of Dubinin found a large series of very different translocations with one break at the Bar-locus, or nearby, or even at a considerable distance from it, which always produced the Bar effect. These facts exclude, of course, an interpretation in terms of gene-neighborhoods, for these are different in any individual instance; and, as a matter of fact, it would require quite a bit of contortionism to find in these facts room for an actually existing Bar-gene.

A very important point ought to be added to this discussion. Sturtevant, who is certainly not suspected of heterodox views regarding the gene, was forced to conclude from his old genetic analysis of the Bar case that the "Bar-gene" has no wild-type allele. This rather prophetic conclusion is 
exactly the same as that which we must draw now for all actions of chromatin rearrangements (position effects). For all these the normal allele is not a gene, but the normal pattern of the chromosomal section in question or of the whole chromosome as the case may be (see the following examples). The normal allele, which is an extrapolation from the existence of the mutant locus, is, then, not existing in cases of position effect, and not existing at all if mutation should turn out to be positioneffects altogether, as I am expecting.

Let us take now another case elaborated by Muller and others involving a standard recessive "gene" scute, which ehanges the bristles of the fly in definite ways. Here again a number of alleles exist, quite a few of which have beeu shown to be inversions, very small and very large ones, with one of the breaks in the neighborhood of the scute locus at different points, and one also a translocation. There is a certain amount of specificity of action for this group of similar inversions, but, generally speaking, one might say that whenever a break occurs in this chromosome segment, the effect is a reduction of bristles. There is now a nearby locus, called achaete, which also reduces bristles, and another one, Hairy-wing, which increases bristles. The latter has now been found to be a small duplication, comparable to Bar (Alekhanian, Demerec and Hoover). In other words, there is a rather small segment of the $X$ chromosome which influences adversely normal bristle development, whatever happens to it in the form of pattern changes. ("Pattern" in this discussion always means linear pattern along the chromosome, which is changed by breaks and their consequences, in form of inversion, translocation, or duplication of parts.) I may add at this point that it is typical for the genetic structure of the chromosomes in Drosophila that at many points (Jones has counted over 50) clusters of a number of mutant loci are found which have a similar effect upon the phenotype, just as in the case under discussion. But only a few of such chromosomal sections of different size have thus far been studied in regard to the action of breaks, as was done in the example just reported. (Another such section is near yellow.)

A frequent type of genic action is the enlancing or inhibiting effect of so-called modifiers. Here is an example for a parallel position effect. The so-called dominant mutant Beaded in Drosophila produces a slight nick on the wing-margin in only a few per cent of the individuals. If an inversion is present in the sister chromosome, whether long or short, near or away from the Beaded locus, the Beaded action is enhanced to high grade scalloping in up to 100 per cent of the flies (Goldschmidt and collaborators). Here the neighborhood of the genes is not involved at all, but a generalized effect upon development which is caused by different changes of pattern in another chromosome. In this case the sister chromosome is involved. But there are also cases where the effect is produced by rearrangements in non-homologous chromosomes. There are, for example, in the second chromosome of Drosophila a number of alleles producing a definite effect upon wing venation, some of which are known deficiencies. The effect of each of these separately, as well as of their compounds, is considerably enhanced if a translocation from the third to the first chromosome is present (Goldschmidt and collaborators).

Another frequent type of modifying "genes" are those which affect the dominance of a definite locus. Dubinin found that the recessive action of cubitus interruptus in the fourth chromosome of Drosophila becomes dominant in the presence of any translocation between this and the Y-chromosome. We found that the recessive locus vestigial becomes more or less dominant in the presence of many deficiencies, inversions and translocations in other chromosomes under certain conditions (Goldschmidt and Gardner).

Only one more rather strange positioneffect may be mentioned here. A mutant, mottled (eyes and pigmented membranes) was found by Muller in Drosophila. It has been shown since that this mottling is 
caused by a number of pattern changes in the chromosomes, especially translocations, provided that one break is near the white locus in the X-chromosome (Muller, Patterson and collaborators, Schultz and others). Griffen and Stone have produced new chromatin rearrangements from such cases by X-raying, which show as visible effects many different kinds of mottling, including different colors. It ought to be kept in mind that the white locus which is near these chromosome breaks tends to produce numerous multiple allelic color mutants and further that in one of the cases of spontaneous mass mutation, referred to above, a series of these alleles appeared (Goldschmidt).

But this is only a small part of the facts regarding patterns which result in mottling and other related effects. There is another set of facts, too complicated to be reported in detail in a short paragraph. We emphasize therefore only the points which are important for our discussion (work of Muller et al., Dubinin et al., Schultz, Noujdin, Patterson et al., and others). It is known that the chromosomes contain special regions of heterochromatin. In Drosophila they are usually called inert regions because typical mutant loci are not found there. There is a large inert region in the $\mathrm{X}$-chromosome (beside others), and the Y-chromosome consists of this inert material. It is this material which has to do with some remarkable pattern-effects. If parts of this material are transferred to other regions of the chromosome by means of inversions, the result is a developmental mosaicism for the effects of loci brought in contact with the inert material. These effects are different for different regions of the inert material, and there are indications that this material is organized into larger blocks. But also the opposite effect is observed, namely, the inhibition of an otherwise present genetic mosaicism. It is claimed further that there is a proportionality between the amount of transferred inert material and the quantity of the effect. This proportionality is especially important in the cases in which the amount of heterochromatin determines the amount of dominance or recessiveness of a locus (Noujdin). (We point here, by way of comparison, to the other above-mentioned position-effects influencing dominance.) This dominance shifting effect of the inert material, by the way, is combined with the production of mosaicism. The same pattern change further produces the phenotype of different multiple alleles of the gene in question (see above Griffen and Stone). There is further an embryological relation between the mosaicism and the rate of differentiation (Noujdin, Surrarer), a relation which also is otherwise characteristic of mutant action as well as of some other position effects (Goldschmidt). We add, finally, that the known genetic actions of the $Y$ chromosome (Stern), usually described in terms of alleles of something within the X-chromosome (suppression of bobbed, etc.), are actually, as far as information goes, actions of whole blocks of this chromosome.

Before we state our conclusions, which are based upon an immense material of which a selection has now been presented, we may be permitted to point finally to one important group of facts which have never been discussed in the light of these recent developments, but which might in the future become of decisive importance for our present problem. I mean the facts regarding the sex-differentiating mechanism. It has been proved now for almost thirty years (by the Lymantria work of the author) that sex-determination is the result of a balance between male and female determiners, and that the $\mathrm{X}$-chromosomes control the two alternatives of this balance by providing one or two sats of determiners of one sex, those of the other sex being constant. There has since been a good deal of discussion regarding the question, rather unimportant in itself, whether there are single sex-genes or multiple sex-genes involved in this decision. This problem has reached a condition of impasse, as both sides (Goldschmidt and followers; Bridges and followers) believe they have proved that the other side has misinterpreted its experimental evidence. (There are only two direct at- 
tacks upon the problem existing-Moewus' claim of a single sex-gene in the Flagellate Chlamydomonas and Hofmeyr's data on crossing over between a sex-determiner and other loci in Papaya.) But very recently two important facts have come to light. The first is that all loci of the $\mathrm{X}$-chromosome in Drosophila have now been covered by duplications in triploid intersexes (Bedichek) without finding a sex-shifting locus. The other is Knapp's proof for the liverwort Sphaerocarpus that some $\mathrm{X}$-chromosome segments of very different length, produced by radiation, shift the sex in the clear-cut alternative, which means that the smallest of the fragments contains all the properties for the decision of the sexual alternative which are located in the X-chromosome. The latter fact shows conclusively that in this case no other sex-genes are littered over the sex-chromosome, whereas Bedichek's case proves only the absence of a single sexdetermining locus, without giving information about an eventual multitude of them. (The latter point has been discussed earlier by Goldschmidt.) These facts then raise the question in connection with our present discussion, whether or not both sides to the old discussion are wrong. Could it not be that there are no sex-genes, one or many, but only an action of the whole chromosome, or in other cases of a segment thereof, in the form of what we discussed as a patterneffect? I realize that this question appears absurd or even ridiculous to the orthodox geneticist, who believes that the $\mathrm{X}$-chromosome is a long string of genes, some of which affect eye-color and wing-structure, etc., others in between being concerned with sexdetermination. Therefore, an action of the whole cannot be distinguished from an added action of the individual genes, according to their conception. But once the idea of the corpuscular gene is discarded, our question ceases to be absurd and even assumes a very important meaning. The future will bring the answer.

Thus we have reached the point at which we may draw conclusions from the selection of material upon our problem which has been presented. The most general conclu- sion is that the entire recent development of genetics leads away from the classic theory of the particulate gene which reproduces itself and plays its own independent (though cooperative) role in controlling the processes of development. I know that there are many geneticists who realize this, but prefer to try first a broadening of the conception of the gene which would make it possible to pour new wine into the old bottles (Muller, Stadler). I think this is patch-work which cannot last and that the body of facts already available justifies a radical change in our conception of the genetic structure of the chromosome. This does not mean that everything is already perfectly clear, or that I do not realize the amount of work which has to be done to clear up every point. But I think that such work is more likely to lead to success if its direction is clearly recognized and if it is not chained to an outgrown theory. I think that the crudeness of the explanation of position-effect in terms of genes and the "genes for mutation" are a sufficient warning. The direction which is indicated by the facts which were reported (and whole groups of facts have not been mentioned because offering indirect evidence only) is, in my opinion, the following: Apart from the chemical interactions between the thymonucleic acid and the proteinic hereditary material, which is not yet understood. the chromosome is in many respects a unit in a chemical sense and acts as such. There may even be concerted actions of more than one chromosome. This action of the chromosome as a whole is bound (to what extent we do not know) to the normal serial pattern of the chromosome, just as the chemical properties of a chain molecule are determined by its serial pattern of radicals. A disturbance of the serial pattern changes the normal action into another one. But there is in addition a more or less localized action of smaller or larger sections or blocks of the chromosome. Any change of serial pattern within these sections produces again a definite abnormality of development, with a possible variability of the effect, according to the type of the new pattern. We do 
not yet know what the lower or upper sizelimits of these sections are, as only a few have been analyzed. But certainly these sections must have a certain amount of independence within the chromosome (they each contain a number of the known loci) as their actions can be recombined or covered by duplicated segments to a certain, but not yet known, extent. But there are a number of facts known from both these fields which ean be interpreted as showing that the independence is only limited, and that the changed action of the sections (the mutant and/or position effect) is in some respects also controlled by the pattern of the whole chromosome. It is extremely probable that these blocks are characterized chemically by something which is a typical ingredient of the general chemical pattern of the chromosome, recurring at many points (model : presence of a definite sidechain). The facts which point to the latter conclusion are usually hidden behind genetical terminology. (An elaborate terminology, deeply driven into the mind of the geneticist, is a great check on progress, because it makes it difficult to think in other terms; the terminology is frequently mistaken for a basic insight.) If we take Drosophila as an example, the great majority of mutants may be divided into a few groups of identical or very similar predominantly pathological action, e.g., shortening of bristles, roughening of eyes, scalloping of wings, intensifying or diluting of eye colors, etc. If this action is localized at different loci, each locus carries a different name for the respective mutants, though they might not be distinguishable at all or only within an overlapping range of variation (if the multiple alleles are included in the comparison). Only in one case a single name has been given to a large group of mutants, the minutes, because a special combination of effects characterize them all. Many elementary facts of this type will assume a very different meaning if reconsidered apart from the theory of the gene.

These, then, are the facts and the conclussions to be derived from them, all pointing in the same direction-the decisive importance of the serial pattern of the chromosome and its blocks of different sizes (in some respects independent), containing a smaller or larger number of loci. The theory of the particulate gene, as derived from mutation, will have to disappear and make way to a new conception. We have indulged in other places in speculating about a possible chemical model for the new conception. Let us refrain here from such speculation, which certainly would have to run abreast of the actually known facts. The program of this symposium requires to keep in mind the parallel with the development of knowledge in the physical world. It is my opinion that the classic theory of the gene corresponds to the conception of the indivisible atom of old physics. Genetics has outgrown this, I hold, and finds itself in a condition parallel to that of physics immediately before Rutherford. I am sure that our Rutherford stage will soon be reached and then we shall be ready for our Planck and Bohr. I am sure that their model of the hereditary material will be the model of the chromosome and not of the gene. But already at the present point of development the facts must be faced clearly, whether they are considered as welcome or as embarrassing. Nothing is gained by hiding the head in the sand, or by erecting sign-boards "Verboten," or by calling names. 


\title{
CELLULAR DIFFERENTIATION AND EXTERNAL ENVIRONMENT
}

\author{
By C. M. CHILD \\ DEPARTMENT OF ZOOLOGX, THE UNIVERSITY OF CHICAGO, CHICAGO, ILL., AND SCHOOL \\ OF BIOLOGICAL SCIENCES, STANFORD UNIVERSITY, CALIF.
}

As long as the biologist remained wholly or chiefly an observer of organisms, living or dead, he was often so impressed by their constancy of spatial and chronological order and pattern that he inclined to regard them as in some way predetermined and independent of environmental factors. Even after the concept of specific vital energy was discredited and the principle of evolution was established, predeterministic theories were still advanced and widely held. Development was often conceived as a sort of construction period with heredity as the constructor. When construction had proceeded to a certain stage the organism began to function in relation to an external world. It is of interest that Willhelm Roux, who played so important a role in the application of experiment to problems of animal development, held essentially this view.

Development of the experimental method in the field of zoology and animal physiology, largely within the past fifty years, has played no small part in altering our conceptions of living things. As experimentation has extended its field and has become more accurate and analytic, we have found it increasingly difficult to separate organism and environment. It has become evident that we know living things, from the cell to man, only in relation to an environment, either organismic or external, and cannot conceive them apart from that relation. We are now pretty well agreed that, so far as the individual is concerned, what we have called heredity is the sum total of potentialities of structure and function; that is, of behavior in the broadest sense, implicit in the physicochemical constitution of the protoplasmic system from which that individual develops; that for realization of any of these potentialities as the structure and function of an individual in development, certain relations to environment, either of the parent organism or external environment, are essential; and that with different environments different potentialities are realized. Here we are concerned only with questions of realization of potentialities in actual development and in relation to an external environment.

Considering the cell as a living individual, we find as the most general characteristic of its pattern a difference of some sort between surface and interior, a surface-interior pattern. The protoplasm adjoining the external medium is usually visibly, as well as physically, and probably to some extent chemically, different from the interior. The so-called plasma membrane is perhaps in some cases no more than a monomolecular or micellar film with molecules or particles definitely oriented in relation to the surface; from this it ranges to a visible morphological surface layer. It is not, however, a dead covering of the cell, but is as much alive as any other part. Beneath this an ectoplasm or cortex may differ in structure and behavior from deeper regions. In unicellular organisms, morphological differentiation is limited to the ectoplasmic or cortical layer. That surface-interior pattern originates in direct relation to external environment appears evident. The transformation of entoplasm into ectoplasm by exposure to the external medium in consequence of section is a characteristic occurrence in Protozoa and many other cells. There is apparently a transformation in both directions in amoeboid movement. In some animal eggs, notably those of ctenophores and ascidians, the ectoplasm becomes so stable that it retains its distinctive characteristics even though removed from the surface by developmental 
activities, and plays a definite role in differentiation.

Nucleoplasm, whether in the form of more or less scattered granules as in some primitive cells, or as a definite nucleus surrounded by a membrane, apparently originated under conditions existing in the cell interior. At present it appears that nuclear material is synthesized only in the interior of a cytoplasmic mass. The nucleus, then, appears to be more or less isolated from external environment except through the mediation of eytoplasm.

Even though we may not agree fully with the view advanced by Just in his recent book on the biology of the cell surface that the ectoplasm is the all-important part of the cell, it is evident that the cellsurface possesses properties important for the life of the cell. The plasma membrane often appears to be more or less elastic, either in consequence of surface tension or structurally, and so may be a factor in determining form of the cell. It carries an electric charge and a double electric layer -a membrane polarization, results from accumulation of ions of opposite sign on or near its external surface separating it from a fluid medium.

It is more or less semipermeable; that is, it permits passage of certain substances or ions exclusively or more readily than others. The permeability for particular substances differs in different cells. In spite of the enormous amount of work on permeability, we do not know in most cases exactly how particular substances penetrate into living cells, nor do we know to what extent results obtained with certain kinds of cells are of general significance. Various hypotheses have been advanced: presence of a lipid layer and penetration of substances dependent on their partition coefficient between it and an aqueous medium; the membrane a mosaic of lipid and water-containing regions, permitting penetration of fat-soluble substances in the lipid regions, water-soluble substances in other regions; penetration by chemical reaction with constituents of the membrane; entrance through pores; penetration de- termined by electric charge of membrane and of ions concerned, and penetration by adsorption on membrane particles.

The semipermeability of the cell surface mediates and controls the material exchange between the external world and the cell interior, but it is by no means independent of external environment. It is altered by change in temperature, by radiation, by the electric current, by the chemical constitution of the medium, and apparently often by mechanical alteration such as stretching. Moreover, it does not determine all relations between cell and environment. Change in temperature may alter permeability, but its effect on rate of metabolic reactions is not dependent on permeability. Action of the penetrating radiations on the cell interior is independent of the permeability of the cell surface. Permeability is not the essential factor in the effects of lack of oxygen or of certain ions.

The surface-interior pattern is not the only pattern of differentiation appearing in the cell. The single cell may become an organism or a part of a multicellular organism with patterns of development referable to an axis or axes superimposed on its surface-interior pattern. These patterns are variously designated as polarity, radial or bilateral symmetry, ventrodorsality, dorsiventrality, etc. The question as to how they originate is of fundamental importance to our conception of living organisms. Do they persist from one cell generation to another, having originated once for all at some past time? Do they arise autonomously in the cell or cell mass through action of the genes or otherwise? Or are they fundamentally behavior patterns; that is, reactions to conditions external to the protoplasm concerned? That at least certain of them can be established, altered, or obliterated by external environmental factors is evident from various lines of experiment. A few examples will serve to show something of these relations to enviromment.

Living protoplasms are irritable; that is, they react or respond by certain changes 
in physiological condition to external or physiological factors which we call stimuli. There is, however, no agreement as to what constitutes a stimulus. For some it is any condition external to the cell concerned, acting temporarily or continuously, which produces a definite change or response in the cell. Many developmental physiologists speak of formative stimuli; according to this definition gravity is a formative stimulus for certain plants and even an anesthetic might be regarded as a stimulus. At the other extreme of definition, a stimulus is a relatively sudden action of an external energy on the living system or some part of its surface, bringing about an activation which we call excitation. According to this concept, the stimulus is merely an initiator, a sort of trigger-action, and the character and energy of reaction depend on the specific constitution, the physiological condition, and the structural differentiation concerned, not on the energy of the stimulus.

We have learned something about the nature of excitation, but much remains to be learned. According to a theory widely held at present, it involves a reversible increase in permeability, a depolarization of the cell membrane, and an accelerated metabolism. Change in the colloid substrate and release of calcium have also been postulated as the essential factors. Excitation appears to be primarily a matter of the cell surface and to be dependent on the character and condition of the superficial cytoplasm.

Irritability or excitability involves more than direct reaction to an external stimulus. Living protoplasms are able to transmit or conduct excitation from the region directly affected by the external stimulus to other regions of the same cell, to other cells or cell groups. Transmission or conduction apparently occurs because a region excited by an external stimulus becomes a stimulus to adjoining regions, whether in consequence of electrical changes involved or in other ways need not concern us here. The secondarily excited regions stimulate others, and because excitation is in general followed by a refractory period during which the region concerned cannot be again excited, excitation may be transmitted as a wave, radially in absence of a definite path or along a structural path, such as nerve, in a definite direction. In protoplasms without differentiated conducting paths, excitation usually undergoes a decrement in intensity or effectiveness with increase in distance from the point of origin, and at a greater or less distance dies out. In other words, an excitation-transmission gradient results from the primary excitation.

Since such an excitation-transmission gradient may extend over protoplasmic regions or cells which were not in any way different from each otlier before the primary excitation, it represents a new pattern of intergration and control superimposed upon the surface-interior pattern. In other words, integration and control on an organismic scale by an excitation-transmission gradient are possible without any preexisting organismic pattern except a surface-interior pattern. For integration and control on the organismic scale by production and mass transport of specific chemical substances to take place, some degree of temporary or permanent differentiation of producing and reacting regions must already be present.

Excitation is commonly regarded as completely reversible after the exciting factor ceases to act, and in the highly differentiated organs of excitation, nerve and muscle, from which our concept of excitation is largely derived, it certainly approaches or attains complete reversibility. However, we often find that external factors, some of which excite when acting suddenly in sufficient intensity, may, with local or differential action of a certain range of intensity and continuing for a certain length of time, determine in a cell or cell mass regional changes and differences which persist as a physiological developmental pattern, a so-called polarity or symmetry, which constitutes the foundation for a pattern of differentiation. In their early stages these patterns appear to be quantitative gradients involving the basal metabo- 
lism of the cell or cells concerned. Some of the external factors which determine such patterns in one kind or another of protoplasm are: differential illumination by visible light, definitely directed electric current, a gradient of oxygen content or of hydrogen-ion concentration. The resulting patterns persist after the external differential has ceased to act. In any case the external factor can be regarded only as initiator; the characteristics of the established pattern are determined by the constitution and condition of the protoplasm in which they appear. In many of the simpler animals a new developmental pattern may result from a transverse section of the body, from a partial section or even from a local wound sufficient to produce a certain degree of cell activation. Here there is unquestionably excitation, but the possibility of production of specific substances at the wound and their transport to other regions also exists. The result, however, is a gradient of greater or less length which, in its physiological characteristics and as a basis for development and differentiation, appears to be exactly like that resulting from an external gradient of oxygen concentration or from directed electric current. At any rate, it is beyond question that a purely quantitative external differential or a local activation can determine in a cell or cell mass a pattern which becomes the basis for organismic differentiation. A few examples will serve to illustrate the fact.

It has long been known that the pattern of branching and even the polarity of various algae can be determined by differential illumination. One of the most interesting cases is the egg of Fucus and related forms. Here light is apparently an inhibiting factor, for with directed illumination the first visible evidence of developmental activity, the primary rhizoid outgrowth, occurs on the less illuminated side. However, the polarity of this egg can be determined by other external differentials. Lund found electric current effective in a certain range of density and action period. In groups of eggs lying close together the rhizoids on each develop toward the center of the group. More recently Whitaker has shown that the polarity of this egg can be determined by a hydrogen-ion-concentration gradient, the rhizoid developing either at the high or low end of the external gradient, according to range of concentration. Also increase of hydrogen-ion concentration to a certain limit increases the group effect. Centrifuging may also be effective when the displaced egg contents are not too rapidly redistributed, the rhizoid developing centrifugally. In eggs remaining elongated after deformation in a capillary tube the rhizoid develops at or near one end of the long axis, but with increased hydrogenion concentration the gradient between free surface and surface in contact becomes more effective than the deformatiou, and the rhizoid may develop from the region in contact. Lowrance, working with a temperature gradient, found the rhizoid developing on the warmer side. Various methods show the presence of a gradient in the egg, at least as soon as the rhizoid outgrowth becomes evident, with the tip of the rhizoid indicated as the high end.

In. animal eggs the foundations of developmental pattern are laid before the eggs are isolated from the parent body, presumably during the ovarian development of the oöcyte. At present we are unable to substitute controlled external factors for the ovarian environment during the oöcyte stage, but it is possible with many animal species to alter or obliterate the pattern established and to determine new patterns in the course of development, or even in adult individuals by means of external differentials.

In the development of the multicellular organism the single cell becomes merely a part of a development pattern on a larger scale. This pattern is characterized by axiate spatial and chronological orders, whether the developing system is a bud, an isolated piece, an embryo or an organ system. The axis concept is, of course, merely a convenient abstraction. The actual pattern may be meridional rather than linear, present only in the superficial cyto- 
plasm of an egg, or in a certain cell layer of an embryo.

In the earlier stages of axiate developmental pattern differences in rate of developmental activities are very generally evident to direct observation at different levels of the polar axis and often of other axes. Graded differences in rate of respiration, rate of reduction of vital dyes in low oxygen, susceptibility to external agents, and other lines of experimental evidence, all agree in showing the presence of quantitative physiological gradients as characteristic features of such pattern in many organisms. In axiate pattern in its simplest terms, as in buds, certain reconstitutions of isolated pieces or cell aggregates, we can find no evidence in early stages of anything more than these quantitative gradients, and it is possible to establish new patterns by means of quantitative gradients of environmental factors. Apparently specific differences in substance and metabolism arise gradually at different levels of such physiological gradients. In a system so complex as a living protoplasm, differences in concentration of oxygen, nutritive substances, water, ions, the various products of synthesis and catabolism, differences in the colloid substrate, and interrelations of different levels along a gradient initiated as purely quantitative, provide ample basis for the origin and development of specific or qualitative differences along its course. In fact, it is difficult to believe that such a gradient, even though primarily quantitative in origin, remains so for any considerable period of development; but it does appear that quantitative differences may remain predominant for a longer or shorter time during development. The gradual progress of so-called determination and of differentiation of parts along an axis suggests the gradual origin and development of qualitative chemical differences in relation to an earlier pattern in which such differentiation has not occurred. It may also be pointed out that a gradient may be an essential factor in determining activation of different hereditary potentialities, or genes, in different cells at different levels of it.

The assumption that developmental pattern in its simplest terms is always to be found in the egg is at least misleading: it may or may not be the case. In some animal eggs there is at present no evidence of anything more than quantitative gradient pattern at the beginning of embryonic development, but complete proof that nothing more is present is lacking. Other eggs show various degrees of regional cytoplasmic organization or differentiation, though a quantitative pattern may also still be present. It does not follow, however, that the differentiation of the egg is an essential or primary feature of the developmental pattern of the species concerned. The ascidian egg, for example, shows a considerable degree of cytoplasmic organization, but this apparently represents a stage in development of pattern in the egg cell rather than a fundamental feature of ascidian developmental pattern. An ascidian can develop from buds of different origins, from pieces of stolen or body isolated by section, and from the cell aggregates often called winter buds. What we know at present concerning these forms of development affords 110 ground for believing that all or any of them have patterns similar to that of the egg at the beginning of embryonic development, but it is evident that all of them acquire in some way the essentials of ascidian pattern, and those essentials appear to be gradient patterns originating in the relations of the systems in which development occurs to their organismic or extraorganismic development. Only by experimental analysis and comparison of the patterns of the different forms of development, their beginnings, and their relations to environmental factors can we hope to distinguish the fundamental factors of developmental pattern of a species from the features incidental to a particular form of development.

According to species, stage and form of development, region of body, relation to other parts and to external environment, the developmental fates of particular cells 
in a multicellular organism may be more or less stably predetermined or dependent on conditions outside themselves, either within or external to the organism. Here we are concerned only with dependence on external factors.

The determination of a new axiate pattern and development of a new individual in coelenterates, flatworms and annelids by the cell activation following transverse section of the body, or in some cases partial section or a local lacerated wound, are familiar to every student of reconstitution. In all these cases the cells primarily activated by the injury resemble a region of primary excitation: first, in that they are activated; second, in that they determine a gradient in physiological condition extending over a greater or less distance. At particular levels of this gradient certain organs differentiate. The activated cells which give rise to the apical region of the hydranth in the hydroid, the head in the planarian and annelid constitute an inductor. The hydroids Corymorpha and Tubularia are excellent examples of this form of development. When the naked cylindrical stem or hydrocaulus of Corymorpha is sectioned transversely, reduction of methylene blue or Janus green in low oxygen indicates an intense activation of cells adjoining the cut end, even after the rapid closure of the wound, and a gradient of decreasing rate of dye reduction more intense than that present in the intact stem extends from this region over a distance of one to several centimeters, according to experimental conditions. The new hydranth develops from the higher levels of this gradient, the two sets of tentacles appearing at certain levels within the region of the hydranth primordium.

The point of chief interest in the present connection is that we can control and vary the length of this gradient by external factors and so determine the scale of organization of the hydranth and the developmental fates of cells at particular levels. By means of inhibiting agents, eyanide, various anestheties, low oxygen, low temperature, etc., it is possible to detcrmine that the gradient following section shall be short, the two sets of tentacles localized nearer the end and nearer each other and the resulting hydranth small. Without experimental inhibition, with high oxygen, with elevation of temperature, the new gradient is longer, its upper parts represent higher physiological levels and the hydranth primordium is longer, with its tentacles localized at greater distances from the end and from each other; that is, the hydranth is organized on a larger scale. Here the differentiations in development of cells at different levels of the stem are altered and determined through their positions in the gradient by quantitative differences in external environment. In planarian reconstitution scale of organization and the developmental fates of cells at particular levels of the piece can also be altered experimentally by external factors which decrease or increase the activation of the cells adjoining the cut end of the piece from which the head develops and so alter the height and length of the induced gradient. Scale of organization in annelid reconstitution can probably be altered in the same way, but the necessary experiments are still to be performed.

In various hydroid species the activation at both ends of an isolated piece is often sufficient to induce hydranth development. By means of electric current, by difference in oxygen content or of hydrogen-ion concentration at the two ends of a piece it is possible to determine hydranth development at one end or the other.

In development of the hydroid under natural conditions one end of the polar axis, the high end of the polar gradient as indicated by respiration, dye reduction, and differential susceptibility, becomes the hydranth; the other end gives rise to one or more stolons or holdfasts, each of which is a gradient with high end at the tip, but of course a gradient of different kind from that of the hydranth-stem axis. Some hydroid species removed from natural conditions to standing water in the laboratory lose their hydranths in a few hours and derelop stolons in place of them, even from 
apical regions, but if returned to flowing, well-aerated water, the stolon tips become hydranths. Similarly, eut pieces with all hydranths removed develop only stolons in standing water, but reconstitute hydranths and stems in flowing aerated water. Here what we may call the physiological level (determined by difference in oxygen supply) determines different lines of differentiation-with low oxygen, the stolon with persistent growing tip, and with high oxygen, the rapidly differentiating hydranth with sensorimotor reactivity. In other species, less susceptible to low oxygen, stolon development in place of hydranths can be induced by various depressing agents, cyanide, anesthetics, etc., and transformation of stolons into hydranthstem axes by return to water.

A striking characteristic of axiate pattern in the earlier stages of development, and in many of the simpler organisms throughout life, is a quantitatively differential susceptibility of cells at different levels to a large number of chemical and physical agents. This susceptibility is to a high degree non-specific for certain ranges of concentration or intensity of different agents; that is, susceptibility decreases in the same direction with the different agents. In general, the higher levels of a gradient pattern, that is, those characterized by greater developmental activity, higher rate of respiration, dye reduction, etc., are most susceptible to inhibiting, toxic, or gradually lethal concentrations or intensities. This has been found to hold for various organisms with anesthetics, cyanides, various salts, strong and weak bases and acids, several alkaloids, vital dyes, increased and decreased osmotic pressure of aqueous medium, visible light with photosensitization by eosin, ultraviolet, $\mathrm{X}$-rays, radium, extreme temperatures, lack of oxygen, and in a few cases supersonic vibrations. Obviously the agents do not all act on living protoplasms in the same way; they do not all inhibit respiration or oxidations directly. How then is the absence of specific regional effects to be accounted for? The interpretation which suggests itsclf is briefly this : the axial differences on which differential susceptibility depends are predominantly or wholly quantitative gradients; granting this, we may expect that any interference with or disturbance of such a system by an external action above a certain threshold, but not immediately destructive of the whole, affecting any essential component or activity, will result in a gradient of effect corresponding in general to the gradient of rate of change constituting the life of the system. Such interference with living protoplasmic systems usually results in toxic effect, retardation or complete inhibition of development, and if extreme, in death. With proper experimental procedure all these effects give evidence of differential susceptibility. This axial differential in effect of external agents makes possible differential modifications of form and proportions in development and alteration of the course of differentiation and the developmental fates of cells.

In differential inhibition of development the higher levels of gradient pattern are most inhibited. In a simple apicobasal or anteroposterior gradient apical or anterior regions are most inhibited, basal or posterior least. The most inhibited regions are not only relatively small in size, but their differentiation is also inhibited more than that of less susceptible regions, and differentiation which normally occurs in a certain region may be shifted to another, but in general results are to a high degree definite, orderly and reproducible. In the echinoderm embryo, entoderm develops from the lower levels of the primary gradient, ectoderm from the upper levels. With differential inhibition, cells which would normally be ectodermal become entoderm; even the whole prospective ectoderm may become entoderm with sufficient depression or inhibition.

Developmental evidence of axiate pattern can be decreased and even completely obliterated by leveling down the gradient concerned through differential inhibition. The ventrodorsal or dorsiventral pattern is usually obliterated with less extreme inhi- 
bition than the polar pattern. Echinoderm larvae with ventrodorsality thus obliterated become completely radiai forms and never show any indication of ventrodorsal differentiation. With obliteration of all axiate pattern, the organism remains spherical and even after recovery following return to natural environment shows no axial differentiation, though it may remain alive for a long time. Embryonic stages of certain hydroids, however, after being made anaxiate in this way can acquire a new axiate pattern by resting undisturbed on the bottom of the container. Hydranth and stem develop from the upper, holdfast from the surface in contact, probably in consequence of the oxygen gradient.

Interesting mediolateral differential inhibitions occur in various animals from planarians to vertebrates. The normal planarian head is triangular with two bilaterally localized ganglionic masses connected with each other, two eye spots dorsal to them and a sensory lobe or auricle at each side of the base of the triangle. With increasing degrees of inhibiting action, inhibition of head development progresses from median to lateral regions in pieces undergoing reconstitution. Eyes and ganglia show all degrees of approximation to the median plane even to a single median eye (eyclopia) and a single median ganglionic mass. With a greater degree of inhibition the median tip of the head is reduced, the lateral lobes develop more or less anteriorly, also approximate the median plane, or a single median lobe develops. The still more inhibited head is anophthalmic with only a rudiment of ganglion and a single median sensory lobe or none, and finally differential inhibition results in a completely acephalic form. It is a point of particular interest that these differential inhibitions do not specifically eliminate particular organs, but eliminate regions progressively from median to lateral, with whatever parts of cephalic ganglia, eyes, ete., are normally localized in these regions.

Essentially similar continuous graded series of head forms occur with differential inhibitions increasing in degree in the embryos of fishes, amphibia, and the chick. With increasing degrees of inhibition, bilateral organs of the head, the nasal openings, the suckers of the anuran, and the eyes, appear progressively nearer the median plane, develop as fused or single median organs, or fail to appear; the brain is correspondingly differentially inhibited, and with extreme inhibition acephaly may be approached or attained. To what extent these vertebrate inhibitions are due to differential inhibition of the inductor underlying the ectoderm or to inhibition of ectoderm need not concern us here; however, the susceptibility of the inductor does decrease laterally from the median region. The important point is that the inhibitions represent continuous graded series of differential effects which are not specific for a particular inhibiting agent.

In the cephalopod embryo a corresponding series of head forms with approximation of eyes, cyclopia, anophthalmia, and parallel elimination of other parts of the head progressively from median to lateral regions results from differential inhibition. Althougl there is nothing that can be called a head in the sea urchin larva, differential inhibitions of development identical in principle with respect to the gradient pattern present occur with all agents used thus far. In early stages inhibition decreases from the apical region basipetally; the oral lobe of the pluteus larva, a differentiation of the apical region, is decreased in size, not fully differentiated, or may be completely absent while basal regions approach normai. A ventrodorsal differential, decreasing laterally from the median ventral region is also present. Under natural conditions two arms with calcareous skeletal rods develop diverging at a slightly variable angle right and left from the basal ventral region. With increasing action of inhibiting agents the angle between the arms decreases, they are approximated to the median plane, become parallel, develop as a single median arm with double skeleton or entircly single, 
or arms are absent and the larva may develop as a completely radial form. The inlibition series of the sea urehin arms and the planarian cephalic lobes are closely similar. The starfish larva differs in form, but shows similar apicobasal and ventrodorsal differential inhibitions. In later larval stages of the starfish the dorsal side of the foregut shows increased rate of dye reduction and increased susceptibility as the foregut extends ventrally to the mouth region. Normally the coelomic pouches develop right and left from the wall of the foregut, but with differential inhibition of the dorsiventral pattern present at this stage the two pouches arise nearer the dorsal mid-line, are more or less fused, a single median dorsal pouch develops, or coelom development and extension ventrally of the foregut are completely inhibited.

All of these differential inhibitions, as well as many others, are similarly related to gradient patterns shown by other methods to be present at the developmental stages concerned. They all constitute continuous graded series of modifications without evidence of specific relation to particular organs; even those organs are differentially inhibited. No death or loss of cells is involved in these cases. Decrease in development or absence of parts is not due to absence of specific cells but to decrease or obliteration of the gradient pattern by environmental factors.

There is another very interesting aspect of differential susceptibility. With certain lower ranges of concentration or intensity of action of inhibiting agents, differential inhibition is of course less extreme and may be followed after a longer or shorter time, even with continued exposure to the agent, by secondary differential modifications of development opposite in direction from the primary differential inhibition. These result from differential tolerance or differential acclimation or conditioning; that is, acquirement of increased tolerance, and after return to natural environment similar modifications result from differential recovery. In these secondary modifications the regions primarily most inhibited are most tolerant, become acclimated or conditioned to the agent most rapidly or most completely, or on return to natural environment recover most rapidly or completely; they may become relatively or even absolutely larger than in the normal animal and are relatively overdeveloped.

For example, secondary modifications of the planarian head, differentially inhibited to cyclopia, which occur with differential conditioning or recovery, consist in the following: two additional eye spots which are normally localized right and left; the ganglia approach normal; and the median head region often develops into an elongated proboscis-like outgrowth with sensorimotor differentiation, something not found in any planarian under natural conditions. With concentrations or intensities of external agents lethal in the course of a few minutes to a few hours, death of the planarian progresses from the head posteriorly. With certain lower ranges of the same agents animals may live and remain intact for some days or even two or three weeks, but with death finally beginning posteriorly and progressing anteriorly. In these cases death may cease at a certain body level because regions anterior to this have become conditioned to the agent and continue to live in it indefinitely. Still later a new posterior end may regenerate and remain alive in the same environment that killed the original posterior end.

Secondary modifications of the sea-urchin larva give forms with relatively enormous oral lobe, small body, and angle between arms increased up to 180 degrees. Relatively megacephalic fish embryos and amphibian tadpoles may be produced in this way. As might be expected, it is the higher levels of the gradients present which are most tolerant, become most rapidly conditioned to, or recover most rapidly or most completely from, the inhibiting action of the agents. The degree and rate of conditioning and recovery differ widely with different agents. For example, with 
ethyl alcohol and with certain ranges of increased and decreased hydrozer-ion concentration, differential conditioning and recovery occur rapidly; with cyanide and many other agents, more slowly. Frequently when a certain region is inhibited in early stages of development, an organ which would normally develop from it develops from a less inhibited region; with differential conditioning or recovery an organ may involve other cells in addition to those normally concerned.

With progress of development new gradient patterns or systems appear in definite relation to the earlier patterns. These doubtless differ as from earlier gradients, as regards character of reactions, but within each such system the differences are probably at first predominantly quantitative and differential modifications are possible. Later specific differentiations may appear in relation to the gradient pattern. Various axiate organs apparently follow some such course of development. They arise at a certain level of a more general gradient pattern, often as buds in which we can find nothing but a quantitative gradient pattern decreasing from a center, and later differentiation may occur within this pattern, but until it has attained a certain stage its course is alterable by external factors.

In conclusion, it may be suggested that organismic patterns, whether of a single cell or a multicellular system, represent in origin the most general behavior patterns of living protoplasms, their most general responses to environmental factors, either external or within other organisms. Even in those cases of fission in Protozoa and Metazoa and of reconstitution of pieces isolated by section in which a part of the parental pattern becomes the basis for development of the new pattern, the partial pattern is altered by the altered conditions associated with fission or experimental isolation of the piece. Moreover, we know that it can be further altered experimentally in many cases. As noted above, it is now generally held that embryonic developmental pattern originates in relation to enviroumental factors within the parent organism, and it, too, can be modified experimentally. According to this view, the organism itself and the differentiations of its cells represent behavior of living protoplasms no less truly than do the reactions of the adult organism which the patterns of differentiation make possible. 


\title{
CELLULAR DIFFERENTIATION AND INTERNAL ENVIRONMENT ${ }^{1}$
}

\author{
By ROSS G. HARRISON \\ OSBORN ZOOLOGICAL LABORATORY, YALE UNIVERSITY, NEW HAVEN, CONN., \\ AND NATIONAL RESEARCH COUNCIL, WASHINGTON, D. C.
}

IT may not be inappropriate in beginning this discussion to refer to a passage from Psalm 139, which seems to be germane to the subject.

14. I will praise Thee; for I am fearfully and wonderfully made: marvelous are Thy works; and that my soul knoweth right well.

15. My substance was not hid from Thee, when I was made in secret, and curiously wrought in the lowest parts of the earth.

16. Thine eyes did see my substance, yet being unperfect; and in Thy book all my members were written, which in continuance were fashioned, when as yet there was none of them.

There are several remarkable things about this text. First, it refers to development as a personal experience; and, indeed, all of us have been through it. This in itself should arouse our curiosity, but unfortunately we have no recollection of the adventure. It is also to be noted that the process of development is described here as a sort of epigenesis. "And in Thy book all my members were written, which in continuance were fashioned, when as yet there was none of them." It does not picture development, in the naive manner, as a mere unfolding or "evolutio" of something already present.

While this symposium deals with the cell in all of its aspects, the topic assigned to me, "Cellular Differentiation and Internal Environment," clearly concerns the development of the organism and implies that the treatment of the subject should be in terms of the cell as a unit. With this I am wholly in agreement, for in my opinion none of the attacks that have been made upon the cell theory have shaken it to any appreciable degree.

1 The lecture was illustrated by numerous lan. tern slides.
It seems to be a characteristic of the human mind to describe the phenomena of nature in terms of units or particles. Physics, chemistry, and crystallography have all profited immensely by this device, even though modern physics tells us that nature cannot be fully described in such terms alone. Such theories are oversimplifications and are sooner or later modified; witness the atomic theory of the 19th century. But it may be doubted if science can advance without the aid of over-simplified hypotheses.

The cell theory differs from other particulate theories in the circumstance that the units can actually be seen under the microscope and sometimes even by the naked eye. Each unit is composed of two main constituents-nucleus and cytoplasm. However, the fact of individual visibility does not mean that there are no difficulties or uncertainties connected with the theory.

One of the notions that has frequently aroused opposition is the concept of the organism as a cell state made up of quasiindependent or autonomous units, the cells. The inadequacy of this concept was emphasized by Conklin, who declared that there is something in the organization of the individual that makes it more than the sum of its parts. While this statement in itself may be unobjectionable, the mystical haze that often surrounds the word "organization" has no place in science.

I doubt if there is any astute and serious observer who thinks of particulate units at any level as wholly independent of one another. The relations of the particles are part of the system, and it is their behavior in relation to one another that constitutes "organization." These relations are amenable to experimental investigation and are usually expressed in some kind of a con- 
figuration. This occurs at all levels, and may concern electrons, atoms, molecules, cells or individual organisms. No particle or unit can be wholly understood or its behavior predicted unless its reactions with others are taken into consideration. The cell theory of the organism concerns, then, not only the cells as independent units but also their structural and functional relations to each other.

Whitman's notable essay on "The Inadequacy of the Cell Theory of Development" (1893) is often cited as opposed to the cell concept of the organism. However, this paper is in essence a plea for the recognition of a microstructure as the basis of organization, and is in no sense the negation of the cell as a living unit, although "cellular interaction" as an explanation of formative processes, is summarily dismissed as a term of reference. "If the formative processes," says Whit-

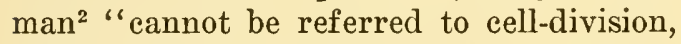
to what can they be referred? To cellular interaction? That would only be offering a misleading name for what we cannot explain; and such an answer is not simply worthless, but positively mischievous, if it put us on the wrong track. Loeb's experiments in heterogenesis [heteromorphosis?] furnish a refutation of the interactive theory. The answer to our question may be difficult to find, but we may be quite certain that when found it will recognize the regenerative and formative power as one and the same thing throughout the organic world. It will find, as Wiesner has so well insisted, a common basis for every grade of organization, and it will abolish those fictitious distinctions we are accustomed to make between the formative processes of the unicellular and multicellular organisms. It will find the secret of organization, growth, development, not in cell-formation, but in those ultimate elements of living matter, for which idiosomes seems to me an appropriate name."

The cell theory may be subjected to various experimental tests of its adequacy, many of which have been devised since 2 Op. cit., p. 657.
Whitman wrote his essay. In the sense of those who emphasize "organization" as the chief characteristic of living creatures, "inadequacy" may be measured to a limited extent by the differences in behavior between cells associated in the organism and those acting alone or in small groups. This has been done by means of tissue culture and other types of isolation, including separation of blastomeres. A cell from the neural tube of an embryo, isolated in a suitable medium, forms a nerve fiber, and a presumptive heart cell may develop striations and beat rhythmically by itself (Burrows, 1912). However, the nerve fiber does not function as such without connections, and the heart muscle cell does not form an organ that pumps blood. On the other hand isolated blastomeres may give rise to a whole organism. Thus a cell, when isolated, may do either more or less than it would presumably have done if left in normal relations to its associated elements.

That isolated cells often achieve so little is no indication of limitation in what they can do, since the conditions under which they are isolated are too restricted. Until such cells are tested under a great variety of conditions, or better still, under all such as are possible, their full capacity will not be known.

One of the more concrete matters of disagreement over the cell theory concerns the mode of connection between cells in the organism. Are they completely separated from each other by membranes or is their internal substance or eytoplasm continuous? Much importance has been attached to alleged protoplasmic bridges between cells and to the supposed syncytial nature of the tissues. Adam Sedgwick (1894) once described the vertebrate embryo as an organism with nuclei lying in a continuous reticulum, using this misconception to bolster up an erroneous theory of the histogenesis of the nerve fiber. That this question is not of such fundamental importance as some would attribute to it is shown by many considerations.

While the eggrs of insects and many other 
arthropods proceed through their early development as syncytia without cell membranes, the cells in other embryos are from the first sharply divided from one another. There may be regional cytoplasmic differentiations in single cells that are as sharply defined as cells are from one another, but as division proceeds the various regions become separated from one another by the cell walls.

Certain tissue elements, such as striated muscle fibers in vertebrates and arthropods, are multinueleate and surrounded by a common membrane. Conmective tissue cells are often described as forming a syncytium, but their ability to move about independently and the difficulty of resolving optically the delicate connections between fine cell processes invite caution in accepting this interpretation. Cells growing. in culture media outside the body have thrown light upon this question. While fibroblasts, muscle cells, neuroblasts have often been described as forming syncytia, it has been shown that supposed nerve nets may often be resolved later by separation of the apparently fused processes (Harrison 1910; Levi 1917). ${ }^{3}$ Similar observations have been made on mesenchyme (Lewis 1922) and heart muscle (Levi 1925).

Viewed pragmatically, the experimental analysis of the processes of development is greatly facilitated by considering the embryo as made up of discrete units associated with each other in various degrees of intimacy.

In relation to development, the most important fact in connection with the cell theory is that each organism begins its independent existence as a single cell, which, barring parthenogenesis, is the product of fusion of two unlike cells, one derived from the body of each parent. This is the narrow bottle-neck through which we have all passed, the book in which all our members were written, when as yet there was none of them.

Since every organism develops in a certain environment within rather narrow physical limits, its developmental processes can be properly considered only in relation

\footnotetext{
3 For the contrary view see Bauer (1932).
}

to this environment, as Child has already emphasized. In arranging this symposium Taylor has distinguished between external and internal environment, and has left to me the task of interpreting the meaning of the latter. I shall therefore define the internal environment of a cell as the sum of all those factors with which it is in relation that lie within the organism but ontside of the cell in question. These factors affecting the differentiation of the cell change with the successive phases of the development of the organism.

Strictly speaking, a single cell has only an external environment. However, the germ cells that unite to form the fertilized egg do have in a certain sense an internal environment inside the body of the parent organism. When they are cast loose they cease for a time to have such an environment, and it is only after cleavage begins that the resulting cells acquire a new internal environment in their sister cells. For a short period this is the only internal factor that counts, there being as yet no general milieu intérieur. However, during this period, which in the vertebrate embryo includes segmentation, gastrulation and neurulation, the most important differentiations oceur. Later, after the establishment of a circulating medium and the primitive nerve paths, an internal environment of the ordinary sort is again present.

The ovum, as it grows, acquires a large amount of cytoplasm which enters into the composition of the embryo, though much of the material may be mere inclusions of a purely nutrient nature. So long as the egg is part of the maternal body, its exact relations to the contiguous cells of the parent organism, and, secondarily, to the circulating medium are of prime importance in setting up its organization or configuration. At this time the egg is either attached to the maternal tissues at one pole or is tightly enclosed in a capsule lined by follicle cells. In many, if not in all cases, but especially in those of the first group, the material is laid down in the egg around a polar axis but with marked gradients along this axis, by which a visible polarity is established in the egg. The nucleus lies 
on this axis but usually excentrically placed with reference to the egg as a whole. Substances emanating from the nucleus may therefore act vectorially on material entering the egg from without.

At maturation, when a large amount of fluid is discharged from the nucleus into the cytoplasm, and accompanying or following the entry of the sperm, a major commotion occurs, during which there is a lively streaming of cytoplasmic materials, resulting in their partial rearrangement. After this many eggs become visibly bilaterally symmetrical, while others show a clear asymmetry. It is at this period that the egg loses its original internal environment and is discharged either to the exterior or to the oviduct of the maternal parent, where a greater or lesser part of its development may take place.

The polar differentiation acquired while the egg was part of the maternal organism may last in part through maturation and fertilization in spite of the streaming and rearrangement that occurs then. After fertilization the new arrangement of materials follows a certain pattern peculiar to the species, as is well exemplified in the eggs of ctenophores, molluses, annelids, and ascidians, though less definitely marked in many other forms. When cleavage occurs the resulting cells are thus already to a certain extent differentiated from one another, as measured by what they do in forming the primitive organs of the embryo.

Little is known with regard to how these differentiations come about, but it may be assumed that they are related in some way to the physico-chemical properties of the material entering into the composition of the egg and to the direction from which they enter it. Of first importance in this connection are the protein molecules, which to the best of our knowledge are polarized and asymmetric. They would thus tend to orient themselves within the cell as they increase. Other substances, either combined with the proteins or separate, would tend to concentrate near one or the other pole of egg according to their electrical charge.
While the asymmetry of protein molecules does not preclude them from combining to form crystals of high degree of symmetry, as in the case of pepsin, it may be assumed that, in some way related to this molecular asymmetry, there arises sooner or later in the development of the embryo a macroscopic asymmetry, which characterizes most if not all organisms and is merely masked by a superficial bilateral or radial symmetry.

Superposed upon the polar arrangement there are also differences between cortex and deeper portions of the egg cytoplasm. This, too, may be due primarily to molecular orientation at the surface. In this cortical or ectoplasmic layer, which is usually free from inclusions, we probably have the characteristic protoplasm of the species in its purest form. The behavior of this material in early stages of development, i.e., during maturation and segmentation, has been followed by many observers in a great variety of eggs, since G. F. Andrews (1897) first described the amoeboid spinning movements in the cortical layer of starfish and sea urchin eggs. In the eggs of Beroë a very peculiar streaming of this layer takes place during cleavage (Spek 1926). Everything points to the importance of this cytoplasmic constituent in the early processes of development (Just 1939).

The use of the term protein molecule in the foregoing requires some further explanation. As stated by Chambers, the proteins extracted from cells or those in dead cells are different from living protoplasm and are doubtless much less complex in their configuration. Such arrangements as occur in the living are upset at death or by the chemical processes used in separating the constituents known as pure proteins. These changes are, so far as we know at present, irreversible, so that study of the properties of pure proteins alone can never give an adequate picture of living protoplasm, though knowledge of these substances is essential to an understanding of it.

Both the arrangement of materials in 
the ovarian egg and the later arrangement assumed after maturation and fertilization show regional differences, which must be the result of a sorting out process. This requires energy and, according to some, even intelligence. It may be related in some way to the bioelectric potentials of both the ovum itself and the surrounding maternal tissues.

In the orientation of the protein molecules of the egg cell, due to their dipole character, a paracrystalline configuration is set up, and large numbers of molecules of water and electrolytes enter into definite relation with it. There are also associated carbohydrates and lipoids. Some of the material is built up into the living protoplasm, and the composition of this protoplasm shows regional differences corresponding to the main axis of the egg. The ground cytoplasm of the egg varies along this axis, retaining throughout, however, the configuration characteristic of the species. In addition to the material that becomes a part of the ground cytoplasm there is also other material which forms aggregates that do not enter into the composition of the cytoplasm so intimately but take on granular or vesicular form and constitute visible inclusions, such as pigment granules, oil droplets, mitochondria, and yolk.

The inclusions are also re-distributed in a definite way after fertilization and since they are parcelled out to particular cells which give rise to particular organs, they have often been termed organ-forming substances. Experiments in centrifuging eggs show, however, that they usually play no such role, for they may be distributed very abnormally by this treatment without producing abnormalities in the resulting embryo.

In accordance with the foregoing, the polarity of the egg may be based upon three factors, the dipole character of the protein molecules and their resultant orientation, regional gradational differences in the composition of these molecules, and regional differences due to cytoplasmic inclusions. The first is a polarity of orien- tation (Richtungspolarität), the third a polarity of stratification (Schichtungspolarität) (Boveri 1901; Driesch 1908; Przibram $^{4} 1913$ ), while the second is a polarity in which probably both orientation and stratification are concerned. The position of the nucleus in the cytoplasm also has a definite relation to the polarity of the egg.

According to the hypothesis here adopted, the polarity of the egg, and hence that of the resulting organism, is referable primarily to the orientation of large molecules, the arrangement of which is determined in relation to their internal environment within the maternal body as well as by their mutual relations. The asymmetry of the organism may likewise be assumed to follow ultimately from the asymmetric configuration of the molecules. While these relations are normally fixed, they may, however, be inverted by external factors, as in the production of situs inversus (Spemann 1906; Pressler 1911) or in the inversion of the polarity of the Fucus egg by means of directed light and other physical factors (Whitaker 1931, 1936).

While the correlatives of the form and structure of the adult organism are to be sought in the molecular characteristics of the substances composing the egg-and these must be considered as persisting throughout all stages of development-a more definite macroscopic topographic relation between egg and organism than existed before is entered into after the streaming that follows maturation and fertilization comes to repose. To what extent this secondary arrangement is correlated with the differentiation of the embryo is a question to which many have addressed themselves. There is much variation in the answer according to the species of egg studied.

Rapid changes take place in the egg cytoplasm during maturation and fertilization and immediately thereafter. If fragments are removed from the egg in the early part of this period, the embryo may develop without defect except in size, especially when the egg is cut vertically, i.e., parallel

${ }^{4}$ Op. cit., p. 35. 
to its axis. As the time interval between fertilization and removal of the fragment increases, the defects become more marked and more specific. These statements are based upon experiments with eggs of nemerteans (Wilson 1903; Zeleny 1904), Dentalium (Wilson 1904) and ascidians (Dalcq 1932). One of the most striking cases of defect after removal of portions of the cytoplasm of an unsegmented egg is found in the ctenophore, Beroë ovata (Driesch and Morgan 1895; Fischel 1903; Yatsu 1912). In this form there is a definite relation between the position and the amount of the cytoplasm removed and the number of rows of swimming plates present in the embryo which develops from the remainder.

Experiments of this kind show that there are regional differences in a given egg and also differences between species of eggs with respect to their germinal localization. There is likewise variation in the extent to which defects in the early stages of development may be made up by the material that is left, and this holds both for the unsegmented egg and the egg which has undergone cleavage. Driesch thought all cells of the sea urchin blastula to be alike, as measured by what they can do in the course of development (prospective potency), and that what they actually do is a function of their position in the whole. On the other hand, gastropod, annelid, ctenophore and ascidian eggs have been characterized as mosaics, in which the role of the constituent cells is fixed from the beginning and cannot be changed. Cleavage has correspondingly been described as indeterminate or determinate and the course of development in the respective classes as regulatory or mosaic.

It is obvious that eggs do differ in this respect, but no egg is wholly in either class. If mosaic development were the rule my theme would end here, for subsequent changes in the embryo would then take place according to the initial structure of the germ, and could not be modified by the internal environment.

In the egg of the molluses, Ilyanassa
(Crampton 1896), Dentalium and Patella (Wilson 1904, 1904a), each cell when separated from the rest gives rise to just what it would, were it left in place in the embryo. Here, then, the internal environment of blastomeres may be assumed to have no effect on differentiation. Wilson found, however, that each fragment of an unfertilized egg, when divided vertically and fertilized, develops into a whole larva, thus showing regulation within the single cell. On the other hand, removal of the polar lobe results in a deficiency of the apical organ and the post-trochal region that is not made up. The case of Tubifex, an oligochaete, which like the gastropods and scaphopods has a spiral cleavage and a mosaic development, is nevertheless interesting in showing a considerable amount of regulation under certain conditions (Penners 1924, 1925). When the polplasm is divided equally at the first cleavage, which takes place frequently as a result of low temperature, both cells contain teloblast material and the result is a double embryo (duplicitas cruciata). When the $A B$ cell is killed by ultraviolet radiation, the $C D$ half, and probably also the D-quarter when all three remaining cells are destroyed, give rise to whole embryos. The above facts imply considerable powers of regulation in these eggs with highly determinate cleavage and also that in such eggs the cells constituting a mutual internal environment do normally restrict the activity of neighboring elements.

The ascidian egg, which according to Conklin (1905, 1905a, 1911, 1931 )holds to a very rigid cleavage mosaic, shows considerable lability before fertilization. It may then be deprived of large amounts of cytoplasm and still develop normally (Reverberi 1931; Daleq 1932). Even two complete embryos, one of which is merogonic, may sometimes be obtained from a single egg. There is, however, indication of bilateral symmetry at this early stage. Evidences of regulation in the fertilized egg have been found by v. Ubisch (1938), who describes the development of a single giant larva from two fused eggs. In embryos derived from one of the first two 
blastomeres there may also be a restricted regulation, as shown by the movement of myotome cells around the tip of the notochord to the defective side (Cohen and Berrill 1936). Evidence of induction of cerebral vesicles with sensory cells by means of certain underlying cells has also been obtained (Rose, 1939; Vanderbroek, unpublished $^{5}$ ). v. Ubisch (1939), however, failed to find such induction in Ascidiella.

Again, in Clavelina, which probably also develops through a strictly "determinate" cleavage, there are certain totipotent reserve cells which enter into the winter buds in unorganized clumps and later give rise to new ascidiozooids (Spek 1927; BrienGavage 1927). In regeneration also, the several types of cells and tissues show much lability in their powers of differentiation. These facts indicate that the strictly mosaic cleavage pattern is only of temporary significance as far as germinal localization is concerned. There is a possibility that it is due to nothing more fundamental than the peculiar aggregate state of the cytoplasm at the time.

Likewise in the ctenophore egg, which also undergoes determinate cleavage, there are evidences of regulatory development in the formation of the aboral sense organ and the gastral pouches (Driesch and Morgan 1895). Chun's (1892) observations on the later stages of development indicate that the partial larvae which develop out of separated blastomeres are transformed by a mode of "postgeneration" into whole etenophores.

While the three best known types of "mosaic" eggs thus show that "determinate" cleavage may lead to an embryo having some lability with respect to differentiation, an examination of the so-called "regulation" eggs shows, on the other hand, a considerable degree of localization within the cytoplasm. In the Hydromedusae (Clytia, Laodice) single blastomeres of the eight-cell stage may give rise to a whole organism (Zoja 1895-6). However, in many hydrozoan eggs there is a concentric ${ }^{5}$ Cf. Daleq (1938), p. 104. stratification with definite ectoplasmic and endoplasmic layers, so arranged that each of the early blastomeres receives both substances, and it is only later that cells of pure ectoplasm or pure endoplasm arise by cleavage parallel to the surface.

It was with reference to the sea-urchin egg that the complete totipotence of individual blastomeres was first maintained. This interpretation goes back to Driesch (1891, 1892), who found that blastomeres isolated in the two- or four-cell stage, while segmenting as fractions, close over in the blastula, gastrulate normally and give rise to uormal plutei of reduced size. Later Driesch claimed that even single blastomeres of the 32-cell stage would gastrulate and he showed conclusively that two eggs or blastulae could be fused together so as to give a single normal embryo. However, the sweeping conclusion drawn by Driesch $\left(1894,1929^{6}\right)$ from the above facts, that "the prospective value of any blastula cell is a function of its position in the whole" does not hold. The experiments on which it was based were not sufficiently controlled to warrant the conclusions, nor were the methods available at that time adequate to carry out the requisite experiments.

Driesch's generalization implies that cells in their differentiation must be subjected to the action of surrounding cells, their internal environment. That is, the term "position" means their location with reference to other cells. However, the gastrular invagination begins at a certain point on the spherical blastula, and surrounding cells are carried in with it; this must mean either that there is something peculiar to the cells at that point, which is contrary to Driesch's hypothesis, or that the point is determined by environmental factors of an accidental nature. The latter alternative is highly improbable.

It remained for von Ubisch (1925, 1925a, 1931, 1933, 1933a, 1936, 1939) and Hörstadius (1928, 1935, 1937, 1938, 1939), by means of ingenious devices, to explore the ways in which blastomeres act upon one another in gastrulation and in various proc-

6 Op. cit., p. 55. 
esses of differentiation. The methods used are similar to those first suecessfully employed with amphibian eggs, i.e., transplantation and vital staining, besides methods of separating individual blastomeres and parts of older embryos with due regard to the exaet origin of each cell or cell group used in the experiments.

The sea-urchin egg shows graded differences along its main axis, about which the cytoplasmie substances appear superfieially to be radially symmetrieal (Boveri 1901a). The polar axis is not shifted by centrifuging but its degree of fixity is a matter of dispute. Tennent, Taylor and Whitaker (1929) elaim that in Lytechinus it may be shifted by cutting the egg, while Hörstadius (1937) finds that in the egg of Arbacia it is fixed. Development of egg fragments shows, too, that even in the unfertilized egg there is a considerable degree of cytoplasmic loealization. While the eggs of but few echinoderms have actually been shown to be bilaterally symmetrical, with dorsoventral polarization, this is probably true for the group generally, though the plane of symmetry may be shifted and the polarity of the dorso-ventral axis fixed by such external faetors as stretching (Boveri 1901; Lindahl 1932), centrifugation (Runnström 1926 ; Lindahl 1932a; Pease 1939) or chemicals (Lindahl 1932). However, the details are not all in agreement. When the egg of Dendraster, the Pacific Coast sand dollar, is eentrifuged, the eentripetal pole is found to lie on the ventral side though frequently not in the median plane. Pease concludes from his experiments on this form that two faetors are concerned in fixing the dorsoventral axis, one, loeated in the cortical layer, which is not movable, and the other, located in the endoplasm, which may be shifted by centrifuging. The direetion of the axis, and with it the median plane, is the resultant of the interaction of the two factors, the ventral side being in the region of maximum reactivity. When eggs are eut in the frontal plane during cleavage stages, the dorso-ventral polarity is reversed in the dorsal half (Hörstadius and Wolsky, 1936). The bilateral symmetry of the embryo usually first becomes visible when the primary mesenchyme cells group themselves on the two sides, prior to laying down the larval skeleton, in response to stimuli emanating from the ectoderm (Driesch, 1896).

By means of isolation and grafting experiments Hörstadius (1935) has made an exhaustive analysis of the action of the material in the suceessive layers along the primary axis of the egg. Of great interest are the eases in which the segmenting egg of from 16-24 eells is divided "horizontally" by tiers, whieh are allowed to develop by themselves or in various combinations. The results show that the combination must contain material from both the animal and vegetative regions of the egg in proportions that do not deviate too far from the normal. An animal half of the egg or the uppermost tier of cells in the animal hemisphere gives rise to a blastula in which the apieal tuft of stiff eilia is much enlarged. If mieromere cells from the opposite pole are added, the tuft is reduced to proper proportions and a normal small pluteus may develop. In faet, two normal plutei may be obtained from a single egg after horizontal division, provided the middle part is left intaet and the mieromeres are joined to the "most animal" eells. This involves a considerable amount of regulation, in whieh partieular cells give rise to structures quite different from those they would normally form. Animal (ectodermal) cells may be endodermized by the presence of micromeres, and a certain amount of vegetative material is necessary to inhibit the spread of the apical tuft. On the other hand some animal material is necessary for gastrulation to take place.

In such proeesses of differentiation there must be a lively reaction between the ehanging cell and its internal environment of other eells. This must either take place through direct contact, as when the micromeres induce presumptive ectoderm to invaginate (gastrulation), or be mediated by substances diffusing through the blastocoele from cells at a greater distance, e.g., in the 
mhibition of the spread of the apical tuft by the presence of micromeres at the opposite pole. In contrast with the mosaic eggs referred to above, the sea-urchin egg gives much more evidences of interaction between parts after development has started, but there is no such complete isotropy in the sea urchin egg as Driesch supposed. The material of the vegetative portion of the egg is different from that of the animal portion, and some of each is necessary for normal development.

According to the Runnström-Hörstadius theory, there are in the egg two material gradients oriented in opposite directions; one diminishes as the other increases from one pole to the other. At the animal pole, the "most animal" region of the egg, the power to form structures characteristic of that region is most intense; at the vegetative pole, the "most vegetative" region, the power to invaginate and form structures normally arising there (archenteron, mesenchyme) is at a maximum. When any portion of the egg is cut out there is a tendency toward a rearrangement of these materials so that the gradients are restored approximately to their original scale. Before the third (equatorial) cleavage membrane is established this might take place by rearrangement of coarsely particulate material, but the fact that the phenomenon occurs even after the egg is divided into many cells indicates that the reestablishment of the gradients after disturbance is brought about by subtler changes in the egg materials.

While there are many processes in the development of the sea urehin that are either of a self-regulatory character or are dependent upon the internal environment for realization, the marked regional differences in the several layers of the egg as regards their powers of differentiation show that the mosaic quality of this egg is not negligible.

The amphibian egg, thought by Roux (1888) to be the archetype of mosaic development, is now known to be about as regulable as the sea-urchin egg. However, all amphibian eggs that have been studied show a certain amount of germinal localization at the time cleavage begins-a cortical layer, the gray crescent, and peculiarities of yolk and pigmentation in the two hemispheres. These eggs are enclosed in a tight membrane and are very fluid, so that removal of parts of the unsegmented egg by pricking to test their function in development has not yielded results that can be clearly interpreted (Brachet 1923). On the other hand, the effects of separation and rearrangement of cell constituents by means of the centrifuge and by gravitation (inversion of eggs) have given results of interest.

When the egg of a frog is turned there is a marked rearrangement of constituents. The cortical layer, which holds most of the pigment, and the main part of the gray crescent remain in position, and the main mass of heavy white yolk rotates as a unit. The position of the dorsal lip of the blastopore in such eggs indicates that it is formed in definite relation to the gray crescent (cortical field) and the yolk mass (Weigmann 1927; Daleq and Pasteels 1937). In other words, turning the egg does not result in indiscriminate mixing of the elements but in an orderly rearrangement, which may be such that a normal embryo may develop from it. When the egg is inverted in the two-cell stage the rearrangement takes place independently in the two cells. This may result in the formation of two separate dorsal blastoporic lips followed by the development of a twin embryo (Schultze 1894). All of this goes to show that even in the earliest stages, development is affected by the interaction of cell constituents according to an orderly topographic arrangement. The internal environment of the cell constituents within the cell thus plays an important role. The nature of the reactions is, however, in total obscurity.

The amphibian egg shows perhaps better than any other the combination of mosaic and regulative qualities. The normal scheme of germinal localization has been mapped in great detail by vital staining, first applied in a wholly satisfactory and exhaustive way by Vogt $(1925,1929)$. The 
areas determined by this means are, however, not organ-forming areas in the strict sense, for practically any piece of the egg of sufficient size may, if isolated or placed in new position, give rise to more than it would have-or at least to something different-had it been left in place. This is shown by many types of isolation and recombination experiments (Bautzmann 1929; Holtfreter 1929, 1931, 1938).

It has been shown beyond doubt that the egg after fertilization has a bilaterally symmetrical structure, which may, in fact, even be antecedent to fertilization. When the first cleavage furrow divides the egg approximately in the plane of symmetry, which is the presumptive median plane of the embryo, separation of the blastomeres is followed by the development of each into a complete embryo (Ruud 1925). The coblastomere of the two-cell stage therefore constitutes an internal environment which, if present, restricts its mate to forming half an embryo. Here, however, the regulative process may be little more than a flow of materials within the single remaining cell, for a dead cell, if not removed, may have the same effect as the living cell (Roux 1888). The amphibian egg contents are very fluid and in them there is obviously not the same hindrance to flow as in ascidian eggs. When the first cleavage is at right angles to the plane of symmetry, it divides the germinal material into presumptive dorsal and ventral halves. The former, when separated from the rest of the egg, has sufficient power to readjust its internal arrangement to form a normal whole embryo. The latter, which contains no gray erescent material, lacks this power and forms a very defective "Bauchstück" or ventral piece, which is without notochord and nervous system. Some readjustment of material takes place in this piece too, but it is insufficient to produce a normal embryo. An essential constituent is wanting. Two eggs fused together in the twocell stage may form either a single normal embryo of large size or double or multiple monsters, according to the relative position of the gray crescents in the combination.
This, likewise, shows the power of adjustment of the egg substance and the limitations imposed upon it by eytoplasmic differentiation (Mangold and Seidel 1927).

Even through the blastula stage the two lateral halves of the newt embryo retain the ability to readjust and form a complete embryo after separation (Spemann and Falkenburg 1919; Ruud and Spemann 1922), except that the side originally turned toward the other cell may be defective. The right-hand partners in pairs of twins produced in this way may have their asymmetry (situs viscerum) reversed. Regional areas along other axes of the blastula become more and more specialized as development proceeds, but at the same time show much dependence upon surrounding parts (internal environment) for their proper differentiation.

The most striking case of dependent differentiation is that of the central nervous system, which is formed in the outer layer of the embryo by reaction with the material underlying it, which is turned in during gastrulation. This material, because of its marked general effect upon the development of the embyro, has been termed the organizer by Spemann (1924, 1927), its discoverer. The material which is invaginated and which acts upon the overlying tissues forms the pharyngeal roof, head mesenchyme, axial musculature and notochord.

Several of the earlier experiments leading to the conception of the organizer are the following: (1) When two newt's eggs are divided down the midline in the blastula stage and the two right halves or the two left halves are grafted together, so that the two half dorsal lips are not exactly opposite one another and point in opposite directions, each one forms or organizes a whole embryonic axis with the incorporation of adjacent material from the other half, and double embryos result. (2) When half the dorsal lip and adjacent material is grafted into another less specialized region of the embryo, it invaginates and reacts upon its surroundings so as to produce a whole new embryonic axis in the host organism. 
Pieces of presumptive ectoderm and presumptive neural plate, when interchanged in the blastula or early gastrula, develop in harmony with their new surroundings (Spemann 1918). (4) Pieces of presumptive ectoderm, when grafted into the dorsal lip of the early gastrula, acquire the properties of the latter and arc able to act as organizer material (Spemann and Geinitz 1927).

What it is that gives the organizer cells these properties, which are so effective as an internal environment to the overlying cells, and what the nature of the reaction in the surrounding tissues is has not been ascertained. Spemann (1931a) himself experimented with organizer material the structure of which had been destroyed. Later Holtfreter (1933, 1933a, 1934) discovered that a great variety of animal tissues both adult and embryonic and from almost any phylum could, when placed in the blastocoel so that it ultimately came to lie under the ectoderm, stimulate the formation of a thickened area (neural plate) in the overlying tissue, which might fold over and close in as the neural tube does. Even pure chemical substances held in an agar matrix may have a similar effect. There is a difference, however, between the response to living normal organizing material and that to dead material, the former stimulating the formation of a complete neural plate and tube with normal regional differences, while the latter produces simply a thickened plate which may close to a tube without, however, showing such regional differentiation.

Much effort has been spent to find out the nature of the chemical substance that produces these effects, and several different conclusions have been tentatively reached. The fact that eertain embryonic tissues which have no organizing effect when living do so act when dead has led to the view that the substance responsible for the effect is free only in the active regions but exists in a bound condition in other parts of the embryo. Needham, Waddington and co-workers (1935, 1938) have isolated sterol derivatives from the or- ganizer and have found that synthetic sterols when applied in an agar matrix do induce the formation of neural-plate-like structures. Another fact that may be of significance is the occurrence of an intense carbohydrate metabolism in the organizer (Woerdeman 1933; Heatley and Lindahl 1937 ; Boell et al. 1939 ; Brachet 1939).

Differences between the action of the natural organizer in its normal position and that of dead material and chemical substances may be due to the circumstance that the former is distributed in a gradient llaving different local concentrations. Another factor that may have some influence is the possible variation of the intensity of action with respect to time. A normal induction might be achieved only through the action of a living system, because this might require the action to start with a low intensity, increase to a maximum, and then taper off; or it might require several cycles of variation in intensity, which dead material could not afford. Regional differences in the reacting material must also be taken into consideration, as shown by the different respective reactions of presumptive head and trunk regions to similar implanted organizer material (Spemann 1931).

What happens in the ectodermal cells that become transformed into neural plate is of much importance in any theory of organizer action but it is almost totally unknown. The neural plate contains relatively more water than the embryo as a whole (Glaser 1914), and it seems to be the inner portions of the neural plate cells that are the most swollen. We might assume, then, that the organizer produces a chemical change, which leads first to an orientation of particles that makes the cells columnar, followed by a greater hydration of the protein lattice localized in the basal halves of the cells. This would lead to the folding of the plate to form a groove and its ultimate closing into a tube. The changes underlying the process would thus be of a chemical and paracrystalline nature.

It must also be borne in mind that the agencies effecting the differential changes 
in the central nervous system are heterogeneous in composition. Underlying the fore brain is the pharyngeal roof and some mesenchyme, and under the rest of the brain and spinal cord the notochord occupies the midline with the myotomes on each side. All of these factors are known to have a specific effect on the overlying neural plate (Lehmann 1926, 1928, 1938).

Since the word "organizer" connotes a master regulator which creates the organization, and since there are in the course of development many actions of the same general character that could hardly be accorded such a role, it is perhaps more appropriate to use the word "induction" to denote processes of this kind. Outside the area of the central nervous system there are many other ectodermal organs-balancer, gills, hypophysis, etc.- that are dependent upon other structures for their differentiation. Whether the ectodermal structures just referred to arise in situ through some localizing factor in the ectoderm itself, or whether they are produced by reaction with the underlying tissue is still uncertain in some cases.

An experimental study of the development of the ear shows that, beginning with the late gastrula or early neurula stage, at least four factors are concerned in its differentiation (Harrison 1935a, 1938a). Three of these lie within its internal environment. The cellular material is, as is well known, supplied by the ectoderm. While an ear vesicle may arise from any ectoderm of the gastrula, in the early neurula stage the cells of the auditory placode, out of which it normally develops, are already predisposed toward ear formation (otogenesis). The underlying mesoderm is still involved at this time and it is probably this layer, acting at a still earlier stage, that has induced the just mentioned condition in the ear placode. A second effective factor in the internal environment of the developing ear is a certain spot in the hind brain region of the neural tube with which the ear placode is brought into contact as the neural folds rise and close over. A fourth factor is the position in the embryo in which the ear vesicle develops. By means of grafting experiments all of these factors have been varied, but the results do not indicate that they singly have any markedly specific role to play, except that the hind brain seems to be significantly associated with the development of the endolymphatic duct and sac. The development of a normal ear vesicle seems rather to be dependent on a series of factors acting in turn, and furthermore the orientation within the organism of at least two of them-the ear placode and the myelencephalon-have at the appropriate time an effect upon the asymmetry of the ear that develops.

Again nothing is known with regard to the actual processes involved in the development of this organ and the nature of the action of one part upon the other. There is evidence, however, that an orientation of some structural element of the earplate cells takes place about the time of closure of the neural folds (Harrison 1936).

There is a certain similarity between the formation of the neural groove and that of the auditory pit in that cells elongate in a direction perpendicular to the surface and a vesicle is ultimately folded off from a plate. There are differences in degree of elongation, in shape, and in the fact that the neural folds rise above the surface, while the auditory pit sinks in and the folds remain even with the surface. One might again assume a hydration in the protein lattice of the auditory cells and a consequent change in the lattice spacing, with a resulting change in the shape of the cells which brings about a modification of the shape of the rudiment from a plate to a vesicle. Subséquent changes, which produce the internal ear or labyrinth out of a simple vesicle involve complicated folding and constriction of its walls. Certain conditions in the internal surroundings, possibly the failure of the endolymphatic duct and sac to develop, often bring about osmotic disturbances in the vesicle, which then swells considerably and becomes cystic. Normal folding fails to take place and the sensory areas develop incompletely. 
The induction of the crystalline lens by the optic vesicle is another notable example of dependent differentiation. This case is complicated, however, by the fact that in some species of amphibia and fish the lens is capable of self-differentiation without the influence emanating from the optic cup. The natural conclusion to draw from these facts is that the lens rudiment itself includes the factors necessary to form a lens and that the optic cup is needed in some cases to set off the chain of reactions that produce it out of its ectodermal rudiment, while in other cases this specific action is not required.

The amphibian limb is an organ that is localized at least as far back as the gastiula or perhaps even earlier, as shown by both transplantation and defect experiments (Detwiler 1929; Suzuki 1928). However, it was found by Balinsky (1925, 1931, 1933), and later confirmed by others, that by implanting in the flank of an embryo such organ rudiments as ear placodes, nasal placodes, pieces of brain or, in some cases, even small pieces of celloidin, more or less perfect limbs could be induced Here, cells that would ordinarily form axial musculature and mesenchyme on the flank of the organism, are now activated to form an appendage with all of the complex arrangements in muscle, cartilage, bone, etc., that constitute a limb and are quite foreign to that region. No satisfactory explanation of this has been given.

All the reactions described in the foregoing, with the possible exception of the inhibition of the spread of the apical tuft in the sea urchin, apparently take place between cells that are in contact. When neither the nervous system nor the circulation is developed, it is indeed difficult to imagine a reaction at a distance. Protoplasmic transmission is a slow process, and there is in fact almost no evidence of reaction between cells that are far removed from one another in the early stages of embryonic development. The clearest case is a phenomenon observed by Twitty (1937) in experiments in which small grafts (eyes) from Triturus torosus were implanted in amphibian embryos of other species. Such grafts completely paralyze the host embryo for a time, and this action takes effect before the circulation begins. It can only be explained by the diffusion of the toxic substance through the tissues of the host.

In growth, as well as in differentiation, cells and cell groups are dependent upon one another. The proportions of an organism are acquired through the maintenance of the normal relative growth of its parts. Delicate adjustments are here necessary, but they are little understood, though known to be governed by both genctic and environmental factors. Rates of growth are specific, and each organ or part has its characteristic rate relative to that of the whole. Relative growth rates are susceptible to external and internal environmental influences, though in a much less degree than the general growth of the whole organism.

The specificity of growth rates is strikingly shown by grafting organs, such as limbs and eyes, between different species (e.g., Amblystoma tigrinum and A. punctatum) which grow at different rates. Grafted organs retain their characteristic rates and the result is an organism, often grotesque in appearance, with a limb or an eye that is either much too large or too small for it. Such cases show that although subjected to the circulating medium of the host, congenital specific factors control the relative growth rate of the graft (Harrison 1924, 1935).

Germ layer chimaeras in the case of limbs, i.e., individuals in which either the ectoderm or the mesoderm is transplanted alone, show that the relative growth rate of the appendage as a whole is governed almost entirely by that of the mesoderm, the ectoderm having ver'y little effect upon it. In the eye, however, both optic cup and lens are concerned in maintaining the relative growth rate of the whole organ. Each of these components stimulates or retards the growth of the other, according to relative growth rates in the two species, so that an eye of approximately correct internal proportions, though still out of scale with 
the animal as a whole, develops out of the heteroplastic combination. This effect must be attributed to the mutual regulation of growth and division rate of cells by their associated cells constituting the internal environment (Harrison 1929).

Within the nervous system there is much interdependence in respect to growth and differentiation between functionally associated nerve centers and between center and end organ. Both hypoplasia and hyperplasia of centers have been observed, according as connecting tracts are diminished or increased in volume (Detwiler 1920, 1936; May 1933; Hamburger 1934, 1939). A large eye, for instance, sends out a correspondingly large optic nerve which stimulates the mid-brain of the opposite side to hyperplasia (Harrison 1929; Twitty 1932). There are also influences emanating from nerve centers that affect growth and development of other organs, but this subject is still largely controversial. One of the most striking effects of this kind is the tendency to atrophy or stoppage of growth in muscles after severance of the nerve supply. However, the initial differentiation of muscle is not dependent upon its connection with the nervous system (Harrison 1904; Hamburger 1928).

As stated above, there is almost no evidence that regions which are far apart affect one another during early stages of development, but as soon as the circulation and nervous connections develop, factors influencing differentiation become effective through these media. An exhaustive treatment of this subject would include a large part of the field of endocrinology, with all of the complications involved in the origin and control of secondary sex characters. Since this would require space greatly in excess of that available, I shall limit myself here to a single topic, the development and distribution of pigment.

Pigmentation in the lower vertebrates, as well as in certain invertebrate forms, is due to cells, known as chromatophores, which are scattered in the mesenchyme or concentrated on membranes surrounding other organs such as blood vessels, fascia, peritoneum and meninges. In amphibian larvae many lie embedded between the epidermal cells. The pigment of the early embryonic stages is already developed in the ovarian egg and is merely distributed, mainly to the ectoderm cells, during segmentation.

The pigmentary system of vertebrates, both in its developmental stages and later, is subject to a variety of influences-intercellular, nervous, humoral and outer environmental (temperature and light). Moreover, the several actions may be mediated in different ways, either directly or reflexly. The processes involved are therefore complicated, and much ingenuity has been exereised in working out experimentally the interplay of factors.

We are concerned here not with transitory changes in pigment cells, which are largely adaptive to external conditions, but with quasi-permanent or irreversible transformations involved in the development of the pigmentary system. In the embryo the prospective chromatophores are wandering cells and hence their place of origin must be ascertained before their distribution can be understood.

It has now been established beyond doubt that the neural crest is the principal, if not the sole, source of pigment cells (exclusive of the retinal tapetum) in at least two classes of vertebrates, amphibians ( $D u-$ Shane 1935) and birds (Dorris 1939). The neural crest is a strip of cells lying between the neural plate and the ectoderm, which becomes separated from both of these structures either during or shortly after the closure of the neural folds. The pigment cells thus start from a position on the dorsal side of the spinal cord and wander from there ventrally under the ectoderm and in the interstitial tissue. Associated with presumptive pigment cells in the neural crest are other cells destined to give rise to a variety of tissues-visceral cartilages, mesenchyme, spinal ganglion cells, sheath eells, sympathetic ganglia, chromaffine tissue.

This origin of pigment cells has been demonstrated by means of tissue culture, transplantation and defect experiments 
with both amphibian and chick material. While the recorded observations deal mainly with melanophores, the above probably applies also to the xanthophores, which contain a diffuse yellow lipochrome and to the guanophores containing granular pigment with metallic luster.

When the cells of the neural crest start out from their dorsal position, the potential chromatophores are indistinguishable from their accompanying cells. They are at first without pigment and reach remote positions in the embryonic body before showing their differentiation. There is evidence that many of them are not self-differentiating but require activation by something derived from other cells in order to produce pigment (DuShane ${ }^{7}$ 1935; Harrison 1938).

The above facts are shown by simple experiments. When the neural erest is removed bilaterally from the trunk region of an amphibian embryo, the whole flank remains without pigment. When neural crest is transplanted to the abdominal region, much pigment develops and spreads from the site of the graft. Neural crest explanted in vitro develops many pigment cells (Dorris 1938; Twitty and Bodenstein 1939).

Pigmentation is frequently not diffuse but is distributed according to patterns that have definite relations to organs and regions. By means of transplantation experiments with embryos of three closely related species of Triturus and their hybrids, Twitty (1936) has shown that such markings are the result of interplay of a multiplicity of factors, some inherent and some environmental. ${ }^{8}$ The latter may be either of the intimate cell-to-cell type or humoral.

The stripe along the dorsal margin of the myotomes characteristic of larvae of $T r$. torosus is not formed when neural crest of $T r$. rivularis, which does not have stripes but a much more extensive diffuse pigmentation, is grafted in place of the neural crest of the torosus embryo. Reciprocally, neural crest of torsus forms stripes on rivularis. However, the stripes do not form in the absence of the myotome ridge in either

7 op. cit., p. 18.

8 See also Twitty and Bodenstein (1939). species. Both grafting and tissue culture experiments show that the rivularis neural crest cells tend to spread much farther from their seat of origin than do those of torosus. This seems to be correlated with the slowness of rivularis cells to differentiate pigment as compared with cells from torosus. Movement and differentiation are in inverse relation to one another.

In the amphibian embryo the pigmentary system is the first tissue that can be observed to respond to hormonal action through the medium of the blood. When the hypophysis rudiment is removed in early embryonic stages, the melanophores, which begin to differentiate about the time the circulation of the blood starts, do not expand. The larvae acquire a silvery or yellow appearance, according to species, owing to the preponderance of other pigment-bearing elements. This effect is produced primarily through the distribution of the pigment within the individual melanophores and in this respect is like the adaptive color changes in organisms in response to temperature, light and color of the background. However, it has been shown that continued absence of the hypophysis results in the disappearance of some of the non-melanophore pigment in the epidermis, just as the presence of more than the normal amount (by grafting supernumerary hypophyses) produces an organism with more than the normal amount of pigment, due partly to "expansion" of the melanophores and partly to increase in the non-melanophore pigment in the epidermis (Blount 1932). The pigmentary system thus may participate in more rapid changes of a physiological nature and in slower differentiating changes that may be more or less permanent, both taking place as a result of hormonal action.

In many organisms the pigment pattern is very sharply defined and highly specific, often in great detail, and in certain fishes, amphibians and birds it is known to be associated with sex and sexual activity through mediation of hormones. Experiments have also shown that other endocrine secretions and related substances, e.g. 
thyreoglobulin and thyroxin, have a marked effect on the plumage of birds.

The feather is a complicated structure and no complete understanding of the effect of the internal medium upon its differentiation is possible without detailed knowledge of its development and growth. For the present purpose, however, it will suffice to say that the epithelial feather germ grows from its base, the tip of the feather being pushed out from within (Lillie and Juhn 1932). The more distal barbs are therefore the older. The individual barbs grow likewise from the base, and their growth rate is higher at first, i.e., when the tips of the barbs are formed, and it gradually tapers off. The barbs are attached obliquely to the shaft so that a transverse bar on a feather cuts successive barbs at different levels. When a feather is plucked, it regenerates from the remaining follicle in essentially the same way as the original feather develops. Thus it is possible to carry out on adult birds experiments which show the effect on the feather pattern of substances circulating in the internal medium.

The response to injections of thyroxin is expressed by a dark pigment spot or stripe on the brown or yellow feathers of the brown Leghorn chicken. The same injection, if the amount is appropriately gauged, may affect individual feathers differently according to their position on the body of the bird. This is owing to certain factors, which vary according to position. The threshold of reaction and the rate or amount of reaction are directly proportional to the growth rate, and the latent period is inversely proportional (Lillie 1932). Since these factors are different in the individual barbs, the effect produced on the feathers may vary all the way from a narrow spindle-shaped black spot centered on the shaft to a transverse bar, running elear across the feather. As many as five or six successive injections, if properly spaced, may be recorded in this manner on a single feather. The female sex hormone has similar effects when injected into capons. According to dosage and position it produces brown spots or bars on feathers that without treatment would have become black, or it may produce whole brown feathers. These hormones also affect the form and texture of the feathers.

The natural barring of feathers, such as occurs in the Plymouth Rock breed, is apparently brought about in a different way (Montalenti 1934). It is to be referred rather to a rhythmic activity of the genes in each feather folliele, the exact nature of which is unknown. The fact that the same phenotypic effect may be produced in such different ways is of great interest.

\section{Conclusion}

The foregoing sketch, which makes no pretense to completeness, calls attention to some of the facts regarding the action of the internal environment upon the differentiation of cells, i.e., upon the process of dependent differentiation in contradistinction to self-differentiation (Roux 1885). With the growing mass of evidence for the former and, hence, for the theory of epigenesis, an exhaustive treatment of the subject would extend far beyond the scope of a single paper. So, bearing in mind the examples given above, we may now review the salient points in the theory of development here presented.

The egg cell from which each organism is derived is composed of protoplasm peculiar to the species and different from that of any other species. This substance is laid down with collaboration of the nucleus and in continuity with the tissues of the maternal parent, perpetuating its specifie characteristics thereby. The growth period of the ovum is thus an important one in the development of the individual-one that has been relatively neglected by the embryologist.

The material is deposited in the egg according to a certain configuration which is oriented in relation to the surrounding parental tissues. This configuration must be conceived as related to the molecular structure of the protoplasm, more particularly to that of the proteins. Althongh the gross pattern of the egg is much changed at the 
time of maturation and fertilization, the new arrangement also is a function of its molecular constitution and has a definite topographic relation to the form of the future organism.

Since cellular differentiation takes place in the cytoplasm, we are concerned here more directly with this constituent of the cell, bearing in mind, however, that the cytoplasm is accompanied and ultimately controlled by the genic complex in the shromosomes. Since the latter is presumably the same for all cells of the organism, differences between cells must arise through interaction between the constant genom and the locally variable cytoplasm, in which they ultimately become visible.

In the sense that the organism is made up of the same specific protoplasm as that occurring in the egg, together with its products or differentiations, the characters of the organism are predetermined in the germ. The actual realization of these characters, however, comes about during development in a variety of ways. In the so-called mosaic eggrs, i.e., those with "precocious segregation," to use Lankester's (1877) term, local differentiation arises before cleavage and a minimum of modification in response to internal environmental factors is involved in subsequent development. In other eggs the protoplasm long remains labile with respect to its prospective differentiation, and in these many organs of the embryo develop only through the interaction between the cells producing them and other elements in the internal environment, i.e., other cells and the internal medium. In such eggs local predetermination is reduced to a minimum. 'Their members in continuance are fashioned, when as yet there is none of them.

\section{References Cited}

Andrews, G. F. 1897. Some Spinning Activities of Protoplasm in Starfish and Sea-Urchin Eggs. J. Morph., 12: 367-389.

Balinsky, B. I. 1925. Transplantation des Ohrbläschens bei Triton. Roux' Arch., 105: 718731.

. 1931. Zur Dynamik der Extremitätenknospenbildung. Roux' Arch., 123 : 565-648.

1933. Das Extremitätenseitenfeld, seine
Ausdehnung und Beschaffenheit. Roux' Arch., 130: 704-746.

BAUER, KarL. 1932. Beobachtungen über das Wachstum von Nervengewebe in vitro. Zeit. $f$. mikr. anat. Forsch., 28: 47-80.

BAUTzMANN, H. 1929. Über bedeutungsfremde Selbstdifferenzierung aus Teilstïcken des Am. phibienkeimes. Naturwiss., 17: 818-827.

Blount, R. F. 1932. Transplantation and Extirpation of the Pituitary Rudiment and the Effects upon Pigmentation in the Urodele Embryo. $J$. Exp. Zool., 63: 113-141.

Boell, E. J., Косн, H. and NeedhaM, J. 1939. IV. Respiratory Quotient of the Regions of the Amphibian Gastrula. Proc. Roy. Soc. (B), 127 : 374-387.

Boell, E. J., Needham, J. and Rogers, V. 1939. Morphogenesis and Metabolism. I. Anaerobic Glycolysis of the Regions of the Amphibian Gastrula. Proc. Roy. Soc. (B), 127: 322-356.

BoverI, TH. 1901. Über die Polarität des Seeigeleies. Verh. Phys.-Med. Gesell. Würzburg., 34: 145-176.

1901a. Die Polarität von Ovocyte, Ei und Larve des Strongylocentrotus lividus. Zool. Jahrb., Abt. Anat. u. Ont., 14: 630-653.

BRACHET, A. 1923. Recherches sur les localisations germinales et leurs propriétés ontogénétiques dans l'oeuf de Rana fusca. Arch. Biol., 23: $343-430$.

Brachet, J. 1939. Etude du metabolisme de l'oeuf de Grenouille (Rana fusca) au cours du developpement. V. Le métabolisme protéique et hydrocarbone de l'oeuf en relation avec le problème de l'organisateur. Arch. Biol., 50: 233, 267.

Brien-Gavage, P. et E. 1927. Contribution a l'étude de la Blastogénèse des Tuniciers. III. Bourgeonnement de Clavelina lepadiformis Müller. Rec. Inst. Zool. Torley-Rousseau, 1: 31-81.

Burrows, M. T. 1912. Rhythmische Kontraktionen der isolierten Herzmuskelzelle ausserhalb des Organismus. Münch. med. Woch., pp. 1-10 (pagination of reprint).

Снun, C. 1892. Die Dissogenie, eine neue Form der geschlechtlichen Zeugung. Festschrift für Leuckart, Leipzig. (Cited from Schleip, p. 50.)

Cohen, A. and Berrill, N. J. 1936. The Development of Isolated Blastomeres of the Ascidian Egg. J. Exp. Zool., 74: 91-117.

Conkuin, E. G. 1905. The Organization and Celllineage of the Ascidian Egg. J.Acad. Nat. Sci. Philadelphia, 2nd Ser., 13: 5-119.

—_. 1905a. Mosaic Development in Ascidian Eggs. J. Exp. Zool., 11: 146-221.

- 1911. The Organization of the Egg and the Development of Single Blastomeres of Phallusia mamillata. J. Exp. Zool., 10: 393-407.

. 1931. The Development of Centrifuged Eggs of Ascidians. J. Exp. Zool., 60: 2-77.

Crampton, H. E. 1896. Experimental Studies on Gasteropod Development. Roux'Arch., 3 : 1-19. 
DALCQ, A. 1932. Etude des localisations germinales dans l'oeuf vierge d'ascidie par des expériences de mérogonie. Arch. d'Anat. Microsc., 28: $223-333$.

- 1938. Form and Causality in Development. Cambridge, Univ. Press. vii, $197 \mathrm{pp}$.

DalcQ, A. et Pasteels, Jean. 1937. Une conception nouvelle des bases physiologiques de la morphogénèse. Arch. Biol., 48: 669-710.

Detwiler, S. R. 1920. On the Hyperplasia of Nerve Centers Resulting from Excessive Peripheral Loading. Proc. Nat. Acad. Sci., 6: 96-101.

1929. Transplantation of Anterior. Limb Mesoderm from Amblystoma Embryos in the Slit-Blastopore Stage. J. Exp. Zool., 52: 315-324.

. 1936. Neuroembryology. New York, Macmillan Co., x, 218 pp.

DorRIs, F. S. 1938. The Production of Pigment in vitro by Chick Neural Crest. Roux' Arch., 138: 323-333.

- 1939. The Production of Pigment by Chick Neural Crest in Grafts to the 3-Day Limb Bud. J. Exp. Zool., 80: 315-345.

DrIEsch, H. 1891. Entwicklungsmechanische Studien. I. Der Werth der beiden ersten Furchungszellen in der Echinodermenentwicklung. Experimentelle Erzeugung von Teil- und Doppelbildungen. Zeit. wiss. Zool., 53 : 160-178.

- 1892. Entwicklungsmechanische Studien. III. Die Verminderung des Furchungsmaterials und ihre Folgen (Weiteres über Teilbildungen). Zeit. wiss. Zool., 55: 1-10.

- 1894. Analytische Theorie der organischen Entwicklung. Leipzig, Engelmann. xiv, $184 \mathrm{pp}$.

- 1896. Die taktische Reizbarkeit der Mesenchymzellen von Echinus microtuberculatus. Roux' Arch., 3 : 362-380.

- 1908. Zur Theorie der organischen Symmetrie. Roux' Arch., 26: 130-145.

- 1929. The Science and Philosophy of the Organism. 2nd Edition, London, Black, xii, 344 pp.

Driesch, H. und Morgan, T. H. 1895. Zur Analysis der ersten Entwickelungsstadien des Ctenophoreneies. I. Von der Entwickelung einzelner Ctenophorenblastomeren. II. Von der Entwickelung ungefurchter Eier mit Protoplasmadefekten. Roux' Arch., 2: 204-226.

DuShane, G. P. 1935. An Experimental Study of the Origin of Pigment Cells in Amphibia. $J$. Exp. Zool., 72: 1-30.

Fischel, A. 1903. Entwickelung und Organ- Differenzirung. Roux' Arch., 15: 679-750.

Glaser, O. C. 1914. On the Mechanism of Morphological Differentiation in the Nervous System. I. The Transformation of a Neural Plate into a Neural Tube. Anat. Rec., 8: 525-551.

Hamburger, Viktor. 1928. Die Entwicklung experimentell erzeugter nervenloser und schwach innervierter Extremitäten von Anuren. Roux' Arch., 114: 272-363.

- 1934. The Effects of Wing Bud Extirpation on the Development of the Central Nervous System in Chick Embryos. J. Exp. Zool., 68: $449-494$.

- 1939. The Development and Innervation of Transplanted Limb Primordia of Chick Embryos. J. Exp. Zool., 80: 347-389.

Harrison, R. G. 1904. An Experimental Study of the Relation of the Nervous System to the Developing Musculature in the Embryo of the Frog. Am. J. Anat., 3: 197-220.

- 1910. The Outgrowth of the Nerve Fiber as a Mode of Protoplasmic Movement. $J$. Exp. Zool., 9: 787-846.

- 1924. Some Unexpected Results of the Heteroplastic Transplantation of Limbs. Proc. Nat. Acad. Sci., 10: 69-74.

-1 1929. Correlation in the Development and Growth of the Eye Studied by Means of Heteroplastic Transplantation. Roux' Arch., 120: 1-55.

ㄴ.. 1935. Heteroplastic Grafting in Embryology. Harvey Lectures, 1933-34. 29: 116157.

. 1935a. Factors Concerned in the Development of the Ear in Amblystoma punctatum. Anat. Rec., 64: 38-39.

2. 1936. Relations of Symmetry in the Developing Ear of Amblystoma punctatum. Proc. Nat. Acad. Sci., 22: 238-247.

- 1938. Die Neuralleiste. Verh. Anat. Ges., Erg. Heft Anat. Anz., 85: 3-30.

- 1938a. Further Investigation of the Factors Concerned in the Development of the Ear. Anat. Rec., 70: 35.

Heatley, N. G. and Lindahl, P. E. 1937. Studies on the Nature of the Amphibian Organization Centre. V. The Distribution and Nature of Glycogen in the Amphibian Embryo. Proc. Roy. Soc. (B), 122: 395-402.

Holtfreter, J. 1929. Über die Aufzucht isolierter Teile des Amphibienkeimes. I. Methode einer Gewebezüchtung in vivo. Roux' Arch., 117: 421-510.

-1931. Über die Aufzucht isolierter Teile des Amphibienkeimes. II. Züchtung von Keimen und Keimteilen in Salzlösung. Roux' Arch., 124 : $404-466$.

- 1933. Nachweis der Induktionsfähigkeit abgetöteter Keimteile. Isolations- und Transplantationsversuche. Roux' Arch., 128: 584-633.

. 1933a. Eigenschaften und Verbreitung induzierender Stoffe. Naturwiss., 21: 766-770. . 1934. Der Einfluss thermischer, me chanischer und chemischer Eingriffe auf die Induzierfähigkeit von Triton-Keim Teilen. Roux' Arch., 132: 225-306.

ㄴ. 1938. Differenzierungspotenzen isolier- 
ter Teile der Urodeleugastrula. Roux' Arch., 138: 522-656.

- 1938a. Differenzierungspotenzen isolierter Teile der Anurengastrula. Roux' Arch., 138: $657-738$.

Hörstadius, Sven. 1928. Über die Determination des Keimes bei Echinodermen. Act. Zool., 9: $1-191$.

-1935. Über die Determination im Verlaufe der Eiachse bei Seeigeln. Pub. Staz. Zool. Napoli, 14: 251-479.

- 1937. Investigations as to the Localization of the Micromere-, the Skeleton-, and the Entoderm-Forming Material in the Unfertilized Egg of Arbacia punctulata. Biol. Bull., 73: 295-316.

ㄴ... 1938. Sehnürungsrersuche an Seeigelkeimen. Roux' Arch., 138: 197-258.

1939. The Mechanics of Sea-Urchin Development, Studied by Operative Methods. Biol. Rev., 14: 132-179.

Hörstadius, Sven and Wolsky, Alexander. 1936. Studien über die Determination der Bilateralsymmetrie des jungen Seeigelkeimes. Roux' Arch., 135: 69-113.

Just, E. E. 1939. The Biology of the Cell Surface. Philadelphia, Blakiston, ix, $383 \mathrm{pp}$.

LANkester, E. R. 1877. Notes on Embryology and Classification. Quart.J. Micr. Sci., 17:399454.

LEHMANN, F. E. 1926. Entwicklungsstörungen in der Medullaranlage von Triton, erzeugt durch Unterlagerungsdefekte. Roux' Arch., 108: 243282.

- 1928. Die Bedeutung der Unterlagerung für die Entwicklung der Medullarplatte von Triton. Roux'Arch., 113: 123-171.

-1938. Regionale Verschiedenheiten des Organisators von Triton, insbesondere in der vorderen und hinteren Kopfregion, nachgewiesen durch phasenspezifische Erzeugung von lithiumbedingten und operativ bewirkten Regionaldefekten. Roux' Arch., 138: 106-159.

Levi, G. 1917. Connessioni e struttura degli elementi nervosi sviluppati fuori dell' organismo. Men. R. Accad. Lincei, s. 5, 12: 142-182.

_._. 1925. Conservazione e perdita dell' indipendenza delle cellule dei tessuti. Arch. Exp. Zellforsch., 1: 1-57.

Lewis, W. H. 1922. Is Mesenchyme a Syneytium: Anat. Rec., 23: 17 $7-184$.

LilliE, F. R. 1932. Growth Rate and Hormone Threshold with Reference to Physiology of Development. Am. Nat., 66: 171-179.

Lillie, F. R. and JuHn, MARY. 1932. The Physiology of Development of Feathers. I. Growthrate and Pattern in the Individual Feather. Physiol. Zool., 5: 124-184.

LINDAHL, P. E. 1932. Zur experimentellen Analyse der Determination der Dorsoventralachse beim Seeigelkeim. I. Versuche mit gestreckten Eiern. Roux' Arch., 127: 300-322.
- 1932a. Zur experimentellen Analyse der Determination der Dorsoventralachse beim Seeigelkeim. II. Versuche mit zentrifugierten Eiern. Roux' Arch., 127: 323-338.

Mangold, O. und Seider, F. 1927. Homoplastische und heteroplastiche Verschmelzung ganzer 'Tritonkeime. Roux' Arch., 111: 593-665.

MAY, R. M. 1933. Réactions neurogéniques de la moelle à la greffe en surnombre, ou à l'ablation d'une ébauche de l'anoure, Discoglossus pictus, Otth. Bull. Biol. France et Belg., 67: 327-349.

Montalenti, Giuseppe. 1934. A Physiological Analysis of the Barred Pattern in Plymouth Rock Feathers. J. Exp. Zool., 69: 269-345.

Pease, D. C. 1939. An Analysis of the factors of Bilateral Determination in Centrifuged Echinoderm Embryos. J. Exp. Zool., 80: 225-247.

Penners, A. 1924. Experimentelle Untersuchungen zum Determinationsproblem am Keim von Tubifex rivulorum Lam. I. Die Duplicitas cruciata und organbildende Keimbezirke. Arch. mikir. Anat. u. Entw.-Mech., 102: 51-100.

- 1925. Experimentelle Untersuchungen zum Determinationsproblem am Keim von Tubifex rivulorum Lam. II. Die Entwicklung teilweisse abgetöteter Keime. Zeit. wiss. Zool., 127: 1-140.

Pressler, Kurt. 1911. Beobachtungen und Versuche über den normalen und inversen Situs viscerum et cordis bei Anurenlarven. Roux' Arch., 32: 1-35.

Przibran, H. 1913. Experimentalzoologie, 4. Vitalität. Wien, Fr. Deuticke. viii, $179 \mathrm{pp}$.

Reverberi, GiUsepPe. 1931. Studî sperimentali sull'uovo di Ascidie. (Il comportamento e lo sviluppo dei frammenti d'uovo di Ciona nei diversi momenti compresi fra la deposizione e la segmentazione) Pub. Staz. Zool. Napoli, 11: 108193.

Rose, S. Meryl. 1939. Embryonic Induction in the Ascidia. Biol. Bull., $77:$ 216-232.

Roux, Wilhelm. 1885. Einleitung zu den Beiträgen zur Entwickelungsmechanik des Embryo. Zeitsch. f. Biol., 21: 411-428. Also in Gesam. Abh., 1895, 2: 1-23.

- 1888. Beiträge zur Entwickelungsmechanik des Embryo. Nr. V. Ueber die künstliche Hervorbringung "halber", Embryonen durch Zerstörung einer der beiden ersten Furchungszellen, sowie über die Nachentwickelung (Postgeneration) der fehlenden Körperhälfte. Virch. Arch., 114: 113-153, 246-291. Also in Gesam. Abh., 1895, 2: 419-521.

RunNströM, J. 1926. Experimentelle Bestimmung der Dorso-Ventralachse bei dem Seeigelkeim. Ark. f. Zool., 18A: 1-6.

Ruud, Gudrun. 1925. Die Entwicklung isolierter Keimfragmente frühester Stadien von Triton taeniatus. Roux'Arch., 105: 209-293.

RuUd, Gudrun and Spemann, Hans. 1922. Die Entwicklung isolierter dorsaler und lateraler Gastrulahälften von Triton treniatus und alpes- 
tris, ihre Regulation und Postgeneration. Roux' Arch., 52: 95-166.

SChleip, W. 1929. Die Determination der primitiven Entwicklung. Leipzig, Akad. Verlags. xii, $914 \mathrm{pp}$.

Schultze, O. 1894. Die künstliche Erzeugung von Doppelbildungen bei Froschlarven mit Hilfe abnormer Gravitationswirkung. Roux' Arch., 1: 269-306.

SEDGWICK, A. 1894. On the Inadequacy of the Cell Theory of Development, and on the Early Development of Nerves, Particularly of the Third Nerve and of the Sympathetic in Elasmobranchii. Quart. J. Mic. Sci., 37: 87-101.

SPeK, Josef. 1926. Über gesetzmässige Substanzverteilungen bei der Furchung des Ctenophoreneies und ihre Beziehungen zu den Determinationsproblemen. Roux' Arch., 107: 54-73.

-. 1927. Über die Winterknospenentwicklung, Regeneration und Reduktion bei Clavellina lepadiformis und die Bedeutung besonderer "omnipotenter", Zellelemente für diese Vorgänge. Roux' Arch., 111: 119-172.

SPEMANN, H. 1906. Über embryonale Transplantation. Naturwiss. Rund., 21: 1-7 (pagination of reprint).

1918. Über die Determination der ersten Organanlagen des Amphibienembryo IVI. Roux' Arch., 43: 448-555.

- 1924. Über Organisatoren in der tierischen Entwicklung. Naturwiss., 12: 10921094.

1927. Organizers in Animal Development. Proc. Roy. Soc., B, 102: 177-187.

- 1931. Über den Anteil von Implantat und Wirtskeim an der Orientierung und Beschaffenheit der induzierten Embryonalanlage. Roux' Arch., 123: 389-517.

‥ 1931a. Das Verhalten von Organisatoren nach Zerstörung ihre Struktur. Verh. Deutsch. Zool. Ges., 129-132.

Spemann, H. und Falkenberg, Hermann. 1919. Über asymmetrische Entwicklung und Situs inversus viscerum bei Zwillingen und Doppelbildungen. Roux' Arch., 45: 371-422.

Spemann, H. und Gernitz, B. 1927. Über Weckung organisatorischer Fähigkeiten durch Verpflanzung in organisatorische Umgebung. Roux' Arch., 109: 129-175.

Suzuki, S. 1928. Defektversuche an ventralen und lateralen Bezirken der Randzone von Pleurodeleskeimen. Roux' Arch., 114: 371-457.

Tennent, D. II., TAylor, C. V. and Wirtaker, D. M. 1929. An Investigation on Organization in a Sea-Urchin Egg. Carnegic Inst. Wash. Pub. 391: 1-104.

TwitTy, V. C. 1932. Influence of the Eye on the Growth of Its Associated Structures, Studied by Means of Heteroplastic Transplautation. $\vec{J}$. Exp. Zool., 61: 333-374. logical Experiments on Triturus 1936 . Correlated Gend EmbryoExp. Zool., 74: 239-302.

- 1937. Experiments on the Phenomenon of Paralysis Produced by a Toxin Occurring in Triturus Embryos. J. Exp. Zool., 76: 67-104.

Twitty, V. C. and Bodenstein, D. 1939. Correlated Genetic and Embryological Experiments on Triturus. IIY. and IV. J. Exp. Zool., 81: 357398.

voN UBISCH, L. 1925. Entwicklungsphysiologische Studien an Seeigelkeimen. I. Ưber die Beziehungen der ersten Furchungsebene zur Larvensymmetrie, und die prospektive Bedeutung der Eibezirke. Zeit. wiss. Zool., 124: 361-380.

-. 1925a. Entwicklungsphysiologische Studien an Seeigelkeimen. II. Die Entstehung von Einheitslarven aus verschmolzenen Keimen. Zeit. wiss. Zool., 124: 457-486.

- 1931. Untersuchungen über Formbildung mit Hilfe experimentell erzeugter Keimblattchimären von Echinodermenlarven. Roux' Arch., 124: 181-240.

ㄴ. 1933. Formbildungsanalyse an Seeigellarven. Naturwiss., 21: 183-186.

_. 1933a. Keimblattchimären. Naturwiss., 21 : 325-329.

-1936. Über die Organisation des Seeigelkeims. Roux' Arch., 134: 599-643.

-1938. Über Keimverschmelzungen an Ascidiella aspersa. Roux' Arch., 138: 18-36.

-1939. Keimblattchimärenforschung an Seeigellarven. Biol. Rev., 14: 88-103.

- 1939a. Über die Entwicklung von Ascidienlarven nach frühzeitiger Entfernung der einzelnen organbildenden Keimberzirke. Roux' Arch., 139: 438-492.

VoGT, WALTHER. 1925. Gestaltungsanalyse am Amphibienkeim mit örtlicher Vitalfärbung. Vorwort über Wege und Ziele. I. Teil: Methodik und Wirkungsweise der örtlichen Vitalfärbung mit Agar als Farbträger. Roux' Arch., 106 : 542-610.

- - 1929. Gestaltungsanalyse am Amphibienkeim mit örtlicher Vitalfärbung. II. Gastrulation und Mesodermbildung bei Urodelen und Anuren. Roux' Arch., 120: 384-706.

Waddington, C. H. 1938. Studies on the Nature of the Amphibian Organisation Centre. VII. Evocation by Some Further Chemical Compounds. Proc. Roy Soc. (B), 125: 365-372.

Wadington, C. H., Needham, J., Nowinski, W. W. and Lemberg, R. L. 1935. Studies on the Nature of the Amphibian Organisation Centre. I. Chemical Properties of the Evocator. Proc. Roy. Soc. (B), 117: 289-310.

Weigmann, Rudolpir, 1927. Über dic Bestimmung der Medianebene im Froschei. Zeit. wiss. Zool., 129: 48-102.

WIITAKeR, D. M. 1931. Some Observations on 
the Eggs of Fucus and npon Their Mutual Influenee in the Determination of the Developmental Axis. Biol. Bull., 61: 294-308.

Whitaker, D. M. and Lowrance, E. W. 1936. On the Period of Susceptibility in the Egg of Fucus furcatus when Polarity is Indueed by Brief Exposure to Directed White Light. $J$. Cell. and Comp. Physiol., 7 : 417-424.

WhitMAN, C. O. 1893. The Inadequacy of the Cell-Theory of Development. J. Morph., 8: 639658.

Wirson, E. B. 1903. Experiments on Cleavage and Localization in the Nemertine-Egg. Roux' Arch., 16: 411-460.

- 1904. Experimental Studies on Germinal Localization. I. The Germ-Regions in the Egg of Dentalium. J. Exp. Zool., 1: 1-72. - 1904a. Experimental Studies in Ger- minal Loealization. II. Experiments on the Cleavage-Mosaie in Patella and Dentalium. J. Exp. Zool., 1: 197-268.

Woerdeman, N. W. 1933. Über den Glykogenstoff weehsel des Organisations-zentrums in der Amphibiengastrula. Proc. Acad. Sci. Amsterdam, 36 : 189-193.

Yatsu, N. 1912. Observations and Experiments on the Ctenophore Egg. III. Experiments on Germinal Localization of the Egg of Beroë ovata. Annot. Zool. Jap., 8: 5-13.

ZELENY, C. 1904. Experiments on the Localization of Developmental Faetors in the Nemertine Egg. J. Exp. Zool., 1: 293-329.

ZoJA, R. 1895. Sullo sviluppo dei blastomeri isolati dalle nova di aleune meduse (e di altri organismi). Roux' Arch., 1: 578-595; (1896) $2: 1-37$. 


\title{
CELL AND ORGANISM
}

\author{
By CHARLES A. KOFOID \\ DEPARTMENT OF ZODLOGY, UNIVERSITY OF CALIFORNIA, BERKELEY, CALIF.
}

IN the score of years following the publication of Charles Darwin's Origin of Species, in 1859, two new lines of biological investigation profoundly influenced biological thinking and brought the Cell Theory in line with the concept of the evolution of plant and animal types, especially the latter.

The first of these was the increased attention paid to the development of marine animals, which brought under inspection all of the invertebrate phyla. This resulted in observations on the earliest stages of development of the individual and clarified the ontogeny of species belonging to many phyla and classes on the basis of their cellular structure. Proponents of organic evolution were quick to grasp the significance of these findings which reenforced the germ layer theory. It also gave evidence of the widespread prevalence of morula, blastula, and gastrula stages amidst a diversity of types of cleavage. The evolutionary significance of these similarities was formulated in Haeckel's Gastraea Theory which predicated the universality of these embryonic stages in all phyla, classes, and, indeed, species. It thus laid the foundation for what may be called, for the purposes of this discussion, the embryonic theory of the evolution of the metazoan organisms. Added force was given to this view by Haeckel's further step in his modification of Von Baer's law into his Biogenetic Law that ontogeny repeats phylogeny. Herbert Spencer's concept of evolution as a process of change from homogeneity to heterogeneity still further popularized the concept of the simplicity of primitive forms of life and of differentiation among similar simple cells of the organism as the normal path of evolution of organisms.

Assistance rendered by the personnel of Works Project Administration Official Project No. 65-108-113, Unit C1, is acknowledged.
The second line of investigation was the use of imbedding and sectioning of vertebrate embryos which confirmed and extended the observations of the development of living forms observed by marine zoologists. It made feasible and placed on a firm foundation the extension of the Germ Layer Theory and the Gastraea Theory to the yolk-laden eggs of fishes, reptiles, and birds and to the highly modified eggs of mammals. It also expanded and verified the relatively great simplicity and early similarities of the component cells of the metazoan embryo. The general effect of these findings was to establish the view that the metazoan body was formed as a colony of similar cells which later by histogenesis became differentiated, instead of emphasizing that it was a single organism composed of cells in interacting relations from the beginning.

The early history of the discovery of cells has also inadvertently lent itself to the idea of the individuality, separateness, and independence of cells. The very word cell in itself is based on this idea. It savors of the medieval segregation of the monastic life and of the solitary confinement of prison walls. As a matter of fact, when the English physicist and engineer, Robert Hooke, sectioned and illustrated the polyhedrons of elder pith and designated them as cellula, he was in truth merely viewing the secreted walls of cellulose and lignin of vegetable cells. This picture of the cell is as far from the facts presented by Schleiden and Schwann in their cell theory as dark from daylight, but the name attached to this unit of organization of living bodies has held its place with an extraordinary tenacity, doubtless because of its very unitary basic significance. It has, however, brought with it certain sequelae which distort the relations of cell and organism. Thus we find the words, syncytium, for 
grouped cells without dividing walls, and binucleate and multinucleate cells, so designated because there is no visible partition of the respective zones of influence of each of the nuclei. Thus Paramecium is habitually referred to in textbooks as a one-celled animal and at the same time the two nuclei are differentiated as sexual and somatic. The culmination of this concept that simplicity is a function of unicellular Protozoa, and complexity of multicellular Metazoa is the erratic idea that the Protozoa are noncellular. Thus an extraordinarily complicated Radiolarian with hundreds of elements in its skeleton and sixteen hundred chromosomes in its single large nucleus cannot be cellular; instead it is an organism. With comparable logic one should postulate that the matured germ cell, and the zygote after the fusion of the gamete nuclei and before the first cleavage, are also noncellular!

This seeming incongruity of regarding a single cell as also an entire organism was singled out by the late Professor Whitman who in his Woods Hole lecture (1894) on The Inadequacy of the Cell Theory invited attention to the fact that the Cell Theory postulated that all organisms are composed of cells, and that in this form it made no provision for organisms in the initial onecelled stage and none for unicellular Protista. In other words, what by definition is only a part could never logically be the equivalent of the whole. This led to a modification of the definition of the cell to the simple statement that the cell is the structural and functional unit of organic structure; and that conversely all organisms are composed of one or more cells, and furthermore, that normally at some period, namely, the starting point of their life cycles, all organisms exist as one cell. In this stage, alike in the phylogeny of the plant and animal kingdoms and in the ontogeny or life cycle of the genetic individual, the union of cell and organism in one living entity occurs. The cell is at that time merged in the organism and is the whole of it; and conversely, the whole organism consists of but a single cell.

The physiological significance of the small sizes prevalent among the cells of plants and animals has a bearing on the problem of cell and organism. The living substance is characteristically acquisitive. Growth is a sign of life and the metabolic rate records the speed of living. Acquisition is greatest in the earlier part of the life cycle and slows down with age or adverse conditions, such as the lowering of the temperature below the optimum. The substances stored in the cell as a result of acquisition are sources of energy which in the living organism can be transformed into the activities of life only in the living cell.

Since the initial stage in the life cycle of all organisms is normally a single cell, we may well ask why in the course of evolution did not and does not the primal cell merely increase in size and complexity and thus create the larger organisms in the scale of being and, in ontogeny, also increase the zygote to adult size and complexity?

A survey of cell size in the Protozoa is instructive in this particular. There appear to be rather definite limits in size and volume beyond which these animals do not go, and somewhat similar limits seem to prevail among the Protophyta. Protozoa as small as 2 to $3 \mu$ are known among flagellates and Sporozoa. Reduction in size follows with rapid succession of asexual reproduction by fission. Most Protozoa are less than $100 \mu$ in the largest dimension. A few Dinoflagellata of attenuate form may reach a length of $1500 \mu$. Multicellular stages of Protozoa, as a rule, are larger than unicellular. Some multicellular Radiolaria form colonies of up to five or more millimeters in diameter.

The tissues of the Metazoa and Metaphyta exhibit limits in the sizes of their constituent cells of approximately the same order of magnitude as those in the more primitive Protista, except for yolk-laden ova, but even in these the amount of cytoplasm remains relatively small.

The relations of nucleus and cytoplasm within the cells also exhibit certain limitations which Richard Hertwig sought to express in his nucleocytoplasmic ratio. In many cells the ratio of the volume of the 
cytoplasm to that of the nucleus is in the order of magnitude of 1 to 25 to 1 to 50 . It is also obvious to students of embryonic tissues that the rate of metabolism and stage of growth affect this ratio. Pole cells and primordial germ cells have proverbially larger nuclei than neighboring cells. The shape of the cell and that of the nucleus are also correlated. Both cell and nucleus elongate in the same axis. Branching Suctoria have thread-like branching nuclei in the axes of the cylindrical columns which form the hydroid-like colony.

It is also obvious that the location of the nucleus is correlated with the functional activity of the cell rather than with the spatial relations only. In a yolk-forming oöcyte the nucleus lies near the surface next to the blood supply, not in the center of the cell. In a budding filamentous alga the nucleus lies at the point where the bud is forming.

These basic and universal facts of size, spatial relations, and relations to metabolic activity, so evident in most cells, are indicative of an equally general functional principle, namely, that the activities of the cell can only be carried on within certain rather small limits of size. One of the many factors involved in this by no means simple matter is undoubtedly the ratio of the surface of the nucleus to the volume of the eytoplasm. In this ratio the nuclear membrane and the peripheral chromatin are directly involved. Peripheral chromatin provides for intimate interaction of the contrasted chromatin and cytoplasm across the nuclear boundary. It is wont to be more abundant in rapidly growing trophozoites than in encysted stages. In premitotic phases of Amoeba the chromosomes are lined up against the nuclear membranes and split while in this position. In leucocytes whose activity is great and whose life may be brief the relatively large amount of peripheral ehromatin is noteworthy.

Since the surface of the nucleus increases only in the ratio of the square while its volumes of eytoplasm and nucleus increase in the ratio of the eube it is mathematically evident that an increase in the size of the eell would decrease the relative contact of nucleus and cytoplasm. The volumetric units of eytoplasm increase at a higher rate than the units of surface of the nuclear membrane and thus the efficiency of the nucleus with its contained chromatin and genes drops rapidly with the increase in the volume of the cell. The Protista are small and tissue cells are limited to small dimensions simply because the activities of living demand, for efficient action, certain surface-volume relations of nuclear membrane to the enveloping cytoplasm in which all structural differentiation and much functional activity occur. It is equally obvious that other factors enter into the functional activities of the cell, such as temperature, light, food, age, location, contacts, stimuli, and past history, all of which may singly or in various combinations accelerate or diminish the metabolic rate and other activities of living.

Since the living substance is by nature acquisitive and the primitive one-celled organism increases its volume by growth, there inevitably follows a lowering of efficiency which is, however, restored by cell division and a resumption of the optimum surface-volume relations. It is therefore of basic significance that asexual reproduction by fission is prevalent in the Protista, among bacteria, and in primitive Protozoa and Protophyta. In fact, it is the only method of reproduction known among these primitive forms. It is only among the higher Protozoa and Protophyta that sexual reproduction, based on proved meiosis, has as yet been detected.

If, then, in the course of the evolutionary process, the organism is to acquire increased energy and to add to its fourth dimension of time, it must have recourse to an increase in the number of its working mechanisms, the cells. This increase also affords space, volume, and time for diversification in function among the units within the organism.

We, therefore, turn naturally to the Protista for concrete evidence of the method by which the primitive organisms have met this problem of their evolution from the unicellular to the multicellular state. Becausc of a greater familiarity with the Pro- 
tozoa than with the Protophyta, I shall utilize information from the former rather than the latter. The border line between the two lies in the Flagellata in which the two kingdoms, plant and animal, are merged. It has been the custom for botanists to regard groups containing species with chromatophores as in the plant kingdom and for zoologists to return the compliment by regarding all flagellates as animals. Morphologically the group is an indivisible one. Some genera have species on both sides of the fence and certain species of Euglena belong to both and can be shifted experimentally from one to the other overnight. In the light their chromoplasts are green and their metabolism is synthetic. In the dark in nutrient solutions the chromoplasts turn to leucoplasts and the metabolism becomes saprozoic. The Dinoflagellata illustrate the intermediate position of flagellates very amply. Many of them have chromoplasts and a rigid cellulose exoskeleton while a very large group, less well known because of their fragile bodies are completely holozoic, even cannibalistic, in their feeding habits, though many of these animal representatives are brilliantly colored. Still others have become parasites in other Protozoa and in a wide range of marine invertebrates.

Both holozoic and holophytic flagellates, as well as all other classes of Protozoa, tend to become multicellular, in the simplest cases, only briefly at the onset of fission. In not a few others the retention in the organism of the products of division is permanent in a body of characteristic form and behavior. Symmetry and behavior alike assert their organismic individuality. The popular superstition that the Protozoa are unicellular and the Metazoa are multicellular is fostered by the over-simplification required for uninstructed beginners in biology. As a sheer matter of fact the organisms in each group are both unicellular and multicellular, but the time spent in each state may be quite different. All Metazoa are unicellular in the gamete and fertilized egg stages, and all Protozoa have at least a brief existence in the multicellular state and some of them repeatedly re- vert to it in the course of their complicated life cycles. For example, the malarial parasite, Plasmodium vivax, living in the stomach of the mosquito, in the outer walls of the stomach, in the salivary fluid, and in the red cells of blood of man, assumes the multicellular condition in the sporoblast, possibly retaining it during one or more asexual fissions of that multicellular body, and again in the multicellular trophozoite in the red cell. It reverts to the unicellular condition in the gametes, zygote, initial trophozoite, in the oft-repeated merozoite phases, and in the gametocytes. Throughout this complicated life cycle the genetic individual appears in a series of distinctive unicellular individuals each of which speedily becomes multicellular by growth and cell multiplication within the body. In a comparable manner, Paramecium starts its life cycle as a single-celled zygote nucleus in its great grandmother's cytoplasm, goes through division stages to an eight-celled morula without cell boundaries or cleavage of cytoplasm, differentiates into sex and somatic cells, which are then distributed by two binary fissions into the two-celled adult. Yet all youngsters and not a few oldsters continue to regard Paramecium as a unicellular protozoan. The end result in the life cycle of certain Sporozoa is a pansporoblast of six cells, 2 wall cells, 2 thread cells, and 2 germ cells. For purposes of dissemination to new hosts this protozoan utilizes a multicellular body with histological differentiation of tissues, of the minimum possible number of cells to be sure, but still along precisely comparable lines to the processes of development in the so-called multicellular Metazoa. The differences between the Protozoa and the Metazoa lie in numbers of cells attained rather than in the principle of unicellularity of the one and the multicellularity of the other.

The purely temporary nature of the multicellular stage in the primitive flagellates is well illustrated in the genus Trichomonas, a parasite of the digestive tract of many vertebrates and some insects. It forms by repeated mitoses multicellular plasmodia of sixteen cells, but each has the full equip- 
ment of mouth, axostyle, undulating membrane, and parabasal body, and zach ceaselessly struggles to rid itself of its encumbering mates. There is no unity in this multicellular phase of Trichomonas. But in Giardia, a two-celled bilaterally symmetrical organism with 4 pairs of flagella, there are 2 permanent eross commissures in its fibrillar system, and these afford a structural and functional coordination of the two constituent cells so complete that no reversion to the one-celled stage is known. No sexual reproduction is known and fission merely reproduces the parent two-celled stage.

Another superstition widely countenanced in elementary textbooks, seemingly for purposes of enhancing the evolutionary outlook, is the mistaken idea that the Protozoa are simple in structure as well as unicellular. It is true that an amoeba or a monad is relatively quite simple, but so was a vertebrate egg prior to the discovery of organizers. As a matter of fact, every class of protozoans has evolved into great complexities of structure. Evidences of this are seen in the remarkable diversifications of flagella among the flagellate parasites of termites, showing enormous increase in number, up to thousands; diversification of structure into internal axostyles, rods, and spirals, and external flagella of different orders, sizes, and structures; repeated sets of neuromotor equipments without attendant nuclei, nuclear multiplication, and the evolution of various structural types of multicellular bodies. Space does not permit a discussion of the elaboration of skeletal types in the Radiolaria and Foraminifera, of skeletal and flotation devices in the Dinoflagellata, and of fibrillar neuromotor systems in the Ciliata. Truly, the Protozoa are indeed far from simple.

Now two significant features mark these differentiations among the protozoan organisms. The first is that many of them occur within the limits of a single cell. A single striking example of this is seen in that remarkable dinoflagellate, Erythropsis, an organism so unique that when R. Hertwig's description was published in 1884 the ven- erable Carl Vogt, in 1885 , came out with a tirade about the unwarranted "wissenschaftliche Irrthum" in which a young unnamed docent had found a Vorticella that had eaten the eye of a rotten medusa, and had foisted upon the biological world a scientific lie which as Lord Bacon long ago said would ride ahorseback while truth would lag behind afoot.

This Erythropsis has not only the eustomary transverse low-spiraled girdle with its included transverse flagellum and its posteriorly directed longitudinal flagellum, but it also has a contractile tentacle with circular and longitudinal muscle fibrils or myonemes, and, as its name indicates, a red eye composed of a laminated lens, a mobile black pigment mass, and a red core, presumably the sensory organelle. It is carnivorous, even cannibalistic, in feeding habits, and mirabile dictu, has but a single nucleus. Some of the related holozoic dinoflagellates have nettling organelles or nematocysts of patterns comparable to those in the Coelenterata, but the whole organism is the cnidoblast.

Colony formation is rather widely prevalent among the Dinoflagellata. In its simplest and more widely prevalent form this is merely chain formation in which new individuals are formed by repeated divisions putting daughter cells in place of the mother cell. These chains usually are temporary and soon break up into the eonstituent individual organisms or cells. They are most abundant in the marine plankton about 4 A.M., for fissions occur generally before daybreak.

One naked or unarmored dinoflagellate, Polykrikos, habitually is found only in the stage of a linear body of 2,4 , or 8 cells. The ventral longitudinal furrow of each is continuous with that of its neighbors, thus forming for the organism a long ventral mouth whose borders are plastic and send out pseudopodia. By means of this large month the organism captures other dinoflagellates and metazoan ova as food, and does it indifferently with 2,4 , or 8 cells. The cytoplasm contains numerous nematocysts formed by repeated ontgrowths of the 
centrosome. These are reputed to be of aid in the capture of prey.

The possession by dinoflagellates of this peculiar assemblage of organelles, namely, nematocysts, tentacles, eyespots, is suggestive of at least an analogy to the Coelenterata. The resemblance is heightened by the fact that the tentacle in Noctiluca and Erythropsis is at the side or end of the month, and functions in the capture of food, as do also the nematocysts.

These examples bring us face to face with the problem mentioned in the earlier part of this paper, namely, the widespread acceptance of the embryonic method of evolution. In this view of evolution the multicellular bodies of the Metazoa appear to have evolved from the Protozoa by the division of similar simple undifferentiated cells to form morula, blastula, and gastrula and later to become differentiated by cellular specialization in structure and function.

In the light of the differentiations evolved among Protozoa, and their tendency to become multicellular, it seems to the speaker that another method than the embryonic was the one followed in reality; namely, evolution from Protozoa to sponges and coelenterates by multiplication of nuclei in an already differentiated cytoplasm. In this case development of the individual by the embryonic route was secondarily acquired and only tends to obscure the actual mode of evolution of these two metazoan phyla from the Protozoa.

To be specific, Polykrikos has indifferently 2, 4 , or 8 cells. Its common mouth and stock of nettling cells are used as the organism has need. Its near relatives have at least one tentacle per cell and some of them add one eyespot. By a combination in one organism of all of these organelles with the tendency to multiplication of nuclei, we arrive rather near to a primitive coelenterate.

A similar suggestive relationship exists between the craspedomonad flagellates and the Porifera. The Craspedomonadina form colonies of both dendritic and tabular form. The typical collar is not a closed funnel as figured, but in reality a coiled spiral formed by a short attached flagellum of the undulating membrane type with a slight overlap above the mouth. Recent investigations have shown that the collared cells of sponges have a similar structure. Flagellates related to the Craspedomonadina form skeletal structures, some of calcareous (Coccolithophoridae) material and some of siliceous (Silicoflagellata), and some craspedomonads live in a lorica of a material resembling elastin. The flagellates set the stage for the arrival of the sponges in the drama of evoIution. Most of us well remember that Saville-Kent's great work on the Infusoria included the simpler sponges.

The Protozoa have all the basic functions of life to perform. They require organelles for digestion, excretion, locomotion, sensation and transmission, as well as for the capture of food and circulation of its digested products, and the support and protection of the body. An extraordinary variety of patterns of structure and adaptions in function has been evolved among them. Throughout this great variety of structural evolution of cytoplasmic products the number of nuclei present in the organism does not seem to play any conspicuous part. Polykrikos and some other multicellular forms seem to thrive equally well with different numbers of nuclei. A conspicuous example of this indifference to the number of nuclei is seen in the little volvocid colonial flagellate, Platydorina. It is formed by a blastula-like ellipsoid of one layer of cells which flattens with interpolation of the cells of the two faces in a spirally twisted plate of 16 or 32 cells with 3 or 5 posteriorly directed tails. It swims equally well with either number in a spiral course by coordination of the flagellar strokes of the cells of the organism. A parasitic infection sometimes breaks out in the organism and various individual cells are destroyed, but no matter which cells are destroyed the swimming continues in the same pattern. Organisms with only a single cell still continue to rotate, feebly to be sure, for the motive power is reduced, but the pattern of behavior is still that of the organism. 
In view of this indifference of the protozoan organism to the number of nuclei and to the fact that increase in the number of nuclei in the Protozoa, except in the matter of sex and somatic cells, does not seem to be the basis for the remarkable differentiations evolved in the protistan organism, we may infer that the path of structural and functional evolution of primitive organisms has been in the cytoplasm. The relation of genes to this process is not different in principle in the Protozoa and Metazoa. The eytoplasmic differentiations in the absence of sexual reproduction are transmitted, at fission, with restoration of the missing half as in the skeleton of the dinoflagellates, in other flagellates and in ciliates with more evidence of dedifferentiation and redifferentiation. There is therefore in these primitive organisms an inheritance of the acquired eytoplasmic structures.

The transition from these primitive, presumably haploid organisms, to the diploid with the emergence of sexual reproduction seems to have occurred in the higher types in the different classes of Protozoa quite independently of one another. What appear to be encysted zygotes have been found in a very few marine and in one fresh-water dinoflagellate; and sexual reproduction in the classic form is definitely known to occur in the Volvocidae. It is also definitely proved to occur in the Foraminifera, but remains to be proved in the Radiolaria, while it seems to be universal in Sporozoa and Ciliata. Sexual reproduction is, at least as far as is yet known, wholly absent in the more primitive Sarcodina and Flagellata. Since both the Porifera and the Coelenterata reproduce sexually, it is presumable that they evolved from types of Flagellata in which sexual reproduction had already arrived.

Reverting again to the problem of the relation of the Protozoa to the Metazoa and to the method by which the latter evolved from the former, we find two points of view as to the method. According to the widely prevalent view, the metazoan is formed as a colony of unicellular Protozoa which later differentiate as do the cells of the metazoan embryo which in so doing repeat the ancestral history. Underlying this point of view is the old concept of the wall of the cell as an essential part and of structural separateness of the cytoplasm associated with each of the several nuclei, and still more basic is the underlying philosophy that the cell is the determining factor in the living body and not that body itself, the organism as a whole.

The second point of view regards the organism as a whole as the determining factor and the individual cells as its product. The organism is a living pattern of cellular units, self-regulating and self-maintaining. Cell boundaries are not an essential part of the concept of the cell, although this idea has the rigidity and persistence of masonry wall. So long as the nucleus has a domain of cytoplasm for interaction the constructive activities continue. It is quite conceivable that limits of such interaction may shift, overlap, contend with neighboring nuclei, and wax and wane with the impact of external factors. The essential feature of the individuality of the cell is not its boundary, but a functioning set-up of nucleus and eytoplasm.

The temporary independence of each from the other is experimentally proved, at least for the cytoplasm. Enucleated cells continue to live and move as masses of protoplasm capable of katabolic metabolism but soon wear out. They do not form a new nucleus. In fresh preparations of mucus from the intestine of the frog, $I$ have seen Trichomonas, full of activity and ceaselessly moving, with the nucleus with attached neuromotor fibrillar structures consisting of blepharoplast, axostyle, undulating membrane and the full complement of flagella, and with no visible shred of undifferentiated cytoplasm attached thereto. This species has the habit of dropping off bits of cytoplasm from the posterior end of the axostyle. In the instances observed, this process had stripped the organism of all cytoplasm except that part differentiated into permanent structures and structurally adherent to the nuclear membrane. This is not, of course, strictly an isolated nucleus. 
Its fate is unknown but presumably it would soon die for lack of synthetic power to restore the cytoplasm by regeneration in the absence of one member of the pair constituting the cell, namely, the cytoplasm.

The evidence obtainable from structural conditions observed in the Protozoa suggests that our view of the evolution of the Metazoa from the Protozoa must be broadened so as to get rid of the idea of the union of "noncellular" organisms to form a multieellular one. In the life cycle of the organism both are alike unicellular and multicellular and colony formation is only one phase of multicellularity. Among protozoans there frequently occurs the multiplication of nuclei within the cytoplasm of an already highly differentiated organism. Such organisms are as truly multicellular as is a Volvox with cellulose wall about the eytoplasmic domain of each nucleus, pierced, however, by intercellular protoplasmic bridges, suggestive of organismal unity and integration.

This review of the emergence in the Protozoa of the beginnings of organ systems is in harmony with the epigenetic concept of evolution. The elaboration of organ systems in the Metazoa utilizes the intracellular achievements and the multicellular tendencies of the Protozoa as foundations for further evolutionary developments.

The adoption of the pattern or organismal concept of the living body in its early evolution will serve a useful function in clarifying our ideas of the evolutionary process. It may afford us a more reliable and truer picture of the similarities of
Protozoa and Metazoa and eventually enable us to discover more evidence of the paths of descent and relationships emerging from the extraordinarily diverse types of organisms among the Protista.

A second function which the organismal concept may afford the biological sciences is to lay a sounder foundation for the budding scientific discipline of ecology. The organism as a whole is marvelously adapted to its environment. It is linked to it by indissoluble bonds, past and present. The scientific analysis of these complicated and continuing interrelations may be facilitated by regarding the organism not merely as the sum of its individual cells, but as essentially a patter'n of interacting parts, evolved even in the initial phases not by summation but by integration.

This point of view has implications in wider fields. It will establish etiological factors in disease in true relations to the organism and favor treatment of patients rather than diseases. It may bring to agriculture, which is really only a phase of controlled ecology, a new breadth and lengtl of view which will provide a sounder policy of conservation of natural resources and a wider perspective of the problems of distribution. Analysis and synthesis are two inseparable interacting modes of scientific thinking; they are analogues of the nucleus and cytoplasm of the cell. May the next century of cellular biology combine them in a balance of endeavor which will afford unity, give impetus, and insure progress in this basic field of the biological sciences. 


\title{
THE BIOCHEMISTRY OF MICRO-ORGANISMS; AN APPROACH TO GENERAL AND COM- PARATIVE BIOCHEMISTRY
}

\author{
By C. B. VAN NIEL \\ HOPKINS MARINE STATION OF STANFORD UNIVERSITY, PACIFIC GROVE, CALIF.
}

Theodor Schwann (1837), the founder or co-founder of the cell theory, was, with Cagniard Latour and Kützing, among the first to attribute to a micro-organism, the yeast, the vital function of producing alcoholic fermentation. It seems far from excluded that his studies on the morphology and development of this unicellular organism were of decisive importance in preparing his mind for the concept that there exists but one general mode of formation of all organized beings, which is the formation of cells as constitutive units ${ }^{1}$ (Schwann 1839, p. 197). In his discussion of the forces through which constituents of the environment and of the cells themselves are changed, he mentions the process of alcoholic fermentation as a specific and clear-cut example of the idea that such forces are attributes of the cells only. ${ }^{2}$ Such a connection would add another

1 "Die Entwicklung des Satzes, dass es ein allgemeines Bildungsprinzip für alle organischen Produktionen gibt, und dass die Zellenbildung jenes Prinzip ist, und die aus diesem Satze hervorgehenden Folgerungen kann man mit dem Namen der Zellentheorie im weitern Sinne belegen."

2 "Ich habe es nieht vermeiden mögen, die Gährung als Beispiel anzuführen, da sie die am genauesten bekannte Wirkung der Zellen ist, und am einfachsten den Prozess darstellt, wie er sich im lebenden Körper an jeder Zelle wiederholt. Für diejenigen übrigens, welehe die von Cagniard-Latour und von mir aufgstellte Theorie der Gährung noch nicht anerkennen, kann die Entwicklung aller einfachen Zellen, namentlich der Sporen, als Beispiel dienen, und es soll im Text aus der Gährung kein Schluss gezogen werden, der sich nieht auch aus der Entwicklung anderer einfacher und ausser Zusammenhang mit einem anderen Organismus sich entwickelnder Zellen, namentlich der Sporen niederer Pflanzen ziehen lässt. . . U Übrigens dürfte die vorliegende Untersuchung über den Bildungsprozess der Organismen vielleicht Einiges dazu beitragen, auch der fraglichen Theorie der Gährung bei den Chemikern mehr Eingang zu versehaffen.', (p. 234.) case to the already large number of fundamental concepts which have resulted from the study of micro-organisms and their activities. I will discuss some of these concepts and generalizations primarily from the point of view of the biochemist.

No one will challenge the statement that all living organisms have some general characteristics in common by which they ean be recognized as living. Even though it may be difficult to decide upon the true nature of these characters-and the sometimes almost violent controversies on the possible living nature of bacteriophage and virus during the past fifteen years have shown this sufficiently!-it may still be inferred that the common characteristics in their most elementary form will be met with in the simplest of living organisms, and it is not difficult to agree with the remark of Rahn (1932) :

I believe that some of the principles of biology can be found and studied only with the simplest forms of life, and that general physiology has much to learn from the physiology of bacteria.

This has already happened in no small measure, and the prospects for continued contributions of a fundamental nature to this field of endeavor by studies on microbial physiolcgy are as good as ever.

The first important contribution to physiology was contained in observations which were made at a time when no one could yet realize its vast consequences. In his multifarious studies on microscopic forms of life, Antonie van Leeuwenhoek discovered, in 1680, the existence of organisms living in the absence of air (Beijerinck 1913, 1921; Dobell 1932). Only after the discovery of oxygen, at the end of the eighteentl century, when Lavoisier stressed 
the fundamental significauce of this gas as the agent needed for the slow combustion of organic matter-which is respirationcould van Leeuwenhoek's contribution be fully appreciated. But by that time it had been forgotten, so that Lavoisier felt it safe to conclude that oxygen was needed for life. Still, van Leeuwenhoek's discovery implied a basic principle; and confirmation of the occurrence of organisms living in the absence of air was but a matter of time. To the genius of Pasteur we owe the concept of fermentation as the equivalent of respiration, and "the consequence of life without air," a concept which was based entirely upon Pasteur's studies (1876) of the activities of micro-organisms. ${ }^{3}$

The fundamental similarity of respiration and its anaerobic counterpart of fermentation soon became more generally accepted. It will remain one of the great merits of Max Rubner (1909) to have emphasized these two aspects of metabolism as expressions of one and the same principle: the means of providing the living organism with energy. I need but refer to his painstaking and exhaustive studies on alcoholic fermentation (1913) in which he established so conclusively that in the absence of air this process is the only detectable one which can supply the organism with energy. Thus Rubner brought to a close that period, following Buchner and Hähn's discovery of cell-free fermentation, during which a number of scientists had begun to look upon alcoholic fermentation as a process completely divorced from the vital activities and functions of a living organism.

In connection with the importance of the chemical activities of organisms as a source of energy, mention should also be made of the brilliant hypothesis, advanced by Wino-

$3^{3}$ 'En résumé, la fermentation est un phénomène très général. C'est la vie sans air, c'est la vie sans gaz oxygène libre, ou, plus généralement encore, e'est la conséquence $d$ 'un travail chimique accompli au moyen d'une substance fermentescible capable de produire de la chaleur par la décomposition, travail qui emprunte précisément la chaleur qu'il consomme à une partie de la chaleur que la décomposition de cette substance fermentescible met en liberté.", gradsky (1887), that living organisms might be able to utilize the energy released in the oxidation of inorganic substances $(1888,1891)$. If so, such organisms would be able to get along with very much smaller amounts of organic matter, most of which is ordinarily respired away; the inorganic substrate would here fulfill the same purpose and function ${ }^{4}$ (Winogradsky 1887).

Nay, it would even be possible that living organisms might exist which could use part of the energy obtained from the oxidation of inorganic substances for the conversion of carbon dioxide into cell materials, a process known until that time to happen only in the green plants during illumination. This remarkably bold conception of the existence of what has later been termed the chemosynthetic mode of life was first experimentally verified by Winogradsky's studies $(1890,1891,1904)$ on nitrifying bacteria, later by many other workers and for a number of different groups of bacteria. $^{5}$ (Cf., e.g., Knight 1936; Stephenson 1939).

It thus appears that the various types of energy providing metabolic processes which exist in addition to ordinary respiration became known, one and all, through studies

4 " Betrachten wir einen dem gewöhnlichen physiologischen Typus angehörigen Organismus, so sehen wir, dass von den complicirten organischen Verbindungen, Kohlehydraten $z$. B., welche er verbraucht, nur ein Theil zum Aufbau seines Körpers dient; der andere wird verathmet, zerstört, wobei actuelle Energie disponibel wird. Und zwar ist der letztere Theil constant grösser als der erstere, manchmal unvergleichlich grösser. Der grösste Theil der organischen Stoffe wird also zum Gewinnen der für den Organismus nöthigen Arbeitskraft verbraucht. Gerade der Verbrauch dieses grössten Theiles fällt bei den Schwefelbacterien ganz weg. Die Energie beziehen sie ausschliesslich aus dem Schwefeloxydations-Processe."

5 "Die ganze Zeit hindurch ging die Entwicklung wie auch die Oxydation sowohl im Lichte als auch in vollständiger Dunkelheit in bester Weise vor sich, was wohl zu dem Schlusse berechtigte, dass der Nitritbildner normal wachsen und kräftige Wirkung in einem Nährboden ausüben kann, welcher keine Spur von organischer Substanz enthält. Daraus folgte aber mit Notwendigkeit der Schluss, dass dieser Organismus die Fähigkeit haben muss, Kohlensäure zu assimilieren und zwar durch einen vom Lichte unabhängigen Prozess." (Winogradsky 1904, p. 163.) 
on micro-organisms. The broadest generalization of the concept that living beings require energy for the maintenance of life as well as for growth would, consequently, find expression in the following statement, which might well be considered one of the basic working hypothesis of the general microbiologists, viz. :

Any chemical process which, thermodynamically, will proceed with the liberation of free energy can be used by some living organism as the main or even as the sole source for fulfilling its energetic requirements.

Whereas the problem of energy requirements was, from the start, a typical physiological one, it soon aroused the interests of the chemist. The conditions under which the various reactions proceeded were entirely different from those under which similar chemical reactions would go on "in vitro," and for some of the processes a clear" chemical analogon was entirely unknown. Thus, with a view to studying and establishing the means by which such reactions are accomplished by living organisms, the chemists from Liebig on, influenced particularly by the ideas of von Bayer, Moritz Traube, etc., have explored this field.

Though almost entirely theoretical in the beginning, these researches have led to an astonishingly rapid progress in our understanding during the past 25 years. And to the microbiologist it is indeed gratifying to realize how important in this development has been the part played by studies on the chemical activities of microorganisms.

The first great contribution, the significance of which can hardly be overestimated, was the concept that biological reactions should be considered as the final outcome of a series of simple step reactions, chemically intelligible and proceeding in strict succession. The concept is easily traceable to von Bayer, but it was not until Carl Neuberg published his epoch-making studies on alcoholic fermentation, later followed by researches on various bacterial fermentation and oxidation processes, that the general validity and applicability, as well as the tremendous significance, of this hypoth- esis became thoroughly established on the basis of sound and far-reaching experimental results (Neuberg and Kobel 1933). Apart from the evidence in support of the concept of successive step-reactions, this work, later greatly extended by the researches of Kluyver and his school (Kluyver and Donker 1926; Kluyver 19316), and by Stephenson and her co-workers (1939), has also yielded the important result that in the most diverse processes there is a considerable similarity in many of the intermediate steps. This is true not only if one and the same substrate is acted upon by different organisms, but also for the decomposition of different groups of substrates.

Among the groups of substrates that have been studied most extensively the carbohydrates undoubtedly rank first. We are now familiar with the notion that in most cases a sugar molecule is attacked first through the formation of phosphate esters of the monosaccharides, which subsequently undergo the more or less clearly established cleavage processes. This phosphorylation, now recognized as of such wide occurrence in plants and animals and of such fundamental importance for sugar metabolism, was discovered nearly 40 years ago by Harden and Young (1932) as a result of their studies on alcololic fermentation. It is also readily understandable that Meyerhof (1937), one of the ablest investigators of the sugar-breakdown processes, has turned on mally occasions to the microorganisms for experimental material. The recent investigations of Stone and Werkman $(1937,1938)$ have furnished considerable suppori for the view that in bacterial carbohydrate metabolism, which was not studied previously from the angle of phosphorylations, the same intermediate products would also arise.

Most of the evidence in support of the widespread occurrence of phosphorylations during sugar metabolism has been of a somewhat indirect nature, based upon studies with press juice in the presence of more or less specific poisons which prevent

6 For a complete bibliography (1939) see Chem. Weekblad, 36 : 307-323. 
the rapid decomposition of phosphorylated products. It is, therefore, important to mention the recent work of Kruyk and Klingmüller (1939) which indicates that the phosphorylation of sugar by the intact, living yeast, and in the absence of substances which inhibit certain step reactions, is highly probable.

The micro-organisms are, again, largely responsible for the development of another concept which nowadays plays such a governing role in biochemical thought. This is the concept that fundamentally all chemical activities of living organisms must be considered as hydrogen transference reactions. Originally advanced by Bredig and, particularly, by Wieland (1932), this hypothesis was developed on the basis of analogies existing between the purély chemical reactions of alcohol and of acetaldehyde with oxygen in the presence of platinum or palladium catalysts, and the oxidation of alcohol to acetic acid under the influence of acetic acid bacteria. These similarities led Wieland to postulate that respiration consists primarily of a dehydrogenation of the respiratory substrate with oxygen acting as the final hydrogen acceptor, replaceable, however, by a number of other acceptors.

The general aspect of this theory of respiration has long been disputed by Warburg, who stressed the function of oxygenactivation by iron. But von Szent Györgyi (1924), Fleisch (1924), and Kluyver and Donker (1926) have ably defended the thesis that Wieland's and Warburg's theories do not represent two fundamentally different and irreconcilable points of view but that, at least in respiratory (oxidative) metabolism, they are complementary. In the hands of Kluyver and his school Wieland's concept has been expanded to its broadest generalization: the comprehensive survey of microbial metabolism made it possible to formulate the viewpoint that each one of the steps involved in all biochemical processes can be represented by one or more of the following fundamental hydrogen transference reactions:

$$
\begin{aligned}
\mathrm{AH}+\mathrm{B} & \rightarrow \mathrm{A}+\mathrm{BH} \\
\mathrm{AH} \cdot \mathrm{B} & \rightarrow \mathrm{A} \cdot \mathrm{BH} \\
\mathrm{AH} \cdot \mathrm{B} & \rightarrow \mathrm{A}+\mathrm{BH} \\
\mathrm{AH}+\mathrm{B} & \rightarrow \mathrm{A} \cdot \mathrm{BH}^{7}
\end{aligned}
$$

It may here be added that the brilliant investigations of Warburg (1937) have recently proved the intrinsic correctness of this general formulation. Even the enzymes that have so far been studied in this connection behave like components of an $\mathrm{AH}+\mathrm{B}$ system (IVarburg 1937).

The great value of this general point of view has been demonstrated in clarifying a large variety of metabolic processes. Through its application it became possible to consider several processes, which at first sight seemed utterly unrelated, from a central point of view. This, in turn, has led to the development of a mode of thought which tends to correlate the findings in a diversity of fields and on a variety of objects. For this field of scientific endeavor Kluyver has coined the name "comparative biochemistry," and already this has proved fruitful in many cases. A few examples will illustrate its value.

It is well known that Knoop and Dakin have developed the theory that in fat metabolism the degradation of the fatty acid proceeds by the so-called $\beta$-oxidation through which the earbon chain becomes progressively shorter by 2 carbon atoms at a time. In his general survey of this problem Knoop (1931) stated that the fate of

7"This would mean that-apart from hydrolysis and its reversion-the whole of biochemistry, the complex of all biochemical changes brought about by living cells, can be reduced to chains of voluntary primary reactions, each of which consists in a coupled dehydrogenation and hydrogenation.

Since these oxido-reduction reactions differ in detail, we can summarize the essence of biochemistry in the scheme:

$$
\begin{aligned}
& \text { (I) } \mathrm{AH}+\mathrm{B} \rightarrow \mathrm{A}+\mathrm{BH} \\
& \text { (II) } \mathrm{AH} . \mathrm{B} \rightarrow \mathrm{A} \cdot \mathrm{BH} \\
& \text { (III) } \mathrm{AH} . \mathrm{B} \rightarrow \mathrm{A}+\mathrm{BH} \\
& \text { (IV) } \mathrm{AH}+\mathrm{B} \rightarrow \mathrm{A} . \mathrm{BH}
\end{aligned}
$$

It will be elear tliat, if we really accept this hypothesis-and in my opinion quite a sufficient number of arguments point to its correctness-it must have an effect on our general outlook on metabolic processes.", (Kluyver, p. 91-92.) 
these 2 earbou atoms was entirely unknown. Although it seemed probable that they might be split off as acetic acid, there existed no experimental evidence to support this view. This has recently been furnished by investigations which superficially bear no relation to the problem of $\beta$-oxydation.

Fatty acid decomposition by micro-organisms has been known to occur in a large number of cases. In addition to organisms which oxidize fatty acids in the presence of air, either completely or incompletely, some special types are known which carry out the degradation of such compounds under anaerobic conditions. Here, four groups stand out clearly. First, a group of organisms exists that will bring about a decomposition of fatty acids concomitant with a reduction of nitrates. The second group consists of bacteria which reduce sulfate to hydrogen sulfide while decomposing the organic compound (Baars 1930).

Both these processes can readily be conceived as a step-wise dehydrogenation of the fatty acid with either nitrate or sulfate, instead of oxygen, fulfilling the function of final hydrogen acceptor. In general, the oxidation of the fatty acid seems to go to completion in these cases. However, Baars observed that acetate was formed during the oxidation of butyrate, and later disappeared through further oxidation. From experiments with propionate, under the influence of a strain incapable of oxidizing acetate, where the end products agreed quantitatively with the equation

$\mathrm{CH}_{3} \mathrm{CH}_{2} \mathrm{COOH}+$

$$
\begin{aligned}
& \frac{3}{4} \mathrm{H}_{2} \mathrm{SO}_{4} \rightarrow \underset{\mathrm{CH}_{3} \mathrm{COOH}+}{\mathrm{CO}_{2}+\frac{3}{4} \mathrm{H}_{2} \mathrm{~S}}
\end{aligned}
$$

the conclusion was drawn that the complete dehydrogenation of fatty acids would proceed through the intermediate formation of fatty acids with only one carbon atom less. Obviously, this would be contradictory to the Knoop-Dakin scheme.

But the inference is not necessarily correct. It would be entircly conceivable that also a 3 -carbon compound could be dehy- drogenated by means of a $\beta$-oxidation. Whereas the Knoop-Dakin scheme in the case of butyric acid would require the formation of two molecules of acetic acid, it is clear that in the case of propionic acid, which has only three carbon atoms, one of the products must be split off as carbon dioxide. The evidence presented by Baars does not, therefore, justify his conclusion, and the formation of the theoretically required amount of acetic acid might equally well be interpreted as in agreement with a breakdown through $\beta$-oxidation.

The third group of organisms comprises the bacteria causing the methane fermentation of fatty acids. In this fermentation, the fatty acids are converted into carbon dioxide and methane, and the mechanism of this process has long been puzzling. To the recent studies of Barker (1936) we owe at least the first elucidation of this curious process. It appears that it is essentially similar to the previously discussed decompositions; the only difference is that here the acceptor function is taken over by carbon dioxide, which is consequently reduced to methane. This could be proved by studying the fermentation of ethyl alcohol, which agrees quantitatively with the equation

$$
2 \mathrm{CH}_{3} \mathrm{CH}_{2} \mathrm{OH}+\mathrm{CO}_{2} \rightarrow 2 \mathrm{CH}_{3} \mathrm{COOH}+\mathrm{CH}_{4} \text {, }
$$

all four compounds having been determined. If, now, this organism reduces carbon dioxide in the presence of butyric acid, it was observed that for every molecule of butyric acid decomposed not quite 2 molecules of acetic acid were recovered. Inasmuch as it could be shown that acetic acid was also oxidized, it seems very probable indeed that the process initially can be represented by the equation (Barker 1936, p. 413)

$$
\begin{aligned}
2 \mathrm{CH}_{3} \mathrm{CH}_{2} \mathrm{CH}_{2} \mathrm{COOH}+2 \mathrm{H}_{2} \mathrm{O}+ & \mathrm{CO}_{2} \rightarrow 4 \mathrm{CH}_{3} \mathrm{COOH}+\mathrm{CH}_{4} .
\end{aligned}
$$

The last group of organisms capable of decomposing fatty acids in a still different manner is that of the purple bacteria. Particularly Gaffron (1933, 1935) and Muller (1933) have shown that we are here deal- 
ing with micro-organisms whose metabolism again seems to conform to the general reaction scheme

$$
\mathrm{AH}+\mathrm{B} \rightarrow \mathrm{A}+\mathrm{BH},
$$

in which the substrate $\mathrm{AH}$ which is undergoing dehydrogenation, may be a fatty acid. The acceptor $\mathrm{B}$ can be either oxygen or carbon dioxide. The metabolism in the presence of oxygen has not yet been studied extensively; but an important feature with respect to the fatty acid function is that there is good evidence to show that not all fatty acids are used through the same enzyme system. For example it can be demonstrated that two fatty acids as closely related as acetic and propionic acid, or propionic and butyric acid, behave as if they were used independently of each other. The same holds true for acetic and formic acids. To mention an example: if it takes a given number of organisms $n$ minutes to completely use a certain amount of acetate, and $p$ minutes to use a definite quantity of propionate, the time required for the utilization of both when added together is not $(n+p)$ minutes, but considerably shorter, frequently equal to or approaching $p$, though never less. This would imply that while the organisms are using the acetate, they can simultaneously use the propionate, or formate as well, and frequently the rate at which the combined substrates are oxidized is accurately the sum of the rates at which the two acids are used when given separately. Inasmuch as the concentration of the individual acids, in the range employed, has no effect upon the rate of their utilization, this would mean, in our present language, that, although the enzyme system which decomposes the acetate is constantly saturated in the presence of acetate, there is still another enzyme system present which is responsible for the decomposition of propionate, and which works independently of the acetate-decomposing system.

Through studies of this type in the course of time it will be possible to gain information, conceruing the enzyme systems operative in the breakdown of related substances. By a similar mode of approach Sperber and Runnström (1939) have recently made plansible the idea that pyruvic acid and alcohol employ at least in part the same enzyme system in the oxidation mechanism of yeast.

The decomposition of fatty acids by purple bacteria witl carbon dioxide as acceptor is an example of a curious process, because it is entirely dependent upon the supply of radiant energy. It has been shown that the purple bacteria perform a sort of photosynthesis which differs from that of green plants in two respects: (a) The reduction of carbon dioxide is here not accompanied by the evolution of oxygen; (b) The process is completely dependent upon the presence of certain oxidizable compounds.

These facts were incorporated, ten years ago, into a generalized formulation of photosynthesis according to the equation (van Niel 1930, 1931, 1936):

$$
2 \mathrm{AH}_{2}+\mathrm{CO}_{2} \rightarrow\left(\mathrm{CH}_{2} \mathrm{O}\right)+\mathrm{H}_{2} \mathrm{O}+2 \mathrm{~A} \text {. }
$$

This would leave room for the existence of a number of different photosynthetic reactions depending upon the specific hydrogen donors $\mathrm{AH}_{2}$ which the different organisms can use. The photosynthetic metabolism of the purple bacteria has recently made it possible to show that formic acid, long considered by many investigators as the most probable first intermediate product in photosynthetic carbon dioxide reduction, does not play this role, at least in bacterial photosynthesis. It is true that many of the purple bacteria can use formate; but this might as well be explained as being due to an $\mathrm{AH}_{2}$ function of the formic acid. It has now become evident that all strains which can use formic acid ean also utilize molecular hydrogen, a property first established by Roelofsen (1934, 1935). Conversely, the species which are incapable of photosynthesizing with the last-mentioned gas do not attack formic acid either. This correlation is reminiscent of similar observations with other micro-organisms (cf., e.g., Stephenson 1939, p. 96.) and definitely indicates that the acid is used 
as $\mathrm{H}_{2} \mathrm{~A}$. The mere fact that there are species of purple bacteria that cannot use formic acid at all indicates that in the metabolism of such species formic acid cannot replace carbon dioxide as the ultimate hydrogen acceptor, and consequently that for these strains a reduction of carbon dioxide is not likely to proceed via formic acid. From the point of view of comparative biochemistry it is, then, equally possible that the carbon dioxide-reduction mechanism employed by these species may also function in the photosynthetic reactions of other organisms.

"Comparative biochemistry" also shows that the various photosyntheses are not likely to function through a photo-activation of the $\mathrm{H}_{2} \mathrm{~A}$ component. The fact that the decomposition of $\mathrm{H}_{2} \mathrm{~A}$ proceeds also in complete darkness, but with oxygen as acceptor rules this out. The peculiarities of the fatty acid decomposition already mentioned for mixtures, such as acetic and propionic acid, hold good also for the photosynthetic processes. Here again, at sufficiently high light intensity, the rate of decomposition of a propionic and acetic acid mixture may equal the sum total of the rates at which each of the components is utilized. This would lead to the already probable conclusion that the mechanism of the $\mathrm{H}_{2} \mathrm{~A}$ decomposition is independent of the nature of the final acceptor, and, since light is necessary only in case carbon dioxide acts in this capacity, it follows that this mechanism functions without the cooperation of radiant energy.

In view of the fact that many biochemical processes are now known in which carbon dioxide can be reduced in the dark, it is even doubtful whether this compound plays any direct part in the photochemical reactions involved in photosynthesis; the probability has to be seriously considered that the reduction of this substance takes place only after its incorporation into some organic molecule, and as a result of reducing systems, active in the dark, but generated in the light (Thimann 1938; Gaffron 1939).

It will be clear that these few examples have shown how "comparative biochemistry" may aid in distinguishing essential and general principles from secondary and fortuitous phenomena, and how a variety of processes which are at first sight entirely unrelated can be regarded from a central point of view. The occurrence of the almost unlimited variety of metabolic reactions among micro-organisms makes it possible to formulate ever more clearly such general principles; but this fact also enables the investigator to select for biochemical and physiological problems such organisms as show the phenomenon under investigation in its simplest form, unencumbered by the simultaneous occurrence of various side-processes.

This is clearly brought out by the relationships that have recently been discovered between various growth factors for micro-organisms, the vitamin requirements of the higher animals, and the important enzyme systems operative in biochemical reactions. The intensely interesting studies of the Lwoffs and co-workers, as well as those of Knight et al., have made it evident how much can still be learned from studies on microbial metabolism, and how profound an influence such studies may have on the problems of the general physiologist and biochemist (Lwoff 1938).

One of the simplest systems may here be mentioned briefly to demonstrate the present trends. For many years it has been known that common molds, as well as well as higher plants, require small amounts of copper for normal growth. The recent investigations of Kubowitz (1937), which have proved the existence of copper-proteids as oxidizing enzymes in plants, make it plausible that it is for the elaboration of such enzymes that the copper is needed. Bortels $(1930,1936)$ found that the free-living, nitrogen-fixing organism, Azotobacter, requires small amounts of molybdenum. This fact, amply corroborated (Kluyver and van Reenen 1933; Burk and Horner 1935; Krzemieniewski and Kovats 1936; Kovats 1938), has led to the supposition that some molybdenumcontaining bio-catalyst may be needed by 
the organism for the specific purpose of converting molecular into combined nitrogen. The studies of Steinberg (1937), from which it appears that the common mold Aspergillus niger also needs traces of molybdenum, particularly when grown in nitrate media, combined with the studies by Arnon (1938), which show the same needs for higher plants, generally grown with nitrate nitrogen, all point in the direction that for the reduction of nitrogen compounds some molybdenum catalyst is necessary. Observations like these may ultimately lead to the isolation of the catalyst, which, in turn, would materially aid in studying the mechanism of nitrogen fixation. Kuhn (1938) has recently reported the formation by micro-organisms of a specific compound, borocitrin, apparently closely related to the flavin pigments, and like these capable of undergoing reversible oxidation-reductions. The production of this substance is strictly dependent upon the presence of boron in the culture medium, and the elucidation of its physiological function may be expected to throw considerable light on the necessity as well as on the role of boron which has been established as one of the essential elements for plant growth (Hoagland 1937).

The relations between organic "growth factors," vitamins and enzymes also is obvious in many cases. The recent studies by various investigators have conclusively shown the vitamin nature of the active (prosthetic) groups of a number of the most important enzymes. To make this elear, it may suffice to mention the studies on vitamin $\mathrm{B}_{1}$ (Aneurin) and its pyrophosphate derivative, which is identical with the prosthetic group of the enzyme carboxylase; those on vitamin $B_{2}$ and its relation with the "yellow enzymes" of which it is the prosthetic group; and the studies on the anti-pellagra vitamin which is identical with nicotinic acid amide, the most important part of the prosthetic groups of the dehydrogenases. The relationships in other cases are clearly indicated. I need here but refer to vitamin A and the existence of a reversible "enzyme- system" of a similar chemical nature in the retina (Wald 1935); to the spectacular studies of Mocwus et al. (Moewus 1938; Kuhn, Moewus and Jerchel 1938), from which it appears that only one molecule of erocin per cell might induce the activity of flagellae in Chlamydomonas eugametos, and that the methylesters of cis- and transcrocetin in somewhat larger quantity and in different proportions cause either the male or the female gametes to become capable of conjugation; and to the recent isolation and identification of vitamin $\mathrm{B}_{6}$ (Harris and Folkers 1939) as a simple pyridine derivative. These illustrations suggest future discoveries of as many more enzyme systems at present unknown.

In this field the micro-organisms likewise may be of great significance. It is possible now to use them for rapid and inexpensive assaying of vitamins (Snell and Strong 1939), and they may serve as material for studying the particular phases of metabolism in which vitamins, with as yet littleknown functions, operate. Lwoff and coworkers, and Knight et al. have published some fiue examples of studies of this kind.

So far this discussion may have shown how experiments with various types of micro-organisms have contributed towards the development of fundamentally important problems and viewpoints in physiology and biochemistry. Although the details of many of these processes have not yet been satisfactorily and completely worked out, the great lines and general principles are clearly evident.

The preceding review has dealt primarily with the breakdown processes in metabolism. Studies on micro-organisms should also yield much information on synthetic reactions. From the end of the 19 th eentury on, the connection between anabolic (synthetic) and catabolic (breakdown) reactions has been conceived as an energetic one. With the realization that the catabolic processes ean more or less satisfactorily be interpreted as the final result of a succession of chemically simple step reactions, the question of the mechanism of 
the energy transfer during anabolism has come to occupy an increasingly important place.

The most appealing concept of such a mechanism so far expressed is the one in which the catabolic process leads to the formation of products from which a direct synthesis of building stones of the cell constituents would be possible by means of (thermodynamically) spontaneous reactions (Kluyver and Donker 1926; Kluyver 1931; Knoop 1931). Experimental evidence in favor of this hypothesis is certainly not lacking. In the first place one might point out that among the typically catabolic processes synthetic reactions are likewise far from rare. Some specific examples are the formation of 4-carbon from 2 -carbon or 3-carbon compounds, such as acetylmethyl earbinol from acetaldehyde or from acetic acid (Reynolds and Werkman 1937) and of succinic acid, presumably from a 3-carbon acid and carbon dioxide (Wood and Werkman 1936; Elsden 1938). More striking is the production of large quantities of caproic acid from ethyl alcohol during the methane fermentation of the latter substance (Barker 1937). The importance of this conversion is that it shows how readily a synthesis of a 2 carbon to a 6-carbon compound can be achieved as a result of catabolic activity.

Long before this demonstration the formation of fatty acids as a result of condensations of a 2-carbon compounds had been proposed, mainly based upon the studies by Hähn and Kinttof (1925) on the formation of fats by the yeast Endomyces vernalis. The recent chemical synthesis of stearic acid at low temperatures by condensation of erotonic aldehyde and reduction of the resulting unsaturated aldehyde (Kuhn, Grundmann and Trischmann 1937) lends considerable weight to the idea that fatty acids do originate through a condensation process of aldehydes. Reichel and Schmid (1939) have added the important observations that Endomyces vernalis is capable of producing condensation products only from unsaturated aldehydes; the saturated ones are converted into the corresponding fatty acids. With a mechanism available by which unsaturated higher aldehydes can be formed, the synthesis of fatty acids would, then, not offer serious difficulties. The mechanism for this production would thus be the gradual breakdown of the organic substrate which is being attacked in eatabolism, with the formation of intermediate products from which a direct spontaneous synthesis is possible.

The spontaneous synthesis of amino acids on an equal basis from keto- or unsaturated acids and ammonia is an established fact. It has been shown to occur chemically (Knoop and Oesterlein 1925, 1927) as well as biochemically, under the influence of enzyme preparations from Pseudomonas fuorescens (Virtanen and Tarnanen 1932) and of yeast (Haehn and Leopold 1937).

These examples may show that in a few cases there is not necessarily a qualitative difference between anabolic and catabolic reactions in the sense that only the latter would occur as thermodynamically spontaneous reactions. Given the proper initial substances, these anabolic, synthetic processes also take place spontaneously. And one is thus led to consider the possibility that catabolic processes are not as important in supplying the energy for various vital activities as they are in furnishing the raw materials from which the assimilatory processes take place as "modified" catabolic reactions. Such a concept is supported remarkably well by a number of recent studies.

In the first place, a theoretical consequence of this point of view would be the existence of a stoichiometric rather than of an energetic relationship between the possible synthetic and the breakdown reactions. For if a substrate were available to assimilatory reactions only after it had given rise to e.g., acetaldehyde, then the maximum possible assimilation would depend upon the maximum producible aldehyde, rather than upon the amount of energy liberated during the conversion of the substrate into acetaldehyde. 
The first important contribution to this problem concerning the relationship between catabolism and anabolism was made by Barker (1936), who showed that of a number of simple oxidation substrates, such as ethyl alcohol, glycerin, the lower fatty acids, or glucose, only a small proportion of eacl substrate is actually burned to carbon dioxide and water by the colorless alga Prototheca zopfi. Though constant for each substance, this proportion varied between about 20 and 50 per cent of the total available carbon for different compounds. The experimental results made it seem probable that during the oxidation of the substrate the remainder, comprising 80 to 50 per cent of the carbon, was converted into some cell material of the approximate composition of a carbohydrate, and possibly of the nature of a storage product.

Similar experiments with different $S p i-$ rillum species acting upon a variety of simple respiration substrates soon led Giesberger (1936) to the conviction that this phenomenon is far from rare; that, in fact, it might well turn out to be a generally occurring phenomenon. Giesberger also drew the conclusion that under normal conditions and even with non-growing organisms assimilation is apparently inseparable from respiration, and that the pri- mary aim of respiration would be the production of assimilatory substances; the evolution of carbon dioxide during respiration might thus be considered as an accessory phenomenon and representing a waste product of the main reaction.

Clifton (1937) and Clifton and Logan (1939) further extended these studies, first by showing that the phenomenon in general holds good for Pseudomonas calco-acetica and for Escherichia coli, and second by demonstrating that substrates can be completely oxidized without the apparent formation of assimilatory products in the presence of certain poisons, particularly a-dinitrophenol and sodium azide. The work of Winzler and Baumberger (1938) then established the same situation in the case of yeast, that of Doudoroff ${ }^{8}$ for strains of hydrogen-oxidizing bacteria. Hence there seems to be very little doubt that such syntheses as have been reported here are very general in their occurrence.

But the mechanism of this assimilation is still largely unsolved; even the most important stages are a matter of speculation. The different types of micro-organisms. have yielded results which are far from uniform. As an example, the following tentative equations developed in the previously mentioned studies, may be presented:

8 Unpublished results.

Oxidation OF ACETATE

\begin{tabular}{l|l|l}
\hline \multicolumn{1}{c|}{ Organism } & \multicolumn{1}{|c}{ Equation } & \multicolumn{1}{c}{ Author } \\
\hline Prototheca zopfi & $\mathrm{CH}_{3} \mathrm{COOH}+\mathrm{O}_{2} \rightarrow\left(\mathrm{CH}_{2} \mathrm{O}\right)+\mathrm{CO}_{2}+\mathrm{H}_{2} \mathrm{O}$ & Barker (1936) \\
Various Spirillum species & $\mathrm{CH}_{3} \mathrm{COOH}+\mathrm{O}_{2} \rightarrow\left(\mathrm{CH}_{2} \mathrm{O}\right)+\mathrm{CO}_{2}+\mathrm{H}_{2} \mathrm{O}$ & Giesberger (1936) \\
Pseudom. calco-acetica & $2 \mathrm{CH}_{3} \mathrm{COOH}+3 \mathrm{O}_{2} \rightarrow\left(\mathrm{CH}_{2} \mathrm{O}\right)+3 \mathrm{CO}_{2}+3 \mathrm{H}_{2} \mathrm{O}$ & Clifton (1937) \\
Esch. coli & $2 \mathrm{CH}_{3} \mathrm{COOH}+3 \mathrm{O}_{2} \rightarrow\left(\mathrm{CH}_{2} \mathrm{O}\right)+3 \mathrm{CO}_{2}+3 \mathrm{H}_{2} \mathrm{O}$ & Clifton (1937, 1939) \\
Saccharom. cerevisiae & $59 \%$ oxidized, $41 \%$ assimilated & Winzler and Baumberger (1938)
\end{tabular}

Oxidation of Normal Butyrate

\begin{tabular}{l|l|l}
\hline \multicolumn{1}{c|}{ Organism } & \multicolumn{1}{|c|}{ Equation } & \multicolumn{1}{c}{ Author } \\
\hline Prototheca zopfi & $2 \mathrm{C}_{4} \mathrm{H}_{8} \mathrm{O}_{2}+5 \mathrm{O}_{2} \rightarrow 5\left(\mathrm{CH}_{2} \mathrm{O}\right)+3 \mathrm{CO}_{2}+3 \mathrm{H}_{2} \mathrm{O}$ & Barker (1936) \\
Spir. serpcns & $2 \mathrm{C}_{4} \mathrm{H}_{8} \mathrm{O}_{2}+5 \mathrm{O}_{2} \rightarrow 5\left(\mathrm{CH}_{2} \mathrm{O}\right)+3 \mathrm{CO}_{2}+3 \mathrm{H}_{2} \mathrm{O}$ & Giesberger (1936) \\
Spir. tenue & $2 \mathrm{C}_{4} \mathrm{H}_{8} \mathrm{O}_{2}+7 \mathrm{O}_{2} \rightarrow 3\left(\mathrm{CH}_{2} \mathrm{O}\right)+5 \mathrm{CO}_{2}+5 \mathrm{H}_{2} \mathrm{O}$ & Giesberger (1936) \\
Spir. undula & $4 \mathrm{C}_{4} \mathrm{H}_{8} \mathrm{O}_{2}+9 \mathrm{O}_{2} \rightarrow 11\left(\mathrm{CH}_{2} \mathrm{O}\right)+5 \mathrm{CO}_{2}+5 \mathrm{H}_{2} \mathrm{O}$ & Giesberger (1936) \\
Pseud. calco-acetica & $2 \mathrm{C}_{4} \mathrm{H}_{8} \mathrm{O}_{2}+7 \mathrm{O}_{2} \rightarrow 3\left(\mathrm{CH}_{2} \mathrm{O}\right)+5 \mathrm{CO}_{2}+5 \mathrm{H}_{2} \mathrm{O}$ & Clifton (1937) \\
\hline
\end{tabular}


These equations would imply that, although the same product $\left(\mathrm{CH}_{2} \mathrm{O}\right)$ is formed in all cases, the extent of its formation may vary considerably. However, one must bear in mind that these equations are only first and somewhat rough approximatious. The nature of the assimilation product is unknown; it is certain that it does not consist exclusively of carboliydrate, at least for Spirillum serpens where Giesberger has ascertained the formation of volutin. And thus it is conceivable that different organisms may elaborate different assimilation products, and hence that also the more intimate mechanism of their synthetic reactions is not identical.

Of great significance is the fact that Cliftou and Logan (1939) have demonstrated the assimilatory reactions to be functions of the chemical constitution of the respiration substrate rather than of the available energy. Their results have shown that the assimilated fraction of lactic and of pyruvic acid is exactly the same on the basis of the number of carbon atoms; the same holds for succinic and fumaric acids :

$$
\begin{aligned}
& \mathrm{CH}_{3} \mathrm{CHOHCOOH}+2 \mathrm{O}_{2} \rightarrow \\
& \left(\mathrm{CH}_{2} \mathrm{O}\right)+2 \mathrm{CO}_{2}+2 \mathrm{H}_{2} \mathrm{O}
\end{aligned}
$$

$\mathrm{CH}_{3} \mathrm{COCOOH}+1 \frac{1}{2} \mathrm{O}_{2} \rightarrow$

$$
\left(\mathrm{CH}_{2} \mathrm{O}\right)+2 \mathrm{CO}_{2}+\mathrm{H}_{2} \mathrm{O}
$$

$\mathrm{COOHCH}{ }_{2} \mathrm{CH}_{2} \mathrm{COOH}+2 \frac{1}{2} \mathrm{O}_{2} \rightarrow$

$$
\left(\mathrm{CH}_{2} \mathrm{O}\right)+3 \mathrm{CO}_{2}+2 \mathrm{H}_{2} \mathrm{O}
$$

$\mathrm{COOHCH}=\mathrm{CHCOOH}+2 \mathrm{O}_{2} \rightarrow$

$$
\left(\mathrm{CH}_{2} \mathrm{O}\right)+3 \mathrm{CO}_{2}+\mathrm{H}_{2} \mathrm{O}
$$

Now the energy liberated in reaction (1) is certainly considerably greater than that set free in (2), just as that of (3) exceeds the yield of (4). Also, the caloric effect of (3) is definitely larger than that of (1). And yet, from these four compounds it is always only one carbon atom of each substrate molecule that becomes incorporated, at least temporarily, into the cell material. Such results are, however, understandable if it is assumed that during the stepwise dehydrogenation of the four compounds only one intermediate product originates from which the occurring synthesis is pos- sible. It is clear that in the case of the four substrates here discussed such a mechanism is not at all improbable; their gradual degradation can readily be formulated in such a way that one molecule, e.g., of formaldehyde, arises from one molecule of each one of the raw materials. Hence, if the synthetic reactions would function through a condensation of formaldehyde, the experimental results would fit in remarkably well with such an assumption.

Different organisms may well use different intermediate products for synthetic processes. But also the gradual degradation of the substrate may, under the influence of specific agents, proceed by a different path. Thus, referring to the abovementioned differences in the assimiliatory "efficiency" of e.g., Prototheca zopfii and Escherichia coli, in the respiration of acetate, it would be possible to formulate the occurring reactions as follows:

$$
\begin{gathered}
\mathrm{CH}_{3} \mathrm{COOH} \rightarrow \mathrm{CH}_{2} \mathrm{OHCOOH} \rightarrow \\
\mathrm{CHOCOOH} \rightarrow \mathrm{CH}_{2} \mathrm{O}+\mathrm{CO}_{2} \\
\mathrm{HOOCCH} \\
\text { HOOC. } \mathrm{H}_{3} \mathrm{CCOOH} \\
\mathrm{HOCH}
\end{gathered}
$$

Reaction (5) might represent the stepwise oxidation of acetic acid under the influence of Prototheca; each molecule of the substrate gives rise to the formation one molecule of $\mathrm{CH}_{2} \mathrm{O}$. If, however, the dehydrogenation of acetic acid by Escherichia coli were to proceed by way of succinic acid, as shown by equation (6), then one molecule of $\mathrm{CH}_{2} \mathrm{O}$ would result from the oxidation of two molecules of acetate, on the basis of equation (3).

These reflections do not aim at prematurely proposing hypothetical mechanisms for the synthetic processes; they are given here to show how the general idea of a strictly chemical mechanism for assimilatory reactions seems to fit the available experimental data better than one based primarily on energy. They also indicate how difficult it may be at the present time to interpret correctly efficiency determinations based upon measurements of the energies involved without an accurate knowledge of the internal mechanism. 
If it is remembered that the study of these synthetic processes is as yet limitcd to a very small number of investigations, carried out only during the last three years, it is not surprising that our knowledge is still most imperfect and in so incipient a stage. Considering the development in the other fields of biochemical research, there is, however, reason to believe that the anabolic phase of metabolism will soon become as fruitful a field of investigation as catabolism has been during the past quarter of a century. I should like to stress the importance of microorganisms for such studies; the variety of organisms is so large, and one may expect to find so many individual differences that the approach from the viewpoint of comparative biochemistry promises a vastly increased possibility to survey the elementary processes.

Here I may end this cursory review of the basic principles upon which biochemical thought rests today. I hope to have succeeded in showing how a study of the behavior of micro-organisms has aided in the formulation of these principles; how "comparative biochemistry" has come to occupy an important position.

Science rests upon the firm foundation of observation and experimental results, i.e., upon reproducible facts. But the progress of science, even though bound to the recording of such observations, is itself due to the gradual development of hypotheses. It is the great generalizations in which observational data on many apparently unrelated groups of phenomena are linked together into comprehensive points of view-our working hypotheses and theories-that mark the stepping stones by which our scientific outlook has developed.

A century ago Schwann, in formulating one of these broad generalizations, commented upon the fortunate circumstances which had led to an increasing unification of the scientific outlook. This unification has not come to a standstill; the side-byside growth of the various branches of scientific endeavor and discovery has led, and is still leading, towards a mutual fertilization, and we can unhesitatingly subscribe today to Schwann's statement (1837) :

Es ist ein wesentlicher Vorzug unseres Zeitalters, dass die einzelnen Disziplinen der Naturwissenschaften in immer innigere Vereinigung miteinander treten, und gerade dieser wechselseitigen Durchdringung und Ergänzung verdanken wir einen grossen Theil der Fortsehritte, welche die Naturwissensehaften in der neuesten Zeit gemacht haben.

\section{References Cited}

Arnon, D. I. 1938. Mieroelements in CultureSolution Experiments with Higher Plants. Am. J. Botany, 25: 322.

BAARS, J. K. 1930. Over sulfaatreductie door baeteriën. Dissertation. Delft.

BARker, H. A. 1936. On the Bioehemistry of the Methane Fermentation. Arch. Mikrobiol., $7: 404$.

- 1936. The Oxidative Metabolism of the Colorless Alga, Prototheca zopfii. J. Cellular Comp. Physiol., 8: 231.

- 1937. The Production of Caproie and Butyrie Aeids by the Methane Fermentation of Ethyl Alcohol. Arch. Mikrobiol., 8: 415.

BeiJerinck, M. W. 1913. De infusies ende ontdekking der bacteriën. Jaarb. Kon. Akad. v. Wetenseh. Amsterdam. 1921. Verzam. Geschriften, 5: 119.

Bortels, H. 1930. Molydän als Katalysator bei. der biologisehen Stiekstoff bindung. Arch. Mikrobiol., 1: 333. Zentr. Bakt. Parasitenk., II Abt., $95: 193$.

Burk, D. and Horner, C. K. 1935. The Speeific Catalytic Role of Molybdenum and Vanadium in Nitrogen Fixation and Amide Utilization by Azotobaeter. Trans. 3d Intern. Congr. Soil Sci., 1: 152 .

Clifton, C. E. 1937. On the Possibility of Preventing Assimilation in Respiring Cells. Enzymologia, 4: 246.

Clifton, C. E. and Logan, W. A. 1939. On the Relation between Assimilation and Respiration in Suspensions and in Cultures of Escherichia Coli. J. Bact., 37 : 523.

DoBell, C. 1932. Antony van Leeuwenhoek and His Little Animals. Hareourt Braee and Co., New York.

Elsden, S. R. 1938. The Effeet of $\mathrm{CO}_{2}$ on the Production of Suceinie Acid by Bact. coli commune. Biochem. J., 32: 187.

Fleisch, A. 1924. Some Oxidation Processes of Normal and Cancer Tissue. Biochem. J., 18: 294.

GaFrroN, H. 1933, 1935. Über den Stoffwechsel der schwefelfreien Purpurbakterien. Biochem. Z., 260: 1; Biochem. Z., 275: 301.

1939. Chemieal Aspeets of Photosynthesis. Ann. Rev. Biochem., 8: 483. 
Giesberger, G. 1936. Beiträge zur Kenntnis der Gattung Spirillum Ehbg. Mit besonferer Berücksichtigung der Atmungsprozesse bei den Vertretern dieser Gattung. Dissertation. Utrecht.

HAEHN, H. and Kintrof, W. 1925. Beitrag über den chemischen Mechanismus der Fettbildung aus Zucker. Chem. Zelle Gewebe, 12: 115.

HAEHN, H. and LEOPOLD, H. 1937. Über eine Aspartasewirkung der Hefe. Biochem. Z., 292: 380 .

HARDEN, A. 1932. Alcoholie Fermentation. 4th ed. London.

HARRIS, S. A. and Folkers, K. 1939. Synthetic Vitamin $\mathrm{B}_{6}$. Science, $89: 347$.

Hoagland, D. R. 1937. Some Aspects of the Salt Nutrition of Higher Plants. Botan. Rev., 3: 307.

KluYver, A. J. 1930. Atmung, Gärung und Synthese in ihrer gegenseitigen Abhängigkeit. Arch. Mikrobiol., 1: 181.

- 1931. The Chemical Activities of Microorganisms. Univ. of London Press.

Kluyver, A. J. and Donker, H. J. L. 1926. Die Einheit in der Biochemie. Chem. Zelle Gewebe, 13 : 134-190.

Kluyver, A. J. and VAN Reenen, W. J. 1933. Über Azotobacter agilis Beijerinck. Arch. Mikrobiol., $4: 280$.

KNIGHT, B. C. J. G. 1936. Bacterial Nutrition. Med. Res. Council (British), Spec. Rep. Series No. 210. London.

KNoop, F. 1931. Oxydationen im Tierkörper. Stuttgart.

KNoop, F. and Oesterlein, H. 1925, 1927. Úber die natürliche Synthese der Aminosäuren. $Z$. Physiol. Chem., 148: 294; 170 : 186.

Kovats, J. 1938. Über den Einfluss von Eisen und Molybdan auf die Stickstoffbindung durch Azotobakter in Gegenwart von Humussubstanzen oder von deren Aschen. Bull. Acad. Polon., Ser. B, Sci. Natur., 91 .

KRUYK, K. and KLINGMÜLleR, V. 1939. Über Vorgänge bei der alkoholischen Gärung der lebenden Hefe. Biochem. Z., 300: 343.

KrzeMieniewski, S. and Kovats, J. 1936. Über den Einfluss von Eisen und Molybdän auf die Stickstoffbindung durch Azotobacter chroococcum Beij. Bull. Acad. Polon., Ser. B, Sci. Natur., 169.

Kunowitz, F. 1937. Über die chemische Zusammensetzung der Kartoffeloxydase. Biochem. Z., 292 : 221.

KuнN, R. 1938. Relations Chimiques entre Vitamines et Ferments. Réun. Intcrnat. de Physique, Biol. Paris, VII, 1 .

Kunn, R., Grundmann, C. and Trischmann, H. 1937. Synthese der Stearinsäure. Z. Physiol. Chem., 248: IV-V.

Kunn, R., Moewus, F. and Jerchel, D. 1938. Über die Chemische Natur der Stoffe, welche die Kopulation der männlichen und weiblichen Gameten von Chlamydomonas eugametos im Lichte bewirken. Ber. Deut. Chem. Ges., 71: 1541.
LwoFf, A. 1938. Les facteurs de croissance pour les microorganismes. Ann. Inst. Pasteur., 61: 580 .

MEYERHoF, O. 1937. Über die Intermediärvorgänge der enzymatischen Kohlehydratspaltung. Ergeb. Physiol., 39: 10.

Mozwus, F. 1938. Carotinoide als Sexualstoffe von Algen. Jahrb. wiss. Botan., 86: 753.

Muller, F. M. 1933. On the Metabolism of the Purple Sulphur Bacteria in Organic Media. Arch. Mikrobiol., 4: 131.

Neuberg, C. and Kobel, M. 1933. Untersuchung von Gärflüssigkeiten. Handb. d. Pfanzenanalyse, 4: 1253-1344.

Pasteur, L. 1876. Etudes sur la Bière, 261-262. Paris.

Rahn, O. 1932. Physiology of Bacteria. Blakiston, Philadelphia.

Reichel, L. and Schmid, O. 1939. Über den Mechanismus der Synthese von Fettsäuren und Fett durch den Hefepilz Endomyces vernalis. Biochem. Z., 300: 274.

Reynolds, H. and Werkman, C. H. 1937. The Intermediate Dissimilation of Glucose by Aerobacter indologenes. J. Bact., 33: 603.

Roelofsen, P. A. 1934. On the Metabolism of the Purple Sulphur Bacteria. Proc. Acad. Sci. Amsterdam, 37: 660 .

-2. 1935. On Photosynthesis of the Thiorhodaceae. Thesis. Utrecht.

Rubner, M. 1909. Kraft und Stoff im Haushalte der Natur. Leipzig.

- 1913. Die Ernährungsphysiologie der Hefezelle bei Alkoholischer Gärung. Leipzig.

Schwann, T. 1837. Vorläufige Mittheilung betreffend Versuche über die Weingährung und Fäulniss. Poggend. Ann., 41: 184.

___ 1839. Mikroskopische Untersuchungen über die Übereinstimmung in der Struktur und dem Wachstum der Thiere und Pflanzen. Berlin.

Snell, E. E. and Strong, F. M. 1939. Microbiological Assay for Riboflavin. Ind. Eng. Chem., Anal. Ed., 11: 346.

Sperber, E. and Runnström, J. 1939. Über die Konkurrenz eininger Substrate um die Enzyme der lebenden Zellen der Bäckerhefe. Biochem. Z., $300: 373$.

Steinberg, R. A. 1937. Role of Molybdenum in the Utilization of Ammonium and Nitrate Nitrogen by Aspergillus niger. J. Agric. Res., 55: 891.

Stephenson, M. 1939. Bacterial Metabolism. 2nd ed. Longmans, Green \& Co., New York.

Stone, R. W. and WerkmaN, C. H. 1937, 1938. Pliosphorylation by the Living Bacterial Cell. Biochem. J., 31: 1516; 32: 101.

Szent-Györgyi, A. voN. 1924. Über den Mechanisnus der Succiu- und Paraphenylendiaminoxydation, Ein Beitrag zur Theorie der Zell atmung. Biochem. Z., 150: 195. 
Thimann, K. V. 1938. The Absorption of $\mathrm{CO}_{2}$ in Photosynthesis. Science, 88: 506.

VAN Niel, C. B. 1930. Photosynthesis of Bacteria. Contributions to Marine Biology, Stanford Univ. Press. 1931. Arch. Mikrobiol., 3: 1. 1935. Photosynthesis of Bacteria. Cold Spring Harbor Symp. on Quant. Biol., 3: 138. - 1936. Arch. Mikrobiol., $7: 323$.

Virtanen, A. T. and Tarnanen, J. 1932. Die enzymatische Spaltung und Synthese der Asparaginsäure. Biochem. Z., 250: 193.

WALD, G. 1935. The Chemistry of the Visual Purple System. Cold Spring Harbor symposia on Quant. Biol., 3 : 251.

Wabrurg, O. 1937. Chemische Konstitution von Fermenten. Ergeb. Enzymforsch, 7: 210.
Wieland, H. 1932. On the Mechanism of Oxidation. Yale Univ. Press.

WiNogradsKy, S. 1887. Über Schwefelbacterien. Botan. Zeitung, Nos. 31-37.

- 1888. Zur Morphologic und Physiologie der Schwefelbacterien. Leipzig.

-1891. Ann. Inst. Pasteur, 4: 213, 257, $760 ; 5: 92,577$.

-1904. Die Nitrifikation. Handb. $d$. techn. Mykologie (Lafar), 3: 132-181.

Winzler, R. J. and BAUMBerger, J. P. 1938. The Degradation of Energy in the Metabolism of Yeast Cells. J. Cellular Comp. Physiol., 12: 183.

Wood, H. G. and WerkMaN, C. H. 1936. The Utilization of $\mathrm{CO}_{2}$ in the Dissimilation of Glycerol by the Propionic Acid Bacteria. Biochem. J., 30 : 48; 32 : 1262. 


\title{
THE STRUCTURE OF VIRUSES ${ }^{1}$
}

\author{
By W. M. STANLEY \\ DEPARTMENT OF ANIMAL AND PLANT PATHOLOGY, THE ROCKEFELLER INSTITUTE \\ FOR MEDICAL RESEARCH, PRINCETON, N. J.
}

THE atomic theory of matter, the germ theory of disease, and the cell theory of life may appear at first to be quite diverse and unrelated. However, it will be my purpose not only to present the recent advances in virus research, but also to indicate that the successful continuation of this work may be dependent upon an intimate knowledge of the three theories just mentioned and even, perhaps, upon their integration into a new and unified philosophy. The atomic theory, which was probably first stated before 1000 B.c., has been subjected to continual modification in detail as a more exact knowledge of atomic structure has been gained, yet the original and basic concept of matter as a discontinuous rather than as a continuous or homogeneous phase has remained unaltered. The germ and cell theories have been subjected to less modification than has the atomic theory, perhaps because of their more recent origin; with time and new knowledge, it would not be unexpected if they too should require further alteration. It is an unfortunate fact that knowledge gained before its due time frequently results in a strong desire to overthrow useful theories, and it is only later, following understanding, that reconciliation and accord are achieved. For example, it is known that many present-day facts are entirely inconsistent with the atomic theory as stated by Dalton in 1808, yet the evolution of the theory has been such as to account for these facts and to provide today a valid and coherent atomic theory. The newer knowledge of viruses may appear inconsistent with present-day theories, yet there is every reason to believe that a more complete understanding of the structure or architec-

1 This lecture was adapted from an article by the writer which was published with an extensive bibliography in Physiological Reviews, 19: 524 (1939). ture of viruses will permit the blending of hypotheses and facts into a unified philosophy without the overthrow of timehonored theories.

The word "virus" was originally used only in the singular and meant a poison such as a snake venom. Later it was used to denote infectious disease-producing entities without regard to their nature, and more recently it has been applied only to those infectious agents capable of passing through filters that retain ordinary bacteria. Today, properties ascribed to viruses include not only their ability to pass through fine membranes but also a set of general properties which emphasize the intimate relationship that exists between viruses and their host cells. Among these properties is the fact that viruses reproduce, but only within certain living cells; the fact that during reproduction they may change or mutate; the fact that many virusinfected cells contain inclusion bodies; and the fact that most virus diseases (but not all) are followed by a lasting immunity in recovered hosts. Tobacco mosaic, the first virus discovered, was shown to be filterable by Iwanowski only 47 years ago and was recognized as a new kind of infectious agent by Beijerinck 41 years ago. Other viruses which have been recognized since then include those responsible for the footand-mouth disease of cattle, louping ill of sheep, hog cholera, rabies, dog distemper, fowl pox, smallpox, psittacosis, yellow fever, St. Louis encephalitis, horse encephalitis, poliomyelitis, fever blisters, certain types of tumorous growths in fowls and other animals, various yellows and mosaic diseases of plants, and even for the production of unusual colors in the flowers of plants, which in tulips is called tulip break. Still more viruses are being discovered from time to time. 
It should be emphasized that viruses were first recognized and have continued to be recognized only by means of their biologieal activity, that is, by the diseases which they cause. They were regarded merely as infectious disease-producing principles, and with the exception of viruses of the elementary body type which are as large as accepted organisms, attempts to isolate a virus in tangible form had resulted in failure; hence little or nothing was known of their true nature. An element of mystery tended to surround them, and they were regarded variously as invisible forms of ordinary bacteria, as Protozoa, as some new type of invisible living orgainism, as enzymes, as unusual products of cellular metabolism, as toxins, and as different kinds of chemical principles. However, because viruses were known to reproduce and to mutate, and because of certain other properties, most of the workers in the field considered viruses to be living organisms somewhat similar to the bacteria. $\mathrm{A}$ new viewpoint became possible in 1935, following the chemical isolation of a material from mosaic-diseased plants, which appeared to be a high-molecular-weight protein and which was distinguished by the fact that it possessed the properties of tobaceo mosaic virus. This material could be crystallized in the form of long, thin needles. When earefully prepared it was found to be homogeneous in the Svedberg centrifuge and in the Tiselius electrophoresis apparatus. The material first isolated was referred to as a globulin because of its solubility characteristics and because no phosphorus was found in the samples which were first prepared for analysis. Later the material was found to contain abont 0.6 per cent phosphorus, and after the isolation of nucleic acid from purified preparations almost simultaneously by Bawden and Pirie and by Stanley, the view was advanced by the former workers that the material was a mucleoprotein. Subsequent work from both laboratories has substantiated this view and the material is now generally accepted as a nucleoprotein, although it should be recognized that it differs markedly from the ordinary nucleoproteins composed of nucleic acid and protamine or histone. The discovery of this material was followed by the isolation (by the same or similar chemical methods or by means of differential centrifugation) of similar high-molecular-weight nucleoproteins possessing the properties respectively of aucuba mosaic, enation mosaic, tobacco ring spot, latent mosaic of potato, severe etch, Shope rabbit papilloma, bushy stunt of tomato, cucumber mosaies 3 and 4, and tobacco-necrosis viruses, and of a staphylococeus bacteriopliage. The presence of high-molecular-weight protein material in very active preparations of chicken tumor I, equine encephalitis, and foot-and-month-disease viruses has also been demonstrated, although Claude's isolation of a fraction from normal chick embryo that is quite similar to the purified chicken tumor I preparation casts some doubt upon the significance of the results in the cases of the first two viruses. The isolation of the different high-molecularweight nucleoproteins was of importance because at last tangible materials possessing quite definite physical and chemical properties were available for study, and thus the possibility was offered of correlating virus activity with such properties. Although some of the mystery surrounding viruses was removed by the isolation of the nucleoproteins carrying virus activity, the isolation really represented but a small step towards the solution of the problem of the ultimate nature of viruses. Protein structure may be expressed in many different ways, as in hormones, enzymes, toxins, respiratory materials, and perhaps as in chromosomes and as in protoplasm, and, since practically nothing is known about protein structure, the addition of viruses to this diverse group aided but little in the establishment of their true nature. All viruses appear to have a high molecular or particle weight; yet this fact alone cannot be used as a criterion of virus activity, for some of the virus nucleoproteins may be inactivated by appropriate treatment without changing their size greatly. However, no entity having a size smaller than that 
corresponding to a molecular weight of about 400,000 has been found to possess virus activity; hence it is probable that a certain amount of structure may be necessary to support such biological activity.

At the present time, the solution of the virus problem appears to be in the elucidation of the structure which is peculiar to materials carrying virus activity. This problem is mole complex than that involved in protein structure as such, for, of the virus materials so far isolated, none has been found to yield only amino acids on hydrolysis. The simplest appear to be composed of protein plus nucleic acid; the more complex, of protein, nucleic acid, and carbolydrate; and the most complex, of materials indistinguishable from those found in bacteria. These results may be interpreted as indicating that viruses are protein or protein-like in nature; but there is little justification for the tendency to accept the results as demonstrating unequivocally that viruses are non-living and are merely ordinary protein molecules similar to egg albumin. Although the physical and chemical properties of the virus nucleoproteins are similar to those of ordinary proteins, the biological properties are quite different; and it is because of the virus activity, which implies the ability to multiply and to change or mutate, that it is difficult to conclude that they are ordinary protein molecules. Despite this difficulty, the virus nucleoproteins which have been found to have the chemical and physical properties of molecules will be referred to as molecules. Others may wish to refer to these same particles as organisms or cells, but the question of nomenclature is of secondary importance, as will be indicated later. The virus activity is undoubtedly a consequence of the unique architecture of the materials that have been isolated, but beforc proceeding with such an assumption it is necessary to ascertain whether or not it can be demonstrated that the virus preparations are essentially pure and that the virus activity is a specific property of the major component. This demonstration is dependent upon the correlation of eliemi- cal and physical properties with activity; hence virus activity and its measurement become all-important and must, therefore, be considered.

The most characteristic and at the same time the most important property of viruses is their biological activity, their infectiousness or ability to multiply or reproduce when introduced into certain living cells. It is this property that resulted in the original discovery of viruses, and it is this property, more than any other, that has caused viruses to be regarded as elementary living organisms, for the ability to multiply within an essentially non-specific and variable environment has been generally considered to be one of the essential characteristics of living organisms. This property also distinguishes viruses from ordinary protein molecules, such as those of egg albumin and of hemoglobin, or even from the biologically active enzyme proteins, such as pepsin or trypsin, which have the ability of multiplication in that they can cause the autocatalytic conversion of specific precursors to pepsin and trypsin. It may be noted here that if specific inactive virus precursors should be found, the virus reaction would then resemble that of the enzymes, pepsin and trypsin.

During most of the early work with viruses no attempt was made to measure virus activity quantitatively. The activity determinations were merely qualitative and were made to determine whether or not a given preparation could cause infection. In these tests a number of animals or plants were inoculated, and the appearance of disease symptoms was used as an indication of the presence and transfer of virus. Attempts to make this method quantitative were successful only to the extent that tenfold differences could be detected. The inability to titrate accurately and to follow the major portion of the virus was a great handicap to the earlier workers. However, as a result of the discovery by Holmes in 1929 that tobacco-mosaic virus eaused local lesions on the leaves of certain plants about two days after inoculation and that the number of such lesions could be used as an 
index of the amount of virus applied, a very accurate method for estimating the concentration of this virus was developed. By means of this method differences in virus concentration of 10 per cent or greater can be detected without undue effort. The fact that tobacco-mosaic virus can be titrated accurately made possible the correlation of virus activity with the chemical and physical properties of the protein. This was of paramount importance, because the demonstration, beyond a reasonable doubt, that the virus preparations (or at least the major component in each of the preparations) actually consisted of virus, and the further consideration and the acceptance of the purified preparations as virus were directly dependent upon such work. Although much of the work done since the isolation of the purified virus preparations has been devoted to a study of this problem, there will be presented here briefly only the more significant results, most of which have been obtained with tobacco-mosaic virus. This virus has one of the widest host ranges known, for 46 different species of plants, representing 14 widely separated families, are susceptible to the mosaic disease. Although attempts to obtain purified preparations from all of these have not been made as yet, it is of considerable significance that virus preparations possessing essentially the same chemical, physical, and biological properties have been obtained from different batches of diseased Turkish tobacco, Burley tobacco, tomato, phlox, spinach, petunia, and nightshade plants. This is a definite indication that infection of widely different hosts with the same virus is followed by the production in these different hosts of the same nucleoprotein, a material which is characteristic not of the host but of the disease. The yield of nucleoprotein obtained was found to vary widely depending: upon the host, for Turkish tobacco plants gave a yield of 2 to $3 \mathrm{mg}$ of purified virus per ec of juice, tomato plants about $1 \mathrm{mg}$ per ec, and spinach and phlox plants considerably less than $1 \mathrm{mg}$ per ce. It should be noted that some of these plants, such as phlox and spinach, are far removed from the tobacco family. For example, no serological relationship was found by Chester between the protein from normal tobaceo plants and that from normal phlox plants. The fact that on infection these two different plants foster the production of the same virus is an indication that virus is not produced by the simple polymerization of serologically active normal proteins.

There is good evidence that viruses occasionally change or mutate during production in a host and give rise to new strains which may be isolated, grown, and studied apart from the parent virus. Many strains of tobacco-mosaic virus are recognized and to date 4 of these have been isolated in purified form. Preparations of strains of the same virus have been found to have somewhat similar general properties, yet it was found that it is possible to distinguish each of the 4 preparations by means of definite and characteristic chemical, physical, and serological properties. This finding is of considerable importance, for it indicates that when a virus changes or mutates, the change is accompanied by the formation of a new and slightly different nucleoprotein. Furthermore, the concentration reached in a given host was found to vary widely with the strain of virus. The amounts of the different purified viruses obtainable from a given quantity of starting material have also been found to vary widely. For example, some batches of badly diseased Turkish tobacco plants have been found to contain one part of virus per 200 parts of fresh green plant material, whereas Turkish tobacco plants diseased with cucumber-mosaic-1 virus contain only about one part per million as virus. Beard and Wyckoff obtained about one part of papilloma virus per five thousand parts of the starting material (based on the whole rabbit), and Northrop estimated that the crude culture of the staphylococcus with which he worked contained about one part per million as bacteriophage. It should be recognized, therefore, that the amount of virus occurring in a host may vary tremendously, depending 
upon the virus and the host, some viruses occurring in amounts as great as a part per 200 and others in amounts as small as a part per million, with the possibility that other viruses may occur in still smaller amounts. In those cases where it has been found impossible to isolate weighable amounts of virus, or to demonstrate the presence of virus by immunological reactions, it is possible that the virus was extremely unstable or existed in such great dilution that it escaped detection by means other than activity measurements. The purified preparations of the various viruses, such as latent mosaic, tobacco ring spot, bushy stunt of tomato, and the Shope rabbit papilloma viruses, and a staphylococcus bacteriophage, have been found to have quite different and highly characteristic chemical, physical, and serological properties. It may be concluded, therefore, that the different viruses, as well as the various strains of a given virus, reach widely different concentrations in their hosts, and that the respective purified preparations possess definite and highly characteristic chemical, physical, and serological properties which may be correlated with the biological or virus activity.

The purified viruses that have been isolated have been found to consist largely of protein which is susceptible to digestion with certain proteolytic enzymes and which may be denatured by appropriate treatment. In every instance so far studied, the digestion or denaturation of the protein has been accompanied by the loss of virus activity and, in general, the rate of digestion or of denaturation and the rate of loss of activity have paralleled each other, although in certain instances the inactivation reaction was somewhat the more rapid of the two. The studies have included denaturation by acid, alkali, heat, dodecyl sulfate, urea, etc. It should be noted that the purified preparations of the different viruses were found to be stable only over ecrtain ranges of hydrogen-ion concentration which were definite and characteristic for each virus. In most instances, at the same $\mathrm{pH}$ that caused loss of activity, there occurred a break-up of high-molecular-weight material that could be demonstrated by means of the analytical ultracentrifuge. It has also been found possible to inactivate some virus preparations, such as those of tobacco mosaic, cucumber mosaics 3 and 4, and latent mosaic, with nitrous acid, hydrogen peroxide, formaldehyde, or ultraviolet light without the accompanying gross change in properties that is usually referred to as denaturation. The general chemical, physical, and serological properties of the inactivated preparations are very similar to those of active preparations. For example, in the case of tobacco mosaic the preparation still consists of a highmolecular-weight nucleoprotein which may be crystallized and which reacts specifically with antiserum to active virus. Should it prove possible to inactivate a virus with but a very slight change in its makeup, it is possible that very sensitive chemical or physical tests might be necessary in order to detect the change. However, despite the great similarity in general properties, in every case yet studied it has been possible to demonstrate that the inactivation was accompanied by a measurable change in one or more of the chemical, physical, or serological properties of the preparation. In the treatment of tobacco-mosaic virus with formaldehyde, the inactivation was accompanied by a decrease in amino nitrogen as measured colorimetrically or by means of the Van Slyke gasometric method, and by a decrease in the color developed by Folin's phenol reagent. Of considerable importance in connection with the correlation of chemical with biologica! properties are the facts that it was found possible to reactivate the formolized virus, and to demonstrate that the reactivation was accompanied by an increase in amino nitrogen, as measured by the color developed with ninhydrin, and also by an increase in the color developed with the phenol reagent. This correlation indicates that the virus activity is a property of the nucleoprotein and provides information concerning the structure necessary for activity. The action of 36 per cent urea in $0.1 M$ 
phosphate buffer at pH 7 on tobacco-mosaic virus has been studied in detail, and the virus was found to be rapidly disintegrated into low-molecular-weight protein components free of mucleic acid, with loss of virus activity, serological specificity, and ability to show stream double refraction. The denaturation was accompanied by the appearance of sulfhydryl groups, as indicated by a positive nitroplusside reaction, and the low-molecular-weight protein which was formed was soluble in water but insoluble in $0.1 M$ or more concentrated salt solutions.

The fact that the virus preparations that have been isolated have consisted essentially of high-molecular-weight protein material has been utilized in still another type of experimental approach. The materials can be sedimented from solution by means of a high-speed centrifuge because of their unusually high molecular weight, and, since they are protein and have an isoelectric point, the sedimentation of negatively charged protein, of positively charged protein, and of neutral or uncharged protein can be studied. In the case of tobaccomosaic virus, it was found that regardless of the charge the protein and the agent carrying the virus activity sedimented at exactly the same rate. This is good evidence that the activity is a property of the protein, for, if the activity were due to a small amount of some material of a different size mixed with the protein, it is obvious that under one of the conditions cited the mixture would have been separated and the activity would not have been found with the high-molecular-weight protein. By the high-speed centrifugation of mixtures of tobacco-mosaic virus with egg albumin, globin, trypsin, or pepsin, it was found possible to separate the characteristic high-molecular-weight nucleoprotein with unchanged activity. Gratia and Manil obtained similar results with mixtures of tobacco-mosaic virus and a bacteriophage.

Neurath and Saum, using the refractometric method of Lamm, found the diffusion constant of chemically purified tobacco-mosaic virus to be about $3 \times 10^{-8}$ square em per second, and Frampton, using the same method, obtained a value of $2.1 \times$ $10^{-8}$ square em per second. The diffusion constant obtained by Hills and Vinson by means of the Northrop-Anson diffusion cell is probably far too large, since these workers did not use sufficient electrolyte to eliminate the accelerating effect of small ions on the virus. In most of their experiments, virus was permitted to diffuse from a dilute electrolyte solution into distilled water, and in the remaining experiments, from a trypsin solution into a trypsin-free solution. Purified preparations of tobaccomosaic virus have been subjected to a careful immunological study; when sufficiently purified it was not found possible to detect material other than the virus protein even by the sensitive precipitin and anaphylactic tests. Evidence of a different nature but also indicative of homogeneity was provided by the results obtained by means of the analytical ultracentrifuge and the electrophoresis apparatus, for in each case a single sharp boundary characteristic of a single molecular species was obtained. It was found impossible to separate virus activity from protein by filtration through collodion or other types of filters. The ultravioletlight-absorption spectrum of purified tobacco-mosaic virus preparations was found to agree essentially with the destruction spectrum of virus activity, thus indicating a close relationship between the two.

A great amount of experimental work on the purified virus preparations has already been completed, and an even larger volume is now in progress. Still more viruses are being obtained in purified form from time to time and ever-increasing amounts of the ones already purified are being made available for experimentation. In all of the work that has been reported to the present time, or that is known to me, not a single bit of experimental evidence has been obtained that is incompatible with the idea that the various purified and unaltered virus preparations, or at least their chief components, actually consist of the active agent. On the contrary, there is an imposing array of evidence which indicates 
that several of the viruses have been isolated in an essentially pure form, and that the biological activity is a specific property of the respective nucleoproteins. There is always the possibility that the virus materials may represent a unique situation and that there is something which has not been comprehended as yet. However, it seems to me that the time has arrived when it can be said that virus activity is a specific property of the nucleoproteins with essentially the same degree of assurance as when it is said that the properties of water are those of the water molecule or that the hormone properties of insulin belong to the protein molecule known as insulin. On the basis of information now available, therefore, it may be concluded, that the different nucleoproteins represent the respective viruses in essentially pure form. The chemical makeup of these active materials thus becomes of importance. Quantitative chemical analyses of several of the viruses have been completed and in general they contain about 50 per cent carbon, 7.5 per cent hydrogen, and 16 per cent nitrogen, together with a little sulfur and phosphorus. No lipoid or fat has been demonstrated in the smaller viruses or in the plant viruses, but it has always been found in purified preparations of vaccine and chicken-tumor viruses. Although much of the lipoid is removable, it has not been determined whether all of the lipoid can be removed without loss of virus activity. In the case of the chicken-tumor agent, attempts to remove the final 5 per cent of the lipoid resulted in inactivation. It is possible, therefore, that lipoid may represent an integral component of these viruses. MacFarlane and Salaman have reported that purified vaccine virus shows phosphatase and catalase activities but not dehydrogenase activity, and they consider that the enzymatic activities are specific properties of the virus. No other purified virus preparation has been reported to have such enzymatic activity. Rischkov found purified tobaccomosaic virus to have none of the ordinary enzymatic activities.

In the immediate future it is unlikely that studies on the composition of most of the viruses will consist of more than routine quantitative elementary chemical analyses, for at present most viruses are readily available only in amounts measurable in milligrams. However, there is no reason why the makeup of at least one typical virus, that of tobacco mosaic, should not be studied in great detail, for it is possible to obtain this virus nucleoprotein in $100-\mathrm{gm}$ lots withont undue effort. Preliminary studies have been completed, and to date the virus material has yielded on hydrolysis only amino acids and a nucleic acid of the yeast nucleic acid type. The amino acids that have been identified include arginine, aspartic acid, cysteine, glutamic acid, leucine, lysine, phenylalanine, proline, serine, tyrosine, and tryptophane. Histidine, alanine, and glycine are either absent or occur in amounts that have not been measurable as yet. Ross has found the glntamic acid to be the naturally occurring dextro-rotatory glutamic acid. This is of interest because of the striking demonstration by Kogel and Erxleben of the occurrence in cancerous tissue of glutamic and other amino acids having markedly lower optical rotations, which indicates the presence of the unnatural isomers. In view of the apparent dependence of insulin activity upon the presence of the disulfide linkage in the molecule, the distribution of sulfur in the tobacco-mosaic virus preparation was studied. Of the 0.24 per cent sulfur usually found, about 0.18 per cent occurs as cysteine sulfur and 0.04 per cent or less as sulfate sulfur. Although methionine determinations frequently yield results as high as 0.04 per cent methionine sulfur, the results are always somewhat lower following dialysis and it is doubtful if the material actually contains methionine.

Loring, in preliminary studies on the nature of tobacco-mosaic virus nucleic acid, demonstrated not only that the acid is a true nucleic acid by the isolation of guanine, adenine, cytosine, and uridylic acid but also that the acid differs in certain respects from all known uncleic acids. He found the diffusion constant of virus nu- 
cleic acid in $0.4 M$ borate buffer at $\mathrm{pH} 7.7$ to be 0.10 square $\mathrm{cm}$ per day, which on the basis of a spherical molecule would correspond to a molecular weight of about 37,000. The manner in which the protein and nucleic acid are combined in tobacco-mosaic virus is not known. However, the fact that the two are immediately split apart on treatment with 5 per cent sodium hydroxide at $0^{\circ} \mathrm{C}$, with 5 volumes of glacial acetic acid, with 36 per cent urea in 0.1 $M$ phosphate buffer at $\mathrm{pH} 8$, or on heating to $75^{\circ} \mathrm{C}$, and that a fairly rapid disintegration occurs with 0.5 per cent dodecyl sulfate at $\mathrm{pH} 8$ argues against the possibility that they are combined through stable chemical bonds. The fact that it has not yet been found possible to secure evidence for the dissociation of the two in the presence of various concentrations of salt, after the manner in which sperm nucleoproteins are dissociated, indicates that the linkage is different and is probably somewhat stronger than the usual salt bonds. It is possible that the linkage is a very weak ester or amide bond, or perhaps of the hydrogen bond type that is being postulated so freely at present in connection with protein structure. Bernal and Fankuchen first deduced from $\mathrm{X}$-ray data that tobacco-mosaic virus contained equal subunits about $22 \times 20 \times 20 \AA$ in size; and on the basis of X-ray work with nucleic acids, Astbury has suggested that this sub-unit, which would have a molecular weight of about 7000, must consist of one nucleotide combined with 54 amino acid residues. However, Ross has calculated from data on the amounts of some of the amino acids which occur in small amounts that if the virus is built up from similar repeat-units, the minimum molecular weight of this subunit must be of the order of 20,000 to 40,000 . This value is in accord with Bernal's more recent estimate of 40,000 and with results obtained by means of the analytical ultracentrifuge on alkali-dissociated virus and by means of osmotic pressure and diffusion determinations on virus dissociated in 36 per cent urea, all of which indicated a molecular weight of the order of 50,000. It should be emphasized that these sub-units cannot be regarded as virus, for they are not active. In the case of alkali degradation, evidence was obtained by means of the ultracentrifuge that the virus is first broken down into large inactive units, and these then continue to break up until eventually the small units are obtained. It has not been determined whether or not the large units still contain nucleic acid. It seems likely that a similar gradual breakdown occurs in the degradation of virus in concentrated urea solution, but it has not been demonstrated experimentally as yet, although such studies are in progress. The results indicate that the virus activity is not due to a dissociable prosthetic group, but rather to a unique architecture that is characteristic of the large molecule as a unit. Nucleic acid appears to play an important role in this structure, for it has been found in all of the viruses that have been purified. The nature of the combination appears to vary somewhat, for it has already been found that the nucleic acid is bound far more strongly in latent mosaic than in tobaceo mosaic virus. The elucidation of the intimate structure which is characteristic of viruses may appear hopeless in view of the complexity and differences already found. However, if they contain somewhat similar sub-units, a study of the various degradation products should yield information concerning the general nature of the sub-units, and although the elaboration of their detailed structure may not be achieved at an early date, it is possible that the manner in which they are combined to form the virus may be learned and with this the secret of the activity.

The fact that the addition of salts to solutions of tobacco mosaic virus may cause the nucleoprotein to come out of solution in the form of long, thin, solid, needle-shaped structures which are readily visible under the microscope and which have been regarded as crystals, and that the material could be crystallized repeatedly in a similar manner have attracted much attention. It should be noted, however, that crystalline 
form and the retention of constant properties following repeated crystallization have been used as eriteria of purity with such great success in the chemistry of inorganic and simple organic compounds that the layman has tended to place undue confidence in them. Henderson Smith has stated that there was "attached a kind of sanctity to the word 'crystal'" and that crystallinity "was a sort of a guarantee of purity." On the other hand, chemists, and especially protein chemists, who are familiar with the great tendency of proteins to form solid solutions and to carry along impurities on crystallization, have long recognized that while crystallinity and the retention of constant properties on repeated crystallization are very useful tests in the determination of the purity of a material, they are not infallible tests; they are less well suited for purity tests in the case of proteins, and most certainly they are not an absolute guarantee of purity. Nevertheless, following the announcement in 1935 of the "isolation of a crystalline protein possessing the properties of tobacco-mosaic virus," the fact that the material could be obtained in crystalline form was more instrumental than any other in securing the acceptance of the material as pure and as the virus, although to me and to many others it was perhaps the least convincing of the experimental evidence. The fact that the protein could be repeatedly crystallized with retention of constant properties was a more significant bit of evidence. The crystallinity of the protein also caused many individuals to decide that the virus was non-living because they considered it impossible for living organisms to take on a crystalline structure. However, crystallinity is simply a structural regularity and actually there need be no incompatibility between the living and the crystalline states. Nevertheless, if the protein had not been obtained in crystalline form, it is very probable that it would have been generally considered as a minute living organism somewhat similar to ordinary bacteria, because of the general conception of viruses as living organisms. The erystallinity was useful in that it focused attention on the other physical and chemical properties of the protein, and although some workers doubted that the virus activity was a property of the protein, the material was generally accepted as being composed essentially of large protein molecules. It should be emphasized that crystallinity, of itself, offers no evidences as to the living or nonliving nature of a material and is no absolute guarantee of purity, and that retention of constant properties following repeated crystallization should be regarded as merely one of a great many tests used to determine purity, any one of which may be fallible and all of which should be used before a decision regarding purity is reached. It has not been found possible to crystallize some of the unstable virus proteins, and it is likely that more viruses will be isolated which cannot be erystallized. In the cases of unstable viruses, the continual breakdown may provide sufficient impurity to prevent crystallization, and in other cases it is possible that pure preparations may be obtained which will fail to crystallize; hence failure to obtain a virus in crystalline form should not be considered as a definite indication of an impurity.

Tobacco-mosaic and its strains, aucuba, masked, and enation-mosaic viruses, the closely related cucumber-mosaic-3 and -4 viruses, tobacco-necrosis virus, and bushystunt-of-tomato virus have all been obtained in the form of crystals readily visible under the microscope. All of the first-named viruses were obtained in the form of long, thin, pointed needles, while the bushy-stunt virus was obtained in the form of rhombic dodecahedra, and the tobaceo-necrosis virus as thin plates. Latent-mosaic-of-potato virus has not been obtained in the form of distinet erystals, but the pellet obtained on high-speed centrifugation was found to be doubly refracting. When 1 to 2 per cent solutions of latent-mosaic virus or of tobaceo-mosaic virus or its strains are allowed to stand, they gradually separate out into two distinct layers, the lower of which is liquid crystalline. No purified viruses other than those mentioned above have been 
obtained in crystalline form to date. Bernal and Fankuchen made X-ray diffraction studies on oriented erystals and on solutions of virus preparations and found no difference between strains of latent-mosaic virus, and only doubtful ones in the case of the cucumber-mosaic-3 and -4 viruses. However, they foumd definite differences in intensity of the intermolecular pattern in the case of the strains of tobacco-mosaic virus, although the intramolecular pattern appeared to be the same. In every case the intramolecular pattern was found to be independent of the concentration of the virus while the intermolecular pattern varied continuously and quantitatively with the concentration. The intramolecular pattern of the bushy-stunt virus was found to be of essentially the same type as that of tobacco-mosaic virus, indicative of a repeat-unit of approximately $20 \times 20 \times 22$ A. Bernal came to the interesting conclusion that the individual molecules of tobacco-mosaic virus have an internal crystalline structure, that this structure is analogous to that of other crystalline proteins, and hence that each molecule may be regarded as a crystal. Although the beautiful dodecahedric crystals of bushy-stunt virus are regarded as true crystals, Bernal believes that the intermolecular pattern of crystalline tobacco-mosaic virus indicates the presence of long molecules arranged with a perfect hexagonal, 2-dimensional regularity at right angles to the length but with no regularity in the direction of the length. He is of the opinion that the solid needle-shaped particles which are visible under the microscope and which have been referred to as crystals have only this type of regularity and are therefore really in a liquid crystalline state and should be referred to as liquid or para-crystals. Wyckoff and Corey have also studied the X-ray diffraction pattern of crystalline tobacco-mosaic virus, and although they obtained essentially the same pattern as that reported later by Bernal, they interpreted it as resulting from true crystals.

Recently, Kausche reported that he had succeeded in preparing in vitro the hexa- gonal crystals of tobacco-mosaic virus which previously had been noted only within living cells. Beale had previously described the transformation of the hexagonal crystals within living cells into the needle crystals upon the addition of acid. Kausche reported that he had observed under the microscope the reversal of this phenomenon, namely, that bundles of the needle crystals fused together to form the hexagonal crystals. He considers that the molecules, the short and long fibers or filaments described by Best, the needle crystals, and the hexagonal crystals form an unbroken series. The preparation of the hexagonal crystals in vitro should make it possible to determine whether or not they are more complex in composition than the needle crystals, a possibility which was sugg'ested by Beale. Bernal has stated that the hexagonal erystals occurring within cells "possess end as well as side faces and undeniably show 3-dimensional regularity" and Bawden also considers them to be true crystals. However, Bernal and Bawden consider that the needle erystals are not true crystals and possess only a 2-dimensional regularity; hence, if the hexagonal crystals are formed from the needle erystals, a rather unusual realignment of the molecules must occur. It appears preferable to leave the question of the kind of crystallinity open for the present. Whether crystalline tobacco-mosaic virus possesses a 2- or 3-dimensional type of regularity is not important from the standpoint of the virus worker, even though it may be quite important to the crystallographer, for, as mentioned above, crystallinity is not a vital issue with respect to either the purity or the nature of viruses, and regardless of the final decision the general virus problem will remain unchanged.

In most of the work on the estimation of the sizes of viruses, it has been tacitly assumed that the virus particles were essentially spherical in shape. Recently, however, Lauffer and I demonstrated that some viruses are very asymmetrical in shape. The earliest indication of the asymmetry of a virus was obtained by Takahashi and 
Rawlins, who noted that double refraction of flow was exhibited by the juics from a plant diseased with tobacco-mosaic virus but not by the juice from normal plants. In view of Freundlich's work on the vanadium pentoxide sols and because of the nature of the double refraction of flow, they concluded that tobacco-mosaic virus or some material regularly associated with it was composed of rod-shaped particles. Since that time, and following the isolation of the virus in purified form, an imposing mass of evidence has been obtained, chiefly by Lauffer, that tobacco-mosaic virus consists of molecules having a cross section of about $12 \mathrm{~m} \mu$ and a length of the order of 400 $m \mu$. The strains of tobacco-mosaic virus, the related cucumber-mosaic-3 and -4 viruses, and latent-mosaic-of-potato virus have also been found to have similar rodlike shapes. Tobacco-ring-spot, rabbitpapilloma, vaccinia, and bushy-stunt-oftomato viruses have not been found to show double refraction of flow and hence probably liave relatively symmetrical shapes.

An interesting phenomenon shown by viruses having a very asymmetric shape and apparently directly dependent upon a rodlike shape, is the formation of two distinct layers when rather concentrated solutions of sucl viruses are allowed to stand. The line of demarcation is very sharp and gradually rises with time. The upper layer is the more dilute and shows double refraction only when caused to flow, whereas the lower layer is the more concentrated and is spontaneously doubly refracting. The lower layer appears to result when the rod-shaped virus molecules become sufficiently concentrated so that they lose their ability to rotate about their two shorter axes, and appears to consist, therefore of a 3-dimensional mosaic of regions arranged at random to each other but in each of which all of the molecules lie approximately parallel. The phenomenon appears to be quite analogous to that first reported by Zocher and Jacobsoln for vanadium pentoxide sols. Lauffer concluded that the lower layer represents a special case of double refraction because it has no extinction direction. He found that the double refraction exhibited by tobacco-mosaic virus is due largely, if not entirely, to the shape of the particles, and scarcely, if at all, to intrinsic double refraction.

The marked asymmetry of some of the viruses has thrown doubt upon sizes estimated from ultrafiltration, ultracentrifugation, and diffusion data, since few studies have been made on the manner in which rod-shaped particles filter, sediment, or diffuse. Frampton has stressed the facts that certain moderately concentrated solutions of tobacco-mosaic virus do not obey $\mathrm{Po}$ isenill's and Fick's laws, and that even dilute solutions exhibit anomalous viscosity. $\mathrm{He}$ interprets these results as being due to inter-particle attraction and considers that molecular weight values calculated from sedimentation, diffusion, and viscosity data are wholly ambiguous. Although it is generally accepted that in moderately concentrated solutions inter-particle forces are present which are sufficiently strong to influence the rates of sedimentation, diffusion, and viscous flow, there appears to be little justification for assuming such an extreme viewpoint; the data from which molecular weight values were calculated were obtained with dilute solutions, and there is much evidence which indicates that these forces are negligible in dilute solutions. Furthermore, Robinson recently showed that even the anomalous viscosity exhibited by dilute solutions may be explained without reference to inter-particle attraction. It may be concluded, therefore, that even in the case of asymmetrical viruses such physico-chemical data may be used with considerable justification in the calculation of molecular weights. In the case of tobacco-mosaic virus, Lauffer has shown that different methods of estimating molecular weight from viscosity, sedimentation, and diffusion data, one of which is independent of assumptions concerning the shape of the particles, give values that agree closely. The cross section of the molecule, calculated from the length to width ratio of $35: 1$ which was obtained 
from viscosity studies and from the molecular weight of about $50 \times 10^{6}$, is $12.3 \mathrm{~m} \mu$, which is in agreement with the results of ultrafiltration, if it be assumed that the width of the particle represents the limiting dimension. This value for the cross section is approximately the same as that of $15.2 \mathrm{~m} \mu$ suggested by Bernal on the basis of X-ray data and that of $12.5 \mathrm{~m} \mu$ suggested by Langmuir and Schaefer as a result of studies on monolayers of the virus. Lauffer's general conclusions regarding size and shape of the particles of tobacco-mosaic virus were confirmed recently, when by direct observation by means of the electron microscope, Kausche, Pfankuch and Ruska found that most of the particles in a dilute solution of a chemically prepared sample were about $330 \mathrm{~m} \mu$ in length and about 12 to $15 \mathrm{~m} \mu$ in cross section.

Bawden and Pirie found that the purification of tobacco-mosaic virus by chemical means resulted in a loss in activity and filterability and an increase in stream double refraction, and concluded that the purification had caused an aggregation of the virus. Similar results have been reported in the cases of other viruses, and as a result there has been a tendency on the part of virus workers to assume that purification as such must invariably cause aggregation of virus and hence that it is impossible to isolate virus in an unaltered condition. The question of the aggregation of tobacco-mosaic virus was studied by the writer with Loring and Lauffer, and it was found that virus purified by rapid chemical treatment in the cold, or preferably by means of ultracentrifugation in the cold, was entirely comparable to the virus in untreated juice with respect to specific activity, filterability, and stream double refraction. However, merely allowing such purified virus to stand for a short time at room temperature and in the presence of low concentrations of salt was sufficient to cause aggregation. Similar results have been obtained with latent-mosaic and tobacco-ring-spot viruses. It should be recognized, therefore, that although viruses may be aggregated readily by chemi- cal treatment and most of the chemically purified virus preparations that have been isolated have consisted of aggregated virus, it is possible nevertheless to isolate tobacco-mosaic virus which is comparable to virus in unpurified preparations and which resembles it in specific activity, filterability, and stream double refraction.

The occasional suggestions that in untreated juice tobacco-mosaic virus consists of small units, or that active low-molecularweight material may be produced following a given treatment, are not in accord with results obtained in the writer's laboratory. If active low-molecular-weight material existed, it would not be possible to sediment the active units in a centrifuge at a speed at which other low-molecular-weight material, such as hemoglobin, fails to sediment. However, it is an experimental fact that when untreated juice or preparations which are supposed to contain low-molecular-weight active material are mixed with hemoglobin and centrifuged at a speed which will sediment ordinary tobaccomosaic virus but not hemoglobin, the virus activity is found in the sediment and not with the unsedimented hemoglobin in the supernatant liquid. This is good evidence that virus in untreated juice does not consist of low-molecular-weight material. Similar results have been obtained by Hughes, Pickels and Horsfall in a study on the differential centrifugation of proteins. These workers demonstrated that hemocyanin can be separated from egg albumin and that yellow-fever virus can be separated from serum protein without any difficulty by means of differential centrifugation. It may be concluded that to date there has been no convincing demonstration of the existence or production of lowmolecular-weight material carrying virus activity.

The isolation of several of the viruses in the form of high-molecular-weight proteins, and the demonstration beyond a reasonable doubt that the preparations are essentially pure and that virus activity is a specific property of the proteins, necessitate a consideration of virus activity in terms of these 
materials. The viruses vary in composition from the amino and nucleic acids of tobacco-mosaic and tobacco-ring-spot viruses to the amino acids, nucleic acid, carbohydrate, and lipoid that go to make up vaccine virus. Despite the variation in composition and size, there is no reason to believe that viruses differ among themselves in any fundamental respect, or that there is other than a continuity of structure from small to large viruses. All viruses have in common the ability to reproduce or multiply when placed within susceptible living cells, and since no virus has been found to multiply under any other conditions, they may be considered obligate parasites. The manner in which viruses multiply has been, and remains, a matter of much conjecture. In the case of phage, Northrop considers that multiplication can be more simply explained by analogy with the autocatalytic formation of pepsin and trypsin than by analogy with the far more complicated system of living organisms. This seems a reasonable attitude, especially in view of Krueger's evidence for the existence of an inactive precursor or pro-phage. However, many difficulties become apparent when this viewpoint is adopted for viruses in general, for no evidence has been obtained for the existence of inactive precursors having chemical properties similar to those of the viruses, no virus has been produced de novo or in the absence of living cells, and a multiplicity of precursors must be postulated, since a given host cell is capable of producing any one of hundreds of different viruses or virus strains.

Nevertheless, it is quite possible that the basic idea of catalysis may be correct with respect to virus activity. Bergmann has shown experimentally that a catalyst, a protein enzyme, can cause the formation or synthesis of a peptide linkage. There is every reason to believe that proteins are produced through the formation of peptide linkages; hence, it is but a step to consider that proteins may result from the eatalytic action of still other proteins, and but another step to consider that a protein may catalyze reactions resulting in the forma- tion of replicas of itself. The latter protein, catalyzing such reactions within a cell, would conform, of course, to our definition of a virus. The virus reaction may, therefore, resemble the pepsin and trypsin activation reactions and the reaction postulated for phage, except that the virus reaction is far more complicated, requiring not one but a series of reactions and special conditions which so far have not been reproduced outside of a cell.

The introduction of a virus most certainly diverts the normal metabolic activity of a cell, yet the influence of the virus might be likened to that of agents already present which direct normal metabolism, except that the virus exerts a dominating influence. The mechanism by means of which virus is synthesized within a diseased cell must be very similar to that by means of which normal proteins and constituents are synthesized within a normal cell. Levaditi has suggested that in the case of a virus-infected cell the "constructive" factor of the virus superimposes itself and dominates the normal factor. Similar ideas have been advanced in the writings of other workers, especially when cancerous cells were under consideration. In some instances the loss of a factor rather than the addition of one has been postulated. One great point of difference is that in the case of the virus reaction the "key" to the disrupted metabolism, the virus, can be separated, isolated in pure form, and studied apart from the system, whereas in the cases of normal cells or of cancerous cells similar "keys" have not been found separable as yet. The "key or keys" must be contained within the chromosome and probably are represented by genes or gene derivatives, and therefore may be nucleoproteins. The fact that all viruses so far isolated have been found to consist of nucleoprotein or to contain it may be of special significance, and the possibility that they may have been derived from genes or nuclear material has been considered from time to time by different writers. Although it is quite possible that viruses may have arisen originally in such an en- 
dogenous manner, it should be emphasized that it is recognized today that virus activity results only from the introduction of virus from without. There is, however, a strong and growing tendency to consider that viruses or similar factors may, upon provocation of the cell, originate endogenously and give rise to tumors or cancer's. Whether such viruses are actually derived from normal cell constituents or are formed by the mutation of a "masked" virus which is normally or usnally carried within the cell, but which in reality is alien to the eell, is not known. The probability that the synthesis of viruses does not differ fundamentally from the synthesis of normal proteins within cells, and the faet that, although viruses may be removed and studied apart, they nevertheless possess most of the properties of living organisms, cause the attack on the nature and mode of aetion of viruses to become of signal importance, for it is in reality an attack not only on the problems of abnormal and normal metabolism, but also on the nature of life. The difficulties, diseussed by Bohr, which are involved in making studies of the living state without affecting conditions by the rery aet of study, are lessened in the case of viruses, since they may be removed from cells, subjected to various studies, and then reintroduced into cells without measurably affecting them. This property of suspended animation is unique with viruses and is possessed by no other entity to a similar degree, for the same difference that exists between viruses and ordinary living organisms must exist between viruses and the seeds or spores that are usually cited as examples of suspended animation. This and other preeeding statements are necessarily limited by one's understanding of the nature of the difference between viruses and living organisms, hence this question will be considered.

The ehemist, after a perusal of the properties of the purified viruses that have been isolated and adequately studied, has no difficulty in coming to the conclusion that they are protein moleeules. They merit the term molecule becanse, despite many attempts, it has not been found possible to sub-divide the large units without the loss of virus activity. The ehemical and physical propertics are admittedly those to be expected of large protein molecules, and the chemist, well acquainted with the eatalytic synthesis of a peptide bond and the autocatalytic formation in vitro of the pepsin and tryspin proteins, views virus activity as but a logical and not unexpected extension of the expression of chemical structure. True, the duplication of conditions necessary for the expression of virus activity in vitro has not yet been accomplished, and but little has been done with the large and complex viruses such as vaccine virus, but the chemist, seeure in the knowledge already gained, considers that such problems lend themselves to experimentation and looks forward with confidence to their eventual solution.

On the other hand, the pathologist and biologist, long interested in the expression of virus activity and its results, have considered viruses to be small living organisms. Reeently, however, there has been a tendeney on the part of some of these workers to aceept the view that some or all viruses may be something other than living organisms. Rivers has suggested that the large viruses may be small living organisms, the middle-sized viruses representatives of an unknown form of life, and the small viruses non-living agents, but that it is impossible to draw lines dividing the groups and that very probably one group shades off into its neighbors. Rivers appears to believe, therefore, that although the large differ from the small viruses, they nevertheless form a continuum from small non-living to large living viruses. Green and others have suggested that viruses are simplified fragments of living protoplasm which arise from organisms by a process of retrograde evolution under parasitism, involving loss of function and associated substance, and that this process may result in forms varying from a single colloidal molecule to entities almost indis- 
tinguishable from ordinary living organisms. Laidlaw has presented a similar view and has assembled much evidence in its support. Doerr has just published a masterly discussion of the nature of viruses and bacteriophages in which he has presented and evaluated the ideas held by different workers. He points out that the large viruses are similar to the small viruses in all important respects, that there is no reason for attempting to separate them on the basis of size, and that, furthermore, no fundamental difference between viruses and living organisms has been demonstrated. In Doerr's opinion, the chief point of issue is whether non-living infectious agents should be accepted along with living infectious entities, or the smallest virus accepted as a living agent, and after a thorough discussion he tends to resolve the conflict in favor of the acceptance of viruses as living even though they may consist of a protein molecule. The pathologist has been able to rationalize his knowledge of viruses with his knowledge of living organisms so that he is willing to accept the smallest virus, even though a large nucleoprotein molecule, and the largest living organism, as representatives of a common series in which there is a definite but almost imperceptible gradation of substance and of complexity of function.

We come, therefore, to the interesting situation where the pathologist and the chemist have a common meeting ground, a territory never before accessible with certainty. Needham has argued the necessity of a bridge between morphology and biochemistry, and the essence of this bridge now appears to have been achieved between pathology and chemistry. The chemist, always interested in atoms and molecules, has recently extended his knowledge in two directions. At one extreme, nuclear chemistry has achieved the transmutation of elements and at the present time is pushing vigorously ahead with studies on the manner in which the protons and electrons that make up the atoms are arranged and on ways and means of breaking up large and complex structures into simpler ones. Instead of being homogeneous, the atoms appear to consist of a virtual maze of discontinuities, but are nevertheless in perfect order, as shown by the formation of a barium atom during the disintegration of a large uranium atom. At the other extreme, the chemist has found the virus proteins, molecules larger than those ever known before. However, the chemist realizes that just as the chemical, biological, and physical properties of ordinary molecules are a direct result of their structure, so too must the properties of atoms and of the viruses be a direct result of their structure. This structure, whether evidenced by the proton and electron of the hydrogen atom, by the atoms of the water molecule, or by the units combined to make up a virus, must be fundamentally the same. The recognition of the essential identity of the structure of entities, regardless of their nature, that is, of structure as a continuum from smallest to largest, is of fundamental importance. Although recognizing the significance and importance of structure, many have been led astray because of attempts to separate the living from the non-living on the basis of certain characteristics, not realizing that, as has been stated many times before, the word "life" is merely a definition of degree. Attempts to arrive at a definite line of division have resulted in failure in the past and appear doomed to a similar fate in the future. Fortunately, the classification of an entity as living or non-living, or as a cell or a molecule, is of little or no importance, whereas the complete realization of the expression inherent ir structure is of tremendous importance.

I expressed the view two years ago that from the standpoint of structure there is no reason why a single structural entity, which we call a molecule, should not be larger than the ordered group of structural entities which we call a cell. The overlapping of structure in the case of atoms is well known, and the recent demonstration of the formation of barium and other atoms from a single uranium atom brings it even more forcibly to attention. A similar situ- 
ation may prevail at the other extreme of size. Neither the cell nor the atomic theory should be handicapped by a reference to the living state, but should be utilized only to define certain accepted orders of structure. It should also be recognized that there may be such a gradual transition between these accepted orders of structure that the designation of intervening entities as molecules or as cells becomes one merely of personal preference. The nature of the bonds between units within cells, as well as the nature of the bonds which hold together the large nucleoproteins, requires much more investigation before they can be completely understood. However, at the present time there is no reason to believe that they differ in any fundamental respect from the forces already known to exist in atoms and molecules. We must, therefore, recognize a continuous series of structures ranging from atoms and molecules, through the viruses to living organisms. The secret of life is not bound up exclusively with the latter, for although I quite agree with the statement that Conklin made in the first paper that there is life in organization, I do not think that organization, that life, suddenly disappears below the cell. A hydrogen atom represents organization, a protein molecule tremendous organization, and in man a still higher degree of organization is represented. The expression of the structure or organization encountered in man is, in reality, but little more surprising or mysterious than that encountered in atoms and molecules.

Consider the vast array of expressions involved in going from carbon and hydrogen atoms, two pairs of which may form the gas acetylene, to the related molecules of benzene, napthalene, anthracene, dibenzanthracene, the carcinogenic hydrocarbons, the sex hormones, ergosterol, vitamin $\mathrm{D}$ and perhaps those interesting materials which Dr. Harrison mentioned, the mammalian organizers. These are not complicated structures, for their molecular weights are less than 500 , yet they exhibit an amazing range of activities. It is not surprising that this range should be widened in the case of proteins, whose molecular or particle weights are measured not in hundreds but in thousands and in millions, to include activitics that are indistinguishable from those which have been regarded as characterizing living organisms. There is, therefore, a continuum from what have been ealled living organisms to what have been called molecules. We should recognize that both may, in fact, be regarded either as organisms or as molecules, that they differ only in the degree of organization, and that the terms living and non-living may be applied only to entities at the two extremes, in much the same way that the terms acid and alkaline are used to describe hydrogen-ion concentration. No difficulty is encountered so long as the degree of life, or of inanimateness, or of acidity or of alkalinity is sufficiently great, but in each instance there is an intermediate zone where it becomes impossible to effect an exact definition based on such terms without the use of some arbitrary point of division. With the realization that there is no definite boundary between the living and the nonliving, it becomes possible to blend the atomic theory, the germ theory, and the cell theory into a unified philosophy, the essence of which is structure or architecture. The chemical, biological, and physical properties of matter, whether atoms, molecules, germs, or cells, are directly dependent upon the chemical structure of the matter, and the results of the work with viruses have permitted the conclusion that this structure is fundamentally the same regardless of its occurrence. 


\section{STRUCTURE AND FUNCTION OF SOME ENZYMES}

\section{By HUGO THEORELL}

BIOCHEMICAL DIVISION, THE NOBEL INSTITUTE FOR MEDICINE, STOCKHOLM, SWEDEN

SoMewhat more than 100 years ago, 1836 , the Swedish chemist Berzelius originated the concept of catalysis and pointed out that the catalytic reactions, which were beginning at that time to be recognized in inorganic chemistry, must be similar in principle to the chemical reactions in the living cells. This theory of Berzelius has later been fully confirmed by the work of several scientists, as Tamman, Arrhenius, Henri, Michaelis, Hopkins, Wieland, and v. Euler, but first and foremost by Warburg. The analogy between inorganic eatalysis and enzymatic eatalysis is evident from the fact that in most cases the catalyst, as well as the enzyme, exerts its action by means of circle reactions, the enzymes forming reversible compounds, i.e., being oxidized and reduced alternately.

The name "enzyme" is due to Kühne. He and others, as Payen, Persoz, Schwann, and Buchner, recognized that the reactions in the cells are performed by substances produced by the living cells, but not living themselves. Our knowledge about the chemical nature and function of enzymes is, however, of a much more recent date. The prerequisite for any deeper knowledge about the chemical nature of any substance is its preparation in a pure state. The first enzyme obtained in this form was urease, which was crystallized by J. B. Sumner in 1926. This important step solved one of the questions about the enzymes insofar as it proved this enzyme to be a protein. The extensive work of J. H. Northrop and his co-workers on the proteolytic enzymes demonstrated the protein nature of this important group of enzymes. It may seem nearly superfluous to point out the protein nature of enzymes today, since nobody has any doubt on that point; but the demonstration of the protein nature of enzymes was a very important advance, considering the fact that in the same year of 1926 when Sumner crystallized urease, the German chemist Willstätter, in a lecture given in the "Deutsche chemische Gesellschaft," drew the conclusions from his extensive work on enzymes that they could be neither carbohydrates nor proteins, and that the enzyme activity is due to some unknown natural force. However, since that very time, it has become evident that enzymes are proteins nevertheless, and, furthermore, that no new sort of natural force is involved in their activity. We are today convinced that enzymes perform chemical reactions of essentially the same kind as those which we know in organic chemistry. However, only for some of the oxidation enzymes are we able to give a picture of their action by means of chemical formulas. This is at present not the case for the hydrolytic enzymes. The difference depends upon the fact that we have found in the former, but not in latter, so-called prosthetic groups. This low-molecular part of the enzyme molecule can be regarded as the seat of the enzymatic action, because the circle reactions take place there. The ferments which contain heavy metals carry a stream of electrons by means of the metal atom which oscillates between two different oxidation levels, such as ferrous $\rightleftarrows$ ferric, or cuprous $\rightleftarrows$ cupric. The metal-free oxidation enzymes carry a stream of hydrogen from the substrates toward the oxygen by means of their ability to oscillate between the reduced and the oxidized state, their prosthetic groups (flavin compounds or nicotinic acid amide compounds or others) taking up and giving off hydrogen in the same way that well-known dyestuffs form leuco-compounds with hydrogen, and may be oxidized again. The protein part of the oxidation enzymes has the function of differentiating the prosthetic group for its special purpose. Thus the same prosthetic group may occur in enzymes of very different functions, such as hemin in the respiratory pigment of Warburg, the cytochromes, the catalases, 
and the peroxidases. Alloxazin or riboflavin compounds oceur as prosthetic groups in another series of enzymes, some of them differing from one another only with respect to their protein parts. The substrate of the ferment is determined by the protein part, the general manner of action by the prosthetic group. A flavin enzyme always carries hydrogen, and a hemin ferment in most cases carries electrons, whatever the substrate may be. It is obvious that the interaction between the prosthetic group and the protein part of the enzymes is a question of the greatest importance, and therefore I will explain something about our present knowledge of three different classes of enzymes with respect to this particular point of view, namely the proteolytic enzymes, the hemin ferments, and the flavin enzymes.

The hydrolytic enzymes have the ability of loosening the linkages between carbon and oxygen in the polysaccharides, or carbon and nitrogen in the peptide linkages. Their special function is to break down the foodstuffs in order to facilitate their absorption from the intestine and to make it possible for the cells to build up new substances. These reactions do not deliver any energy. The oxidation enzymes on the contrary loosen the linkages between earbon and carbon, thus delivering the energy necessary for life.

\section{Proteolytic Enzymes}

A great many proteolytic enzymes have been crystallized-pepsin, pepsinogen, chymotrypsinogen, chymotrypsin, $\beta$ - and $\gamma-$ chymotrypsin, trypsinogen, trypsin inhibitor, carboxypeptidase, ficase, and papain. Of course further investigation was needed to prove that the crystals really were the enzymes themselves: there was a certain possibility that the enzymes were only some small part of the material, adsorbed to inactive protein erystals. However, all attempts to separate the enzyme activity from the crystallized proteins have been unsuceessful. Ultracentrifugation, electrophoresis, and diffusion experiments showed, on the whole, identity between protein and activity. The solubility in strong ammonium sulfate solutions, which is a very sensitive test for the homogeneity of proteins, indieated homogeneity for at least some of the preparations. Irradiation with ultraviolet light destroyed the activity in proportion to the light absorption coefficient of the proteins at different wave-lengths, and recrystallization showed no influence on the absolute activity of the crystalline enzymes. The most probable conclusion must be that the crystallized proteins with hydrolytic activity really are the enzymes themselves.

The molecular weight of the enzymes is high, for pepsin, 35,000. It seems unbelievable to me that every atom of this big molecule could be of equal importanee, each taking part directly in the hydrolysis of the substrate. From analogy with the oxidation enzymes one should expect even the proteolytic enzymes to contain a prosthetic group, which goes through some eircle of chemical reactions, i.e., taking up and giving off hydrogen and hydroxyl ions. As a matter of fact, we have no sufficient evidence against such an assumption. I may recall to your mind that no single highmolecular protein hitherto has been completely analyzed with respect to its content of the various known amino acids. Let us take an example: even if we could account for 99 per cent of the amino acid composition of pepsin, which is certainly far from the truth, there would still be space for a prosthetic group of the molecular weight of 350 . The absence of particular light absorption in the ultraviolet, besides the usual protein spectrum, cannot show the absence of a prosthetic group. Furthermore, all attempts to cleave the proteolytic enzymes reversibly (in analogy with the yellow oxidation enzymes) have failed, which proves only that the linkage between the prosthetic group and the protein may be stronger than the petide linkages; and the same is true about one of the oxidation enzymes, namely, eytochrome-c. I will not especially argue in favor of some prosthetic group being present in the hydrolytic enzymes. ${ }^{1}$ I only point out that this possibility should still be kept in mind.

1 The words "enzyme" and "ferment" formerly were used for two slightly different kinds of 
On the whole, we must admit that the isolation of the most important hydrolytic enzymes in a crystalline state has not yet brought us any knowledge about the chemical mechanism of their action. And it is probably not possible to clear up these questions before we know much more about the structure of the protein molecule, the thermodynamics of the peptide linkages, the protein synthesis in the living cells, and last, but not least, the accurate amino acid composition of protein.

\section{The Hemin Ferments}

Two metals have hitherto been known as forming ferments with proteins, namely iron and copper. The iron first forms compounds with porphyrins, and the iron-porphyrins are then linked to protein to form ferments, in which the iron may be regarded as the "active" group and the iron-porphyrin as the prosthetic group. In the copper ferments no porphyrin is present; the copper atom is both the "active" and the "prosthetic" group.

We have been especially interested in the iron-porphyrin ferments, because they seem able to give more general information on the interaction between "active" group, "prosthetic" group, and protein. The ironporphyrin ferments known to date are the following: (a) Warburg's respiratory ferment, $(b)$ the cytochromes- $a,-b$ and $-c,(c)$ the catalases, and $(d)$ the peroxidases.

If we add hemoglobin and myoglobin, which from some points of view could be regarded as ferments just as well as the other compounds, we shall find that the properties of the iron atom, which is the "active group" in each one, have been strongly modified under the influence of various porphyrins and proteins. Some

eatalysts. The enzymes were those which eould be extracted without losing their activity, while ferments were those which could not be separated from the structure of cells without being destroyed. There is little reason for maintaining this difference now, since it turns out to be merely a technical question whether or not it is possible to extract the catalysts. Furthermore, even some of those which have been successfully extracted are surely linked to the cell structure under physiological conditions. may add oxygen or carbon monoxide, as Warburg's respiratory ferment is supposed to do, or make very rapid oscillations between the ferrous and the ferric state at a suitable potential level, as in the cytochromes, in catalase, in Warburg's respiratory ferment, and probably in the peroxidases in certain cases. Warburg's ferment and the cytochromes- $a$ and $-b$ are not yet accessible for preparative purification, as they cannot be extracted, and so at present only cytochrome-c from beef heart, some catalases, and some peroxidases have been prepared in a more or less purified form.

Cytochrome-c, as well as the other cytochromes, was discovered by Mac Munn in the years 1886 to 1889 . In spectroscopic studies of different tissues, such as muscles, he saw some absorption bands which he believed could not possibly be due to hemoglobin. He recognized the bands as belonging to hematin compounds which are of importance for tissue respiration, and even succeeded in extracting part of his "histohematin" or "myohematin" in the form of "modified myohematin," which, as we now can conclude, must have been some impure cytochrome-c. Mac Munn was attacked by Hoppe-Seyler and Levy, who declared his new substances to be only hemoglobin, and so his discovery was forgotten for 40 years, until Keilin, in 1925, rediscovered these substances and demonstrated their general distribution in the living cells, their important function in tissue respiration, and their composition as three different types of hemochromogens, the cytochromes- $a,-b$, and $-c$.

We obtained eytochrome-c in Stockholm in 1935 in a highly purified form, and even thought it was definitely pure, because it had the same iron content as hemoglobin, 0.34 per cent. Keilin and Hartree confirmed our view two years later, aftel. reaching the same degree of purity by sevcral different methods. However, some months ago we reinvestigated the preparations by means of Tiselius' electrophoretic method and were able to remove some colorless impurities, so that the iron content in- 
ereased to 0.43 per cent. We have some reasons to think that these preparations are definitely pure. The analytical data do not differ very much from those of any common protein (52.5 per cent $\mathrm{C}, 7.76$ per cent $\mathrm{H}$, 16.66 per cent $\mathrm{N}, 1.5$ per cent $\mathrm{S}=6$ atoms per mol., 0.43 per cent $\mathrm{Fe}=1$ atom per mol.). The molecular weight is 13,000 . transformed reversibly one into another, giving dissociation curves, which enabled us to measure the dissociation constants spectrophotometrically. Ferrocytochrome-c, on the contrary, at any $\mathrm{pH}$ value shows the typical, two-banded spectrum, 550 and 520 $\mathrm{m} \mu$. Some of the results with ferricytochrome are given in Table 1.

TABLE 1

\begin{tabular}{|c|c|c|c|c|}
\hline Type & $\begin{array}{l}\text { Dissociation } \\
\text { constant }\end{array}$ & Bands, $\mathrm{m}_{\mu}$ & Color & $\begin{array}{l}\text { Molal magnetic } \\
\text { susceptibility }\end{array}$ \\
\hline $\begin{array}{r}\text { I } \\
\text { II } \\
\text { III } \\
\text { IV } \\
\mathrm{V}\end{array}$ & $\begin{array}{l}\text { I-II : } 0,44 \\
\text { II-III : } 2,5 \\
\text { III-IV : } 9,5 \\
\text { IV-V : } 12,7\end{array}$ & $\begin{array}{l}637,535,507 \\
623,525 \\
695,(560), 530 \\
(560), 507-545 \\
570,530\end{array}$ & $\begin{array}{l}\text { Brown } \\
\text { Reddish brown } \\
\text { Brownish red } \\
\text { Red } \\
\text { Brownish red }\end{array}$ & $\begin{array}{l}14 \text { to } 15,000 \\
11,000 \\
3,000 \\
\text { " } \\
\text { " }\end{array}$ \\
\hline
\end{tabular}

Cytochrome-c shows some striking features. It gives no addition compounds witl oxygen, carbon monoxide, hydrogen cyanide, fluoride, or azide around the neutral point, which indicates that the iron atom of the hemin is blocked by some strongly linked groups of the cytochrome molecule itself. Furthermore, there is another strong linkage between the protein part and the porphyrin, because unlike hemoglobin, cytochrome-c cannot be split up into hemin and protein by means of acetone and hydrochloric acid. As a matter of fact, no less drastic treatment than hydrobromic acid in glacial acetic acid will liberate the porphyrin from the residues of the protein component. Now eytochrome-c has an amazing property that has made it possible for us to find out a great deal about its constitution. It is probably the most "pH-stable" protein yet known. Neither normal hydrochloric acid nor normal sodium hydroxide destroys it, at least for a reasonably short time at room temperature. Therefore, it has been possible to study its spectral behavior, its magnetic susceptibility, and its formation of compounds with $\mathrm{CO}, \mathrm{HCN}$, and fluoride in acid or alkaline solutions.

It was found that ferricytochrome-c forms not less than five spectroscopically different compounds, depending on the $\mathrm{pH}$ of the solutions. By changing the $\mathrm{pH}$ they are
The spectral behavior of ferricytochrome may be explained on the assumption that the hemochromogen-forming basic groups are primary amino groups, probably belonging to the protein component. The five different spectral types then should correspond to the following constitutional types :

At physiological hydrogen-ion concentrations ferricytochrome-c occurs exclusively as type III, which does not give any compounds with azide, fluoride, or cyanide. Under the same conditions ferrocytochrome-c gives no addition compounds with oxygen or carbon monoxide. This means that the six valencies of the iron atom are here so firmly occupied by the six nitrogenatoms that none of the compounds mentioned can replace any of the nitrogenatoms. There may also be a sort of steric hindrance, if we postulate the flat, discshaped haem molecule to be inserted into a crevice of the protein molecule:

It will be seen from the formula of cytochrome-c, that the haem is connected with the protein in a twofold manner, the ironatom by means of amino groups and the a-atoms of the side chains in the 2-and 4-positions by means of very stable ether linkages. $^{2}$ These latter linkages are the cause of the high stability of cytochrome-c

2 Possibly thio-ether linkages with cysteine sulphur (Theorell). 


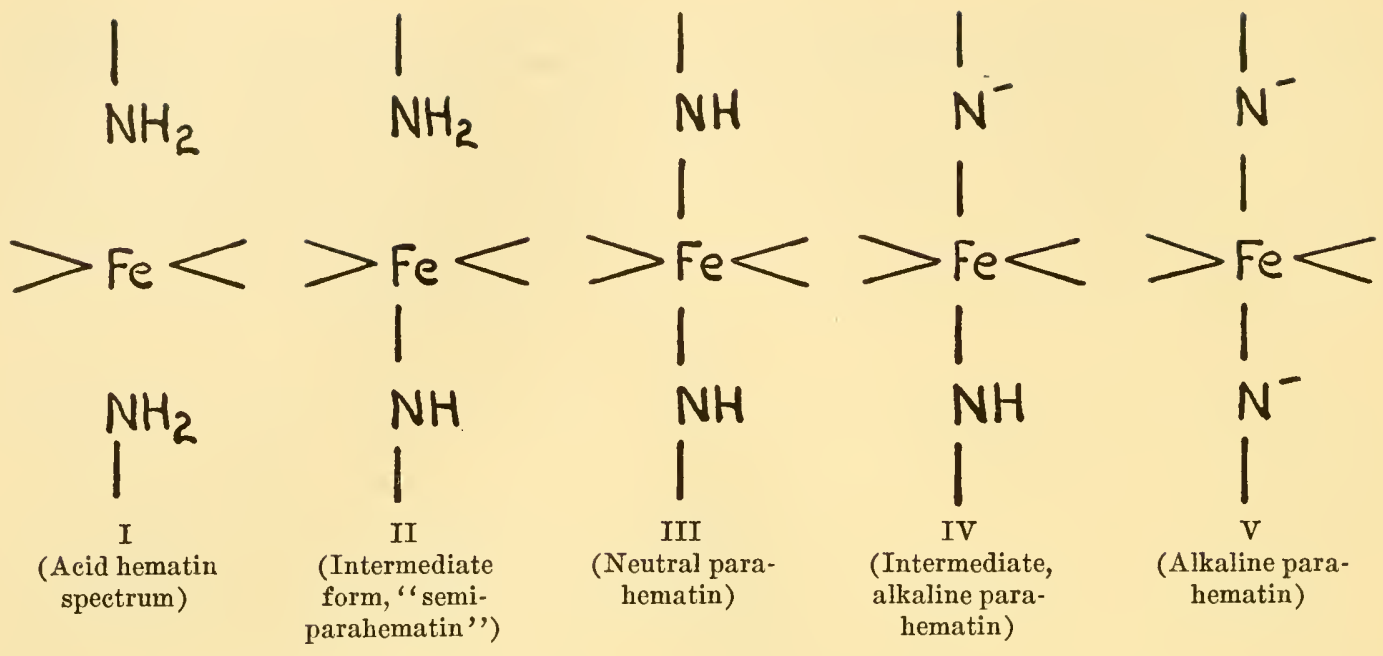

as shown in the treatment with acid acetone already mentioned. The amino residues attached to the iron atom deprive the cytochrome of the ability of forming addition compounds with oxygen (or earbon monoxide, and so on). One may ask why na-

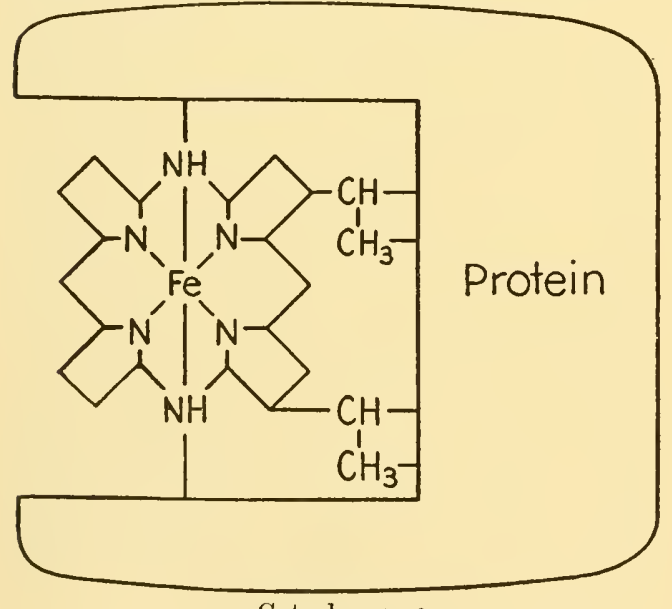

Cytochrome- $c$

ture has specialized eytochrome-c in this way, enabling it to perform the valency change

$$
\mathrm{Fe}^{++} \rightleftarrows \mathrm{Fe}^{+++}+e,
$$

but not the addition of oxygen. I imagine the answer must be that the formation of a compound $\mathrm{Fe}^{++} \mathrm{O}_{2}$ would be an unfavorable property for a hemin ferment acting by means of valency oscillations. We may see this from a comparison with hemoglobin.
Only hemoglobin, but not oxyhemoglobin, can be oxidized to methemoglobin. Thus oxygen and carbon monoxide to an even greater extent have a certain tendency to preserve the iron in the divalent state by decreasing the concentration of the hemoglobin in favor of the oxygen hemoglobin. Thus, just as the formation of methemoglobin is unfavorable for the special function of hemoglobin, the formation of an oxygen compound of ferrocytochrome- $c$ would possbly mean a hindrance to its function.

Type III of the ferricytochrome, which occurs at physiological $\mathrm{pH}$ values, is the one which the iron atom best preserves against complex formation with inhibiting reagents; type II forms a fluoride compound, the fluoride entering into a compound with the iron and thus replacing the amino group. Types IV and V form CN-complexes. CO complexes are formed by ferrocytochrome in both acid and alkaline solutions, $\mathrm{CN}$ complexes in alkaline solutions.

In the case of eytochrome- $c$ we thus have a nice demonstration of the interaction between the prosthetic group and the protein component, and that is how the protein can greatly modify and specialize the properties of the prosthetic group of a ferment.

The eatalases are ferments, oceurring in practically all living cells. As you all know, they split hydrogen peroxide into water and oxygen. Zeile and Hellström pro- 
vided, in 1930, strong evidence for the catalases being heminproteids. The haem in the catalases, in constrast to the haem in eytochrome- $c$, is loosely attached to the protein, so that treatment with acid acetone immediately liberates the hemin from the protein. Sumner and Dounce crystallized eatalase from beef liver in 1937. At the same time, and since 1935, we had been working in Stockholm upon the purification of horse liver catalase, and in 1937 Agner obtained a pure preparation with about the same iron content and the same molecular weight as Sumner's preparation, but with an activity twice as high. For some time the difference was thought to be due to different protein components; recently the question has been cleared up to a certain extent. Sumner's eatalase contains not 4 hemin groups per molecule as was first stated, but only 2 or 3 , and some iron impurity, whereas Agner's horse liver catalase contains 4 hemin groups and only the corresponding amount of iron. I mention these results because it seems quite unexpected that two such closely related animals as cattle and horses could possibly contain catalases with different prosthetic groups. ${ }^{3}$ As it is nevertheless a fact, preparation of catalases from different animals, in order to determine how many hemin groups there are per molecule, would be an interesting study in comparative biochemistry. Perhaps this will give a new classification of the animal kingdom!

\section{The Yellow Enzymes}

In 1932 Warburg and Christian found a thermolabile factor in yeast that catalyzes the reaction between oxygen and Robison ester, when this latter is activated by a co-ferment and a ferment produced from red blood corpuscles. The new factor from yeast was submitted to chemical purification in various ways. It gradually appeared that the preparation showed, in proportion as the purification proceeded, an increasingly yellow color. The strength of the yellow color proved to bear a direct ratio

3 Both catalases contain biliverdin, the signifieance of which is not yet clear (Stern, Lemberg). to the activity of the preparation; if reducing substances were added, as for example hydrosulphite, the ferment solution lost its color, but the color returned when the solution was shaken in air. These and other experiments showed that the new enzyme was a pigment that manifested itself by alternately taking up and giving off hydrogen, and was analogous to many previously known pigments that are hydrogenated and form leuco-compounds. This led to the strictly chemical proof of Weiland's theory that a loss of hydrogen enters into the mechanism of combustion. It is an ironical turn of destiny that Warburg should have been the man to supply this proof!

The first task was to discover what happened during irradiation. This became clear through Kuhn's investigations when he succeeded in producing from whey a yellow pigment, lactoflavin, in the pure state; this was reached from another point of departure, namely in the course of his search for vitamin $B_{2}$. The lactoflavin proved to contain four carbon, eight hydrogen, and four oxygen atoms more than lumoflavin. If the lactoflavin were irradiated in an alkaline solution, the side chain $\mathrm{C}_{4} \mathrm{H}_{8} \mathrm{O}_{4}$ was split off and lumoflavin, soluble in chloroform, was formed. Kuhn showed that lactoflavin had a vitamin effect, while lumoflavin lacked it. The sugar-like side chain $\mathrm{C}_{4} \mathrm{H}_{8} \mathrm{O}_{4}$ was therefore assumed to possess a function that remained, however, for the time obscure. Kuhn now synthesized condensation products between lumoflavin and various pentoses. At the same time he was given an opportunity of finding out whether his synthetic products were identical with the prosthetic group of the yellow ferment, because just at that time I had prepared in the pure state, in Warburg's laboratory, the yellow ferment, and had also succeeded in splitting it into a yellow pigment component and a colorless protein component. Kuhn now mixed his first obtained synthetic product, $l$-araboflavin, with the protein component. He considered himself in a position to state that the yellow ferment was then resynthesized, and thought he had thus carried out the first synthesis of an enzyme 
except for the protein component, which was not capable of synthesis. This was, however, not correct. Four days after Kuhn's work was published a work of mine appeared showing that the prosthetic group of the yellow ferment is not lactoflavin but a lactoflavin-monophosphoric acid ester. The discovery of the lactoflavinphosphate is a case of good luck. It did not seem unreasonable to suppose that phosphoric acid might be the intermediate link between lactoflavin and protein. The only material at my disposal at the time was a long since spoiled solution of the prosthetic group of the yellow ferment that had been split off with methyl alcohol. Several weeks previously, however, when it was still fresh the flavin concentration had been determined; the phophorus could not, of course, have disappeared. A microanalysis of the phosphorus showed that the solution contained the same concentration of phosphorus as there had been flavin at the begining. A new preparation of the prosthetic group showed again a content of one atom of phosphorus per molecule of flavin. But it was necessary to prove that the phosphoric acid was really esterified with the lactoflavin. This was a delicate task, as all that remained of the prosthetic group contained only about $50 \mathrm{mg}$. of lactoflavin. The electrophoretic method previously used enabled us to solve the problem. Lactoflavin in neutral solution is electrically neutral and thus remains motionless on electrophoresis. If now the prosthetic group of the yellow ferment were esterified with phosphoric acid, in neutral solution it should migrate as an acid toward the anode. It was even possible, on the basis of previous studies on other phosphoric acid esters, to predict the speed of migration that a lactoflavin monophosphoric acid ester should show. The experiment was very exciting, as the solution of the prosthetic group was so weak that no color at all was visible. Not until the experiment was finished could the electrophoretic apparatus be placed before a mercury lamp. The yellow fluorescence, which is an extremely sensitive indicator of flavins, showed that the prosthetic group had migrated towards the anode, and even quantitatively at the calculated speed. When the pure ferment was afterward produced on a larger scale, the calcium salt of the lactoflavin phosphoric acid was crystallized.

The production in the pure state of the yellow ferment was of a certain methodological interest, as it could be carried out by the direct electrophoresis of a preparation containing only 3 per cent of the pure ferment. For the production on a larger scale, however, the electrophoretic purification had to be supplemented with ammonium sulphate fractionation. It was found to be a flavoproteid. ${ }^{4}$ On the assumption that one molecule of the ferment contained one molecule of the prosthetic group, the riboflavinphosphate, the molecular weight was calculated as 75,000 ; this value was confirmed in Svedberg's institute by means of ultracentrifugation. The light absorption curve of this "old" yellow ferment is similar to that of the free flavin (see Fig. 1). However, it should be noticed that the absorption bands of the prosthetic group are displaced about $20 \mathrm{~m} \mu$ towards the red end of the spectrum when it is linked to the protein to form the ferment. This displacement is interesting because it means that the activation energy of the

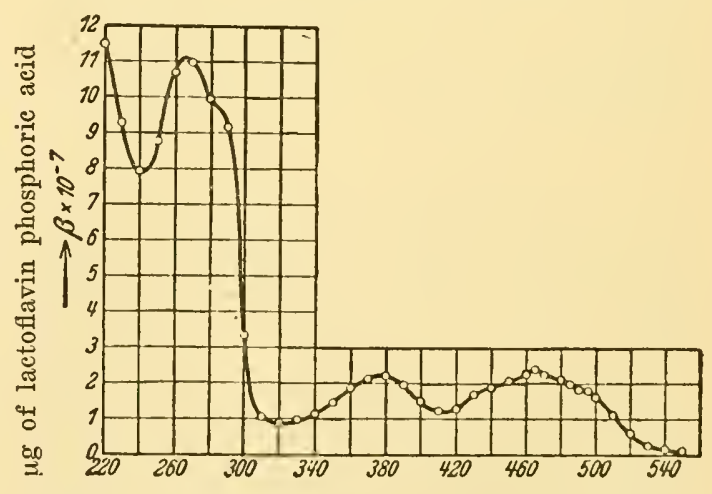

FIG. 1a. Absorption spectrum of the "old" yellow ferment (Theoreli). Wave length in $m \mu$

4 Because of the high content of polysaccharides in the crude preparations, it had previously been considered that the ferment might be a flavopolysaceharide. 


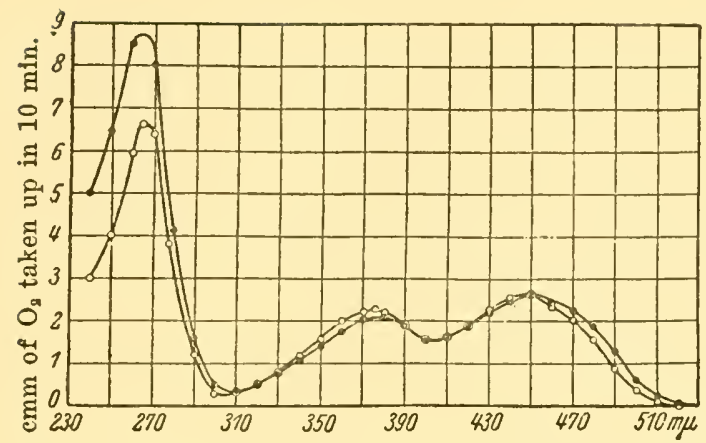

FIG. 1b. Absorption spectrum of the lumiflavin $(\mathrm{O}-\mathrm{O})$ and of the flavin-adenine-dinucleotide

(ㅇ) (Warburg and Christian). Wave length in $\mathrm{m} \mu$

flavin is decreased by the linking to the protein, or, in other words, the prosthetic group is activated by the specific protein.

If now salt-free solutions of the ferment were dialyzed at $0^{\circ}$ against weak hydrochloric acid the ferment was split up into the prosthetic group, which passed through the membrane, and a colorless protein, which remained within the cellophane tube. The protein was found to be denatured after this procedure, but could to a great extent be made native again by dialysis against water. If this protein were mixed with the prosthetic group, the yellow ferment appeared again (see Fig. 2) .

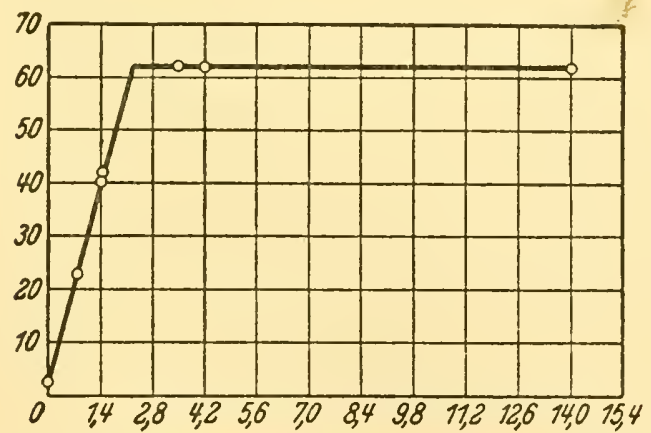

Fig. 2. Resynthesis of the yellow ferment. The catalytic activity on adding increasing amounts of the prosthetic group to a constant amount of the protein component.

Determinations of the catalytic activity in the test system (oxygen; yellow ferment; triphosphopyridine proteid; Robison ester), as well as of the isoelectric point and of the sedimentation constant, gave the same values as with the ferment that had never been split. So it was proved that the yellow ferment had been submitted to a really reversible cleavage. It was the first time that an enzyme had been split into a prosthetic group and a protein, and resynthesized again. The experiment constituted a direct proof of the correctness of the old theory that enzymes consist of two radically different parts, a so-called active group and a bearer. The chemical constitution of the "old" yellow ferment has been clarified as far as possible-and that means to 0.65 per cent, which is the percentage of the prosthetic group. The composition of the protein part, 99.35 per cent of the molecule, is of course as unknown as that of all other proteins.

The clearing up of the composition of lactoflavin and lactoflavin phosphoric acid was earried out, after the fundamental work of Warburg and Christian, mainly by Karrer and his co-workers in Zürich and by Kuhn and his co-workers in Heidelberg. Their investigations led to the formula presented on page 144.

It is a most interesting fact that each of the many parts of the molecule of the prosthetic group exerts its own influence upon the properties of the enzyme.

The nitrogen atoms (1) and (10) are the carriers of the hydrogen stream from the substrate according to the formula:

By means of the "one-step"-reaction of Michaelis the reduction of the yellow form proceeds with one hydrogen atom at a time over the monohydroradical to the leuco form, or vice versa. The transference of one hydrogen atom at a time must be a more probable, and thus faster, reaction than the direct reduction to the leuco form by means of two hydrogen atoms simultaneously. The monohydroradical of the free riboflavin can exist only in a strongly acid solution. The yellow ferment, on the contrary, seems to give a monohydroradical that can exist in neutral solution (Haas). Perhaps this is the mechanism of "activation" of the lactoflavin phosphoric acid by the protein component. It seems most 
tempting to assume that even other "activations" by means of specific protein may be performed in an analogous way. Not only other prosthetic groups of ferments, such as pyridine nucleotides and thiaminpyrophosphate, but also substrates such as the phosphoric esters of sugar and their fermentation products, might be enabled to Kuhn et al., another linkage of the prosthetic group to the protein. This bond is supposed to be responsible for causing the oxidation-reduction potential of the ferment to be higher than that of the free flavins, and for extinguishing the fluorescence of the flavinphosphate when attached to its protein.

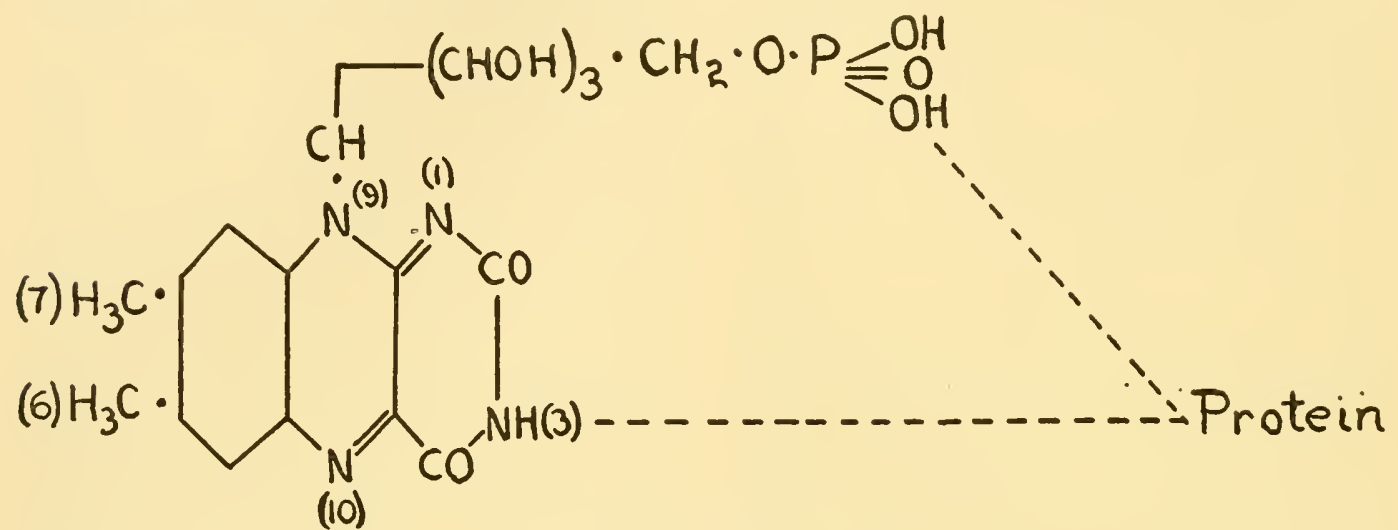

The "old" yellow ferment.

by the protein to form monohydroradicals. Further research is needed to clear up this point.

The 6- and 7-methyl groups are important, because they diminish the toxicity of the flavin, and further they decrease the oxidation-reduction potential of the flavins to a suitable level. Thus the 6- and 7-positions are optimal, and the methyl groups are indispensable for the ferment activity (Kuhn et al.).

The nitrogen atom (9) serves to link the isoalloxazin nucleus to the pentose chain ( $d$-ribose), which carries the phosphoric acid residue. The phosphoric acid, as mentioned above, attaches the whole prosthetic group to the protein component.

The nitrogen atom (3) gives, according
As the protein component and the prosthetic group are bound to each other in two places, the distance between these two atomic groups must obviously be about equally great to enable combination. We found in our experiments on conditions for the combination of the lactoflavinphosphate and protein that such an extremely slight operation as the warming of the free protein component for 10 or 20 minutes to $38^{\circ}$ C. changed it, so that it did not now combine with lactoflavinphosphate to form a catalytically active ferment. If after this slight warming the protein component was brought to room temperature, the capacity to combine gradually returned. Progressively more lactoflavinphosphate was used on consecutive titrations of a certain volume

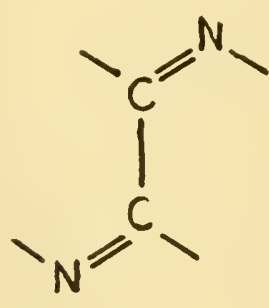

Monohydro radical

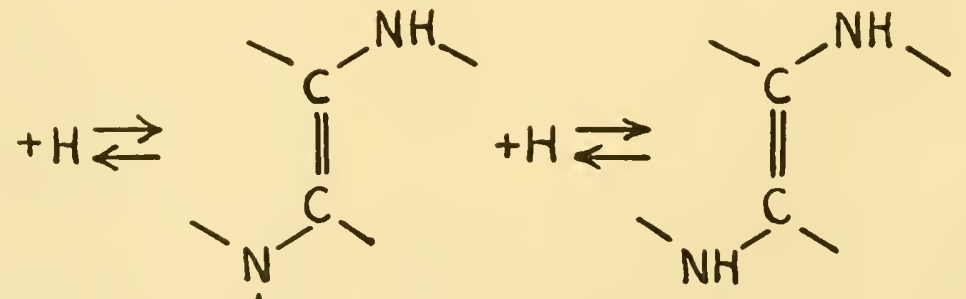

(10) Yellow form 
of the protein solution to a faint permanent fluorescence. The catalytic activity returned in parallel with the capacity to extinguish the fluorescence.

These results may be interpreted to mean that the protein component becomes somewhat deformed through the warming, thus altering the distance between the unknown groups of the protein so that they no longer coincide and therefore cannot combine with the phosphoric acid and the amino group (3) of the flavinphosphate. One may even draw the conclusion that the activation of the lactoflavinphosphate by the specific protein to form a ferment probably depends only on the combination of the protein with the $-\mathrm{NH}$ group, for the return of the catalytic activity parallels the extinguishing of the fluorescence. The most reasonable assumption appears to be that the combination of the protein with the phosphoric acid residue also takes place in the protein even when this has been changed by heating, but that the catalytic activity does not return until the protein can also combine with the $-\mathrm{NH}$ group. The phosphoric acid ester would thus have importance only for diminishing the dissocation between protein and prosthetic group. This is in accord with Kuhn's observation that a large excess of lactoflavin combines to some extent with the specific protein to produce a strongly dissociated compound, whose undissociated molecules are as catalytically active as lactoflavinphosphate proteids. These experiments with heating of the protein component give a striking illustration of Emil Fischer's well-known metaphor of enzymes and substrates as keys and locks. The same metaphor can obviously be applied to the inner structure of the enzymes.

\section{FlaAin-Adenine-Dinucleotides}

The old yellow ferment suffered from the same lack of knowledge from which ascorbic acid still suffers: one could say in detail how it could function, but not where it really functioned or with what system it reacted physiologically. It was therefore to be assumed that there might possibly exist still other yellow ferments of different composition and function. Karrer imagined that the flavins might, as easily as the nicotinic acid amide, be conceived to exist in dinucleotides with adenine; and he succeeded also in preparing from liver flavinphosphate containing adenine. When he sent them to Stockholm for us to attempt to combine them with the protein component of the old yellow ferment, we found that the new preparation behaved rather differently from lactoflavinphosphate.

About a year ago a number of rather sensational experiments from different institutes were published almost simultaneously. Krebs's $d$-amino acid oxidase was found by Straub to be a flavoproteid; Warburg and Christian reported almost at the same time that they had already prepared in the pure state the prosthetic group, which proved to be flavin-adenine-dinucleotide. The protein component of the amino acid oxidase was prepared in a highly purified form by Warburg's collaborators Negelein and Brömel. Since then the list of new yellow enzymes has rapidly increased.

Table 2 shows the different yellow ferments known at the present time. It is of course to be expected that the list will increase in the future. On the other hand, possibly, some of the ferments may turn out to be more or less identical. The nomenclature is introduced by Warburg: "Alloxazin" means riboflavinphospate, Alloxazin-Adenin means riboflavin-adeninedinucleotide.

\section{TABLE 2}

\section{The Yellow Ferments}

1. The "old", yellow ferment (Warburg and Christian; Theorell)

="Alloxazin-Proteid $\mathrm{O}_{2}$, Dihydropyridine."

2. Alloxazin-Adenine-Proteid $\mathrm{O}_{2}$, Dihydropyridine, prepared by Warburg and Christian by coupling "Alloxazin-Adenine-Nucleotide" with the protein of the "old" ferment.

3. Krebs's d-Amiuo acid oxidase = Alloxazin-Adenine-Proteid $\mathrm{O}_{2}$, am1no ac1ds. (Das, Straub, Warburg and Christian.)

4. Haas's Alloxazin-Adenine-

Proteid (Methylene blue) Dlhydropyridine.

5. Ball's Alloxazin-Adenine?-Proteid $\mathrm{O}_{2}$, xanthine.

6. Corran's and Green's Alloxazin-Adenine-

Proteid $\mathrm{C}_{\text {ytochrome-c, Dlhydropyrldine. }}$

7. Straub's Alloxazin-Adenine-

Proteid Cytochrome, Dihydropyridine [= Coenzyme factor (Dewan and Green); Diaphorase (Adler, Euler and Hellström)]. 
All the yellow ferments are, as it seems, rather similar in the matter of external properties, such as molecular weight, absorption spectrum, and flavin content. The purest preparation of the old yellow ferment contained 0.65 per cent flavinphosphate. Haas's ferment contained 0.7 per cent, and Straub's purest "coenzyme factor" contained 0.65 per cent, Ball's xanthinoxidase 0.63 per cent. The majority of the yellow ferments resemble the old one in so far as they are only slightly dissociated. Only amino acid oxidase is so strongly dissociated that it could not be prepared as such, and the prosthetic group and the protein component each had to be prepared separately.

In the matter of function, all the yellow ferments resemble one another in that they transfer hydrogen; the differenees lie in the source of the hydrogen, where they transfer it, and in the speed with which this takes place.

It is a striking fact that some of the flavin ferments (and, so far as it is known, all of the pyridine-nucleotide ferments) are largely dissociated, while others of the flavin ferments are practically undissociated into prosthetic group and protein at a physiological $\mathrm{pH}$ value. So far as we know it seems to be a general rule that the enzymes which react directly with the substrates are greatly dissociated, such as the pyridine ferments and the flavin ferment acting as $d$-amino acid oxidase, whereas the intermediate catalysts, such as the flavoproteids taking their hydrogen from dihydropyridine, or the cytochromes, or the oxidases are undissociated. I think we may find this arrangement by nature to be very remarkable. The ability of the living cells to make different proteins seems to be unlimited, whereas animal cells cannot synthesize most of the prosthetic groups, e.g., thiamin, flavin, and nicotinic acid amide. This is the reason why these have to be taken up by the animals from plants and have the character of vitamins. Now, the animal cells have to transform a great variety of substances, such as sugars, amino acids, lactic acid, pyruvic acid, and so forth. It seems perfectly possible that the cells make one specific protein for each of these substrates. Some few prosthetic groups can then form dissociable enzymes, one time with one protein and again with another, thus picking up hydrogen from different protein-substrate compounds much as a bee picks up honey from different flowers.

The hydrogen from different substrates may then enter the main highway of combustion, where a stream of hydrogen from the substrate side meets a stream of electrons from the oxygen side with subsequent formation of water. The intermediate catalysts in this highway have no reason for dissociation: they take electrons or hydrogen always from one certain catalyst, giving these to another.

If, finally, we summarize our present knowledge about phosphoric acid ester compounds with proteins, we shall find a great many highly important substances belonging to this group. I have already mentioned ferments consisting of nucleotide proteids (flavin- and pyridine-proteids). These are beyond doubt the most important of the enzymes involved in delivering energy, because they may be used both in oxidation and in fermentation. They are present everywhere from the higher animals to the anaerobic bacteria, which have no hemin proteids because they do not need them.

If we consider further that the cell nucleus, the chromosomes, and the genes consist of nucleotide proteids, as well as the viruses, we can perhaps arrive at the conclusion that living material arises from dead when nucleotides are coupled with proteins. There has been much diseussion about whether the viruses are living or dead, and generally about the limits between living and dead materials. As far as I can see there is no more sense in such a discussion than in, for example, Descartes' theory that the soul has its seat in the pineal gland. But it could perhaps be worth while to point out the analogy between the viruses and the metal-free ferments transporting hydrogen: both are built up of nucleotides plus protein. 


\title{
PLANT HORMONES
}

\author{
By F. W. WENT
}

WILLIAM G. KERCKHOFF LABORATORIES OF THE BIOLOGICAL SCIENCES, CALIFORNIA institute OF TECIINOLOGY, PASADENA, CALIF.

Synthesis of ideas is impossible without a preceding analysis, if only because no synthesis is possible as long as we conceive a process or complex as a unit. For this reason the cell theory was one of the first, and certainly the most significant, of the steps in the understanding of the living organism. It gave us the smallest unit which still possessed the properties we associate with "living." For many functions and processes the cell was recognized as the smallest structural and functional unit. Still, in the course of the last century it was recognized that an organism is more than a mere colony of cells, as pointed out in many of the previous papers. This was more clearly indicated in animals than in plants, for in animals the cells were functionally tied together by the nervous system. But also in plants it was found that different parts were dependent upon each other; this was expressed by the statement that correlation existed. Amongst the earlier investigators who stressed the importance of such correlation were Sachs, Vöchting, Darwin, Goebel, and Errera. This synthetic view of a plant reached its full development with the hormone concept of plant growth. The hormone concept transcends the differentiation of the organism into cells: hormones integrate cells into an organism. Therefore the cell theory and the hormone concept are mutually supplementary in the understanding of an organism. Thus the function of a hormone is essentially transcellular, but its formation, translocation, and action are definitely cellular problems.

Let us begin by considering a very recent disclosure of plant hormone function, namely, its relation to root growth, since this provides the simplest example of plant hormone effect. It is evident that a root cannot grow by itself, since it must obtain its food from the assimilating aboveground parts of the plant. In certain cases where the roots are green, they have acquired the ability to grow by themselves (Taeniophyllum, Podostemonaceae); but ordinarily a food-correlation between roots and leaves exists. We can now ask, how independent are the different parts of a plant; or in more conerete terms, are roots able to grow by themselves in a medium containing water, salts and sugar? Kotte (1922) and others found that this was not the case. Robbins (1922) showed that with the addition of yeast extract to the medium much better growth of isolated roots was obtained. But it was left for White (1934) to demonstrate that yeast extract contained all that was necessary for the unlimited growth of isolated root tips in a medium consisting of sugar and the necessary salts. Then simultaneously Bonner (1937), and Robbins and Bartley (1937), discovered that vitamin $B_{1}$ is the main growth factor present in yeast; later Addicott and Bonner (1938) added nicotinic acid, and Robbins and Schmidt (1939) added vitamin $B_{6}$ to the list of essential growth factors for certain roots; all these were supplied through the yeast extract in White's experiment. It is now established that pea roots can grow indefinitely in a solution containing salts, sugars, thiamin, and nicotinic acid. Therefore such a medium supplies everything necessary for the synthesis of all pea root cell components, such as proteins, enzymes, nucleic acids, etc. These pea root cells can synthesize purine, sterole, imidazole, indole, and scores of other molecular nuclei, but they have completely lost the ability to form pyrimidine, thiazole, or pyridine nuclei. This ability, however, is possessed by the above-ground parts of the pea plant, and therefore the root system of a 
pea depends upon the top. We can imagine any other number of combinations of substances which cannot be synthesized by root cells, and future work will show what variations on this general theme are found in nature. But as far as information is available, we can say that vitamin $B_{1}$ is a general root growth hormone in the higher plants. It is produced in the leaves in light.

Root growth provides us with the information necessary to trace the phylogeny of the hormones, because it will clarify a number of puzzling facts which we will encounter later. Consider a self-sufficient or autotrophic primitive acellular plant, such as a bacterium. With available energy it is able to build up its food, which will serve as a source of energy, or according to van Niel (1940), as a source of break-down units for its metabolism and growth. For our purposes we can disregard the difficulties involved in the synthesis of the complex proteins, nuclei-proteids, etc., which are essential for its growth. But as building units for these proteins, enzymes, etc., a number of molecular nuclei, such as benzole, pyridine, pyrimidine, purine, imidazole, thiazole, and sterole, must be available. These cannot be produced by simple dehydrogenations or dehydrations, the most common chemical reactions occurring in living cells. Whereas the partly heterotrophic organisms can derive some of these building stones from their surroundings, the completely autotrophic cell is compelled to synthesize them from very simple materials. As soon as a cell has lost the ability to make one of these building stones, it becomes dependent upon other cells. In this way a basis for interdependence of cells or organisms is laid.

Hormones and vitamins are essential building stones of cells, or they have at least definite functions in cells, although cells are unable to produce them. In the case of hormones other cells in the organism have not lost the ability to form them; hence an absolute dependence of the using cells upon the producing cells develops.
If for other substances the reverse relationship exists, then the two groups of cells are absolutely interdependent. The first cannot grow without a certain activity of the second, but again that second will be limited by the first. Such a simple principle underlies the unity of an organism. How simple and how flexible it is has also been stressed by Szent-Györgyi, and is demonstrated by the fact that for rats and plants ascorbic acid is not a vitamin, because they synthesize it themselves, but for other animals it is a vitamin. Thiamin is a vitamin for animals, a hormone for most plants, and a vitamin for some other plants (Bonner 1937a). Nicotinic acid is a hormone in some plants, a vitamin for animals. All of these substances are rather simple building stones for the cell, just as flavine, adenine, etc. Therefore we may look forward to the discovery of many more simple molecular nuclei as hormones or vitamins, and to discovering in which specific reactions known hormones take a part.

In discussing the correlations in the above-ground parts of plants, it is desirable to go back historically. Sachs (1880, 1882) gave the first logical analysis of the phenomenon of correlation. He based this analysis on the following considerations. In the course of development there is an increased differentiation of cells. When different organs develop from cells out of homogeneous tissue, the principle of causality implies that at some time the initial cells of these organs differed in some respects. Since at the outset they were supposed to be equal, this difference must have developed later. Further consideration of teratological cases and galls led Sachs to the conclusion that minute amounts of certain chemicals, so-called organ-forming substances, were responsible for this development of difference. He supposed that these substances were transported polarly in the plant, and thus the polar organ formation, according to Sachs, was due to the polar movement of organ-forming substances.

In the subsequent 30 years a number 
of correlation phenomena were discovered, and often they were supposed to be due to chemical substances. Thus Fitting (1909) could show that a substance present in pollinia induced the typical swellings of the style of orchids after fertilization, and that this swelling was not due to fertilization itself. Doposcheg-Uhlar (1911) was able to influence the nature of the buds developing in leaf axils with certain extracts. Boysen Jensen (1911) showed that the transmission of the phototropic stimnlus is due to some agent of substantial nature. In all these studies we see indications of the future work on auxins. But the basis for the auxin concept was laid by Paal (1919). He definitely established the fact that growth in grass coleoptiles is regulated by a diffusible agent per cent amounts of auxin of the order of one ten-millionth of a milligram. The test consists of decapitating oat seedlings, thereby removing the production center of growth substance so that the growing zones of these seedlings become deficient in auxin. Application of growtl-promoting substances absorbed in small cubes of agar to one side of the cut surface of such a decapitated oat seedling will lead within one and a half hours to a curvature of the seedling towards the opposite side. This eurvature is directly proportional to the amount of applied auxin. A second auxin was also isolated from plant material, and after a chemical analysis Kögl and Erxleben (1934) were able to establish the following two formulas for auxin- $a\left(\mathrm{C}_{18} \mathrm{H}_{32} \mathrm{O}_{5}\right)$ and auxin- $b\left(\mathrm{C}_{18} \mathrm{H}_{30} \mathrm{O}_{4}\right)$.

Auxin- $a$

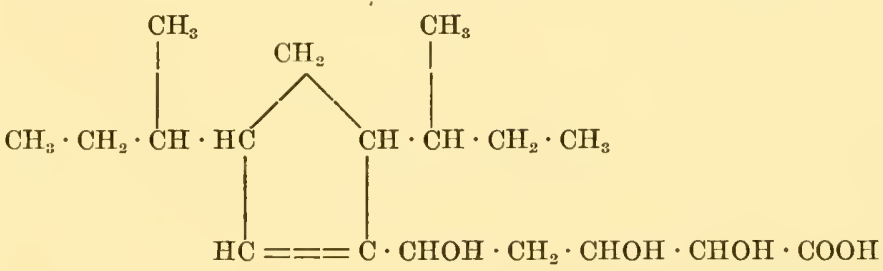

Auxin-b<smiles>CCC(C)C1=CC(C(C)CC)CC1C(=O)OCC(=O)O</smiles>

coming from the tip of these coleoptiles and moving down from cell to cell. The phenomenon of transmission of a phototropic stimulus across a cut surface, discovered by Boysen Jensen, was interpreted by Paal as a differential transmission of his growth regulators due to light.

From then on a rapid development took place, culminating in the chemical isolation of the growth substance, or auxin, by Kögl and Haagen-Smit (1931). The basis for this chemical isolation lay in a good quantitative biological test for growth substances, the Avena test (Went 1928). With this test it is possible to determine with an error of not more than 5
Auxin- $a$ and auxin- $b$ are extremely diffcult to obtain, the Utrecht Laboratory alone so far having succeeded in crystallizing them, and they obtained only slightly more than one gram. Therefore the further discovery of Kögl, Haagen-Smit and Erxleben (1934) that indole acetic acid acted in essentially the same manner as auxin- $a$ in inducing growth was of the greatest importance, since it made auxins-sub-

1 It is interesting to point out that in the animal female sex hormones the two naturally occurring products, estrone and estriol, also differ by the elements of water; this is due to the presence of two hydroxyl groups in the one against one keto group in the other. 
stances causing cell elongation in the Avena test-readily available for physiological investigations.

Let us now rapidly review some of the reactions these auxins can induce in a plant (Went and Thimann 1937) :

1. The most typical and direct reaction of auxins is cell elongation, which can be noted within a quarter of an hour after application. Since the main part of visible growth of a plant is cell elongation, auxins regulate most of the more spectacular phenomena of plant growth. The ultimate effect of auxins in causing cell elongation is by increasing the plasticity of the cell wall, which then yields to the turgor pressure.

2. The relation between the position of a plant and its surroundings is due to differential growth. Accordingly geotropism and phototropism are for the largest part auxin-regulated, either by redistribution of auxin within the growing organs or by differential inactivation of auxin, or by both.

3. Recently effects of auxin oll germination have been described, which seem to be essentially effects on the early stages of growth.

4. A very different effect of auxin was discovered when it was found that the inhibition of lateral buds by the apical bud is caused by the auxin produced by the apical bud. Here we have definitely a case where auxin, as long as it is coming from the apical bud, inhibits growth; whereas in the absence of the apical bud, the lateral buds begin to grow out under the influence of the auxin produced in their own tips.

5. In most cases the fruit develops only when the egg cells have been fertilized and are growing out into embryos. Prevention of pollination leads to premature shedding of the young fruit. Gustafson (1936) discovered that it is possible to produce normal sizc fruits without pollination if auxin instead of pollen is applied to the style. In many plants, such as tomato, tobacco, and Bell pepper, normal size parthenocarpic fruits have been produced through auxin applications.
6. In root formation auxin takes part in a complex system of reactions: sugars, auxin, biotin, vitamin $\mathrm{B}_{1}$, amino-acids, carotene-each plays its role in root formation. This effect of auxin is particularly interesting since it is an organization: first a meristematic condition is induced, and later within the apparently undifferentiated meristem a differentiation of root primordia occurs. Still since many of the peculiarities of the auxin effect on cell elongation have their counterpart in the effect of auxin on root formation, growth and cell differentiation are closely allied phenomena.

7. Another auxin effect which involves cell division is cambial growth.

A number of other rather disconnected auxin effects are known, but will not be mentioned here. In reviewing these widely differing effects one becomes impressed by the wide variety of reactions. This led to the concept that auxin is a stimulant rather than a specific agent (Fitting 1936). This view was strengthened by the wide variety of substances effective in growth.

If I continue to discuss especially the effect of auxin on growth, it will be necessay to show why auxin, of all plant hormones, is worthy of such a detailed analysis. In the first place, auxin is a very typical growth factor. The other substances necessary for growth, vitamin $B_{1}$, $\mathrm{B}_{6}$, nicotinic acid, adenine, etc., all have a known function in metabolism in general and without them no life, and consequently no growth, is possible. For this reason alone auxin deserves special attention, for either we can discover its function in metabolism in general, or it will lead us closer to the problem of growth itself.

We will first take up the molecular specificity of auxins and their relative molar activities. If we observe the various substances effective on growth by use of the Avena test, we find a 10,000-fold range in activity (Fig. 1). This is not due to such enormous differences in their effectiveness in producing growth, because if another test be employed, say submergence of the Avena coleoptiles in the solutions, the 


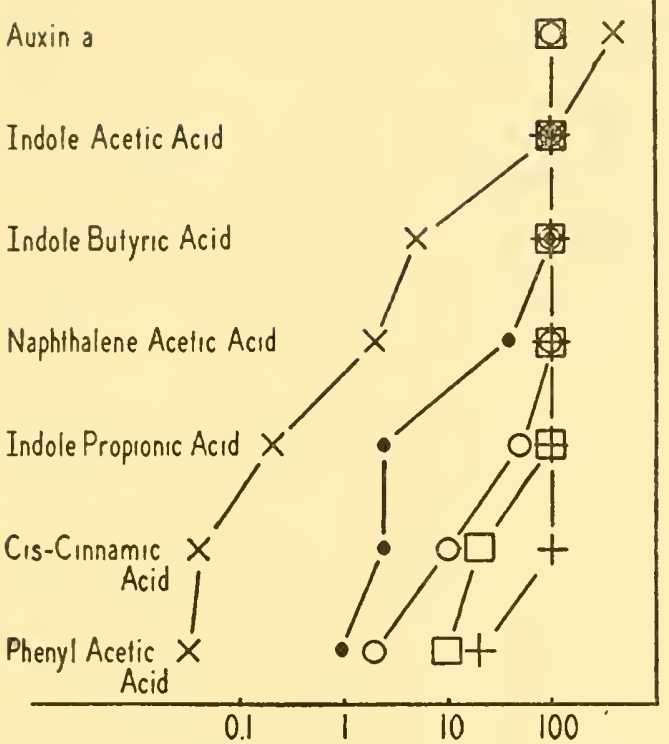

FIG. 1. Relative molar activities (abscissa) of 7 growth promoting substances in 5 different tests. Activity of indole acetic acid is always taken as 100.

X Activity in standard Avena test.

- Activity in Avena coleoptile section test (sections immersed in solutions).

Activity in standard pea test.

Activity in pea test when preparatory reaction is not limiting (activity in growth reaction proper).

+ Activity in pretreated peas, but corrected for undissociated growth substance molecules.

range of specific activities is greatly reduced. It was Thimann (1935) who first determined this fact and explained it on the basis of relative differences in the rate of transport of the several substances.

If we employ the same substances in the pea test which is another method for determining growth activity of substances, consisting of submerging halved pea stems in the solution to be tested (Went 1934), we find again a smaller range of activities, and many substances have the same molar activity as indole acetic acid. This range can be narrowed still further by distinguishing between two separate and successive reactions in which auxins participate in this growth response of pea stems (Went 1939). The first, or preparatory reaction, only conditions the cells for the actual growth reaction which follows, but does not by itself lead to measurable growth. This preparatory reaction, lowever, limits the growth activity of most substances. Therefore, if we test the various substances on peas in which the preparatory reaction is practically completed, the molar activities for the growth reaction proper are even less divergent (D. Bonner 1938).

Since it is known that the effectiveness of auxins is much greater at low $\mathrm{pH}$, which parallels the decreased dissociation of auxin at more acid $\mathrm{pH}$, and since not all tested substances have the same pK or dissociation, the activities have been corrected for the number of undissociated molecules at the $\mathrm{pH}$ of the cells (D. Bonner 1938). This brings the molar activities of all but one substance in Fig. 1 up to unity.

If we consider now the close stoichiometric relationship between the auxin applied and the growth produced and compare it with the above-mentioned fact of unit activity for equimolar solutions of growth substances which differ widely chemically, we come to the inevitable conclusion that the growth reaction is a chemical reaction, in which a constant amount of growth results per mole of any applied growth-producing substance (Went 1939a).

When we obtain deviations from this relationship in our experiments, we have seen that this is caused by a number of factors affecting the availability of auxin at its place of action, or changing the reactivity of the cell. Thus, in comparing activities of physiologically active substances, we must first ascertain whether these substances actually reach the point where they react, since innumerable secondary properties of the substances may affect their ability to penetrate the cell, move through the tissues, etc. If we are reasonably sure that this is the case, we must determine whether the applied substances affect the responsiveness of the cells to different extents. If these and other precautions have been taken, quantitative comparison of molar activities becomes significant.

If all these growth substances take part 
in a specific chemical reaction, as we reasoned in the preceding section, it must be possible to find a common denominator for all of them, or in other words, to discover a specific molecular arrangement which is involved in this growth reaction. After the discovery of indole acetic acid as a growth-promoting substance, Kögl (1935) suggested that either this substance performs the same function in connection with growth as a pass key in forcing a lock, or it opens a different lock altogether, a sort of back door to growth. This second possibility is now ruled out, and we can try to find out which bits in the key to growth are necessary to open the lock; that is, to take part in the growth reaction. The grooves which are not essential for the actual process of opening, but which only determine whether the key will be able to penetrate the lock, could be compared with the secondary properties of growth substances, which are essential only for their penetration into the cell.

As a result of an extensive comparison of the different substances able to produce growth, involving the preparation of a number of critical compounds (Koepfli, Thimann and Went 1938), we can now say that a substance must contain a ring with a double bond; next to the double bond it must have a side-chain with a carboxyl group; this carboxyl group must be at least one carbon atom removed from the ring; and must in addition have a very definite space-relation towards the double bond. It is immaterial whether the configuration is realized with an auxin, indole, naphthalene, anthracene, or benzole nucleus; within this series activity depends only upon reactivity of the double bond. Thus, out of the almost infinite complexity of widely differing activities of very different compounds in producing growth, there appears an exceedingly simple picture of the effect of substances in the growth reaction.

After clearing up the activity of so many seemingly unrelated compounds, we will consider how it is possible that anxin takes part in so many processes inside the plant.
To reach a better understanding, we must first distinguish between two different states in which the auxin is present. In the first place, a certain amount of auxin is moving freely in the plant and can be obtained by letting it diffuse out of the tissue into agar. This free-moving, or diffusible, auxin is responsible for the correlation phenomena which are affected by auxin, such as bud inhibition, geotropism, etc. In the second place, auxin is present in the plant in a form which does not diffuse out, but can be obtained by extracting the killed cells with organic solvents. It is this form of auxin (bound auxin) which is responsible for growth. There are many differences in properties and behavior between these two states of auxin in the cell (Stewart and Went 1940). The diffusible auxin is not inactivated by light, its effect is independent of $\mathrm{pH}$, the double bond is not essential for activity, and it affects the transport of other growth factors, although it does not seem to combine with them. The story is quite different for the bound auxin. This is inactivated by light, its effect depends upon the $\mathrm{pH}$ of the cell, the double bond is essential for its activity, and it is this form which reacts with other growth factors to produce growth.

If we list now the various processes in which auxin takes part, the differentiation between the effects of diffusible and bound auxin will prove to be significant.

The first known function of auxin was its effect on cell elongation and all processes depending upon cell elongation, such as tropistic responses. A close analysis of the process of cell elongation has shown that the effect of auxin on it is dual: a preparatory reaction precedes the growth reaction proper (Went 1939b). This preparatory reaction, just as the phototropic induction, can be identified with the effect of the diffusible auxin, and depends on the movement of other growth factors along an auxin gradient.

The second auxin effect to be discovered was its role in bud inlibition (Thimann and Skoog 1933). This effect is wholly due 
to the diffusible anxin; only after the inhibition is released does the growth reaction come into play. In the case of induction of parthenocarpy, it is also primarily the preparatory reaction that is important.

But in root formation the situation is different. It has been known for a long time that the formation of roots on stems of plants is a correlation phenomenon. It the subsequent rooting response of the stem. This can be compared with the preparatory reaction in growth. But later the auxin takes part in the more specific rootforming reaction. This reaction is more specific than the growth reaction, so that certain substances like phenyl acetic acid can produce growth but not root formation. This leads to the following scheme:

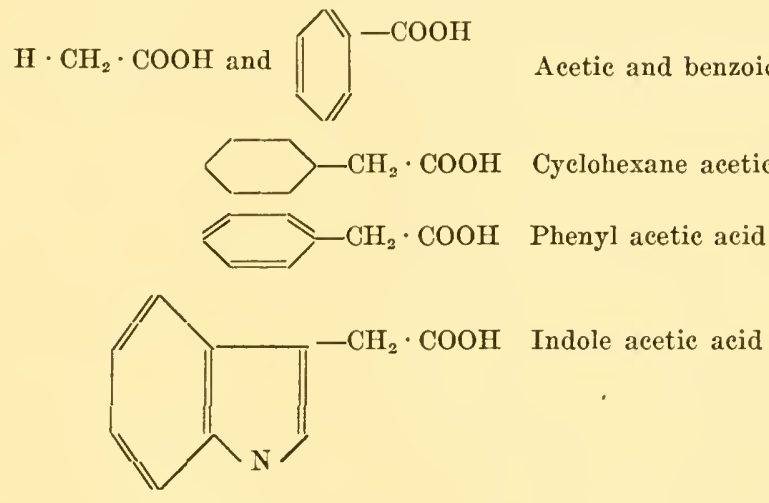

\begin{abstract}
No reaction
Preparatory reaction only

Preparatory reaction and growth
reaction

Preparatory reaction and growth reaction and root forming reaction
\end{abstract}

was shown that some specific hormone-like substance which was present or formed in leaves and buds was responsible for this effect (Went 1929), and finally it was found that in many cases this hormone-factor is identical with auxin (Thimann and Koepfli 1935). Now root formation is a typical organization involving induction of meristematic activity and re-differentiation of cells. Therefore it was of special interest to investigate in what way auxin affects root formation.

As a first point I must mention that a large number of factors proved to be involved in root formation. We can list the following : sugars, auxin, biotin, vitamin $B_{1}$, amino acids, carotene, rhizocaline. They are all necessary in one or another link of the chain of reactions leading towards root formation. If the conditions are carefully chosen, any one of the preceding substances may increase root formation. Still, under conditions of auxin deficiency all but one of the plants investigated respond to the application of auxin with root formation.

It was found that the effect of auxin on root formation is dual just as in the case of growth (Went 1939c). During the first hours of application auxin only increases
It shows that with increasing complexity of the molecule more and more functions can be performed by these substances. Therefore it can be predicted that the complexity of the auxin- $a$ molecule is connected. with still other functions inside the plant, which have not been discovered as yet.

In all cases which have been analyzed so far: cell elongation, bud inhibition, and root formation, the preparatory reaction could be identified with the effect of diffusing or free-moving auxin on the transloeation of other growtl factors necessary for the respective reactions. In this way the specificity of the effect of auxin is only connected with the specificity of the other or co-growth factors and the specific reactivity of the tissues.

Once we have proceeded so far with the analysis of the auxin effect, I am tempted to outline an hypothesis concerning the reaction in which auxin participates to produce growth. Is it possible to come to some concrete picture of part of the chain of reaction which leads to growth? At one end of the chain we feed in simple substances, chemically definable, like auxin, sugars, vitamins, etc. At the other end we obtain growth, which is not as yet de- 
finable in chemical terms. Still, the relationship between applied auxin and the resulting growth shows that auxin is involved in a reaction with a very high rate of combination between auxin and substrate, or carrier, the latter being present in a very small quantity only. This same type of reaction we encounter in enzymatic reactions. The substrate, or carrier, seems to be the factor which is transported under the influence of the diffusible auxin. The combination between auxin and its carrier is probably the process which is $\mathrm{pH}$ de- counterpart of the enzymatic processes, and which is able to account for all available facts. Among these I can mention the fact that although auxin application does not result in an appreciable increase in respiration, aerobic respiration is nevertheless essential for the action of auxin; and that HCN can inhibit its effect (Bonner 1933). This is understandable if the electron transfer and final oxygen disposal are part of the reaction chain in which auxin takes part; this would be expected if auxin acts as a hydrogen acceptor, and the auxin

Phenomenon

Reaction involved

Substances active

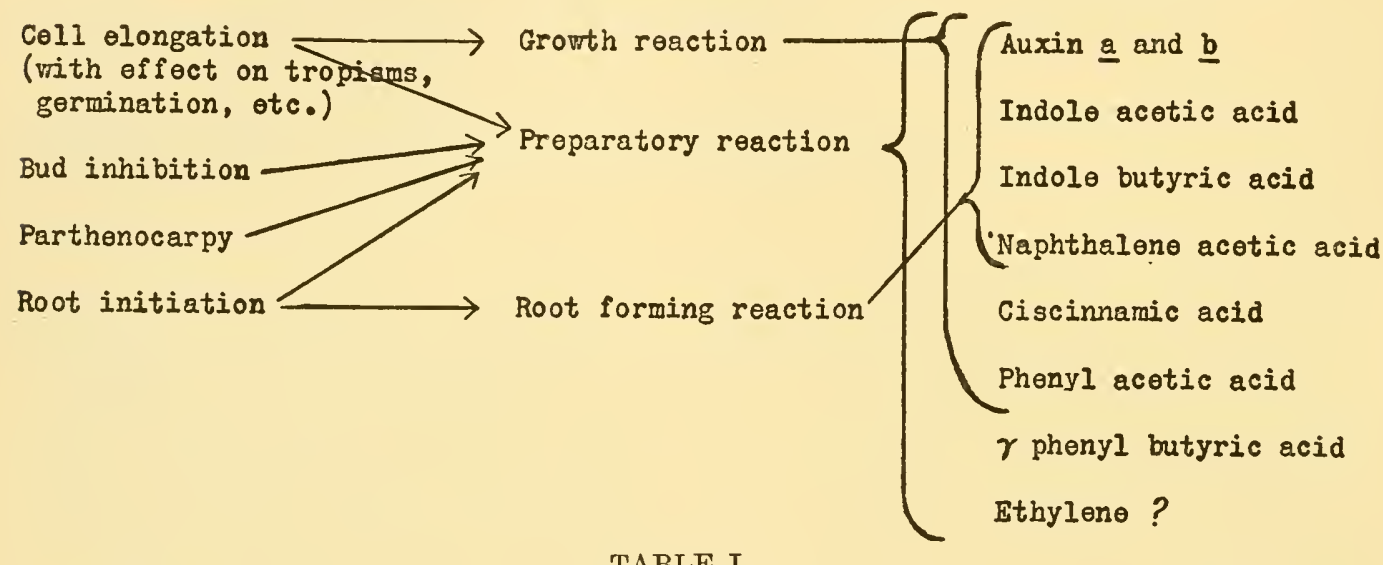

TABLE I

Relation between the Various Growth Phenomena, the Reactions Involved in Each PhenomeNON, AND SOME OF THE SUBSTANCES ABLE TO TAKE PART IN THESE REACTIONS

pendent, so that at low $\mathrm{pH}$ a greater amount of auxin is combined. This implies that the auxin is fastened to its carrier by means of its carboxyl group. This picture is in agreement with the fact that neither the carboxyl group, nor nitriles, nor esters of growth substances are active by themselves, which would be expected if the undissociated auxin-acid were the effective form.

We can complete the picture now by assuming that the other essential part of the molecule - the double bond-has come into the right spacial relationship with a hydrogen donator through its fixation by the carboxyl group, and that the double bond acts as a hydrogen acceptor. In this way we form a mental picture of the first step of the growth process, which is a direct passes on this hydrogen. Another parallelism between respiratory enzymes and auxin action should be pointed out. In enzymes the specificity is not due in the first place to the co-enzyme, but depends upon the protein carrier. In our picture of the auxin action also we had to assume that the type of reaction was not determined in the first place by the auxin, but by the carrier or substrate. In this respect auxin could be compared with adenine in respiration: the protein carrier determines which compound adenine nucleotide will be able to oxidize. I present this mental picture of growth not so much for its intrinsic value, as to indicate that perhaps in the near future we shall be able to build up a picture of growth and differentiation along purcly physical and chemical lines, similar to the 
picture of respiration which has developed with amazing clearness in the past few years. One thing seems certain: the period in which we had to describe growth of plants as a stimulation lies behind us, and a much more concrete chemical concept is developing.

But we are concerned not only with the chemistry of form, but also with its physiology as far as plant hormones are concerned. The problem of organic polarity, or gradients, or fields, which has been discussed by Child and Harrison, based on zoological evidence, can now be approached by the plant physiologist as well. The situation is simpler in plants, since the number of different organs is much smaller and also because of the indeterminate growth of a plant. We can work with plants of any size or age, since there are always meristematic regions, where new differentiation and growth occurs.

The most pronounced polarity in the plant is the apex-base polarity, which may be compared with the head-tail polarity of animals. It has been known, especially since the work of Vöchting $(1878,1884)$, that all stem and root cells possess a fixed apical and fixed basal pole which cannot be distinguished in any way under the microscope, but which appear in regeneration and transplantation experiments. We can very generally say that the basal end of a cut branch will regenerate roots, whereas the apical end will be the place where buds regenerate. This is very similar to the regeneration of hydroids which Child discussed. Only it is more difficalt to influence the type of regenerates in plants than it is in hydroids. In transplantation experiments Vöchting (1892) found that when pieces of tissues are grafted into others, the cells would grow together and the wound would soon heal, if the tissue were grafted in the normal position. But when basal ends of implanted cells touched basal ends of the cells of the host tissue, no growing together would occur. Sometimes vascular elements, when differentiating, would turn through $180^{\circ}$, so that again basal ends would join with the apical ends of the other tissue. But a functional base-to-base or apex-toapex junction never developed. Therefore this morphogenetic polarity is very pronounced in plants, and while of the same type as in animals, cannot be permanently inverted.

Now that we know that root formation is induced by auxin, it is possible to investigate the polarity problem from a hormone point of view. My original idea was that the localized auxin production in the tips of plants furnishes a very nice basis for polar functions in the plant. If hormones are formed only in one place, this must, of course, have an influence on the organization of the plant. This simple viewpoint completely overlooked the problem of why the auxin production was localized. And it also was of no avail in explaining polarity in excised cells. Then another phenomenon was discovered, namely, the polar auxin transport (Went 1928).

Auxins, including the synthetic indole compounds, are able to move only from apex to base in stem, petiole, and hypocotyl tissues, as long as the transport occurs in the living elements of the plant and at physiological concentrations. We have good evidence for believing that in the normal plant auxin moves only through parenchyma and phloem cells, and therefore the auxin moves only from apex (where it is formed) to base. Now we know that auxin induces root formation, and indeed it could be shown that the polarity of root formation is due to the polar movement of auxin. Also in other cases it has been proved that morphogenetic polarity in plants is caused by polar movement of auxin. By light or gravity a second polarization can be superimposed upon this apexto-base polarity, so that even more complex polarities can be based on auxin movements (Went and Thimann 1937). But this means that morphological polarity can be studied in terms of the movement of a chemically known substance, or in other words, that polarity is reduced to a problem of pure physics. I do not say simple problem, because so far it has not been 
possible to comnect this polar auxin movement with any other physical forses which can be measured, such as potential differences (Clark 1937). But I am thoroughly convinced that with the help of a really competent physicist the problem can be solved. And the importance of the problem from a general biological viewpoint is sufficient to justify a very thorough investigation.

When we conclude that organization and correlation in plants is regulated by the polar movement of auxin, then it will be evident that this is also a complete proof of Sachs' conception of correlation (1880; 1882).

Another of the great biological problems, the action of the genes, can be approached by the student of hormones. Many genes affect or determine form. Hormones are the ultimate agents to affect that form. Therefore either the hormones are formed under the influence of the genes, or the genes influence the hormones after they are formed. By a close analysis of the interaction between genes, hormones, and form, the gene action can be approached. I want to cite only one example, the work of van Overbeek (1938) on the genetic dwarfs of corn. In this case he could establish the fact that the different dwarf genes all increasea the oxidative activity of the cells, as measured by catalase and peroxidase activity. This in turn caused an increased auxin destruction, so that the auxin formed in the stem apex practically or completely failed to reach the growing regions, and no elongation of the stem could occur. Therefore a dwarf was produced. This example shows how it is possible to shorten by a hormone analysis the unknown portion of the chain of reactions lying between the gene and its ultimate morphological effect.

Now it becomes necessary to tie all occasional observations on plant hormones together into one composite picture of the plant as a whole - as an organism-as something more than a simple colony of cells.

Transplantation (Went 1938a) and other experiments (Went 1938) have furnished evidence for the existence of another stem growth factor coming from the root system, which has not been chemically isolated as yet, but which will be named caulocaline.

Recently the chemical nature of some factors required for leaf growth has been established by Bonner and Haagen-Smit (1939). These factors are necessary for growth in the surface of the leaf, and are produced by the older, fullgrown leaves. Therefore the correlations between young leaves and the rest of the plant are brought about by other specific growth factors, such as adenine.

One further correlation which is caused by hormones, is shown by recent experiments on photoperiodism (Hamner and Bonner 1938). It was found that the differentiation of a vegetative bud into a flower bud was caused by a factor coming from the mature leaves. Determination of the chemical nature of this flower-forming substance now seems to lie well within practical possibilities, since James Bonner recently obtained active extracts which induce flower formation.

Figure 2 summarizes the different interrelations between the parts of a plant, which have just been discussed. It shows more clearly than any verbal description the large number of correlations inside a plant, all due to the action of hormones. Since all these relations are quantitative, an amazingly great unity within the plant is realized, in order that one part shall not grow too much at the expense of another. Only in this way is it possible for taxonomists to describe a plant in terms of relative dimensions. The picture is the same as for animals.

And it also brings back our original contention that the interrelations between cells and organs can be brought about by the simplest means: that certain cells lose the ability to synthesize one or another simple basic nucleus which is necessary for their build-up.

\section{Summary}

An effort lias been made in this diseussion to bring out especially those facts which have a more direct bearing on the 
nature of the growth process. Although only a few tentative steps towards a better understanding of growth and development could be made, still the evidence in favor

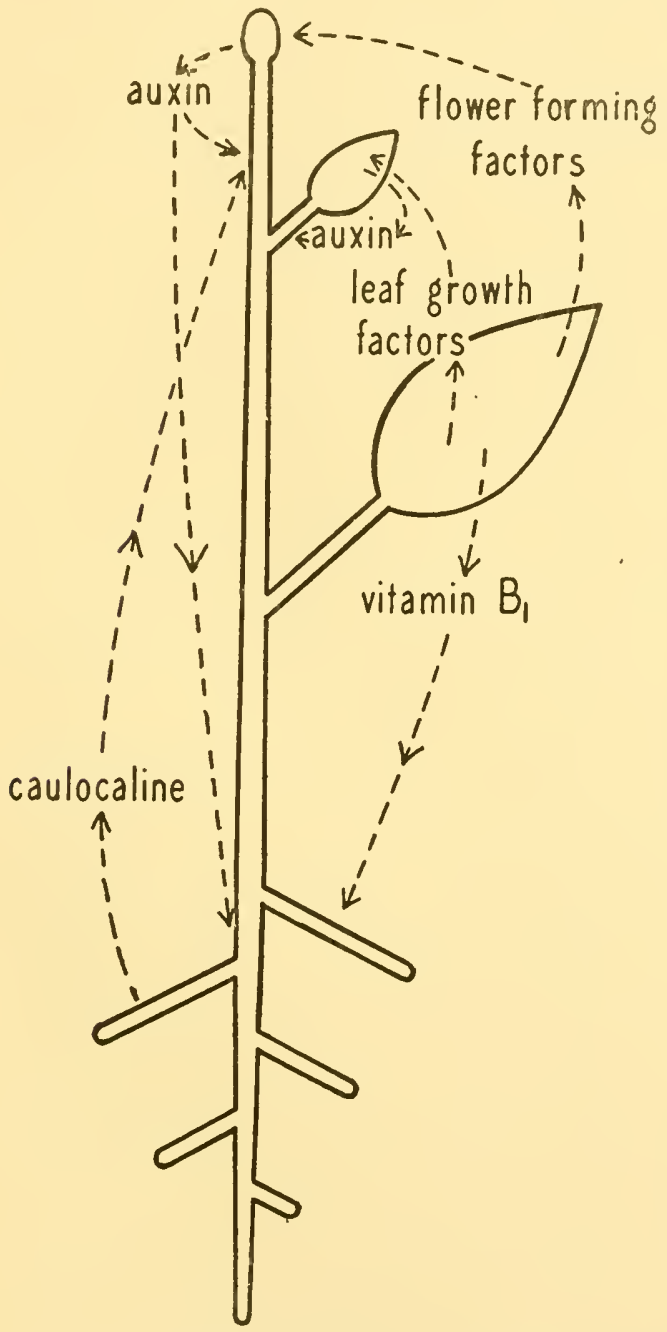

FIG. 2. Schematic drawing of a plant with root system, stem, old and young leaf and apical bud. Some of the known correlations are drawn with broken arrowed lines, indicating the factors responsible for these correlations. The sugar interrelations are not shown.

of a chemical concept has become very strong, and a concrete picture can replace the older stimulus concept. Although we still have a long way to go, the results obtained justify confidence in a rapid and fruitful development of our knowledge concerning growth and development. Conklin in his opening paper stressed the absolute necessity of scientific cooperation, and how every advance has been not so much the discovery of a single individual as a general growth of ideas from generation to generation, a transfer of thoughts between individuals. There are few fields which have so benefitted from interaction between individual scientists, between botanists, physiologists, chemists, geneticists, horticulturists, and biochemists as the field of plant hormones. If I have mentioned names of individuals in the preceding discussion, their work was worth mentioning, but hundreds of others have helped to build up our present picture. In general, a splendid cooperative spirit exists amongst these plant-hormone workers, a spirit which transcends borders and political differentiation.

In the second place, I have tried to view a few of the problems of plant development from so broad an angle that the essential similarity between processes in plant and animal would be stressed. So far botany has learned more from animal physiology than the reverse; let us hope that the investigation of the principles of plant growth will be of help to zoologists as well. The greater complexity of an animal makes it more difficult to establish the fundamental basis of its development, and in this respect the investigation of plants has great advantages over that of animals. Because of their differentiation and organization, the micro-organisms cannot be of the same help to us here as they have been for the investigation of so many fundamental properties of the cell, as van Niel so well pointed out. But in respect to an increase in our knowledge of growth and development, the plants have the same relation to animals as the micro-organisms have to the higher forms of life.

In conclusion, I want only to mention that increase in our knowledge concerning the basic principles of plant growth inevitably leads, and in fact, has led, towards practical applications in agriculture and horticulture. No better example of the application of so-called pure research to practical problems could be quoted than this 
on plant hormones, which means in other words, that a distinction between pure and applied research is highly artificial, and should be dropped, as it is being dropped here in America.

\section{References Cited}

ADDICOTT, F. T. and BoNNER, J. 1938. Nicotinic acid and the growth of isolated pea roots. Science, 88: 577 .

BonNer, D. M. 1938. Relation of environment and of the physical properties of synthetic growth substances to the growth reaction. Botan. Gaz., 100: 200.

Bonner, D. M. and HaAgen-Smit, A. J. 1939. Leaf growth factors. II. The activity of pure substances in leaf growth. Proc. Nat. Acad. Sci. U. S., 25, 184-188.

BoNNER, J. 1933. The action of the plant growth hormone. J. Gen. Physiol., 17: 63.

- 1937. Vitamin $B_{1}$ a growth factor for higher plants. Science, 85: 183 .

- 1937a. The role of vitamins in plant development. Botan. Rev., $3: 616$.

Boysen Jensen, P. 1911. La transmission de l'irritation phototropique dans l'Avena. Bull. Acad. Roy. Danmark, 1: 3.

Clark, W. G. 1937. Electrical polarity and auxin transport. Plant Physiol., 12: 409; 13: 529.

Doposcheg-Uhlar, J. 1911. Studien zur Regeneration und Polarität der Pflanzen. Flora, 102: 24.

Fitring, H. 1909. Die Beeinflussung der Orchideenbliiten durch die Bestäubung und durch andere Umstände. Z. Botan., 1: 1 .

FitTing, H. 1936. Die Hormone als physiologische Reizstoffe. Biol. Zentr., 56: 69.

Gustafson, F. G. 1936. Inducement of fruit development by growth promoting chemicals. Proc. Nat. Acad. Sci. U.S., 22: 628 .

MANiner, K. C. and Bonner, J. 1938. Photoperiodism in relation to hormones as factors in floral initiation and development. Botan. Gaz., 100: 388 .

Koepfli, J. B., ThimanN, K. V. and Went, F. W. 1938. Phytohormones, structure and physiological activity I. J. Biol. Chem., 122: 763 .

KöGL, F. 1935. Über Wuchsstoffe der Auxinund der Bios-Gruppe. Ber. Deut. Chem. Ges., 68: 16-28.

KöGL, F. and HAagen-Smit, A. J. 1931. Über die Chemie des Wuchsstoffs. Proc. Acad. Sci. Amsterdam, 34: 1411.

Kögl, F., HaAgen-Smit, A. J. and Erxleben, H. 1934. Ueber ein neues Auxin ("Hetero-auxin") aus Harn. Z. Physiol. Chem., 228: 90.

KögL, F. and ERxLeben, H. 1934. Über die Konstitution der Auxine a und b. X. Mitteilung über pflanzliche Wachstumsstoffe. Z. Physiol. Chem., $227: 51$.

Kотте, W. 1922. Wurzelmeristem in Gewebekultur. Ber. Deut. Botan. Ges., 40: 269.
PaAl, A. 1919. Ueber phototropische Reizleitung. Jahrb. wiss. Botan., 58: 406.

RobBins, W. J. 1922. Effect of autolized yeast and peptone on growth of excised corn root tips in the dark. Botan. Gaz., 74: 59.

Robbins, W. J. and BARTLEy, M. A. 1937. Vita$\min B_{1}$ and the growth of excised tomato roots. Science, 85: 246.

Robbins, W. J. and Schmidt, M. B. 1939. Further experiments on excised tomato roots. Am. J. Botany, 26: 149.

SACHS, J. 1880; 1882. Stoff und Form der Pflanzenorgane, I and II. Arb. Botan. Inst. Würzburg, 2 : 452 ; 689 .

SteWART, W. S. and Went, F. W. 1940. Light stability of auxin in Avena coleoptiles.

Thimann, K. V. 1935. On an analysis of the activity of two growth-promoting substances on plant tissues. Proc. Acad. Sci. Amsterdam, 38: 896.

Thimann, K. V. and Skoog, F. 1933. Studies on the growth hormone of plants. III. The inhibiting action of the growth substance on bud development. Proc. Nat. Acad. Sci., 19: 714.

Thimann, K. V. and Koepfl, J. B. 1935. Identity of the growth promoting and root-forming substances of plants. Nature, 135: 101.

VAN NIEL, C. B. 1940. Chemical aspects of microorganisms. This book.

VAN Overbeek, J. 1938. Auxin production in seedlings of dwarf maize. Plant Physiol., 13: 587.

Vöchting, H. 1878; 1884. Über Organbildung im Pflanzenreich. I: 1-258; II: 1-200. Bonn. - 1892. Über Transplantation am Pflanzenkörper. Tübingen.

WeNT, F. W. 1928. Wuchsstoff und Wachstum. Rec. Trav. Botan. Neerland., 25: 1.

-1929. On a substance, causing root formation. Proc. Acad. Sci. Amsterdam, 32: 35. - 1934. On the pea test method for auxin, the plant growth hormone. Proc. Acad. Sci. Amsterdam, 37: 547.

- 1938. Specific factors other than auxin affecting growth and root formation. Plant Physiol., 13: 55.

- 1938a. Transplantation experiments with peas. Am. J. Botan. 25: 44.

. 1939. Further analysis of the pea test for auxin. Bull. Torrey Botan. Club, 66: 391.

- 1939a. Analysis and integration of various auxin effects. Proc. Acad. Sci. Amsterdam. 42: 581, 731 .

‥ 1939b. A case of correlative growth inhibition in plants. Am. J. Botan., 26:505.

. 1939c. The dual effect of auxin on root formation. Am. J. Botan., 26: 24.

Went, F. W. and Thimann, K. V. 1937. Phytohormones. New York.

White, P. R. 1934. Potentially unlimited growth of excised tomato root tips in a liquid medium. Plant Physiol., 9: 585. 


\section{VITAMINS}

\section{By ALBERT SZENT-GYÖRGYI}

DEPARTMENT OF MEDICAL CHEMISTRY, UNIVERSITY OF SZEGED, SZEGED, HUNGARY

To understand what vitamins have meant for medical thought we should go back in our thoughts to the end of the last century. At this time medicine celebrated two great victories. One was connected with the name of Pasteur, who showed that epidemic diseases were caused by positive agents, micro-organisms; and it looked as if all diseases must have well-defined positive causes. The other victory was carried by the students of nutrition, Zunz et al., who brought feeding into the realm of quantitative science by showing that food had to have a certain caloric value and that if the three main foodstuffs-protein, fat and carbohydrate-were well balanced, all was well.

There remained in the shade of these victories certain diseases, like beriberi and pellagra, which still wiped out thousands of lives and for which no causative agent could be found. So we can understand the impression caused by the observations of a young Dutch doctor, Eijkman, observations soon completed by another Dutchman, Grijns, which indicated that these diseases were not caused by something positive but rather by something negative - something missing from food. F. G. Hopkins, who continued these studies, showed that the substance which was missing could be present under normal conditions only in minimal quantities which could have no caloric importance. There must be something in food, in minimal quantities, which keeps disease away and keeps us healthy, something connected with the mystery of life; and it seemed doubtful whether this mysterious something was a substance or rather a quality of living matter. At the suggestion of Funk these agents were called "Vitamins."

That disease could be caused by the lack of something, by a deficiency, was an entirely novel idea. I insist on this point be- cause even up to the present day we are unable to give a more satisfactory definition of vitamins than to say that they are the substances that make us ill if we don't eat them. ${ }^{2}$ All other things in the world make us ill only if we do eat them or at least expose ourselves to their action.

A great number of research workers have set out to study these mysterious vitamins, special laboratories have been founded, and funds donated. At the beginning there was naturally much controversy. The smoke of these battles has blown away, and the patient work of all these workers has cleared up the problem. Today most of these vitamins, formerly so mysterious, are not only isolated but also synthesized. They stand in bottles on the shelf of the biochemist in one row with the other chemicals and cannot be distinguished by their looks from common salt, sugar, etc. The only difference may be that the chemist shows them to his visitor with more pride.

We not only have these substances in hand; we also understand them better. We know that that wonderful machine, the cell, is built up of many thousands of different wheels, which the chemist calls molecules. All of them are very small compared to the objects of our daily life, but they vary enormously among themselves. There are small ones with the relative weight of a few grams, some with the weight of a few hundred, and some with the weight of hundreds of thousands or millions. Of some we find little in the cell, of others rather much. All these wheels are equally

1 The definition is not a complete one for there are other substances, too, which make us ill if we don't eat them, like tryptophane, histidine, iodine, etc., etc. There is no use in dwelling upon definitions. We all know, more or less, which substances we mean by saying "Vitamins," and as long as we know this there is no use in giving definitions. If we do not know, a definition will help little. We must say, "Vitamin-you know what I mean." 
important and indispensable, and if any are missing there will be disturbud function and disease. Most of these wheels can be manufactured by the cell itself from other "raw materials" so that they can be replaced when they are used up, even if they are not contained in one's food. There are, however, a few substances of medium size, which our cells cannot put together (a relatively small quantity); these must be taken ready made or almost ready made from our food. If the food does not contain these substances and we are unable to replace a shortage in our own stores, there will be disturbed function, a disease generally called a "deficiency disease." These are the substances we call vitamins. For every single vitamin there will be a corresponding deficiency disease, an avitaminosis.

In the last analysis all these vitamins come from plants, for it does not matter whether we eat the cabbage or the cow that ate the cabbage. This simple fact involves a point of the greatest philosophical importance. If I look upon the cell as a mechanism and upon the molecule as a wheel of this mechanism, then by saying that I take my vitamins from the plant I say that there are two mechanisms, the plant cell and my cells, whose parts, the single wheels, are interchangeable. Two mechanisms, whose parts are interchangeable, cannot be very different. This is the first scientific evidence for the great, fundamental chemical unity of living Nature. There is no real difference between cabbages and kings. We are all recent leaves on the old tree of life.

Research has brought to light such a wealth of observations on vitamins-their nature, action, structure, distribution, symptoms of deficiency, etc.-that it would be a hopeless job to try to review this material. For such a review I lack both time and knowledge, and I could exhaust only you and not my subject. So I will limit myself to a review of the gradual development of our general ideas concerning vitamins.

To start somewhere I will start with the name, "Vitamin," and its implications. "Vita" implies that these substances are involved in the mystery of life; "amin" means that they are chemicals known as amines. Today there is no more mystery and we know they are not amines; that's that. To be sure, life is still a mystery and every substance involved in life is a mystery, but in this connection there is no essential difference between vitamins and common salt. The latter looks much more mysterious to me.

There is another very important implication of the word "Vitamin." This word suggests a quite specific, isolated, and closely related group of substances, in some way fundamentally different from all other biological material. This is a most important point, for there has been much speculation about "equilibria of hormones and vitamins" and the like. If vitamins are really a special sort of substance, this is all right; but if we denote by vitamins only a group of substances which are related by some secondary, accidental factor, then all this is wrong. To make this clear: if $I$ classify together all biological substances which have names beginning with $\mathrm{P}$, for instance, and give them a beautiful name, say Pitamin, evidently any speculation about the equilibrium of Pitamins with hormones would be unjustified.

In what way could Vitamins be different from other substances: their appearance, their structure, their biological action? In appearance the vitamins are in no way different from other substances. There is no uniformity in their chemical structure, either. We find among vitamins the most varied formations, like thiazines, alloxazines, pyridines, carbohydrate derivatives, phenanthrenes, etc.

So our last hope is that we may find some essential unity in the mode of action of vitamins. When we speak of the mechanism of action of any biological investigation what do we mean? Physiology and pharmacology have produced a host of substances with the most striking biological activities, but we are ignorant about the mechanism of these reactions. By mechan- 
ism of action $I$ mean what a particular molecule does in the cell, on what molecule of the cell it acts, and in what way it acts. With these biologically active substances we can produce the most wonderful effects -we can resuscitate the dead, transform the male into the female, and vice versa, inject a pennyworth of mother-love, etc., etc.--but we have no idea what we have really done. The physiologist producing such wonderful reactions with his active substances reminds me of the savage who, with his penny, produces wonderful music from a music box.

This coexistence of the most wonderful success with the most profound ignorance is one of the characteristic features of present-day biology. It can easily be understood. To produce the effect we need only to have the substance and to put it into the animal. To understand its action we must understand both partners of the bargain, the active substance and the cell on which it acts; that is, the penny and the music box. We know all about the first, the active substance, but next to nothing about protoplasmic structure.

We must not be misled by appearances. You will find a huge literature on the action of vitamins. The symptoms of vitamin deficiencies have been carefully studied, and it seems as if we completely understand how the lack of a vitamin produces those symptoms and how the vitamin cures them. So, for instance, in $B_{1}$ avitaminosis we find ataxia and paralysis. The vitaminologist studies the brain and finds polyneuritis and structural lesions which fully explain all the observed symptoms. Now he administers vitamin $B_{1}$ to the animal and sees that the symptoms and lesions disappear, and is satisfied that he has explained the whole action. He calls his vitamin the "antineuritic vitamin," a name which suggests that the substance is there to keep neuritis away. But a brief consideration tells us that this impression is wrong. Rice bran and yeast are both rich in vitamin $B_{1}$, and neither of these has brains. So it cannot be the sole object of aneurin $\left(B_{1}\right)$ to prevent the occurrence of polyneuritis.
This whole problem has been solved lately by a discovery of $\mathrm{K}$. Lohmann, who found that the coenzyme of decarboxylation of pyruvic acid is phosphorylated vitamin $B_{1}$. Now decarboxylation of pyruvic acid is one of the most basic chemical reactions throughout living nature. Naturally, if a basic chemical reaction goes wrong there will be one organ which shows injury first. So, for instance, if I don't breathe I will faint, and my brain will be the first organ to declare itself. This does not mean, however, that oxygen is a neurotropic substance. So if vitamin- $B_{1}$ deficiency has its greatest effect on the brain, this does not mean that vitamin $B_{1}$ is a specific constituent of the nervous tissue. The symptoms we see in the animal tell us practically nothing about the real mode of action of a substance. A few years ago two Americans, Burr and Burr, found that the rat would lose its tail if highly unsaturated higher fatty acids were missing from its diet. It looked as if an "anti-taildrop-off", vitamin had been discovered. Naturally it is not the function of the unsaturated fatty acids to stick the tail to its place by their double bonds. Both vitamin $B_{1}$ and fatty acids have some basic function in the cell. Whether it will be the head end or the tail end of the animal which is affected first gives us little information about the real mode of action, as ataxia tells us nothing about decarboxylation.

It is very important to remember that all these vitamins are not specific substances, present to prevent some specific disease of some specific tissue. They are basic constituents of the cell--all cells, animal and vegetable-and symptoms like capillary fragility, or loosening of teeth give us no information about this basic function.

We are well informed about the mechanism of action of only a few biologically active substances. These are substances that happen to act in cell functions which are sufficiently understood. One of the processes which has perhaps been analyzed most of all cellular processes is biological oxidation. This process is fairly well known, partly because it is a violent re- 
action with violent material changes which lend themselves for analysis, and partly because in principle oxidation is a simple process, a transfer of hydrogen or electrons through a series of substances. Fortunately there are a few vitamins involved in this process, like alloxazines, nicotinic acid, and probably $B_{1}$. The function of these substances is to transfer electrons or hydrogen, and is in no way different from the action of other non-vitaminic catalysts involved in this process.

As far as we can see, therefore, the mode of action of a vitamin is in no way different from the mode of action of other substances and this point, too, fails to distinguish the vitamins as a specific group of substances.

At the beginning of my lecture I defined the Vitamins as substances which make us ill if we don't eat them, because we are unable to make them ourselves. This last specific quality of vitamins remains-that they cannot be made by our cells. One might thus say that here is the real specificity of vitamins which must have some common mysterious quality in their molecules which makes their synthesis impossible within our cells. One might also add that all my talk about the unity of Nature is nonsense, for here is a great point of difference between plant and animal: the plant can make vitamins, the animal can't. This point deserves our full attention and we must try to find out whether it is really some basic quality, or merely an accidental factor which makes this synthesis impossible.

At first thought, we might suspect that there could be no real difficulty about synthesizing a vitamin, or else the plants could not do it either. After all, the cabbage is not much wiser or more elever than we are. But let us follow historic developments.

Some time ago we believed that vitamins were substances synthesized by plants but not by animals. There was a little hitch in this definition. It was known that most animals of our climate, for example rats, did not contract scurvy if fed on a vitamin-C free diet. This observation was dis- missed with the hypothesis that these animals did not need vitamin C. But some fifteen years ago M. Pearce showed that rats could synthesize vitamin C. If she bred rats on a $\mathrm{C}$-free diet, the tissues of the great-grandchildren contained just as much of this substance as those of their greatgrandmother. Today we have good reasons for believing that there is no higher organism which can live without ascorbic acid, vitamin $\mathrm{C}$, and that if most animals of our climate-dogs, cats, rats, fowls, cows, rabbits, etc.-do not contract scurvy, it is not because they can dispense with vitamin $\mathrm{C}$ but because they can make it. For these animals ascorbic acid is not a vitamin at all, and you must be careful what you say to a rabbit, for if you tell him that ascorbic acid is a vitamin he will just laugh at you. For him vitamin $\mathrm{C}$ is not a vitamin at all: he can make it.

It is easy to understand why this should be so ; if the rabbit could not make ascorbic acid it would die from scurvy during the winter when there is no ascorbic acid to be found in Nature, and there would be no rabbit at all.

However this may be, it is evident that the old sharp borderline between vitamins and not-vitamins has vanished. What is a vitamin for one species is not a vitamin for another, and if we say a substance is a vitamin, we should mention the species for which it is a vitamin. Thus, the inability to synthesize vitamins gives us no reason for separating the vitamins from other substances; moreover, there are many substances which we do not call vitamins which we are also unable to synthesize.

All the same, because this question of synthesis is most intimately connected with the whole conception of a vitamin, we must try to understand it still better and try to find out why some species are unable to make some of these substances while others can. We will do best not to lose ourselves in generalitics. Let us take one example and ask, for instance, why we are unable to make ascorbic acid, while the rabbit can make it. But to be more discreet we will talk not about ourselves but about our ex- 
perimental animals. We possess only two experimental animals in which scurvy can readily be produced: the guinea pig and the monkey. What is there specific and common about these two animals? The answer call easily be found; these are the two experimental animals which come from the ever-green tropical surroundings where there is green food (which contains ascorbic acid) all year round. One of the basic laws of Nature is laziness; Nature will not do unnecessary things, and if a species has no need to make ascorbic acid, it will not make it; it will forget, or never learn how to make it. The rabbit cannot permit itself to do this, for it would die during the long winter in our moderate climate.

So you see the ability or inability to make ascorbic acid, perhaps the most classical vitamin, does not reside in some fundamental quality of the molecule or of the animal. It lies in an accidental circumstance, in the living habits of the race in question. To sum up our whole discussion, we ean say that vitamins do not represent a specific group of substances, connected and characterized by some basic quality of their molecule. They are substances related by some accidental factor, like the Pitamins. The word Vitamin has no deep meaning; it does not convey much to the mind.

I do not want to belittle the practical importance of Vitamins, for after all, we become ill if we do not eat them, and we all want to be healthy; so this is, at least practically, a most important point. As the whole importance of vitamins is connected with this question of health and disease, let me devote the rest of my time to this problem. Again this practical, medical application centers around one question: how much of these vitamins should we eat daily to keep fit? I fully realize that this is not a medical conference. But I can formulate this problem also in more general biological terms and ask how much of these vitamins an organism needs for its normal function? Had I been asked this question two years ago I should have answered with precision, giving the quanti- ties of the single vitamins in milligrams. The great progress in this ficld is our understanding that we are unable to answer this question any more.

To see this point better, let us watch the vitaminologist for a moment at his work. We will watch a $\mathrm{C}$-Vitaminologist. $\mathrm{He}$ will take several, perhaps a dozen, guinea pigs and put them on a C-free diet. To different animals he will give different amounts of ascorbic acid. He will observe that the animals with no ascorbic acid die from scurvy ; that animals with $0.5 \mathrm{mg}$ daily show mild scurvy; and that those with $1.5 \mathrm{mg}$ show no scurvy at all. He will be satisfied and will say that those with $1.5 \mathrm{mg}$ have no scurvy, and are therefore healthy, and that $1.5 \mathrm{mg}^{\prime}$ is thus the normal daily dose.

This experience has been extended unconsciously to man. Under ordinary conditions we see no scurvy (and no beriberi or pellagra), and we assume that there are enough vitamins in our food.

All this would have remained unquestioned had the biochemist not synthesized vitamins and given them to the doctor, who could now give unlimited quantities to his patients. These trials have given unexpected results. To quote one example; it has been found that alcoholic neuritis can be cured by the application of vitamin $B_{1}$. The special beauty of this is that we can even go on drinking if we only take a little $B_{1}$ alongside. But how can we explain this effect? We have been told that there was no lack of vitamin. Should we suppose that the vitamin acted like aspirin, a chemotherapeutic agent which will give the greater effect the more we take of it. This would be in contradiction to our classical conceptions. I must make this clearer: we have seen that $B_{1}$ is a co-decarboxylase. Every day we must decarboxylate a certain number of pyruvic acid molecules. For this we need a certain number of $B_{1}$ molecules. If we have this number all is well, for enough is enough. An excess will not help. So we always supposed that most vitamins produced a favorable effect only if there was a shortage, and that an excess would have no action, especially in the case 
of a water-soluble vitamin (because any excess is easily excreted).

To come back to our patient, we were told that the vitamin acted only if there were a lack of it, but that there was no lack. In spite of this, the vitamin helped. It is evident that something was wrong about our basic concepts, and we must find the mistake. I think this can be done if we watch our vitaminologist once more but watch him more carefully. He said his guinea pigs had no scurvy; therefore they were healthy. Here, I think, is the error. Does "no-scurvy" mean "healthy"? Can we divide the world into scurvy and noscurvy? How does he know that his animals were healthy? Just because they had no scurvy? Do you necessarily call it health if you sit in a protected cage, as these animals did, and have no scurvy? But what then is health? Is it the same as no-scurvy? Certainly not. Health, full health is a condition of the body in which all functions work at their best. To find out about this we should not allow our animals to sit in a protected cage, but should subject them to all sorts of strain and determine the level of vitamin intake at which they do best.

To be brief, there are reasons to believe that there is a wide zone between full health and scurvy. From the fact that an animal does not show the gross lesions of scurvy we cannot conclude that it is optimally provided with vitamin C. Between scurvy or any avitaminosis and health there is a wide range of hypovitaminosis, which may show no clinical symptom but which acts all the same as a latent pathogenic factor; and if it associates with another pathogenic factor, like alcoholic intoxication, the two together may lead to a manifest disease. How far we will be able to benefit our man with the application of vitamins depends on the part played by the vitamin in the pathogenesis, and how far the changes are reversible. To repeat: vitamins are basic constituents of the cell. If there is not enough of them the cell cannot work at its best and might be unable to resist pathogenic factors which under opti- mal conditions would have been resisted. In this way vitamins might be involved in the pathogenesis of any disease; this gives us hope that vitamins, if properly understood, will contribute to the reduction of human suffering to an unexpected degree. They have done so in the past; they might do still better in the future.

I will conclude this lecture on a philosophic note. What does all this talk about vitamins, health, and disease really mean? Let us ask a monkey what vitamins mean for him. The only problem is which monkey we should ask, the monkey in the zoo or the monkey in the jungle. For the monkey in the zoo vitamins mean very much. I am told that monkeys in the London Zoo must have ultraviolet irradiation, that is, vitamin D, and that the guard must see to it that they have plenty of vitamin C. To the monkey in the jungle vitamins mean nothing. There are plenty; there is no need to think of them; and these vitamins go through his body with his food. In the form of food and air the jungle goes through the body of our monkey as the monkey goes through the jungle. I mean that the monkey, some day, dies and is eaten by the lion; the lion dies and a tree grows out of it; a new monkey eats the leaves, and so forth, and all the material is in constant circulation. In fact, individual life means very little in the jungle. The whole bound nitrogen of the jungle is present in living form, now a rabbit, then a lion, a cow, a tree, or a monkey. The whole jungle is one big organism and health in the jungle means a perfect adaptation to this organism. Part of this adaptation is that the bociy does not make certain substances, like vitamins. But if you suddenly take our monkey out of this big organism, the jungle, to which he is perfectly adapted, put him on the pavement of a foggy big city, and give him food for which he is not made, because it does not contain all those substances which went constantly through his body in relatively large quantities during millions of years, then our monkey will fail, and become ill. His doctor will call his failure by different Latin 
names by which he means certain diseases; but these are in essence only an expression of a lack of adaptation to new surroundings. So the vitamins in their deeper analysis are but a part of this adaptation, are but one of the strongest links between our body and our old home, the original surroundings in which our race was born.

It has been stressed repeatedly by the lecturers of this conference that a cell is more than an agglomerate of molecules, and that the body is more than the sum of its cells. So the whole living Nature is more than the sum of its individuals. It is a huge organism, of which we are the cells, strictly adapted to our environment. In this adaptation vitamins are one of the most important factors, so I bope that this discussion was not entirely out of place at a cytological conference. 


\title{
MOLECULAR STRUCTURE IN PROTOPLASM
}

\author{
By O. L. SPONSLER
}

DEPARTMENT OF BOTANY, THE UNIVERSITY OF CALIFORNIA AT LOS ANGELES, LOS ANGELES, CALIF.

DURING this conference on the cell and protoplasm various excellent papers have been presented which have given several conceptions of protoplasm so far as constitution is concerned: it was discussed first as seen through the microscope; following this various ideas were proposed introducing submicroscopic and molecular entities, such as viruses, enzymes, hormones, and vitamins which may exist within the protoplasm of the cell; but as yet no very tangible picture of the protoplasm itself has been presented, especially from a molecular viewpoint. What seems to be desirable and what I shall attempt to present is a picture which will bring together these molecular and microscopic visualizations into a single conception.

Practically all of the picture is to be a three-dimensional structure in the submicroscopic region elosely associated with molecular dimensions. The units or building blocks are of molecular and submicroseupic size, and in order to visualize them we resort to models which are built to comply with the known properties of these units.

Obviously the structure must be speculative and hypothetical to a certain extent but must have a foundation in experimental fact. It is to be peculiarly free from precursors, determiners, acceptors, donors, and other indefinite substances which are mostly names without physical, molecular structure. The complexities, details, and known facts concerning protoplasm are so great that it has been necessary in formulating the structure to resort to the usual trick, so commonplace in biological fields and in other fields of science although not always so obvious, of talking in terms of genus or family while thinking in terms of species. The result of this is an ideal which is more or less representative of a large assortment of different speeific forms.
The picture we shall present, then, must be considered as a first approximation, a frame of a sort, which may be modified by substitutions and additions where specific demands require. It is an imperfect and crude model which eould not have been made ten years ago, for our knowledge of molecular structure and atomic dimensions and properties were not then sufficiently advanced. It may be a bit premature at the present time, and we shall not be surprised nor disappointed if new viewpoints nıake consirlerable alteration necessary.

To those who have followed this series of papers and discussions, wholly or in part, it must have become evident that protoplasmic material which could perform in the various remarkable ways described could do so only if it were organized structurally along some definite plan. Perhaps the plural would be better, for it seems highly probable that no single plan could account for all of the various phenomena described by the writers. On the other hand, there are certain features common to the protoplasms of practically all organisms, plant and animal. There must exist, then, patterns within patterns. The versatility displayed by protoplasms, speaking in a general sense, seems far too great to come within a single pattern, for directly or indirectly we have ascribed to the living protoplasm practically all of the processes and activities which may be attributed to living organisms.

"Structure," in the sense of pattern, has appeared time after time in these papers as the theme around which a conception of activities has been built. Structure and organization, to our mechanical minds, require materials from which to be constructed; and the conception of activities demands a dynamic, a changing, moving, active structure. The versatility required seems to force complexity into the structure or, shall we say, demands many struc- 
tures. These three things, materials, activities, and versatility, if we may so speak of them, are the basic concepts towards which we must proceed if a comprehension of vital phenomena is to be attained. How to proceed towards attainment of such an understanding has been a question for the past 100 years, and in our clumsy, human way we have been slowly enlarging our comprehension principally by reducing a chaotic world to a more simplified picture, one which seems to come within our reach. Our task here is primarily with the materials, the structure only.

The discovery that all organisms are constructed of cells was a great leveling and simplifying conception. The further discovery that the slimy cell content is the physical basis for life was again a simplifying step; and when analyses showed us that this material was composed of only a few different chemical elements and that these were the same with only slight exceptions for all living organisms, the hundreds of thousands of species of organisms which formed our vital, chaotic world took on another relatively simple, comprehensible aspect from the point of view of materials involved in construction. From the point of view of activity (within this mass of only a few elements), a great simplifying discovery, to mention only one simple example, was that $\mathrm{CO}_{2}$ is a product of respiration which is common to all organisms. We are still left, however, with the problem of versatility. The elephant, the humming bird, the angle worm, the protozoan, the liverwort, and the redwood tree all fit in with the simplifying concepts of cell structure, of protoplasm, and of respiration; but the elephant certainly has a different outlook upon life than the humming bird, at least as far as locomotion is concerned; what the protozoan, the angle worm, and the redwood tree may think about surrounding conditions and the state of society certainly would not be likely to confirm the opinions of the elephant and the humming bird. Yet all of these derive their opinions from the same few elements, bound up in the same sort of slimy protoplasm, enclosed in the same sort of cells.
Still another common denominator is being recognized in the submicroscopic and molecular range of sizes. This has been sluwly taking shape during the past two or three decades and has been accelerating considerably during the present decade. This common denominator is the molecular structural aspect of protoplasm. From this molecular viewpoint the picture is still foggy, as might be expected at this stage, but through the fog certain general outlines of structure are appearing which give hints of occasional detail. In our attempts to penetrate this fog we shall undoubtedly misinterpret the form which we think we see, but that is to be expected also and may even be beneficial as an incentive to a further clarification of the picture.

The general conception of structure, I presume, is as old with the human race as the ability to form thoughts; and during the ages it has been promptly extended in both directions when new tools were invented, by the telescope in one direction, and by the miscroscope in the other. Even before the tools were made available, imagination had invented the atom as the structural unit of all substances; but it was not until the tools were made and methods of thought developed that very much credence was placed in the theories of the structure of matter.

In the organic world theories of structure have passed through various stages or levels in the size of the structural units. The recognition of similarities between whole organisms brought great simplicity into the notion of a living world and brought into existence our taxonomic structure. The invention of the microscope must have produced a chaotic first impression, to be dispelled only when its extensive use resulted in the simplifying theory accredited to Schleiden and Schwann that cells are the structural building units of all organisms.

About this time a further simplifying notion was propounded-that the slimy material in the cells forms the physical basis of living material; and I presume that this was immediately followed by the unifying idea that this material is common to all 
living organisms. Microscopic investigations of the slimy content of these cells, which was named protoplasm, never became a very popular fashion; and although during this past century enormous advances have been made in biological fields, generally, the conception of structure in protoplasm has advanced very little. Now and then during this time some hardy or inquisitive soul would make a contribution towards a slightly better understanding of some phase of this material. At one time, perhaps a contribution would be made to its chemical nature; at another, to its microscopical appearance; and at still other times, descriptions were presented of its colloidal behavior and of its various physical properties. Taken all in all, the progress has not been very great; but that is not surprising when the difficulties are considered, and especially when it is recognized that a comprehension of this protoplasmic material demands a knowledge of matter which has only recently been developed to such an extent that exploratory studies are now more than possible. I refer here to our modern knowledge of atomic and molecular entities as minute, threedimensional particles.

Information concerning these minute particles has been accumulating during the past decade and has made possible the extension of the microscopic horizon down beyond the ultramicroscopic, or colloidal region, into the molecular and atomic world. This work is so recent, however, that one feels hesitant and overbold in attempting to apply the information to living material, especially since in doing so he must deal with the least well known of molecular substances, the proteins; and also with the least known states of matter, colloidal and molecular solutions.

Among the many difficulties which stand in the way, one of the most obvious is that of an appreciation of comparative sizes when passing from a molecular level up to a microscopic level or in passing in the opposite direction. The cell, it is well known, may be only about $20 \mu$ in diameter. Within it a nucleus occurs of perhaps half that diameter; if it is a plant cell, plastids may exist which are only $2 \mu$ in size, and still smaller particles may be found down to the limit of visibility, which is about half a micron, or about 5000 Angstroms. The latter are the units by which atoms and molecules are usually measured; thus, a glucose molecule is about $5 \AA$ in diameter. In comparison with such molecules, one of the smallest of the microscopically visible particles is equivalent in size to a packet consisting of about a billion glucose molecules. Nevertheless, it is with these small molecular entities that we must deal if we are to comprehend the molecular machinery involved in vital processes.

I have purposely switched the viewpoint from structure to activity and to molecular machinery or mechanisms composed of molecules in order to bring out the relation of structural levels to types of cellular activity, which may also be considered as occurring on different levels. The whole cell may be thought of as a structure consisting of a nucleus embedded in cytoplasm which in turn is surrounded by an enclosing membrane; perhaps its structural nature may be more readily recognized when mitosis is in progress. If a dynamic viewpoint is taken, the cell during mitosis may be looked upon as a machine or a mechanism which is performing in a definite routine way at the level of microscopic vision.

As a step downward in size, one is more likely to form a conception of cell inclusions as structures rather than to think of the whole cell as a single structure. The nucleus considered as an inclusion then becomes a mechanism with many activities ascribed to it as well as a structure; the plastids likewise, but with fewer activities; the mitochondria also become mechanisms, but with perhaps only one function; while the still smaller granules seem to be present without any particular name or duty to perform.

At this point I wish to call attention to and to emphasize the localization of activities within the cell. The chloroplast may selve as an example. Just as the cell is partitioned into structures which have specified activities, so in the chloroplastid one set of molecular mechanisms or a particular 
arrangement of molecules is involved in the synthesis of glucose molecules which consist of some twenty atoms, while another set of mechanisms within the same plastid may be building these glucose molecules into visible starch grains consisting of millions of molecules. One is inclined to think of the formation of the starch grain as being on a much higher level of activity, since it is visible, than the formation of a glueose molecule which is far below visibility. This example is one of many which are in progress in definitely localized regions, and may serve to accentuate the conception of activities within other minute inclusions in the cell.

In order to give these microscopic structures a place in our comprehension of commonplace objects, a comparison is made of this cell to a single drop of water such as might hang suspended on the end of a medicine dropper. The drop is about $2 \mathrm{~mm}$ in diameter; its volume then is about $4 \mathrm{cu}$ $\mathrm{mm}$; as contrasted to this the cell may be $0.02 \mathrm{~mm}$ in diameter and its volume only about .000,004 of one $\mathrm{cu} \mathrm{mm}$. In other words, that small drop of water on the end of the pipette is equivalent in volume to about a million cells; and it may be recalled that each of the million cells is partitioned into functional compartments in which different processes are in progress. When we try to comprehend experimentally what is going on in these compartments, we take, in our clumsy way, not a drop with its million cells but a whole beaker full of drops, stir them up, filter, centrifuge and dissolve them in order to get rid of the impurities and then do something with the "pure stuff" which may be precipitated out. Our little compartments are completely wrecked by this time, and whatever is salvaged in its "pure form" is perhaps too often assumed to pre-exist as a part of a particular mechanism.

I have been trying to emphasize the idea of structure within the cell; but more than that, of structures which involve structural members or units of building materials having different sizes. The discussion presented here is limited to the cytoplasmic region of the cell; and to the structure, not of the cytoplasm as a whole, but instead, of regions and particles within the cytoplasm. The visible components, when the nucleus and plastids are excluded, are principally small unnamed granules and, in addition, an enormous number of much smaller submicroscopic particles which have been revealed by the ultramicroscope. All of these are included within the fluid of the cytoplasm.

In this eytoplasmic material in which submicroscopic as well as visible particles occur, activities of one sort and another also take place. The evidence for these is not so clear as for the processes in plastids and nuclei. There is some evidence, however, for allocating a certain amount of hydrolytic activity to mitochondria and to other very small particles just above this submicroscopic region (Horning 1933). In addition to the activities of the individual particles they may function also in a collective manner. This apparently colloidal material may "set" into a particular form when cell division is taking place. There is then, at this time, structure of a sort in which these minute particles function as building blocks. The question arises as to what extent these submicroscopic particles may function also as structures in which internal localized reactions occur somewhat comparable to the activities in a chloroplast.

To answer this we must step down to a still lower structural level and examine more carefully these submicroscopic particles. Unfortunately our information becomes more diffuse and less certain, for methods have not yet been devised for detailed studies in this region; however, let us turn to the results of observations which at least show that submicroscopic particles exist in great numbers in the clearest of hyaline protoplasm. I refer to observations made by the ultramicroscope. This instrument shows us a highly magnified section of a Tyndall cone; that is, it magnifies the glittering, dancing motes in the sunbeam. Gaidukov (1906; 1910), Zsigmondy (1914), Bayliss (1920), Price (1914) and Taylor (1925) are names asso- 
ciated with this method which was used to study many organisms. In all cases the microscopically optically empty, hyaline cytoplasm was seen to contain, according to Taylor (1925), "hosts of ultra-microscopic particles displaying exceedingly active Brownian movement"; while Bayliss (1920) speaks of "an immense number of very minute particles shown by their bright diffraction images ... in vigorous Brownian movement,... scarcely possible to distinguish separate particles on account of their number." I wish to call attention, in both cases, to the emphasis on "hosts of particles" and "immense number." These are the only data of even a semi-quantitative nature we were able to find.

These small points of light are diffraction dises produced by minute particles which have been estimated, for materials of high density (Gaidukov 1906; Zsigmondy 1914), to be as small as $50 \AA$ to $100 \AA$ in diameter. They are small in comparison to mitochondria or other particles just within the visible range. In fact, one mitochondrium is large enough to contain about a million particles of $100 \AA$ size, and obviously if that were the case, a mitochondrium would be rather extensive as a structure, built from a million such units; but concerning its structure we have no direct knowledge. Particles of $100 \AA$ in size are down in a range where dimensions have been investigated by several methods, and a considerable amount is known about them. Unfortunately, however, there has been relatively little work done from which one feels safe in saying that the particles investigated are truly those which were actually known to exist in the cell.

Existence of these minute particles in the living material is perhaps open to question; the objection being that the disturbance of the protoplasm by excessive heat when the ultramicroscope is employed produces the particles as artifacts. Further. investigation is clearly desirable, but in the meantime one is led to wonder at the amazing coincidence of particle size with the range of microscopic visibility. It seems incredible that the region below the visible and above the molecular should be free of particles; in other words, that particles built from molecules or otherwise of atomic groups should have a lower limit in size which happens to correspond to the visible limit of the microscope. This opens many questions of experimental interest. That particles exist in the hyaline material seems to be the only conceivable condition in the light of ordinary molecular aggregation. Analogy and reasonable inference will have to be accepted until other methods are devised.

Chemical analyses have shown quitc conclusively that a large proportion of these particles have the characteristics of proteins (Chibnall 1926; Pearsall and Ewing 1924-5; Shinke and Shigenaga 1933; Giroud 1929; Milovidov 1928). The particles probably vary from visibility, or about $5000 \AA$, down to $100 \AA$ in size. Svedberg $(1937 ; 1939)$ and others have shown with the ultracentrifuge that proteins in dilute solution may occur as particles of these smaller sizes. They are spoken of as molecules and have had assigned to them molecular weights. Thus, a particle of about 50 $\AA$ corresponds to one having a molecular weight of about 36,000 ; while one of $80 \AA$, corresponds to one with a molecular weight of 300,000 ; and one of $250 \AA$, to a particle with a molecular weight of about $6,000,000$. Those in the larger categories may in many cases be broken down rather easily into the smaller 36,000-size or even to sizes still smaller (Svedberg 1937; 1939).

Analyses from various sources show that in its active state protoplasm contains about 85 per cent water, and of the remaining materials about two-thirds protein. The proteins and water together make up approximately 95 per cent of the living material, and it seems highly probable that the particles we have been discussing are composed principally of proteins. This gives to the molecules of these two substances considerable importance in any attempt to comprehend the molecular structure. During the past decade investigations of various sorts have provided considerable information concerning both of 
these substances, protein and water, and at the present time certain chatacteristics and properties mar be said to be well establisherl. A few of these properties are ol direct importance in ont protoplasmic pictule, and it is to a discmssion of these to which we now turn in order to interprot the ultramicroscopic particles and other. structures which, on account of their nature, do not diffract light.

The moteins with which we are primarily concerned are classed as simple proteins; that is, those which, upon hrdrolysis, vield amino acids (about 15 to 20 different kinds) almost exchusively. That these are attached to one another through peptide linkiges is generally well known and accepted. This trpe of attaclument shomld produce a chain-like molecule of which the anino acid residues are the links, and all bonds are primar valence. It is often spoken of as a "primary valence chain." The simple proteins are the ones most likely to occur in protoplasm where they may be fornd with or withont attached womps of substances other than amino acids. These attached groups, ealled prosthetic gronps, may include fatty acids, lecithin, mucleic acid, carbohydrates and various other moleeules, such as those of the respiratory pigninents.

Although all of the proteins are produced within the living cell, investigations ale almost always carried on after extraction from the cells; and our knowledge of them depends to a great extent upon studies of the material which has been removed from the living matrix. Murh of the knowledge which is useful in our molecular studies of protoplasm inrolves an assmmption that the proteins and particles of protein which are studied in this form are directly comparable to those which exist in the hiving cell. We have accepted this assumption, tentatively, as a working basis, and as we proceed shall attempt to reduce the uncertainties.

The eonception of a molecular chain as the primary structure of proteins has been confirmed in several ways and may be taken as failly well established. The Xray diffraction patterns which are formed by silk fibroin show that the component molecules are long extendal polypepticle chains. 'There seems to be vary little doubt on the pant of the chemist that the amino acid residues are ahmost exchusively linked to one another thromols peptide womps involving a particular carbon atom of the amino acid, the a rarlom atom. These polypepticle cluains oceur in various proteins as slender struetures, about 4.5 i thick hy about $10.5 \mathrm{~A}$ wide, but of unknow length. 'The amount of fohling and attachment through sidechains into packets is uncertain tor the most part. A moleconlar weight of about 35.000 has been ascribed to many proteins, and if the chans were fully extended, they would be about 1000 is loms. 'These molecular dimensions in Nugstroms, marnified to a scale erpuivalent to inches and feet, wonld enlarese the ehain to about one inch in thickness by two inches in width by twenty feet in length.

With the conception of a protein chain as a thin, fiber-like molecule in mind, the particles shown by the ultramicroseope and by the ultracentrifuge take on a new significance, especially when a folding, such as postulated by Pauling and Mirsky (1936) and Astbury (1935), into globular or cubical structures is comsidered. A thousand Inystrom length of the chain, whether in one piece, folded back and forth, of in several pieces of, say, 50 i in length, whether hinked through their side chaims or not, could form a packet about $30 \times 30 \times 50$ I. A particle similar to this or perhaps shightly larger might be one of those seen as a point of light in the ultramicroscope; it would be recognized by the ultracentrifuge; and it might readily be one of the minute reflecting paekets which help produce the diffraction pattern of $\mathrm{X}$ rays. This picture of the particle must be considered as a first approach and may be somewhat misleacling. 'To present a picture which better represents various experimental facts we must turn to several different lines of investigation.

Oux knowledge of proteins is obtained from widely varying fields of experimental effort; and when information from these sources is brought to bear upon the struc- 
ture of the particles in protoplasm, a rather interesting picture is obtained. To gain this, however, it seems necessary to examine the structure of the chain more closely than to merely determine its gross dimensions. A chain with a molecnlar weight of abont 36,000 will serve arbitrarily as a convenient size, and it happens to be a dimension which appears many times in the literature where molecular weights as determined by several different experimental methods are reported for many sorts of proteins. The materials employed for these determinations are usually" "purified" proteins which have been removed from the cell. They are salvaged portions of the wreckage of protoplasm in almost every instance.

More than one kind of protein may be obtained from the broken-down products of protoplasm, for it seems probable that within the cell some forms are normally set asicle from active protoplasm to serve specific purposes. The proteins of alenrone

TABLE I

Diagram of Amino ACid Formulae

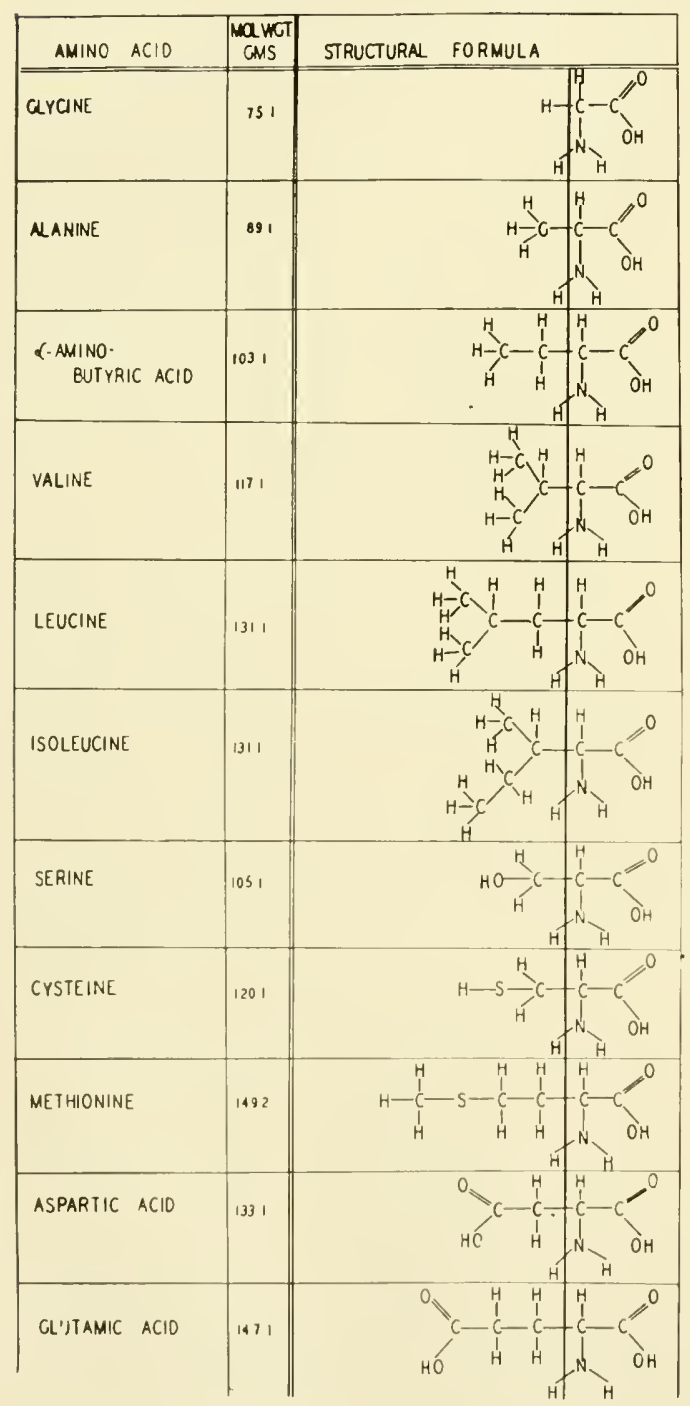

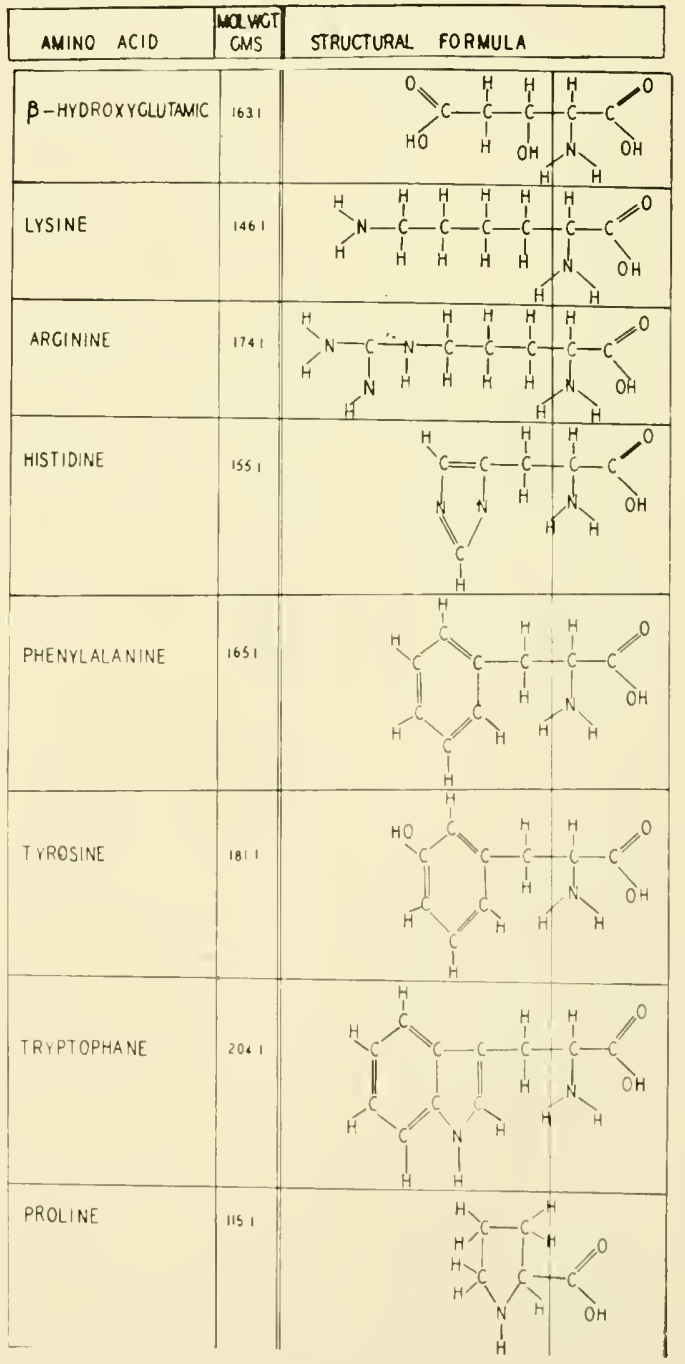


grains, for example, may aut as reserve supplies. Proteins of the muclens and ol some glandular rells apparently have specifie functions; and the formation of keratin in the epidermal aells is obvionsly for structural purposes. These proteins all consist of primary chains with modifie:ations of rarious kinds. For purposes of simplification we shall ignore for the time being these molifications and consicler only the simple chain structure as typical of the protein portion of the particles in protoplasm. We are accepting then a clain of 36,000 molecular weight as a representative rain of the poteins in cytoplasm, one of which when ampletely hyolyzed will

TABLE II

Diagray of a Protein Chain

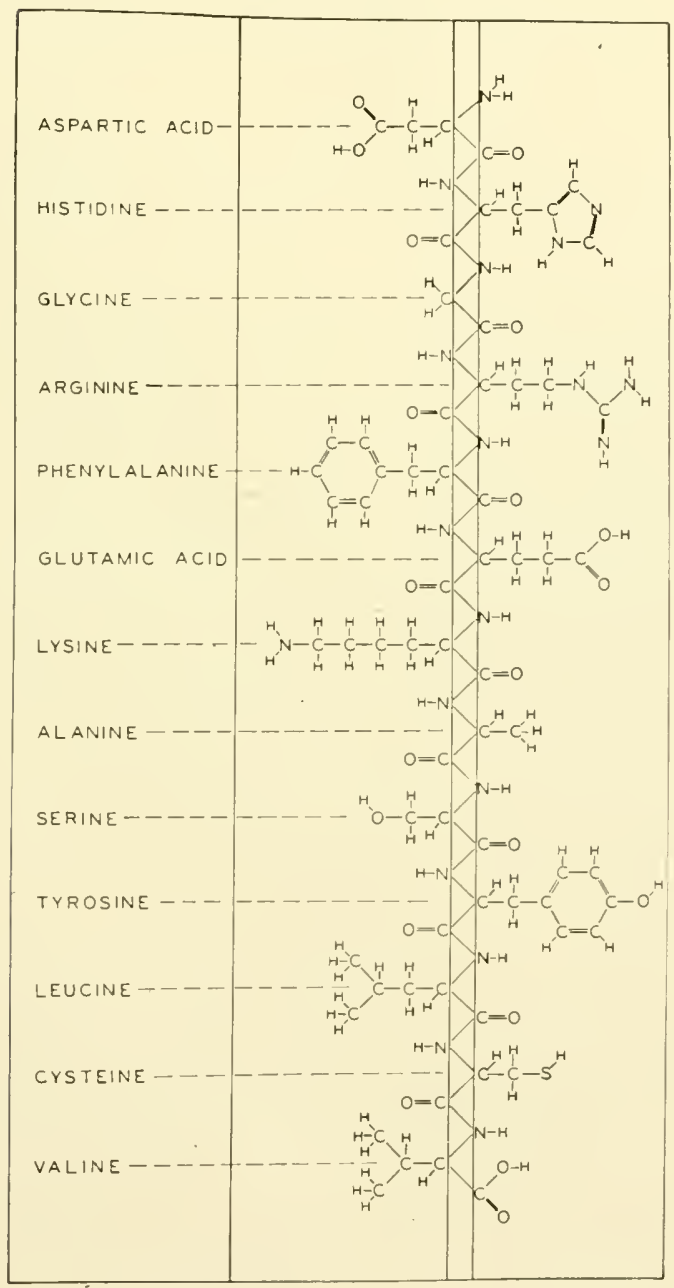

rickl about 300 amino acid molecules of perhaps twenty kinds.

Amino accicls have one characteristic in common. This generic feature is a earboxyl gromp, COOH, and an anino group. $\mathrm{NH}_{2}$ (with one exception), both attached to the same carbon atom, the alpha earbon. The rest of the molecule is the specific portion whieh distinguishes one amino acid from another. The generic gromp is shown on the right-hand side in Table $I$. It is this generic part of the molecules which allows them to be linked together into a dhain structure, such as illustrater in Table II.

In the formation of the chain the alkaline gromp, $\mathrm{NH}_{2}$, of one amino acicl is condensed with the aciel group, COOH, of another, resulting in the splitting off of a water molecule and the formation of a peptide linkage. This is shown in diagram in Fig. 1. With each condensation a carboxyl

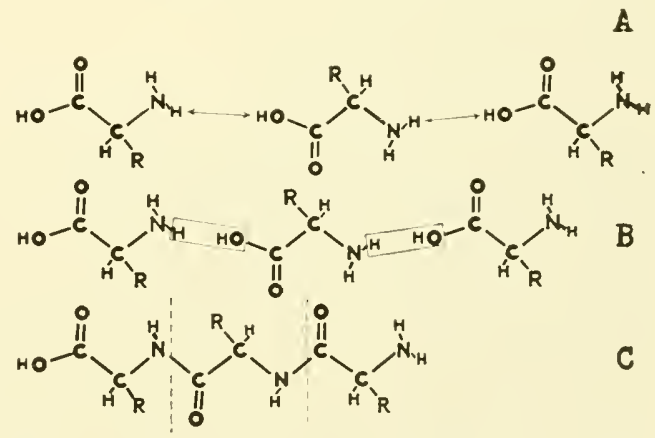

Fig. 1. Diagram to show formation of a peptide linkage. At $A$ three separate amino acids are shown; at $B$ the source of the water molecule is indicated by the rectangle; and at $C$ the completed linkage between the adjacent amino acid residues is shown.

gromp is left at one end of the pepticle chain and an amino eromp at the other end. This allows for extension into a long polypeptide chain, such as illustrated by the reprotuction of a three-dimensional model made to seale in Figs. 2 and 3.

One of the enrions things abont this chain is that the adjoining amino acids are likely to orenr on alternate sides of the pepticle linkage, and as a result a zig-zag back-bone is prodneed whieh consists of a repetition of the pepticle group, carbon- 
carbon-nitrogen, for each amino acid residue. This forms a back-bone to which the remaining parts of the amino acid are attached alternately forming ribs or side chains. The back-bone portion of the chain

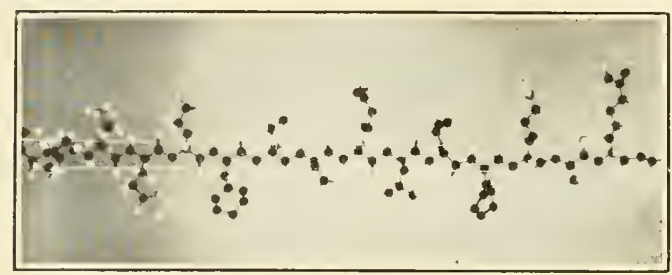

Fig. 2. Reproduction of a protein chain model showing about 15 amino acid residues of rarious kinds. The model was made to scale. The white horizontal lines serve to emphasize the zig-zag back-bone.

varies onjy slightly from one protein to another; the side-chain portion, however, varies to a considerably greater extent. This may be seen by referring to Table II and to the model in Fig. 3.

The dimensions of the models made to scale were based on radii and valence angles of the respective atoms which have been determined from many measmrements obtained from X-ray crystal analyses and from absorption spectra methods. These atomic characteristics are summarized in Table III (Pauling and Hugrins 1934; Pauling 1939).

There are several points of especial interest to us in Fig. 3. One important feature of the protein molecule may be recalled: that every oxygen and every nitrogen aton present is potentially a hydration center; or more specifically, that these atoms are capable of forming hydrogen briclges with water molecules (Huggins 1936; Lassettre 1937) and thus binding the water molecules to the protein in much the same mamner that water of crystallization is bound in a crystal. In a chain of 300 residnes there will be approximately 300 oxygens and an equal number of nitrogens in the back-bone alone, almost regardless of the kind of protein; while, in contrast to this, in the sirle rhains the number of these

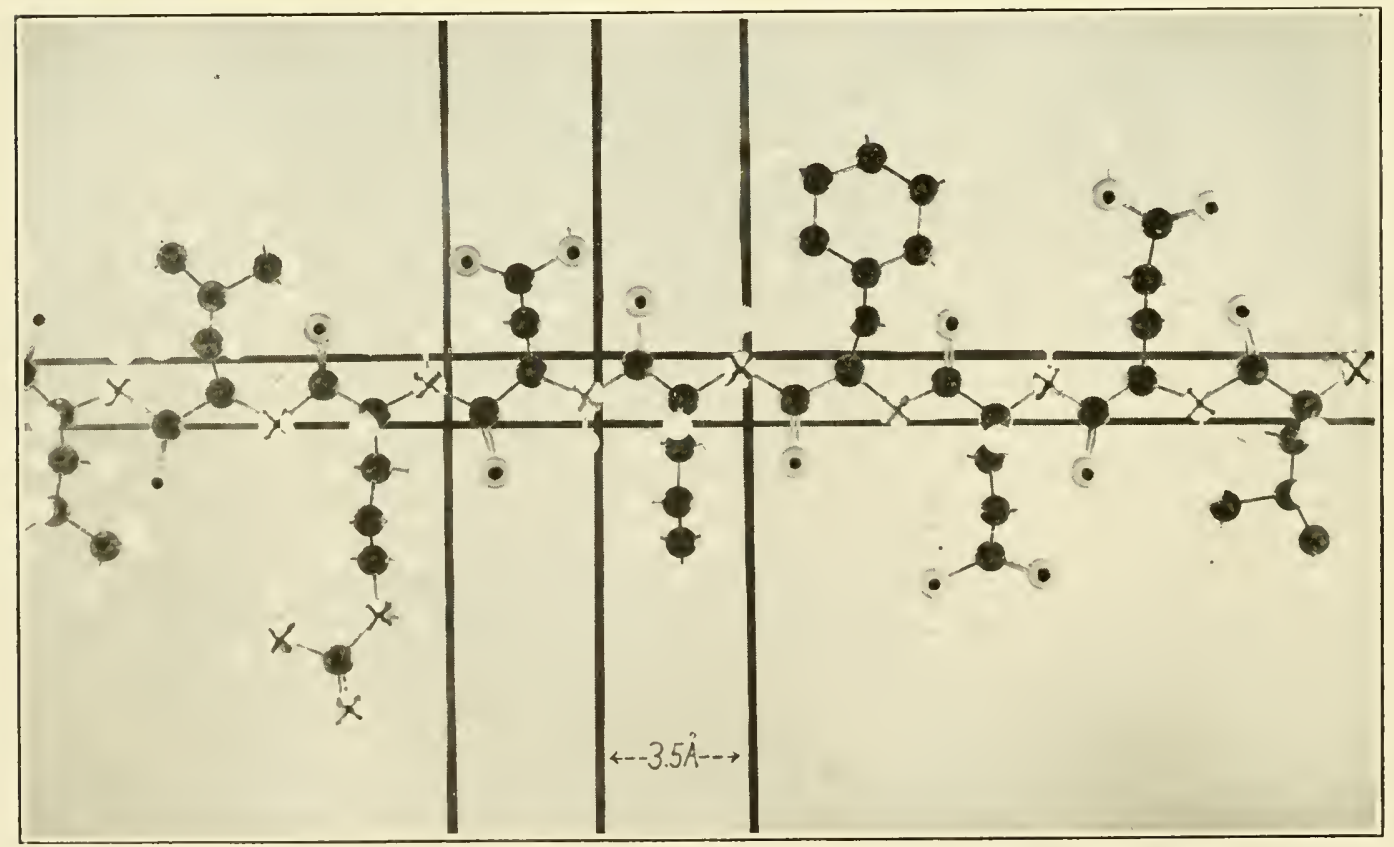

FIG. 3. A model of a polypeptide elain made to seale, slowing eight amino acid residues. The backbone and two residues are aceentuated by the heavy lines. The black balls represent calbon atoms; those with a central dot, oxygen, and those with a central cross, nitrogen. The smaller white balls represent liydrogen atoms. 
TABIE III

Summari of Atomic Radi and of VAlence BONDS IND ANGLES

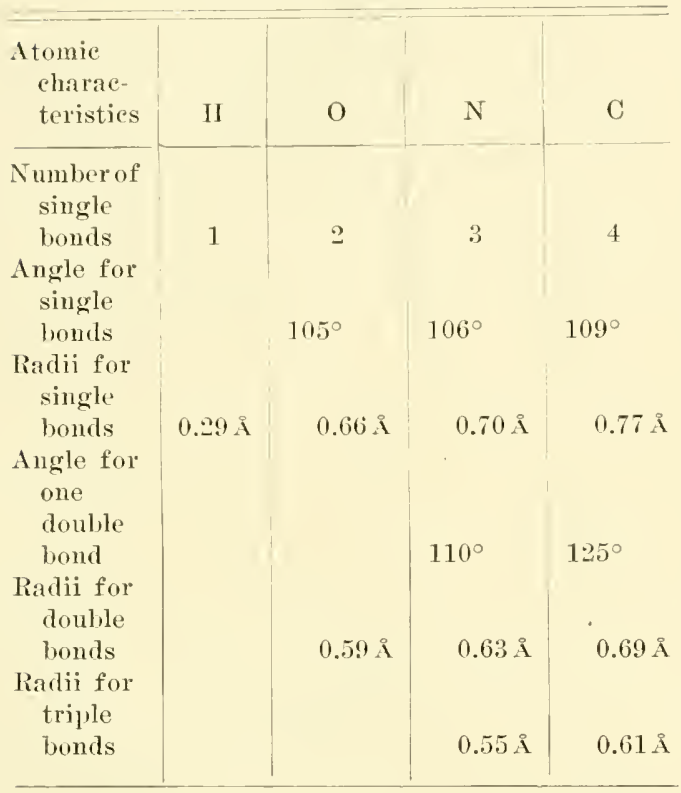

hydration renters is less and will vary with the proportion of the various amino acids present in the chain. It may be seen in Table IV that only a few residnes contain nitrogens and only a few eontain oxygens, aside from those in the bark-bone.

We turn again for a moment to dimensions, since tlimensions are important in establishing the validity of the ehain conception and also in our study of the sizes and forms of the partieles in the protoplasm. I shall not enter into a description of the X-ray methods of determining these dimensions but merely give some of the results which are of direct use to us. It was through the X-ray studies of silk protein in the form of silk fiber's that the repetition distance of the peptide group along the back-bone, $C+N$, was found to<smiles>[CH]1CC1</smiles>

be $3.5 \mathrm{~N}$. This distance varies in different proteins to as low as $2.8 \mathrm{~A}$ in gelatin, where many ploline linkages are involvet. The eomputed distance for the greatest extension of the chain is about $3.65 \mathrm{\Lambda}$, but neighboring atomic groups and proline linkages reluce this in varying amounts. A reasonable value where great exactness is not demanded is $3.5 \mathrm{i}$. This means that each amino acit has allotted to it $3.5 \mathrm{~A}$ of the chain length, and that 300 residues would thus form a chain about 1000 i in length.

The diffraction patterns obtained by Xrays from the rarious proteins, with the exception of protein crystals under eertain conditions, show that minute packets of parallel ehain-leneths oceur in what appear's otherwise to be amorphoms masses of protein. These packets oecur in landom arrangement similar to the minute crystals in a crystal powter, differing, however, in that they are attached to one another to form a hard, solid mass when dry. Stretehing of this mass of protein in some cases may orient these minute packets into a less random arrangenent (Astbury, Dickinson and Bailey 1935; Astbury and

TABLE $1 \mathrm{~V}$

II ydropinlic Groups on Various Protein Moleclles

(Number based on a molecule of 285 residnes.)

\begin{tabular}{|c|c|c|c|c|c|c|c|c|c|c|c|}
\hline \multirow[b]{2}{*}{ Protein } & \multicolumn{4}{|c|}{ On back-bone } & \multicolumn{6}{|c|}{ On side chains } & \multirow[b]{2}{*}{ Total } \\
\hline & & & & Total & & $-\mathrm{VH}$ & $-\mathrm{OH}$ & & & Total & \\
\hline Gliadin. & 288 & 234 & 54 & 576 & 149 & 10 & 15 & 23 & 7 & 204 & 780 \\
\hline Zein ..... & 288 & 258 & 30 & 576 & 95 & 4 & 22 & 11 & 3 & 135 & 711 \\
\hline Edestin ... & 288 & 266 & 22 & 576 & 87 & 44 & 17 & 83 & 7 & 238 & 814 \\
\hline Gelatin & 288 & 224 & 64 & 576 & 18 & 29 & 48 & 37 & 2 & 127 & 703 \\
\hline Casein & 288 & 257 & 31 & 576 & 105 & 36 & 46 & 20 & 12 & 219 & 795 \\
\hline
\end{tabular}


Lomax 1935), giving them a miformity of position from which a diffraction pattern may be obtained with $\mathrm{X}$-rays, somewhat similar to that from a fiber where the long chains are extended full length and arranged in parallel fashion, as has been shown to be the case in silk. In silk they are separated from one another laterally at miform distances of $4.3 \mathrm{i}$ in one direction and about $7.0 \mathrm{i}$ in another. These dimensions are slightly smaller in silk than the corresponding dimensions of most proteins, where they vary over only a narpow range-from 4.4 i to 4.6 i for the thiekness of the chain, as illustrated in Fig. 4. and from $9 \AA$ to $12 \AA$ as extremes for the width. The width is obviously an average depending npon the proportion of long and short side ehains, as may be seen in Fig. 3. Averages taken for a protein chain for general use are about 4.5 i for thickness and 10.5 i for width. See Table VI in which these dimensions are given for many proteins.

There are three ways of arriving at these two dimensions; one is by actual measmements of width and thickness, on a model made to scale from dimensions of the component atoms; a second way is from $\mathrm{X}$-ray diffraction patterns; and a third is from computations involving density and molee-

\section{TABLE V}

Comparison of Width of Tarious Protein MoleCules as Obtained by Different Methods

\begin{tabular}{|c|c|c|c|c|c|}
\hline \multirow[b]{2}{*}{ Protein } & \multirow{2}{*}{$\begin{array}{l}\text { Aver. } \\
\text { mol. } \\
\text { wt. of } \\
\text { resi- } \\
\text { dues }\end{array}$} & \multirow{2}{*}{$\begin{array}{l}\text { Aver. } \\
\text { length } \\
\text { of } \\
\text { resi- } \\
\text { dues }\end{array}$} & \multicolumn{3}{|c|}{$\begin{array}{c}\text { Widtl of protein } \\
\text { molecule }\end{array}$} \\
\hline & & & $\begin{array}{l}\text { From } \\
\text { mol. } \\
\text { wt. and } \\
\text { spee. } \\
\text { gravity }\end{array}$ & $\begin{array}{l}\text { From } \\
\text { residue } \\
\text { lengtl }\end{array}$ & $\begin{array}{l}\text { From } \\
\text { X-ray } \\
\text { data }\end{array}$ \\
\hline I & II & III & $\mathrm{IV}^{\mathrm{T}}$ & $T$ & VI \\
\hline $\begin{array}{l}\text { Keratin } \\
\text { (wool) }\end{array}$ & 114 & $5.9 \mathrm{~A}$ & $9.2 \AA$ & $11.8 \AA$ & $9.8 \AA$ \\
\hline $\begin{array}{l}\text { Edestin } \\
\text { (hemp) }\end{array}$ & 118 & 6.3 & 9.5 & 12.6 & 11.0 \\
\hline $\begin{array}{l}\text { Lactal- } \\
\text { bumin } \\
\text { Zein }\end{array}$ & 128 & 6.3 & 10.4 & 12.6 & \\
\hline $\begin{array}{l}\quad(\operatorname{cor} n) \\
\text { Egg }\end{array}$ & 113 & 6.1 & 9.1 & 12.1 & 9.8 \\
\hline albumin & 124 & 6.6 & 10.0 & 13.2 & 10.3 \\
\hline $\begin{array}{l}\text { Casein } \\
\text { Gliadin }\end{array}$ & 122 & 6.4 & 9.9 & 12.8 & 10.2 \\
\hline (wheat) & 121 & 6.4 & 9.7 & 12.8 & \\
\hline $\begin{array}{l}\text { Gelatin } \\
\text { Silk }\end{array}$ & $9 \overline{5}$ & 4.8 & 9.3 & 9.6 & 9.5 \\
\hline fibroin & 73 & 3.5 & 6.4 & 7.0 & 6.5 \\
\hline
\end{tabular}

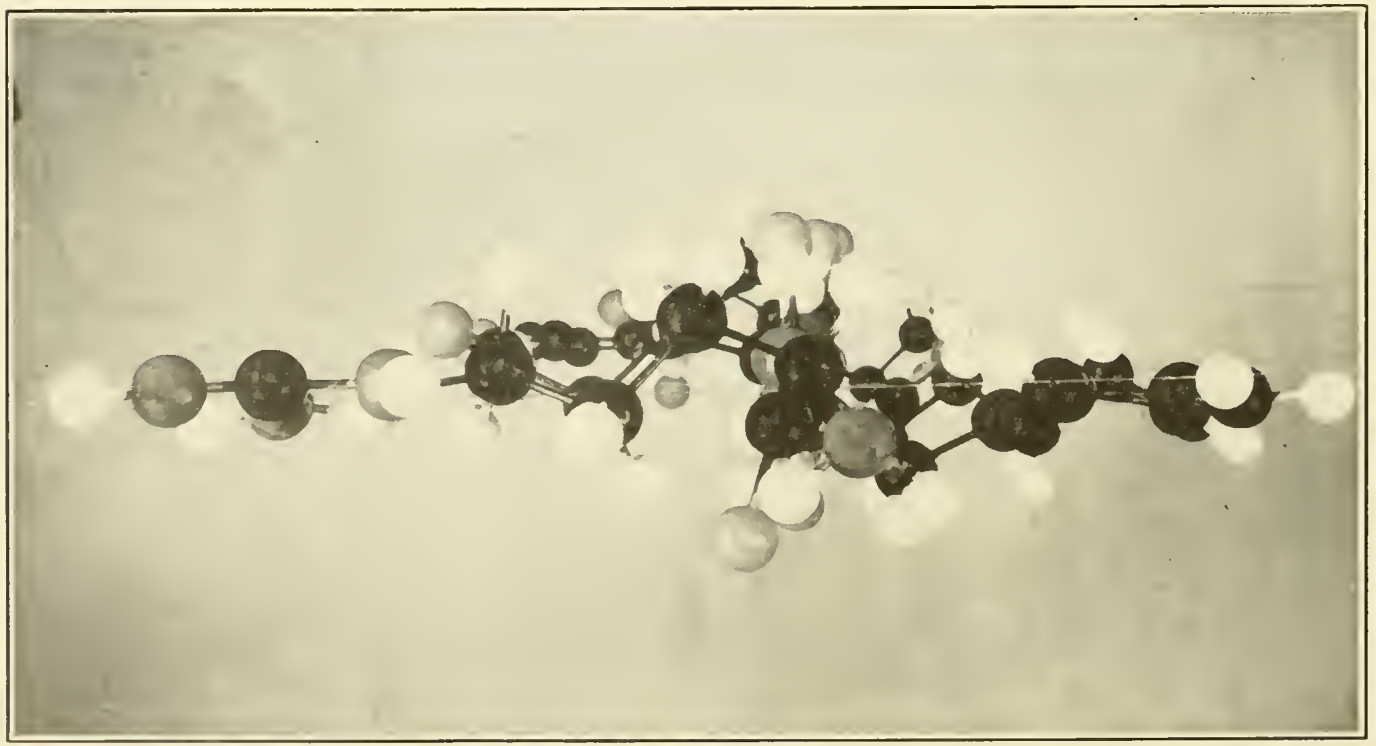

FIG. 4. An and view of a protein model. The rertical thickness in the middle is due to the back-bone and is about $4.5 \mathrm{\AA}$. 
ular weight, with the thickness dimension taken from measmements of $\mathrm{X}$-ray diffraction spacings. These methods are too involved to describe in detail, but several sets of values are given in trable $V$ for comparison. The agreement for a given protein is abont as close as one coutd expect and makes nere coincirlence seem intprobable; especially when the enmulative effect is attained by comparison with the width and thickness valnes given in Table VI, where these two dimensions are pre- undombtedly essential, are innored for the time being.

The structural nature of these protein particles is rery intimately associated with the water molecules which ocent in such large numerical proportion in the ceel]; in far.t, the very nature of the component oxyen and nitrogen atoms of these two substances, protein and water, demands that an association stronger than mere cohesion of the van der Walals' type take place between them. Both of these atoms,

TABLE VI

Occurrence of Batk-bone and Side-Cimain Spacings in Proteins

\begin{tabular}{|c|c|c|c|c|}
\hline Proteins & $\begin{array}{l}\text { Back-bone } \\
\text { spacing }\end{array}$ & $\begin{array}{l}\text { Side-chain } \\
\text { spacing }\end{array}$ & & Reference \\
\hline Pepsin & $4.6 \AA$ & $11.5 \AA$ & Astbury: & and Lomax \\
\hline Tobacco seed & 4.4 & 11.0 & ، & ، \\
\hline Squash seed. & ، & 6 & ، & 6 \\
\hline Edestin & 4.5 & 66 & 6 & 6 \\
\hline Egg albumin & $\begin{array}{c}4.7 \\
6\end{array}$ & $\begin{array}{l}10.6 \\
10.0\end{array}$ & " Niller et & " " \\
\hline Serum albumin & 4.5 & 9.7 & Astbury : & and Lomax \\
\hline Zein $(\operatorname{cor} n)$ & \pm .6 & 9.8 & 6 & 646 \\
\hline Casein (milk) & 4.5 & 10.2 & 66 & “ \\
\hline Trypsin & & 9.8 & 6 & " \\
\hline Fibrin (blood) & 4.7 & 10.1 & Katz and & d Rooy \\
\hline Gelatin $\ldots$ & 4.6 & 10.0 & Astbury : & and Atkin \\
\hline Keratin (hair) & 6 & 9.8 & Astbury: & and street \\
\hline Nerve proteins & $4.6-4.8$ & $11-12$ & Schmitt, & Clark and MIrgudick \\
\hline Bacteria ( $B$. coli) & 4.4 & 10.7 & sponsler & and Bath \\
\hline Cytoplasmic proteins (cabbage) & 6 & 9.5 & 6 & 66 \\
\hline Euglena proteins & 4.3 & 7.9 & ، & $6 \quad 6$ \\
\hline Proteins of beef thyroid gland & 4.6 & 10.1 & 6 & $66 \quad 66$ \\
\hline
\end{tabular}

sented for a great number of proteins. The general likeness in dimensions of these varions proteins makes it seem almost a certainty that the proteins which occur in the living cell have chain dimensions of similar thickness and width. It seems reasonable also to make use of these vahes for visualizing the structure of the particles which abound in such enormous quantities in the submicroseopic region of the eytoplasm as revealed by the nltramicroscope. These particles occur in the cell apparently suspended in water, along with a small percentage of other organic and inorganic substances: the latter, although the oxygen and the nitrogen, when in place in the molecule have strong residual fields which are localized in the atom at tetraheclral points. Fig. 5 is a diagram to illustrate these fonl coordination points. It shows a pair marked $\theta$ oriented at right angles to a pair marked $\ominus$, to which four water molecules are coordinated in a tetrahedral fashion. If a hychoxyl radical were to replace the central water molecnle, only three places would then be left for the coordination of three water molecules. The number varies with the nature of the atomic group in which the oxygen or nitrogen occurs. Theory and experiment are in fairy 


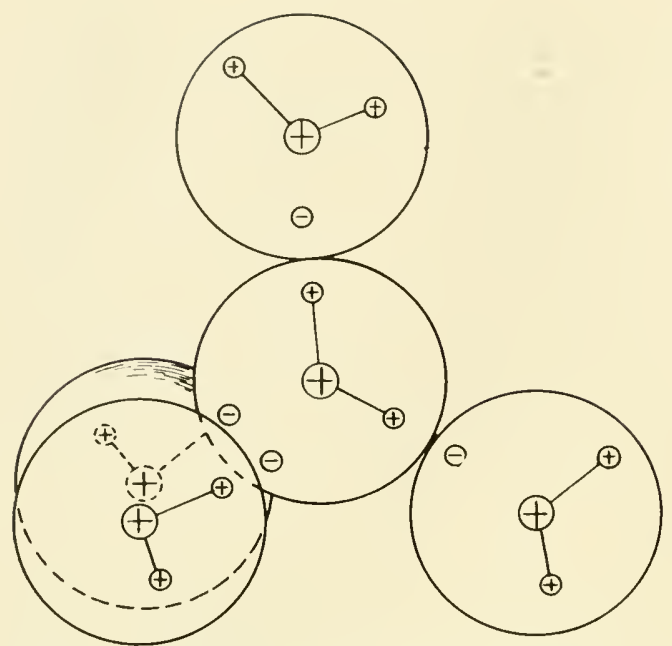

Fig. 5. A diagram to show the perspective arrangement of coordinated water molecules. Each molecule contains two residual plus and two minus charges which are located at the corners of a tetrahedron (Bermal and Fowler 1933).

good agreement, as indicated in Table VII where the principal hydrophilic groups of

\section{TABLE VII}

Coordination of Water by Various Polar Groups

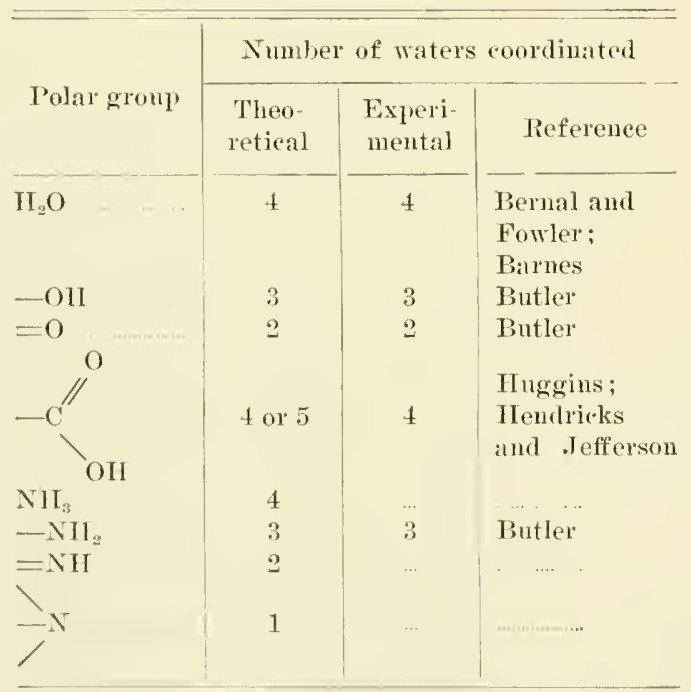

the proteins are shown with the number of water molecules which may be bridged to them.

'That these coordinated water molecules are bound to the protein by hydrogen bridges has been temonstrated by infra-red absorption methocls (Ellis and Bath 1938). A conception of the hydrogen bridge may be formed by the help of the diagram in Fig. 6 where the approath of the plus and

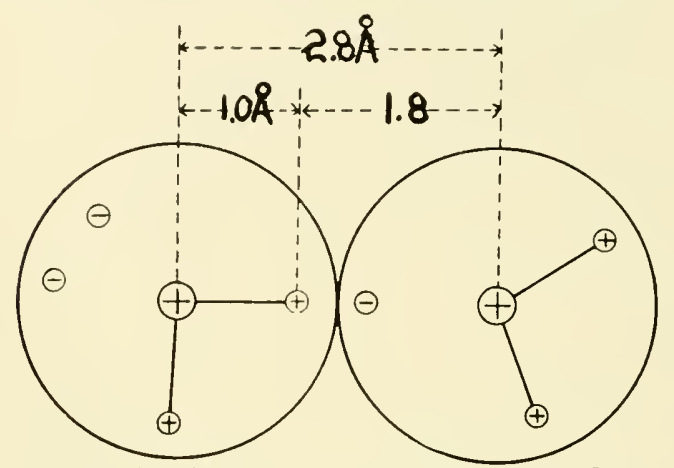

FIG. 6. A diagram to illustrate the hydrogen bridge. Two water molecules are represented by the large circles. The central $\oplus$ circles indicate the positions of the oxygen nuclei which are connected by solid lines to the hydrogen protons, the smaller $\oplus$ circles. The mechanism proposed as the "hydrogen bridge" is indicated by the proton $\oplus$ and the negative charge $\theta$ on the line between the two oxygen nuclei.

minus points bring the respective water moleenles closer together, $2.75 \mathrm{i}$, than the van der Waals' cohesion forces, which usually prodnce a zone approximating 3.5 i between moleeules (Robertson 1935).

As a consequence of the presence of these oxygen and nitrogen atoms, hydration centers occur at various places on the protein chain. There is a potential possibility of two ehains becoming fastened together, in an extreme ease, by means of 150 or more water molecules forming bridges between the two baek-bones where these atoms oeenr uniformly and are spaced only short fistances apart. The layer of water molecules attached in this mamer between the two back-hones would form a strong seam of water molecules between the two chains. separating them by about the thickness of a water molecule.

The hydration centers at the ends of the side chains, on the other hand, are relatively few and even if spaced uniformly are rather far apart. Attachment thromgh these, therefore, should be weaker than throngly the back-bones. These predictions 
seen to be in agleement with the varying water relations ol gelatin as shown by X-ray diffraction patterns. In Table VIII the increase in side-chain spacing may be noted where increase in the amount of to determine with a very great deoree of assulance the existence of the long, extended chain in fluids, although in some solid forms the X-ray work seems to point conclusively to their existruce.

\section{TABLE VIII}

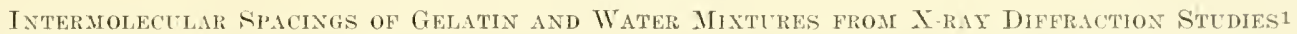

\begin{tabular}{|c|c|c|c|c|c|c|c|}
\hline \multirow{2}{*}{ Spacings } & \multicolumn{7}{|c|}{ Perentage of water } \\
\hline & $0.2 \%$ & $15 \%$ & $33 \%$ & $71 \%$ & $78 \%$ & $81 \%$ & $9 . \% \%$ \\
\hline 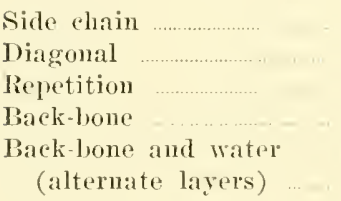 & $\begin{array}{l}10.4 \AA \\
2.8 \\
4.4\end{array}$ & $\begin{array}{l}11.3 \AA \\
7.5 \\
2.8 \\
4.3\end{array}$ & $\begin{array}{l}13.0 \AA \\
7.5 \\
2.8 \\
\\
3.7\end{array}$ & $\begin{array}{c}17.1 \text { i } \\
\ldots\end{array}$ & $\begin{array}{l}7.5 \mathrm{i} \\
2.8 \\
3.6\end{array}$ & $7.5 \AA$ & $\begin{array}{l}7.2 .1 \\
3.3\end{array}$ \\
\hline
\end{tabular}

1 This table is modified from data given by Hermam, Gerngross and Abitz (1930).

water present is accompanied by an inerease in spacing from 10.4 i 11 p to $17 \mathrm{\AA}$; while the back-bome spacing remains mchanged at $4.4 \AA$ intil a sufficient amount of water is present; then at 33 per cent water the chains become separated to about $7.0 \mathrm{~A}$, and the interleaved water moleenles bring about the lialf sparing of about 3.5 i. These alternating back-bone and water layers apparently remain intact even when 90 pel cent water is present; while the side-chain spacings become too irregular at about 75 per cent water to be recognizable in the X-ray photowaph. These changes for the first three cohmmus of 'Table VI1I, where the water content is given as 0.2 per cent, 15 per cent, and 33 per cent, are illustrated by the diagrams in Fig. 7. If the diagrams were given for the remaining columns which have higher water content, the spacings for the sicle cluains only would show increase.

Practically every investigator interested in proteins. where the physical structure is involred, has found evidence of particles of sizes varying from those with a molecular weight of about 9,000 np to many with about 35,000 and 70,000 , and a few even up into the millions (Svelber. $1937 ; 1939$ ). They also vary in shape from robular to much elongated forms (Neirath 1938). Up to the present time it has not been possible
It seems reasonable, then, to assmme that in the construction of protein particles chains of mnknown length exist, either as lory cluains folded back and forth or as short lengths. In the cytoplasm these are probably hydrated, at least to the extent of satisfying the available component hylrophilic groups; that is, the atomic gromps in which oxygens and nitrogens are present. The amount of hydration most likely to occur in these protein particles on this assumption is about 35 to 40 per cent water. Particles in the cytoplasm are known to have a specific gravity of about 1.15, which is equivalent to a water-protein mixture of 40 to 50 per eent water (Heilbrumn 1928; Bechliold and Schlesinger 1931, 1933 ; Schlesinger 1932, 193t). Thus ont theoretical hydrated particle of 35 to 40 per cent corresponds fairly well in water rontent with that of the cytoplasmic particle, and since the latter is known to be mostly protein which, when dried, shows the existence of the chain spacings, 4.5 il and $10.5 \mathrm{i}$, it seems reasonable to make nse of this layered protein-chain particle as a working conception for protoplasmic particles in general.

On this assmmption the particles consist of layers of chains. In one direction the lavers are spaced quite consistently about T i apart, where this is the back-bone dis- 
tance for hydrated particles with a layer of water molecules bridging the back-bone of one ehain directly to that of its neighbor. In the other direction, perhaps at nearly right angles, the side-chain spacing may vary and be far less mniform. The distance between chains may average up to $18 \AA$ to $20 \hat{\Lambda}$, if we may accept studies with gelatin as a basis. The degree of hydration, or the single layers, resembling the monolayers which have been shown experimentally to exist (Langmuir 1938; Langmuir and Schaefer 1939; Astbury, Bell, Gorter and van Ormondt 1938). Or in contrast, these packets of $50 \AA$ size conld eonceivably be built up into much larger three-dimensional particles. There is some experimental evidence for both of these assumptions, but we

HYDRATION OF GELATIN

A
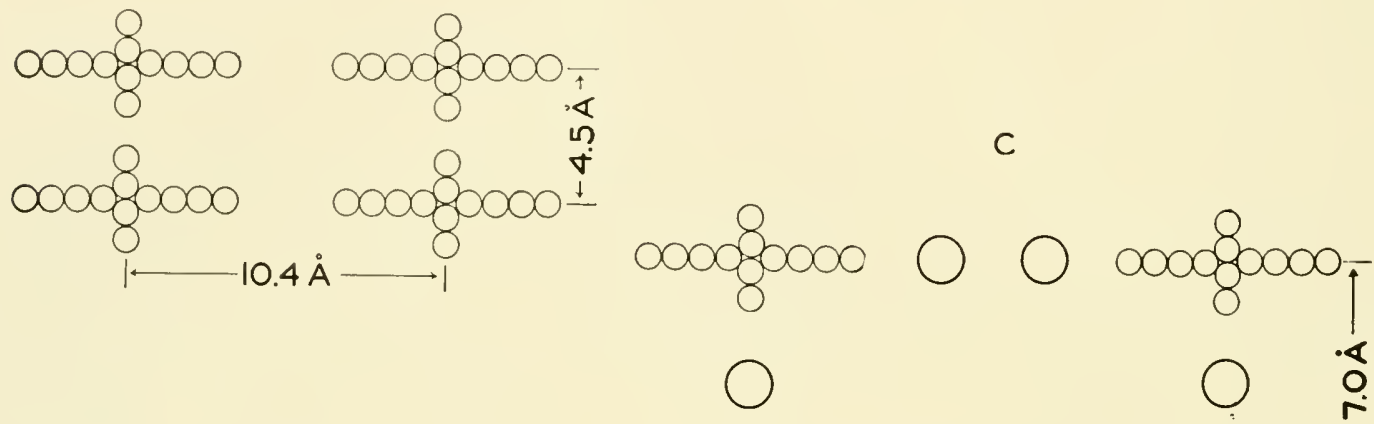

B
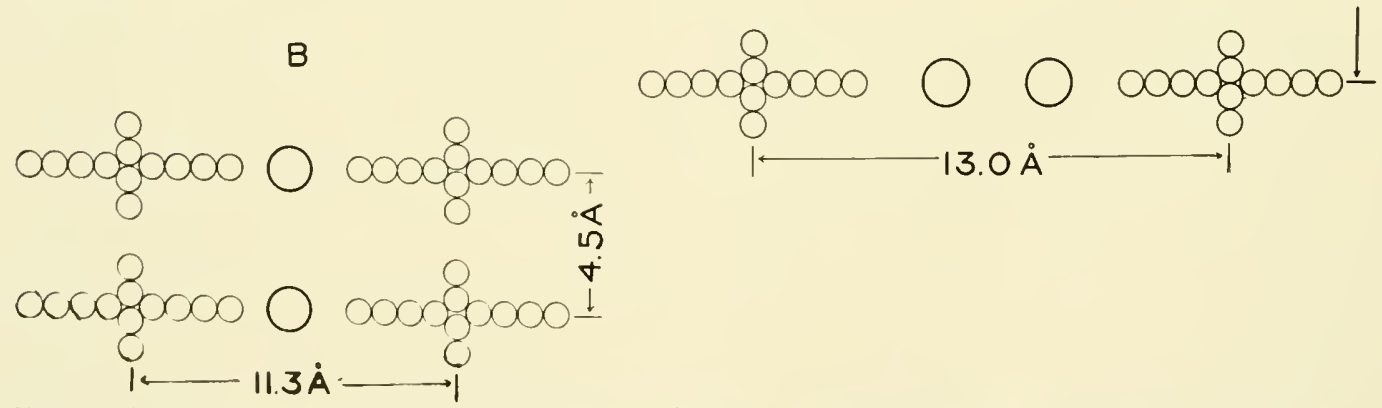

Fig. 7. Hydration of a protein chain shown in diagram. The end riews of four chains are shown at $A$ where $n 0$ water is present. At $B, 15$ per cent water produces a lateral spreading; the water is represented by the large cireles. At $C, 33$ per cent water produces greater lateral spreading and in addition rertical separation also.

amonnt of bound water, will affect considerably the size of the particles. With 40 to 50 per cent water and a density enuivalent to abont 1.15, the density of eytoplasmic particles, a protein particle of 36,000 moleonlar weight could take a slobular ol cubical form of about $50 \times 50 \times 45 \AA$; white if more highly hydrated it might be 50 per cent greater along one or two axial directions.

Conceivably this particle could become completely subdivided into flat dises of need much more before we should accept then without reservation. It is conceivable also that the flat dises of a single layer of chains could berome agrogated laterally and form a so-called nonolarer of abont 10 i to 15 i in thickness, and of more ol less indefinite lateral extent. Althongh there is a certain amount of experimental evidence for this monolayer formation, 110 evirlence of its existence in eytoplasm has been presented up to this time.

These small particles with their layered 
structure of chains are not so liypothetival as one might be inclined to think from first impressions. The ultramicroseope moloubtedly reveals submicroscopie particles which approach in size the dimensions of those shown by the ultracentrifuge to exist in protein solutions. The $\mathrm{X}$-ray diffraction patterns may be associated with layered particles in which the chains fit the dimensions of atomic structures, which in tmm are based on chemical analyses of the proteins and of amino arcids. Diffusion methods, osmotic pressure methods, and ultracentrifuge methods arree pretty well on the sizes of protem particles in dilnte solution. Taken all in all it has seemed to us that further consideration of layered particles is warranted.

The distribution of size classes of the particles below risibility in the cytoplasm is practically mnknown. From the increase in numbers with diminution in size in the visible range and the ultra-violet range, and also from consideration of the enormons numbers of minute particles seen in the ultramicroscope, one may form a rough estimate. For our present purposes we assmme that the number varies inversely with the size.

By making nse of this assmption one may gain a crude picture of the spaces be. tween the particles; that is, of the fluid chamnels in the cytoplasm. At least this gives one a tangible basis for further studies. It mist be kept in mind, however, that we are consideriug cytoplasm with about 85 per cent water and 10 per cent protein, and that this does not include vac1!oles of any appreciable size. When this amount of protein in hydrated condition is hrpothetically cut up into minute chumks of, say, 50 i or $500 \AA$ and mixed with the remainder of the water, one may compute the size of the channels between them. Thus for 50 i particles, ouly, uniformly distributed in the remainder of the water, the space between particles is about 35 i to $40 \AA$; for $500 \AA$ particles, it is about 400 i from one to the next; and for 5000 i particles, it is about $4000 \AA$. This means that the amount of water allotted to each partive is a zone whose leptl is somewhat smaller than the radins of the particle. The significance of this becomes evident when one attempts to inagine how molecules about the size of a cane-sngar molecule can diffuse throngh water channels which are only slightly wider than the molecule itself, as in those between the 50 i particles. There would be sufficient room, however, for really diffusion where the particles are 500 $\bar{i}$ and larger.

These channel dimensions (althongh miform distribution of particles is assumed) must be approximately those in cytoplasm, unless it contains localized density variations. That these variations occul seems very probable, and if so the influence of the large and the narrow channels in this hyaline cytoplasm may perhaps be made evident by the restrictions placed upon diffusion of larger foreign molecules and by the consequent reactions. But this leads us farther afield than we care to go at this time.

These dimensional relationships of particles and chammels are not easily visualized when they refer to a microscopic cell, but perhaps a homely comparison may be helpful. Imagine a 10-micron cubical cell enlarged to a seale in which 1 micron becomes about 10 inches. The cell becomes a nine foot room, and the particles, which are just at the range of microscopic visibility, about 5000 i in diameter, become the size of grapefruits; while the water molecules become about the size of fine grains of sand, such as will pass through a 200 mesh sieve.

We now wish to fill this nine foot room with eytoplasm magnified to a corresponding scale in order to obtain a tangible first approximation to the dimensional interrelations of the eytoplasmic components. Crtoplasm usually has a density of 1.03 (Leontjer 1935) and a water content of 85 to 90 per cent. When all of the materials in the water are aggregated into particles of $5000 \mathrm{i}$ and uniformly distributed, the spaces between them will be nearly equal to the diameter of the particles. These particles enlarged to the size of grapefruits to fit the scale of a 9-foot room are 
now miformly spaced, and the spaces between filled with the fine sand to represent water molecules. The spaees are, say, about 4 inches between grapefruits, which are abont 5 inches in diameter, and form chamnels of sand which are contimuous throughont the room.

If, however, we wish to illustrate the crtoplasm as being completely hyaline in appearance, that is, as containing no visible particles, we may choose only the small 50 A size; then insteal of grapefruits we may make use of some proportionally smaller objects, snch as radish seeds, to represent them. The channels of sand which separate the radish seeds in our 9-foot room are now only abont a millimeter instead of four inches in wilth, and the number has increased enormonsly.

But in the crtoplasm it seems probable that a great variety of particles must exist, ranging in size from perhaps 50 i up to nearly 5000 i-all invisible microscopically. We may assume, for a slightly more detailed picture, that each particle has its allotted portion of water which varies with the diameter of the particle; the small particles are arcompanied by proportionally small rater channels, the large particles by larger chamnels.

It is interesting now to consider some of the possibilities which must follow upon aggregation of these particles. When several particles of varying sizes combine into a larger particle, the allotted water must be considered not only as accompanving them, but also as being squeezed ont from between them to form a deeper layer aromnd the larger clump. A lively imagination may now picture the formation of submicroscopic vacuoles and the chumps forming into sponge-like larger clumps, which may be still invisible - in some cases because they are still submicroscopic in size, and in other instances becanse the portion of the sponge which is formed by the particles is too attenuated, althongh large enongh to be visible in water. Viscosity hehavior, formation of gel and sol states lowlized in varions places in the cell, even the formation of spindle fibers now come within lange of visualization.
With this picture many activities and processes begin to come into view more clearly, althongh they are still surrounded by fog. The introdnction of the protein chain makes the visualization of a structure or a mechanism constructed of submicroscopic and molecular entities become nearly, but not quite, possible. Other molecular structures are essential, however, to the functioning of the machine.

Some of the organic molecules, like those of the flavine and pyridine componmes, the small suceinic acid molecules, or the still smaller molecules or atoms of some metallic elements, are withont doubt necessary to bring abont a condition of activity. The eytoplasmic particle may be many times the size of the small prosthetie gromps which become attached to it. Relatively, the size is comparable to the large automobile and the tiny spark plug; and the analogy may be carried somewhat farther, for the protein particle without the prosthetie group may be about as active as the large automobile without the spark phin.

The manner of attachment of these prosthetic groups is in many eases nncertain; however, they often require two points of attachment. It is interesting to note how nicely certain prosthetie gromps fit on to the motein side-chains. The distances between the polar atomic gromps which are likely to act as points of attachment are in several instances approximately the same in both protein molecule and in the prosthetic groups, that is about $7 \AA$. (See Figs. 8, 9, 10, 11.) This distance between residnes along the protein chain may be also the same as that when the same two residnes ocen attached to arljacent hydrated back-bones.

This interesting spatial correspondence between the probable active regions of the prosthetic gromps and the active ends of the side-chains is niony illustrated by threedimensional models shown in the reprodnctions given in Figs. 8, 9, 10, and 11. By first referring to Fig. 3, the distance from center to center of aldjacent residues on one side of the chain is seen to be $7.0 \AA$. In Fig. 8 a small piece of the protein wain is shown on the left $(\Lambda)$ with two resiches, one of arginine and the other of tyrosine, 
pointine towards a molecule of suceinic acict (B). In Fig. 9 the same two residnes are in close contact with the glucose molecule. In Fir. 10 the active points of attachment of lactoflavinphosphate (Theorell 1937) on

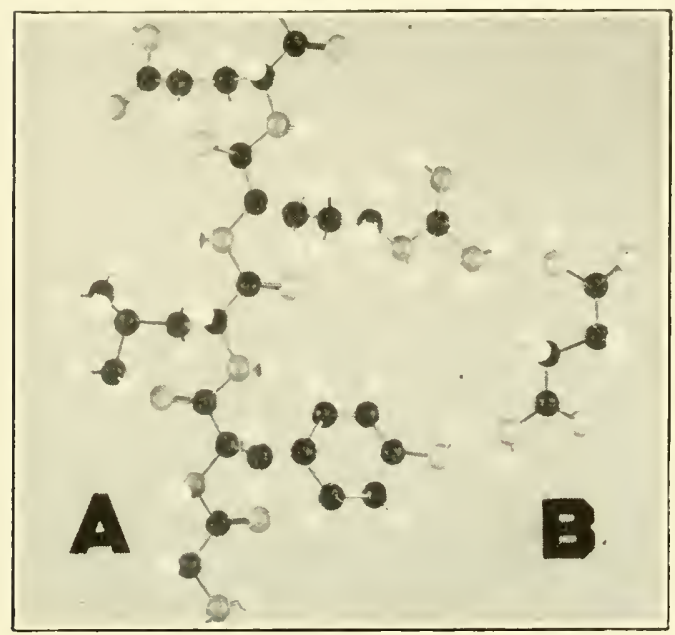

F1g. 8. Reproduction of models to show similarity of spacing, about $7 \AA$, which may exist between the active groups of succinic acid $B$ and the terminal groups of the two resilnes arginine and tyrosine on the protein chain, $A$.

the right are shown in elose approach to the same two residues as in the preceding figures. Finally in Fig. 11 the spatial correspondence is shown between these two

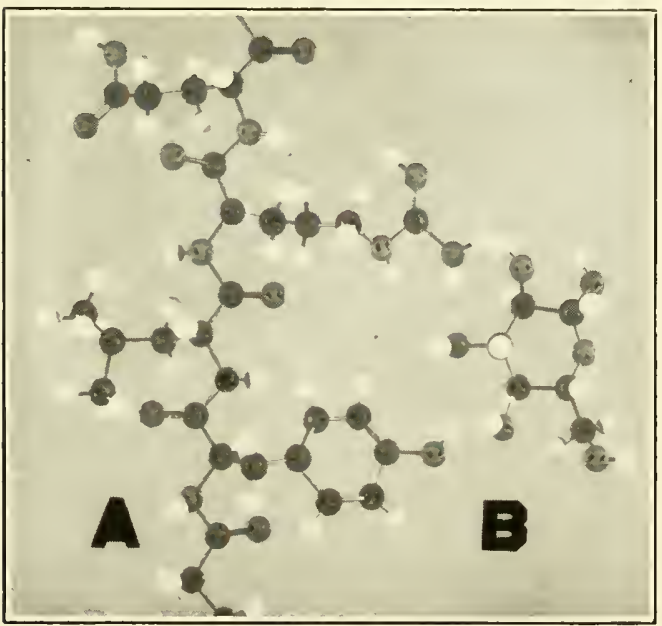

Fig. 9. Reproduction similar to that of Fig. 8 except that the prosthetic group at $B$ is gheose. residues and the probable active groups of lecithin. There is no significance in the chojce of aromine and tyrosine; the distance, $7.0 \mathrm{~A}$, is practically the same regardless of the kinal of residues chosen.

These substances, the prosthetic groups attached to the protein particles, represent, however, a relatively small fiaction of the materials which may occur in the water chamels. They are inclucled principally in the 2 per cent which was assigned to "other" organic ancl inorganic substances," while 1 per" rent was considered as a minimum for fatty molecules, 7 per ant for protein, and 90 per cent for water.

We turn our attention to the water channels which were represented on our enlarged scale by the layers of sand in our 9-foot room. When we assume that most of the oryanie and inorganic substances occur in these chammels, it becomes evident that narrow wammels might easily berome blocked with excess materials. The 3 per cent which we have allotted to three types of substances-to fatty materials, other orwanic compounds and inoromic substances -if apportioned about 1 per cent each will supply for every single protein molecule of 36,000 molecular weight about 5 fatty molecules similar to lecithin, 25 ortranic molecules of the size of a hexose sugar and about 50 ious like $\mathrm{NO}_{3}$. These moleanles, large and small, are numerous enongh when hydrated to prevent ready diffusion muless the proteins form agragegates of a dozen or more of the 36,000 size.

I wish at this point to indulge in some wild speculation which, lowever, may not be excessively wild when examined more closely. I wish to suggest a picture for cytoplasm based upou these moleenlar and submicroscopic entities.

We have seen that the hyaline cytoplasm consists of an enormous number of molecular and submicroscopie particles; that they are mostly protein and probably range in size from about 50 i up to nearly 5000 i where they come just within the visible range. We have seen also from models how the peptide chains of many amino acids may 


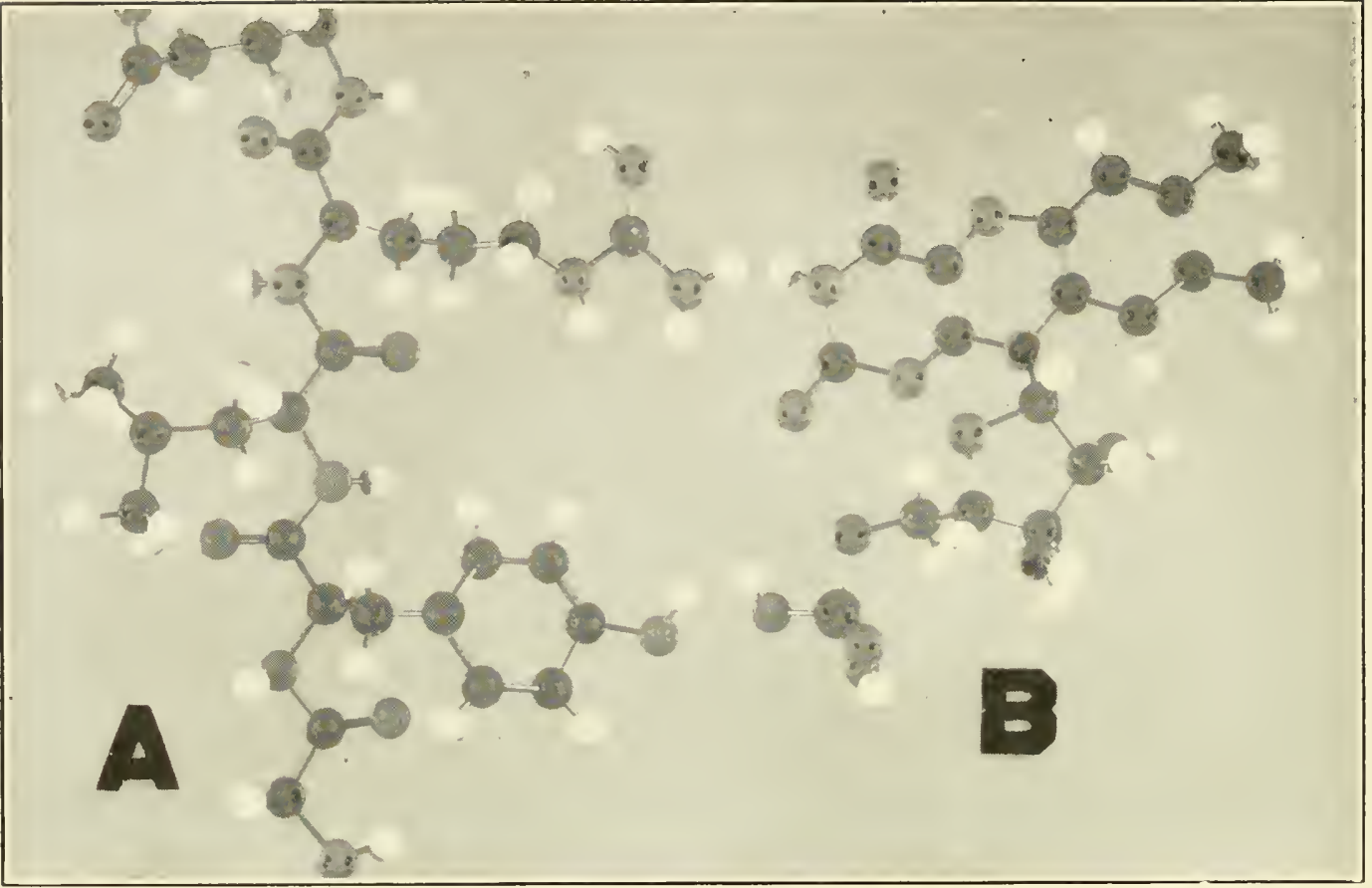

FIG. 10. Reproduction similar to that of Fig. 8 except that the prosthetie gromp is lactoflavimphosphate.

be conceived as being built into particles which are 50 i in size or larger.

It was mentioned also that the ultracentrifnge has shown that proteins may exist in these smaller sizes and that these sizes were confirmed by osmotic and by diffusion methods. X-ray studies have shown that the protein chain occurs as such,

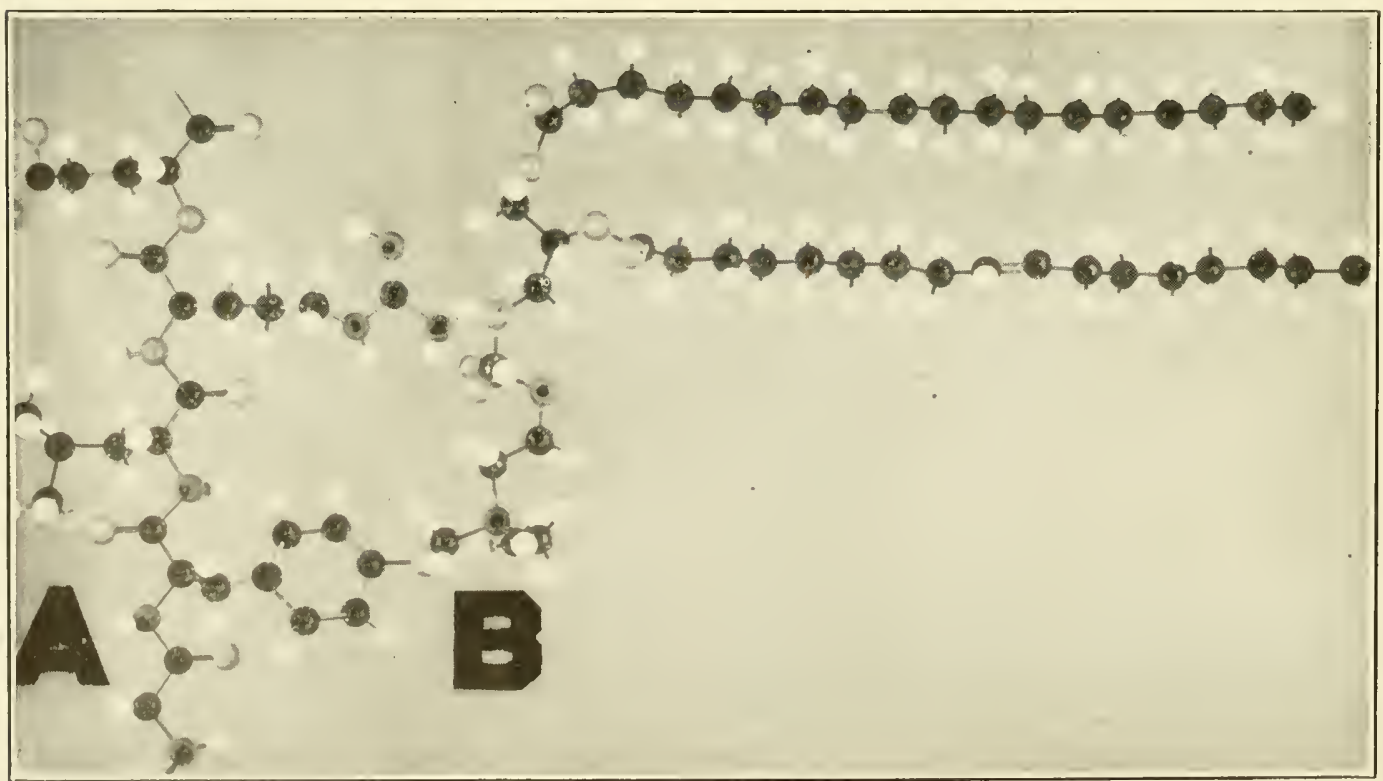

Frs. 11. Reproduction similar to that of Fig. 8 except that the prostluctic group is a form of lecithin. 
and also that parkets of small sizes normally ocemr. Stundies of momo-films have demonstrated that layers of the chains may be formed. It seens to me then that in view of this cumblative information it is not an enormous jump to assume that the particles which may be seen as diffraction spots or visible light in the ultra-microscope are composed actually of these juotein chains in various arrangements.

I want to think of the chain lengths and of the particles they form as being of no standardized size, for a standard size seems to me to be inconsistent with protoplasm, as a biologist knows it. Instead, I should expect to find in the cytoplasm particles of many sizes whiclu are held intact by meaus of primary ralence bonds only. These, for the sake of simplicity, may be considered as structural nnits. I do not feel easy in speaking of them in that way, despite the fact that they are to serve as a first approach and therefore must be devoid of detail to a great extent. This much we may say concerning them : that for some of them the molecular weight may be as low as 9000 or even less, while for other's it may be somewhat larger; and further, that the component protein chains must have arrangements which are specific for specific purposes. These small particles or structural mits may be considered as smper-molecules.

Agruegation of these super-molecules may be accomplished in two relatively distinct and easily conceived ways, which form separate categories of mits on a higher structural level. The difference between these two constructions lies in the closeness or compactmess of the component supermolecules. This rives us now a series of structures of more or less contimnous levels, in which the first is the super-molecules; a second is a compact agregate of supermolecules; and a third, a loose agriegate of super-molecnles together with the compact forms, both acting as components of this loose sponge-like third aggregate.

It will simplify matters if we to not consider intermediate forms of these three structural units, that is, between supermolecules, compact agoregates, and loose agereantes. But a word or two about the second and thiml may charify the conceptions. In order to make the picture more tambible the compact agorerates may be thought of as having perhaps 40 per cent to 50 per cent water and a sperific warity of about 1.15 ; and the water as beine bound, to a very great cxtent, to the livdrophilic groups of the protein by neans of hydrogen briclges. In shape they may be somewhat cubical or elongated, but rectanomar. It would be surprising il they were found to be as regular in outline as these terns imply; but for a first implession the compact agoregates described in such general terms are probably more useful than more specific attents. The angular form seens to be a consequence of being built fom angulax super-molecules.

I think we should digress for a moment here to refer to a possible structure of the super-molecule. As a small packet constructed of polypeptide cluains it will possess a certain degree of internal parallelism. If we accept an extreme as a basis for finther modification and suppose that it eomsists of several larers of parallel chains of indefinite lenoths, built up to form a cubelike packet, the surfaces of the cube sides will be molecularly different in pairs. One pair will have only the ends of the side chains exposed; another pair will have the back-bones exposed, while the third pair will have the ends of the polypeptide chains exposed. Thus, at least three distinct sorts of surfaces are available in which the smaller atomic groups or residues may form mosaic patterns of varions molecular eontent and of various force fields. The prir. of faces which present only the sicle-cllain encls to the water chamnel will probably produce footholds for prosthetic groups.

With this very brief mention of the surfaces of the super-molecules, we return to the discussion of the influence of these suxfaces on the compact ageregates when aggregation takes place. If like surfaces are most effective in producing colsesion of one super-molecule to another, then the larger compact agoregate beeomes an enlared replica of the super-molecule, with similar 
enlarged faces. If, on the other hand, random association is the rule, then the faces of the large agrregate present mosaic patterns in which all the three faces of the super-molecule may appear. Of this form of atriregate, then, there are many sizes, and it is likely that these, for the most part, produce the specks of light in the ultramicroscope; and perhaps they may also be responsible for the protein $\mathrm{X}$-ray diffraction ring's which we obtained from the sediment of various protoplasmic materials.

The third form, the loose aggregate, is a much less concentrated particle and really is not a particle at all in the sense of the first two forms, for it is merely a spongy collection consisting of super-nolecnles and compact aggregates with interpenetrating water channels. This sponge also may oceur in many sizes up to visibility. It is not at all a rigid structure; the components might readily have sufficient ther'mal movement to produce the "shimmering haze" which Bayliss describes as seen in the ultramicroscope. Agrregates of this type, both small and large, may have the inherent organization which biologists demand, and still exist in a particulate state which would permit the streaming of protoplasm or, on the other hand, would permit the whole cell or any part of it to become a gel, as conditions might demand.

The properties of such particles, it seems to me, with only slight modifications would be extremely versatile $j_{n}$ the formation or organization of molecular mechanisms, or the "wheels" of Szent-Gyorgi's discussion. The versatility would result from the varied types of surface mosaies of its denser components; and the positions taken by these particles within the sponge or net conld serve to holal enzyone systems in close proximity, as, may be needed, for example, in the respiration sistem described by Theorell.

This, perhaps, is sufficient belaboring of this three-dimensional network of submiceroseopic particles consisting of two interpenetrating systems, one of water and small dissolved molecules, and one mostly of proteins. It may be worth while to summarize briefly to see how mueh is speculation and how much has an experimental basis. The weakest point is that which we have met in almost every paper of this series; that is, our lack of well-defined knowledge of the proteins. We have carried what little knowledge we have from the molecular range up into the range beyond reach of most of our methods, and have deliberately transplanted conceptions of atomic and molecular structures into the field just below visibility, where we have used them to construct what might simulate replicas of particles which we have strong reason to believe exist there in enormous numbers.

As a basis for onr studies we have accepted chemical analyses of many kinds of protoplasm and selected what seemed to be the minimm essentials. We said that 90 per cent water, 7 per cent protein, 1 per cent fatty substances, and the remaining 2 per cent of other organic and inorganic substances are acceptable as constituting such minima. Of these the water molecule was the simplest conception and the best understood. The protein materials, lowever, ocempied ruost of our time. This substance is the least well known and subject to the widest variations in interpretation. There are certain characteristics, however, which come in for less objection, and these we have made use of to furmish a tangible structure, a frame of reference, in a sense, for the structures in protoplasm.

\section{References Cited}

Astrury, W. T. 1933. Trans. Faraday Soe., 29: 193.

Astbury, W. 'T. and Street, A. 1930; 1931. Nature, 126: 913; Trans. Roy. Sos. (London), $2304: 75$.

Asтвеку, W. T. and Aткіn, W. R. 1933. Nature, $132: 348$.

Astbury, W. T., Dichinson, S. and Bailey, K. 1935. Biochem. J., 29: 2351.

Astbury, W. T. and Lonax, R. 1935. „. Chem. soe. (London), p. 846.

Astbukr, W. T'. Bell, F. O., Gorter, W. and TaN ORMondT, J. 1938. Nalure, 142: 33.

baknes, W. 11. 1929. I'ror. Loy. Soc. (London), $125 \mathrm{~A}: 670$.

Bayliss, W. M. 19:0. Iroe. Roy. Soe. (London). 911: 196.

BeOHIOLD, H. And SCILESINGER, M. 1931: 1933. 
Biochem. Z., 263: 387; Zeit. Hyg. Infectionskrank., 115: 342.

Bernal, J. D. and Fowler, R. H. 1933. J. Chem. Phys., 1: 515.

Butler, J. A. V. 1936. Trans. of Faraday Soc., $33: 229$.

Chibnall, A. C. and Grover, C. E. 1926. Biochem. J., 20: 108; J. Am. Chem. Soc., 48: 728.

Ellis, J. W. and BATH, J. D. 1938. J. Chem. Phys., 6: 723 .

Gaidukov, N. $1906 ; 1910$. Ber. deut. Botan. Ges., 24: 107, 155, 580; Dunkelfeldbeleuchtung und Ultramikroskopie. Jena, 1910.

Giroud, A. 1929. Protoplasma, $7: 72$.

Heilbrunn, L. V. 1928. Colloid Chemistry of Protoplasm. Berlin.

Hendricks, S. B. and JefFerson, M. E. 1936. J. Chem. Phys., 4: 102.

Herrmann, K., Gerngross, O. and Abitz, W. 1930. Z. Physik. Chem., 10: 371.

HoRning, E. S. 1933. Ergeb. der Enzymforsch, 2: 336 .

Hugains, M. L. 1936. J. Org. Chem., 1: 407.

KATz, J. R. DE and RooY, A. 1933. Naturwissenschaften, 21 : 559.

LANGMUIR, I. 1938. Cold Spring Harbor Symposia on Quant. Biol., VI: 171.

LANGMUiR, I. and Schaefer, V. 1939. Chem. Rev., 24: 181.

LASSETTRE, E. N. 1937. Chem. Rev., 20: 259.

LEONTJEV, J. 1935. Biodynamica, 5: 9.
Miller et al. 1932. J.Am. Leather Chem. Assoc., $27: 174$.

Milovidov, M. P. 1928. Compt. Rend. Paris, 187 : 140 .

Mirskx, A. E. and Pauling, L. 1936. Proc. Nat. Acad. Sci., 22: 439.

Neurath, H. 1938. Cold Spring Harbor Symposia on Quant. Biol., VI: 196.

Pauling, L. 1939. The Nature of the Chemical Bond. Cornell.

Pauling, L. and Huggins, M. L. 1934. Z. Krist., $87: 225$.

Pearsall, W. H. and Ewing, J. 1924-5. Brit. J. Exptl. Biol., 2: 347.

Price, S. R. 1914. Ann. Botany, 28: 601.

Robertson, J. M. 1935. Chem. Rev., 16: 417.

SCHLESINGER, M. $1932 ; 1934$. Z. Hyg. Infectionskrank., 114: 161; Biochem. Z., 273: 306.

Schimti, F. O., Clark, G. L. and Mrgudick, J. N. 1934. Science, 80: 567.

SHinke, N. and SHigena, M. 1933. Cytoolgia, $4: 189$.

Sponsler, O. L. and BAtH, J. D. 1940. (Unpublished work.)

SVEDBERG, T. 1937; 1939. Nature, 139: 1051; Proc. Roy. Soc. (London), 127B: 1.

Taylor, C. V. 1925. Proc. Soc. Exptl. Biol. Med., 22: 533 .

THEORELL, H. 1937. Ergeb. Enzymforsch., 6: 111.

ZsigMondy, R. 1914. Colloids and the Ultramicroscope. New York. 


\title{
PROTOPLASM AND COLLOIDS
}

\author{
By L. V. HEILBRUNN \\ ZOOLOGY LABORATORY, UNIVERSITY OF PENNSYLVANIA, PHILADELPHIA, PA.
}

FACED with the problem of understanding the mechanism of the living cell-of its power to divide, to shorten, or to respond to stimuli-our only hope of success lies in our power to discover, insofar as possible, the physico-chemical properties of the protoplasmic material of which the cell is composed. The task is not a simple one. Since protoplasm is obviously colloidal, we must attempt to apply the technique and the point of view of the colloid chemist. But whereas the student of inanimate colloids can introduce his material into any container of his choice, the student of the physical chemistry of protoplasm must devise methods for making measurements within the tiny confines of living cells.

Then, too, the cell physiologist has to do with a material far more complex chemically than anything a conservative or reasonable chemist would care to study. For protoplasm is not only protein; it contains lipids, carbohydrates, and salts as well. Some of these substances are in true solution, others are colloidal; and in addition there may be a very high concentration of suspended material in the form of granules or fat droplets. Finally, the cell physiologist has an additional worry; for although a chemist can ordinarily treat a colloid with any one of a variety of reagents, protoplasm is extremely sensitive. It promptly dies if exposed to drastic reagents, and the dead protoplasm has vastly different properties from the living:

And yet, in spite of all these difficulties, some methods have been devised for the physico-chemical study of the protoplasmic colloid, and at least certain elementary information has been obtained. I shall not attempt to survey all the progress that has been made in various parts of the world, and I hope my listeners will pardon me if, for the most part, I confine my remarks to the work done in my own laboratory.
Study of the colloidal properties of protoplasm should yield two types of information. In the first place, it should provide data concerning the true nature of the colloidal system or systems within the living cell. And secondly, and I feel that this is more important, the colloidal study of protoplasm should interpret the behavior of the cell in physico-chemical terms. It should, for example, explain in so far as possible the annazing sensitivity of protoplasm to the electric current, to mechanical impact, and to ultraviolet radiation. It should show why dilute solutions of ether and other fat solvents are able to prevent protoplasmic activity without seriously injuring the cell; why magnesium is likewise an anesthetic. Eventually, of course, the cell physiologist must seek to interpret all the normal and experimental behavior of a cell in terms of its colloidal properties.

Because of the greater interest of biologists in the behavior and activity of protoplasm I shall pass rather hurriedly over that aspect of my subject which has to deal with the physical make-up of living substance. Within the past 25 years numerous studies have been made on protoplasmic viscosity. It is no longer necessary to hazard rough guesses as to the viscosity of the protoplasmic fluid, for reasonably accurate methods of measurement have been devised. Living cells are remarkably tolerant toward strong centrifugal force; so that by subjecting the cells to such force, it is possible to observe the movement of granules through the protoplasm. From the speed of such movement, one can (with the aid of Stokes' law) calculate the viscosity of the medium through which the granules move. Thus, it has been shown that the protoplasm of the egg of the sea-urchin (Arbacia) has a viscosity only several times that of water. So, too, the interior protoplasm of the ameba is a fluid of low vis- 
cosity. The low values for protoplasmic viscosity which are obtained with the centrifuge method have been checked by determinations made form a study of Browniam movement. These values pertain to the hyaline material in whith gramules are suspenderl. Since ordinarily there is a hearr concentration of eramular material. the riscosity of the whole mass is several times oreater than that of the hraline fluid alone. And indeed in some aases in which the protoplasm is very densely packed with aramules (for example, in Paramecirm), the visoosity of the protoplasm as a whole may he many times ereater than that of the haraline fluid. For references to literature on protoplasmic riseosity, see Heilbrımn $(1928 ; 1937)$.

Earlier studies of protoplasmic viscosity were concernes only with the main mass of the protoplasm in the interior of the cell. Later we became interested in the cortex of the cell. In the mufertilized sea-urehin egre the cortex is so thin and delicate that it remained nmoticed mutil described by Moser (1939). Some minutes after fertilization the cortex becomes much thicker so that it is rearlily visible. In both unfertilized and fertilized Arbucin exs the cortex is so stiff that even hich centrifugal forces are incapahle of moving yomules through it, muless it first be marle fuicl. In Amocba moteus the cortex is much thicker than in the sea-nrohin exg. Moreover, its visonsity can be tested by strong centrifugal forces, for such forres are rapable of prshing gramules through it. In my laboratory we have mate a nmmber of studies of the viscosity of the cortex or plasmagel of ameba. One of the significant facts that we have observed is that the high viscosity of the cortex depends on the presence of calcium ion. If this ion is replated by sodimm or potasinum, or eren by magnesinm, the viscosity of the cortex decreases; a similar decrease oc(-11's if the anlebale are inmersed in oxalate solutions. whiclu can be assumed to remove aleium form the cortex.

Trpically, as las ahready been noted, the protoplasm in the interior of a resting cell is fluid. Suspented in the protoplasmic fluit are immumerable glamular particles. The fact that these tend to remain discrete and separate from each other is an indication that they bear an electriv charese. It is of some importance for us to know the sign of this rhallere on the protoplasmite glamules. And ret very few attempts have been made to determine whether the "harege is positive or nexative. Nor is such a study as simple as it night seem. So semsitive is protoplasm to an electroce collrent that almost any passage of electricity thromgh it is apt to canse destrurtion of the cell. Onl rerent experinests (Heilbrumm and Dangherty 1939) indicate that the charge on the protoplasmie inchusions within ameba protoplasm is positive. This may seem strange to students of inamimate colloids and poteins, especially if the plI of the ceell is as high as sone anthorities rains. However, it is in aceorel with an early observation of Harty on the eytoplasm of the cells of the onion loot tip, as well as with dednctions made from centrifuge viscosity measurements. Apparently the positive charge on protoplasmic inclusions is dne to the presence of earbonic alcid within the cell. If the protoplasm in amedoa is made alkaline, the positive charge is nentralized or reversed. Moreover, in the leaf cells of the water plant Elodea, it is only when carbon dioxide is present that the cell chloroplasts are positively charyed. During active photosinthesis, when earbon dioxide tends to be used up, the chloroplasts are often charged neatively.

Whereas the inchusions within the eytoplasm, and presumably also the mirellae of the protoplasmice colloid, are rharged positively, the rhomatin of the nuclens carries a neative rharge. This has lomg been known for plant cells, Jut it has only recently been shown for any animal cell. In a study of the salivary ylands of fly larvae. Chmmey and Klein (1937) found that the chromatin migrated to the anode. However, the nuclens as a whole moves to the rathocke, a fact which indicates there is a positive chalue on the ertoplasmice colloids surromeding the nuclear membrane. I have said that Chmmey and Kklein were 
the first to show a negative charge of chromatin in animal cells. This is not quite true. Not long ago, I was showing the lantern slide of Chmmey and Ḱlein's experiment at Princeton University when Dr. Dahleren ealled my attention to an observation he had made in 1915 on the nerve cells of the electric ray. Althongh Dahloren was not interested in the question of electric charges, his observation clearly agrees with the later work of Chumey and Kilein (Fig. 1). linizing the protoplasm (Fig. 2). Thus, in sea-mohin eyrs or in amebae the entrance of alkali into the cell canses a remarkable increase in the free fat. In ameba, at least, alkalinization is not the only means of cansing fat release. Irradiation with ultraviolet is also effective (Heilbrumn and Dangherty 1938), as well as certain other factor's now being studied.

In summary, it may be stated that the protoplasmic colloid is essentially lipoprotein rather than protein; that its micellae

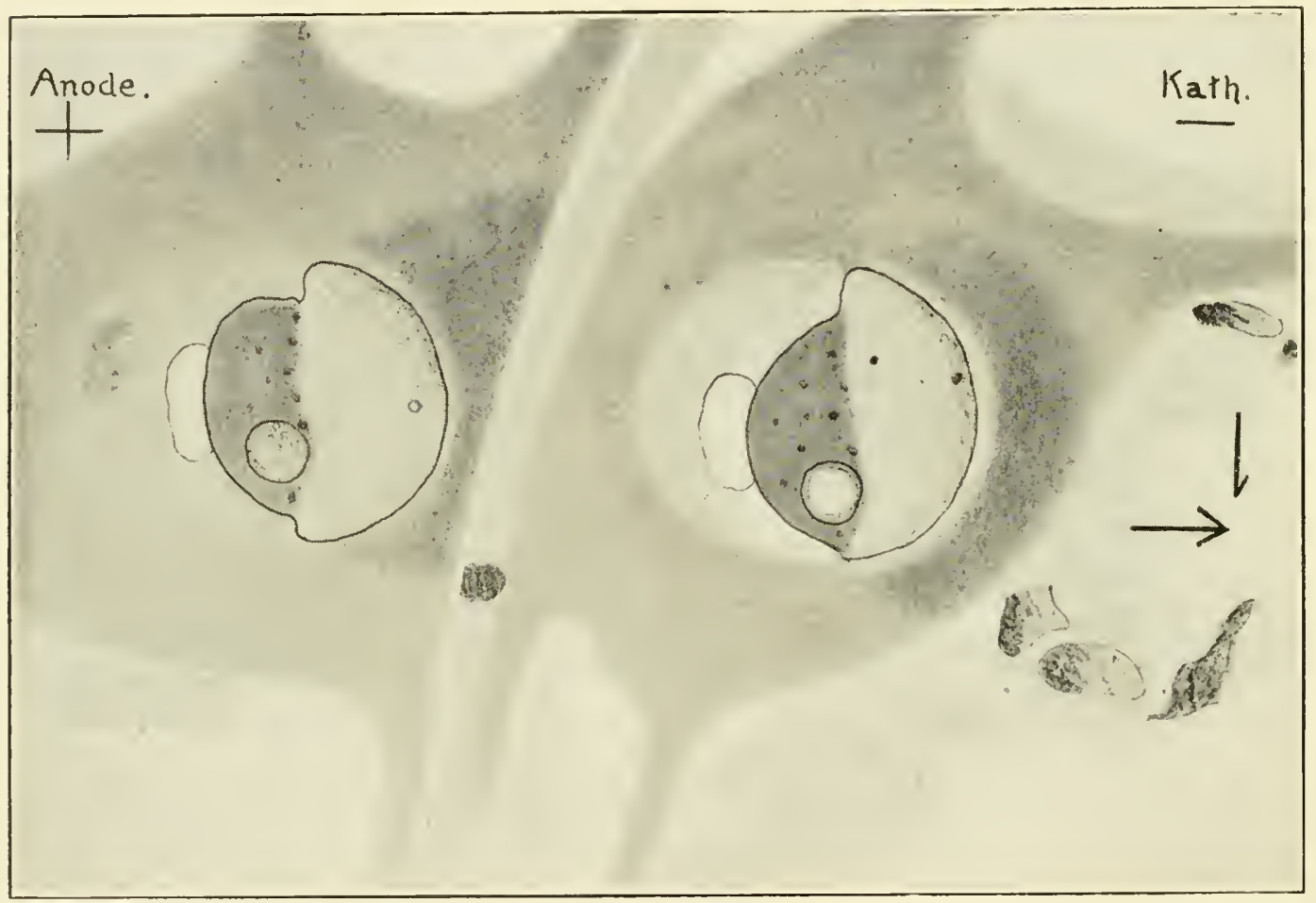

Fig. 1. The resilts of the passage of an electric eurrent through two nerve eells of Torpado ocellata. The muclei have migrated to the eathode, and the chomatin to the anode (after Dahlgren).

As noted previonsly, the protoplasmic colboil is not just protein, but contains fat or lipiel as well. Much of the fat appeass to be bound ehemically in some sort of protein-lipid combination. The amomnt of fores fat within a coell varies markedly. Tn cells morlemoring fatty degenomation, the increase in risible lat is due primarily to a lelease of fiat from protein-lipid combination. Such a realease ean be areomplished (IIeillnum 1936) experimentally by alka- are probably charged positively (except when earbon dioxisle is absent); and that the interior of cells is often fluicl, within a cortex whose rigidity depends on the preseme of ealcinm.

In studying an inamimate colloid it is a simple matter to test the effect of varroms reagents. Living eells ale much more diffirult to study. For if the protoplasm, or a part of the protoplasm, is changed from fluid sol to rigid gel, this may not involve 
any transformation readily aletectable by simple microscopic observation. Fontumately, howerer, the centrifuge is a great help; and by determinations of potoplasmic viscosity one can have a trustwortley inflication of what is happening within living cells.

In some ways protoplasm behaves like an ordinary protein. The usnal protein coagmlants, such as alcoliol, salts of heary metals, etc., have a rapid effect on the fluid protoplasm and soon change it into a stiff mass. But protoplasm differs from an

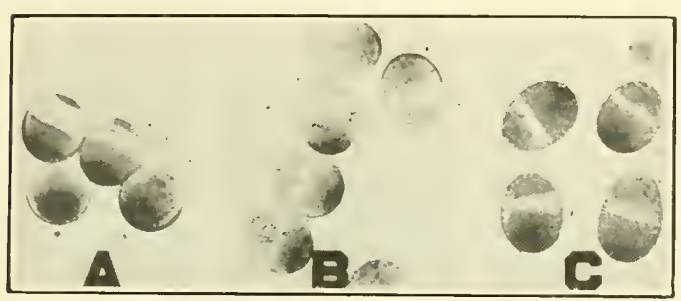

FIG. 2. The effect of alkalinization on sea-melin egg protoplasm. A shows normal centrifuged cells. The lower 2 cells are not properly oriented to show the layers of the protoplasm, but the upper 2 cells clearly show the free fat at the pole of the egg opposite the heavily pigmented region. $\mathrm{B}$ and $\mathrm{C}$ show cells centrifuged after alkalinization; the amount of free fat is much greater than in the control.

ordinary protein solution in being far more sensitive. In addition to the ordinary protein coagulants, various physical and chemical agents, some of which have but little if any effects on proteins, produce violent change within the protoplasm. In the short space of this lecture it is scarcely possible to review adeqnately information already obtained concerning the effect of many different agents on protoplasm. One fact stands ont. Varions diverse trpes of treatment ause protoplasmic gelation; and this relation, if carried to extremes, is associated with a chalacteristic change in the appearance of the protoplasm. Instead of containing only gramules, the rell beromes filled with tiny racuoles until it may look like a foam. The observation that vacnoles may appear in protoplasm is hardly new. The earliest and most famons pioneer in protoplasmic study, Dujarlin, emphasized the importance of vacuolization. Indeed, in some of his writing lie stated that the ability to form vacuoles was the ontstanding characteristic of living snlstance, the very dhalacteristic which most cleally distimguished it from inanimate proteins. Through the rears many authors hare noted protoplasmic vacuolization following exposine of cells to hypotonic solutions, to hypertonic solutions, to heat, to cold, to radiation of various sorts, to the electrice current, and indeed following exposine to almost any type of stimulating arent. However, since Dnjardin, ver:y little attempt has been made to gatler tomether or to coordinate these observations. In sea-molin eoss racuole formation is realily olsserved. When the cell becomes filled with vacuoles it is, of conse, lead; but it is an important fact that all those agents which excite the cell to actirity rause vaculolization when used in excess.

How shall we interpret the racuolization process? One way to nnderstand it is to consider another reneral reaction of protoplasm, a reaction known long before the discovery of the cell theory and ret mutil recently rarely studied. Whenerer a cell is so torn or broken that its contents flow out, a new film tends to be formed about the exuding droplet. This reaction, which I have called the surface precipitation reaction, may produce only a film at the surface, or it may extend more and more deeply into the bodr of the protoplasm. If it extends into the mass of the protoplasm, instead of a single film, it produces coumtless vacuoles. Both film tormation and vacmolization depend on the presence of calcinm. In the absence of calcinm ion there is 110 film and no vacuolization. If, then, we are to nuderstand vacuolization, we must molerstand the surface precipitation reaction.

In many ways the reaction which ocents when a cell is torn or broken is comparable to blood clotting. If we add oxalate salts to blool as it pours from a vessel, the oxalate precipitates ont calcium ancl clotting is prevented. So, too, with the living cell. If we break a cell in the presence of an oxalate solution, the contents of the pro- 
toplasm seatter thronghont the medium, no films appear, and no raenoles are formed (Fig. 3).

As a matter of fact it is logical to suppose that within rells reactions similar to blood elotting may oceur. For practically all cells of the rertebrate anmal contain substances important in blood clottine. 'Thus, for eximple, muscle protoplasm can

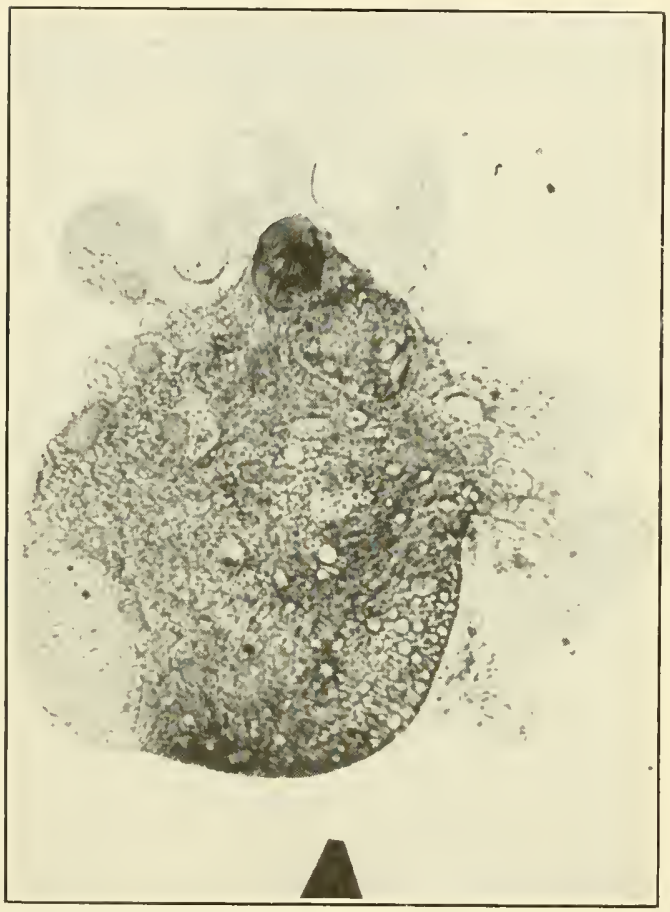

Fig. 3. A, normal surface precipitation reaction in Stentor. B, absence of the reaction when rells are crushed in .32 M sorlium oxalite.

produre as much or more thrombin than an erfual pllantity of blood.

It is not my intention at the present time to disenss the attempts we lave made to incmire into the dratails of the sulfalee mecopitation reatetions. The subject is a complex and a difficult one and progress has been slow. (Mre point I shonlel like to emphasize heranse of its biologiral siernificance. Nlthough strontium is about

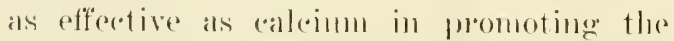
smrlace precipitation reartion, the marnesimm ion is lat less potent. In the case of the sea-urehin egrg a mere trace of cal(imm is suffieient to initiate the reaction. Over 100 times as much magnesim is necessary to produce the same result (Heilbromm 1934). This is a point to which I shall return later.

I have stated that I regard the surface precipitation reaction and the racuolization reaction as akin to blood clotting. More-

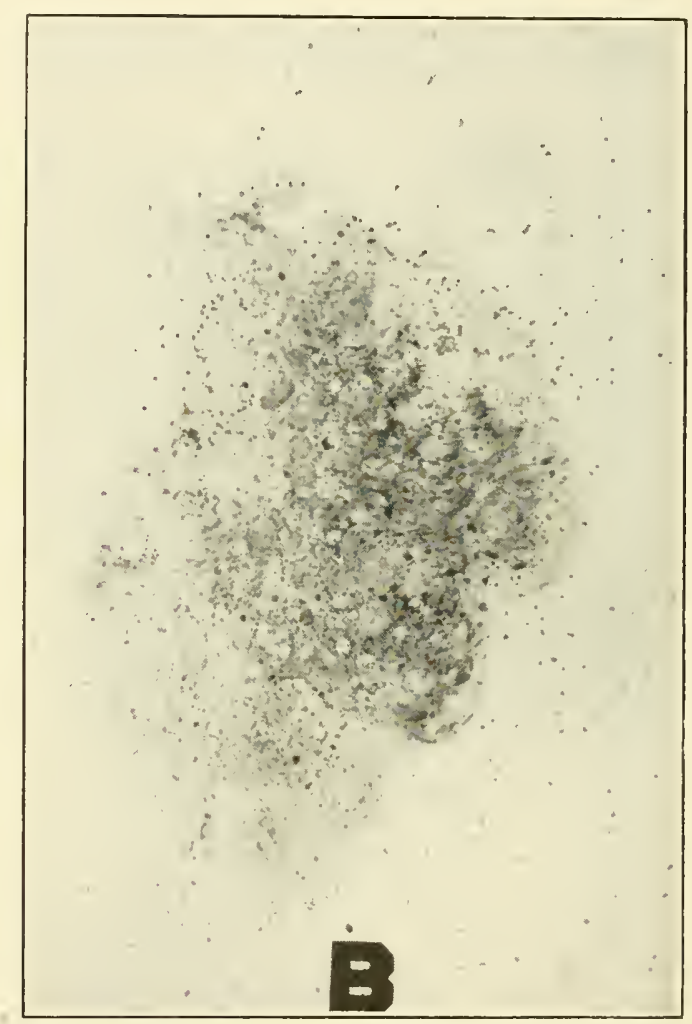

over, I believe that an incipient reaction of this solt oceuls whenerer a cell is stimmlated or alroused to aletivity. Appalently the interiol of the livine cell contains little (1) no free calcinm. When, howerer, al cell is stimulater in one way of another, I believe that ralerom is released form the

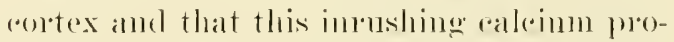
duees all interiol alottine of protoplasm, just as the injection of tree calcium into the blomb streand ratuses the blood there to (.lot.

What is the eviclence for this theory? 
In the first place, let us eomsider some experinents with ameba. Il amelya is subjected to ultraviolet radiation, there is an immediate liquefaction of the cortex or plasmagel. As Angerer (1936, 1937) has shown, similar liquefaction follows mechanical impact or electrical shock (Fig. 4).

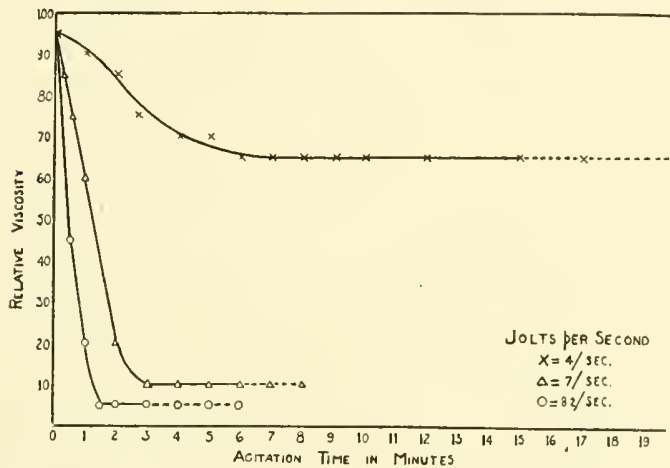

Fig. 4. Effect of mechanieal agitation on the riscosity of the plasmagel of Amoeba protens. Ordinates show relative riscosity, alscissae the time of agitation (after Angerer).

Further evilence for the release of ealcinm following stimulation is shown by the experiments of Mazia and Clark (1936) on Eloden leaves. These cells are comveniently provided with oxalate salts dissolved in theip vacnoles, and this oxalate serves as an indicator for caleium. No matter how the Eloder cells are stimulated-whether with electric or mechanical shock, or with ultraviolet radiation-calcium is released from the protoplasm, enters the vacuoles, and forms readily detectable calcimm oxalate erystals there.

But to retum to the ameba. I have pointed out that when the ameba cell is stimulated, the cortical plasmagel aets as if it had lost calcium. On the other hand, the plasmasol, that is to say, the protoplasm of the ameba interior, behaves as thongh calrimm lad entered it. Following irradiation with ultrariolet, there is a transitory liquefaction of the plasmasol such as $1101^{\circ}$ mally oceurs following the addition of a verer small amomut of caleium iom. Immediately thereafter there is a slarp visrosity increase, indicative of motoplasmic "lotting. Exactly similar changes follow other types of stimulation.
Om results with ameba thus indicate that following treatment with any type of stimnlating anent. calcium is released from the coltex, enter's the cell interior and produces: a speries of clottiug there. Tlus there are two asperts of the response to stimmlation -first, the release of raleium linom the rortex, and second, the effect of arleinm in producine elotting.

Recontly we have been able to consider at least one phase of exeitation in anothel trpe of protoplasmic system, the exo of the worm Noreis. When this are is shed into sea-water, it has a large intact mucleus or gemminal vesicle. This remains intact unless the ego is fertilizerl or artificially stimmlaterl in one way or another. Such stimnlation may, for example. be accomplished by nltraviolet radiation or by isotonic solntions of sodium or potassinm chloride. If the eags are subjected to the radiation from a merenry rapor lamp, a few seronds exposme may be sufficient to canse a complete disappearance of the nuclear membrane. It will be remembered that in most cells breakdown of the nuclear membrane is a necessary preliminary to mitosis.

Experiments with Dereis egas have shown that stimnlation by nltraviolet radiation may be prevented if the ega's are first inmersed in solimm citrate solutions for five to six minntes. The citrate solution presmmably removes alcium from the cell cortex and the ear becomes insensitive. The exo is not killed or severely injured by the eitrate treatment, for on return to sea water it regains its sensitivity to nltraviolet radiation. Sinniar experiments can be performed with sorlinm chloride or potassimn chloride solutions. These too lose their effect if they are tried on egas previonsly immersed in citrate solution. This is in line with experiments which indicate that sodium or potassimm may release cal(.ium into the rell interior. Unfortunately l have no time to refer to these experiments in further detail.

In a rery brief and incomplete fashion. I have ontlined a theory of stimulation in terms of protoplasmic effects, and I have tried to present some of the evidence in favor of this theory. Now the value of any 
theor of stimulation depends on the $n$ mmber of phenomena it can explain. Above all else, a satisfactory theory of stimulation shonld offer an interpretation of the broar facts of anesthesia, ant every major theory of stimulation has attempted to do this. In living eells generally, the effects of stimulation are reversibly inhibited by two sorts of anesthetics. One is the magnesinm ion, the other inchudes a variety of fat solvents and fat soluble substances. Both types of anesthetics are well-nigh miversal.

For all the older theories of stimnlation and anesthesia, the magnesium ion has proved a stumbling block-so much so that one of the leader's in the field of cellular phrsiology has attempted to redefine anesthetics in order to exclude magnesinm. This in spite of the fact that there is no more general anesthetic, inasmnch as magnesium is effective on animals and tissues from ameba to man. The difficulty in interpreting the effect of magnesium lies in the fact that in every case that has been studied magnesium anesthesia is specifically antagonized by calcium. Thus these two bivalent and similar cations are opposed in their effects on the irritability of living systems.

In order to explain the action of magnesimm, it is not necessary to suppose that its effect on protoplasm is the exact opposite of the effect of calcinm. I have suggested (1934) that magnesinm behaves like calcium but in far weaker fashion. Thus, if the calcium of a coll is largely replaced by magnesium, this would result in the replacement of a very powerful ion by one that acts in the same way but not so stronoly. In mannesium anesthesia it may well be assumed that the calcium of the cell cortex is to a considerable extent replaced by magnesium. Upon stimulation of such a magnesium treated cell, it is magnesinm rather than calcinm that is released to the cell interior. Ir, as has been indicated, some rotting reaction essentially similat to the smrare precipitation reaction is involved in excitation, then it is easy to muderstand why excitation shonld be lacking when magnesium rather than calcinm is thrown into the cell interior. For it will be remembered that experiments have shown that magnesium is over 100 times weaker than ealcium in producing a surface precipitation reaction. Here, then, is an explanation of magnesium anesthesia which seems to fit in with known facts. No other theory of stimulation has ever offered any explanation whatsoever.

Now let us consider anesthesia due to fat solvents. Returning again to our theory of protoplasmie stimulation, it will be remembered that it postulates two stages, first a release of calcium from the cell cortex, and second a clotting in the interior of the cell as a result of the presence of tree caleinm there. It can readily be shown that fat solvents, such as ether, higher alcohols, etc., do not prevent the first stage of stimulation. Indeed, instead of preventing the release of calcinm from the cortex of the cell, fat solvents actually favor such a release. This is indicated by the fact that solutions of fat solvents tend to liquefy the cortex of the ameba cell. Moreover, in the case of the Elodea leaf cell with its oxalate indicator for calcinm within the vacnole, it can readily be shown that fat solvents initiate rather than prevent release of calcium from its bound state within the protoplasm (Mazia and Clark 1936).

Clearly, if our theory is to explain ether anesthesia, we must postulate that dilute solutions of ether (and other fat solrents) are able to prevent the clotting reaction. This is easy to show for cells as a whole, and many years ago I was able to demonstrate that dilute ether solutions prevent the relation which normally follows stimulation in the sea-nrehin eogs. But one should be able to show also that etler and other fat solvents suppress the surface precipitation reaction, for this is rearded as fimdamentally akin to the clotting reaction within the cell. My first attempts in this direction were monsuecessful. Anesthetic concentrations of ether in sea water do not in any sense suppless the surface precipiation reaction as it ocens in the sea-11rellin eger. 'This, for real's, was a 
serious disappointment. Finally, however, it occurred to me that whereas sea water is rich in calcium, when calcium is released to the cell interior there may be only a very low concentration of the ion present. Hence it was necessary to test the effect of dihute ether solutions on surface precipitation reactions ocemring in the presence of traces of calcium. Under such conditions, it is a simple matter to show that the surface mecipitation reaction of the sea-urchin egre is prevented by two per cent ether solutions (Heilbrum 1934). Similar results can also be obtained with the fresh-water protozoan Stentor, which lives in solutions normally much lower in calcium concentration than sea water. Stentor shows a beatiful surface precipitation reartion, but this is completely prevented by dihnte solutions of ether. On explanation of fat solvent anesthesia offers a clue to the interpretation of one of the strangest puzzles in physiology and pharmacology. For orer 100 years it has been known that weak concentrations of fat solvents may increase rather than suppress irritability. In subanesthetic concentration, the very substances which suppress and inhibit response tend to arouse and excite the protoplasm. How to explain this parodox has always been a mystery. The only explanations offered have assmmed participation of the central nervous system. Thus, when a cat exposed to ether struggles violently as the ether begins to enter its blood, it is assmmed that inhibitory centers of the brain have been anesthetized by the ether. Such explanation might be valid for an entire animal, but it is of course powerless to explain the stimnlating effect of dilute fat solvents on muscles cut free from their connection with the central nervous system. For this puzzling phenomenon, the theory I have suggested offel's a simple interpretation. Fat solvents favol the first stage of stimulation (calcium release) and tend to suppress the seeond (clotting). A weak solution of ether may be strong enough to prevent the clotting reaction produced by the calcium. Actually, in the case of the interior protoplasm of ameba, Daugherty has berm able to show that one per cent ether acts as a stimulant in cansing increase in protoplasmic viscosity. On the other hand, with 2 per cent ether, the anti-clotting effect of the fat solvent prevails and visonsity dereases (Damgherty 1937). Whether correct or not, this explanation of the stimmlating effect of dilute fat solvents on isolated tissnes is as far as I know the only theory that has ever been seriously proposed.

Until now, I have spoken only of the cells of invertebrates. As a biologist, alive to the advances macle in crtologr, genetios, etc., by studying favorable material such as Ascaris and Drosophila. I have in the past always soluht out the most favorable cells for my work, no matter what phyhm they came from. But whereas biologists are readily impressed by evilence gotten anvwhere in the animal or plant kingdom, physiolowists are often trained in the medi(eal profession, and are somewhat dubions concerning information obtained firom lower oramisms, or from streh unfamiliar material as sea-urchin egas or protozoa. Accordingly, I have tried to do something with vertebrate material, in the hope that the general type of theory that I have been expounding might be of some use in interpreting the activity of a conventional cell like the vertebrate muscle cell. After all, there are advantages in stucloing mus.le cells. An ameba can act in a variety of ways following stimulation. In miscle cells, the primary response is always some form of shortening. The age-old problem of why a muscle shortens is still with us. For although it may be true that the mosin molecules fold or superfokl to produce a decrease in length, we know practically nothing of the mechanism of such a process or of the incentive for it.

Within the last year, I have been busy with experiments on isolated single muscle fibers, and I should like to conchucle this lecture hy discussing them. What I have talked about thus far is work already published, by now a little old and stale. But until the last day or two before I left Philadelphia, I was enjoring some work with 


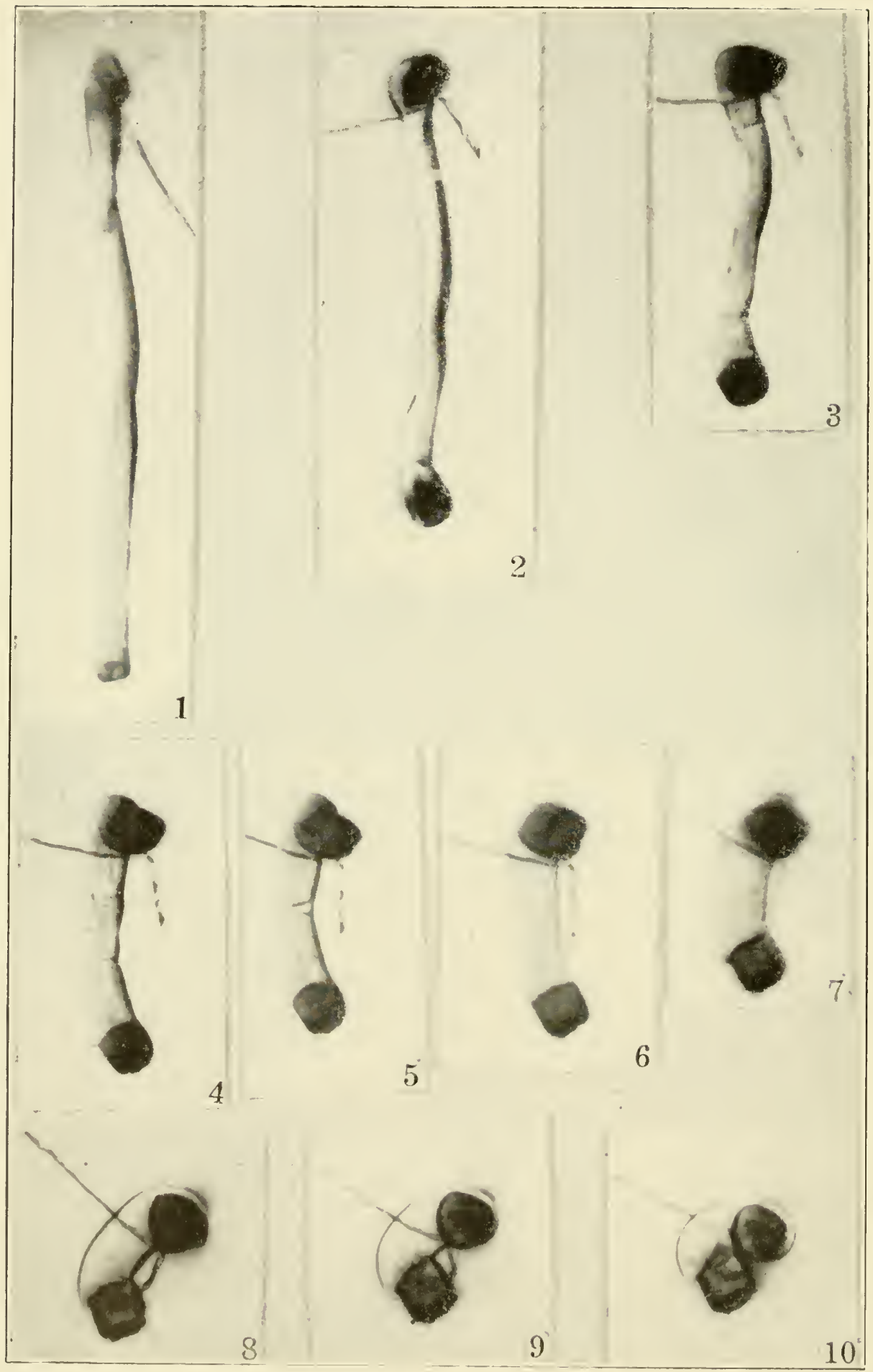

Fra. 5. Slortening of an isolated frog muscle fiber in isosmotie raleium rhloride solution. The sucesssion of stages is from left to right, as on a printed page. The first plotograph was taken in Ringer 's fluid; the second, 10 seeonds after the addition of ealoimm ehloride. Subsegnent piotures were taken at 10 second intervals. 
isolated musele fibers and I hope nur andience will pardon me if I speak of this work with somewhat more enthusiasm.

A single muscle fiber is a rather metty preparation. The fibers I worked with were dissered from the adluetor magmons muscle of the loow. In this I was fortunate to have the help of Dr. E. IV. Ashkenaz, who is an expert at such dissection. The fibers are cut to a convenient length (they may be an inch or more long). At the "ut ends a plue forms. The plug at the cut end of a muscle fiber in all probability represents a surface precipitation reaction. Apparently the formation of the plug is dependent on calcium ion, but more work needs to be done betore this can be definitely established.

If isolated muscle fibers with cut plugged ends are placed in solutions of isosmotic alcinm ahloride, an interesting phenomenon occurs, the fiber rapidly shortens. So meat is this shortening that after two or three mimutes the fiber is only a little over a fourth of its original length. The effect is due to an entrance of calcium into the protoplasm of the fiber: if the fibers are immersed only partially, so as not to expose their ends to calcinm solution, no shortening occurs; on the other hant, if only the ends are exposed, the shortening is as vigorous as usual. If one follows the progress of the shortening under the microscope, it an be seen that bit by bit the protoplasm of this fiber is converted into plug material (Fig. 5). Proceeding from each end, the plugs grow inward, until the entire fiber is transformed into a lifeless, brownish-black mass of phor material. This simple experiment shows two things. In the first place, it provides a striking demonstration of the fact that caleinm ion is capable of making the muscle protoplasm shorten to the rery maximum of shortening. And in the second place, it also indicates that this shortening reaction is a species of clotting or surface preeipitation reaction. For as the muscle protoplasm becomes shorter, it is directly converted into a plug, and it has ahready been urged that the formation of the plug is a species of surface precipitation reaction.
We see, therefore, that the isolated muscle-fiber experiment offers support for the seeond half of ont theory of stimulation. The protoplasm of musele cells is extraordimarily and peculiarly sensitive to calcinm. Aside from barium and strontium, other ations do not act in this way. Iet me take time for a minute to ansillel the effert of magnesinm ion on the isolated muscle fiber. Yon may remember that in the case of the surface precipitation reation in the seaur.hin exw, mannesimm acted like calcinm. but in far weaker fashion. So, too, in the casc of the muscle cell. Calcimm can act in dilution. Thus, for example, solutions of calcium chloride one-half or even onefourth the strength of isosmotic solutions cause rapid shortening of the muscle protoplasm. On the other hand, dilute solutions of magnesimm chloride canse no such effect. Indeed, when a fiber is immersed in a solntion of magnesinm chloricle of one-half the isosmotic strength, the first noticeable change is a lengthening of the fiber. However, in a solution five times the isosnuotic strength there is a rapid shortening. In other words. if magnesinm is sufficiently concentrated it can act like calcium. This is in accord with experiments on sea-nrehin egges.

There is hardly time to comsider other' obscrvations on isolated muscle fiber's.

One point which I shonld perhaps mention is that the fibers behave very much like the Nereis ege in that their irritability is to a large extent lost when they are immersed in solutions which tend to remore calciun. Thus this study of muscle fibers lends support to the first half of the stimulation theory, as well as to the second half.

In this rather long talk, if I have done nothing else. I believe I have shown you the reneral similarity in the behavior of valious trpes of living aells. We have skipped albout from amebae to exg colls to muscle fibers. In all these protoplasmic srstems, so different in external appearance, the colloidal behavior of the protoplasm is essentially similar, and can, I believe, be interpreted in terms of our theory. Protoplasm is sensitive to radiation, to the electric (rurent, to mechanical impact, be- 
canse it has a sensitive cortex which on stimulation releases calcinm to the interior. This calcium then produces a reaction akin to blood clotting, a reaction which is inhibited by dilute solutions of fat solvents.

The theory that I have proposed has much still to explain. If it is correct it will serve as a guide for the study of the colloidal interpretation of protoplasmic behavior. But at best the theory is only a bare outline, and there are huge waps which remain to be filled in. Each phase of the theory requires amplification, and there are dozens of musolved problems which stare ns in the face. For example we are constantly inquiring as to the mechanism of calcium release from the cortex, and we are also busily trying to interpret various aspects of the clotting reaction, aspects which I lid not have time to discuss with your. Moreover, we have hopes of relating calcium release to the electric phenomena which typically acoompany excitation. These are but a few of on problems. The fact that the theory sugrests these problems is a point in its faror. Right or wong, the theory deserves discussion and test, for at the present time, in view of the recent papers which have done much to demolish the experimental support for the permeability theory, there is really no other theory to tie to.

\section{References Cited}

Angerer, C. A. 1936. J. Cellular Comp. Physiol., $8: 329$

— 1937. Anat. Rec., 70 Supp.: 52.

Churner and Klein. 1937. Biol. Bull., 72: 384.

Dahlgren. 1915. Carnegie Inst. Tash., Pub. To. 212: 213.

Daugherty. 1937. Physiol. Zool., 10: 473.

Heilbrunn, L. V. 1928; 1937. The Colloid Chemistry of Protoplasm. Berlin; An Outline of General Physiology. Philadelphia.

- 1934. Biol. Bull., 66: 264.

Heilbrund, L. V. and Daugherty. 1938. Physiol. Zool., 11: 383.

- 1939. Thysiol. Zool., 12: 1.

Mazia and Clark. 1936. Biol. Bull., i1: 306.

Moser. 1939. J. Expt. Zool., 80: 423. 


\title{
STRUCTURAL UNITS IN CELLULAR PHYSIOLOGY
}

\author{
By J. D. BERNAL
}

BIRKBECK COLLECE, LNIVERSITY OF LONDON, IONDON, ENGLAND

THE approath to the study of biologieal structures has been along two converging lines. Through the gradnal improvement of the mieroseope the struetures of tissues, and later of cells themselves, have been ehueidated down to the limits of optical resolution. The second approaleh has been through chemistry, the fimling of the ultimate molecular constituents of solid and fluid tissues, the analysis of more and more complex compounds, and the study of reartions between them. These two lines have get to make contact and the gap between them is still large and particularly significant. The simplest way to express it is in terms of actual scale; even the ultraviolet microscope cannot determine the structure of anything much smaller than 2000 if or $0.2 \mu$, and pure chemieal analysis cannot determine the structmre of a molecrule much larger than $20 \mathrm{~A}$ or $2 \mathrm{~m} \mu$. It is the gap between these dimensions that the new physico-chemieal methods have to fill. It is a rery important gap because in it are found both the larger molecules-those of the proteins that are fundamental for biological processes-and the micellar structures which determine the visible microstructure of cells and tissues. The first approach to this study was that of colloid chemistry and physies. By colloid studies, particnlarly those of the nltracentrifuge and of electrophoresis, we have obtained a general picture of the behavior of matter agoregated in units which lie in this range of dimensions. But until the development of more recent methods this picture was indirect and lacked the sharpness of either the microscope or the chemical evidence. X-rays with their shorter wave length enable us to detect and measure any regularities which occur in the region between $2000 \mathrm{i}$ and $2 \AA$, and from the knowledge of these regularities to build up a picture of the structure itself. This method still lacks the directness of the mieroseope and the direet approach which may be achieved through the derelopment of the electron microscope, but it gives us the best picture we now have of the intinate structure of living materials. Recent sturlies with X-rays, particnlarly on proteins and rirnses, combined with knowledge derived from colloid studies, give $n$ s at any rate some chue to the underlying structure of many of the appearances of living cells which are presented in the microscope.

It must be realized that these explanations are necessarily extremely tentative at this stage. They do not represent direct analyses of actual living cells, but inferences derived from the structure of more easily studied preparations particularly of fiber's, as represented by the great work of Astbury, and of erystalline proteins and viruses. The suggestions put forward here must be considered therefore as purely speculative, intencled to guide the procedure of researeh rather than the claim to be verifiable explanations of the facts.

The earlier work on eell structure las dealt with the more inert parts of the cells, particular?y cell walls, whether it be cellulose or keratin, and the structures derived from them. We have throm the work of Sponster, Astbury and Preston a fairly accurate picture of the underlying molecurlar microstructure of such cell walls and even some hint as to their mode of deposition. It is possible to a a little further and throw light on the intermediate intercellular structures, snch as those of muscle fibers. The myosin of muscle fiber is, as Astbury has shown, essentially a contracted keratin-like fiber molecule which only differ's from the cell-wall keratins by the fact that its degree of contraction can be varied by its environment, a property 
no donbt connected with its high degree of hydration and the relative absenre of sulphur. The difficulty of explaining intracellular structures in general has lain primarily in this great degree of hychation.

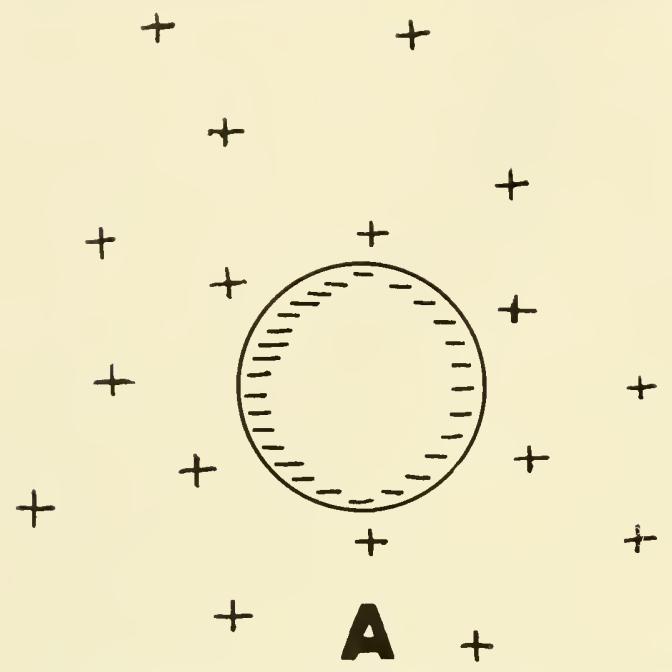

Fig. 1A. Single ionic particles with ionic atmos phere (ions of opposite sign not shown).

It is difficult to explain the presence of any structure in a cell containing 80 to 90 per cent of water, and until very recently all hypotheses as to intracellular structure, fibers, foams, etc., eonld not receive any physicochemical explanations, as the actual structures observed were in most cases artefacts plainly due to the method of preparation of the specimen.

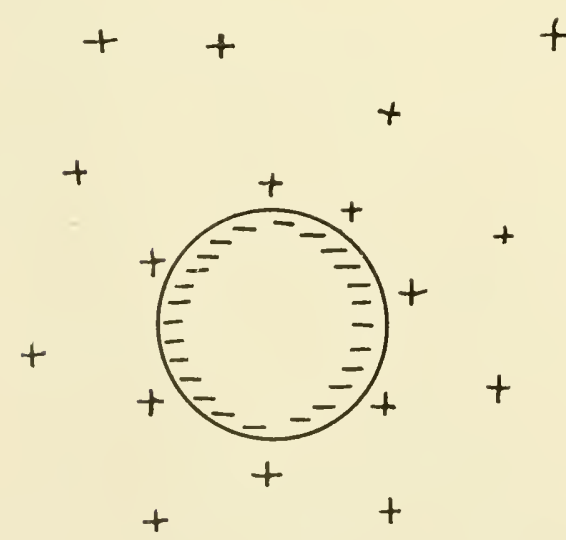

We now have, however, what may be the first clue to the intercellular structures of this intermediate degree of complexity. Theoretical studies of colloids, particularly those of Langmuir and Lerine, combined with the quantitative data provided by the oriented sols of tobaceo mosaic virus have shown indisputably that interparticle forces sufficient to maintain structures ayainst thermal ayitation do exist and that they are susceptible to quantitative theoretical explanation. These long-range forces have long been suspected, but the mechanism previously proposed for them. polarization of water molecules (LondonVan der Waals forces) were plainly physically unacceptable. The clue to the natme of these forces was found in the ionic atmospheres which, according to the DebreHïckel theory, must surround every charged particle in an electrolyte. For a large particle, such as a protein molecule. this atmosphere extends to a distance of the order of a few times the particle diameter (Fig. 1). When two such particles approach one another, the interaction of the charges of each particle on the atmosphere of the other produces, at wreat distances, an attractive force; at smaller distances the interpenetration of the atmospheres makes this force repulsive. In general the interaction between the two partieles can be expressed by the familiar potential energy arve (Fig. 1 D) which
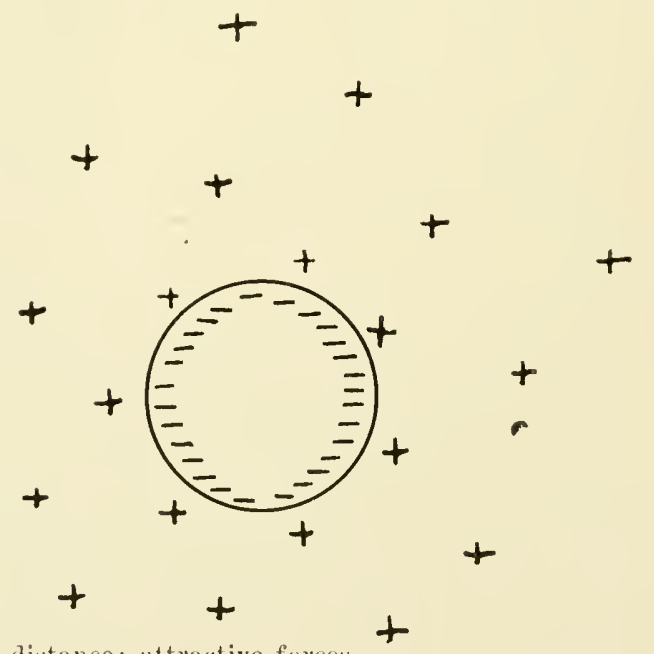

FIG. 113. 'T'wo similar particles at a distance; attractive forces. 
has a minimmm at a definite distance of equilibrium. The physical significance of this equilibrium depends, howerer, on the enerey involved. For two spherical particles of the dimensions of a large protein molerule, diameter $100 \mathrm{i}$, this minimm is of the order of 0.1 of the thermal enerory and eonsequently no equilibrim results, the total effect of the forces being to prevent agrolutination. The situation is very different, however, with larger particles and especially with elongated, needle- or plate-like particles. In this rase the enelor of equilibrium may be much mreater than $k T$, with the result that a stable equilibrimm oecurs at ordinary temperatures.

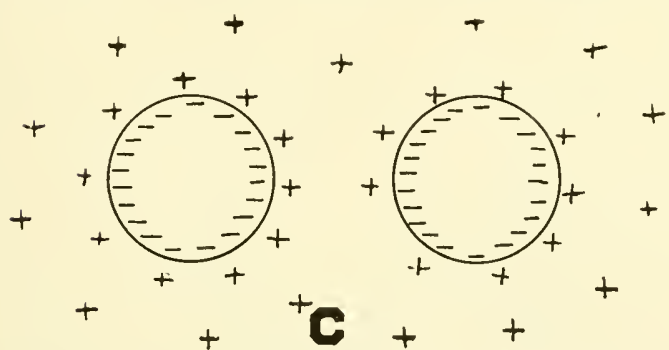

Frr. 14. Two similar particles alose together; lepulsive forces.

This was first olserered in tobareo-mosaic vimus, where the long particles maintain themselves in a regular hexagonal array (Fig. 2), even down to dilutions of about a per cent dry matter; that is, when the particles are $800 \mathrm{~A}$ apart. In the case of flat particles the equilibrimm is even more stable. The existence of these forces furnishes an explanation for the iridescent ferric-hydroxicle gels, which comsist of flat particles in equidistant layers that may be as much as 5,000 i apart, of of the order of the wave length of visible light, so that their regularities wive an effect similar to that of butterfly wings. T'hese long-lanoe Lantmuir-Levine forces are extremely sensitive to changes in the concentration or pH of the medinm, and here we have a mechanism ideally snited for the developments of easily transformable fluid and ret definite structules such as we observe in living rells.

$A$ eharacteristic featme of these forees is the appearance of spindle-shaped bodies, msmatly called tactoids (Fig. 2). The shape of a taretoin depends on the existence of orientation of the long particles on a flee surlace, and thus on the production of a surfares terssion which is rifferent in the two clirections of that surface. The shape ran be ruantitatively aceomuter for on this hypothesis. Romehly it may be said that the spindle shape depends on the lelative ease with which the surface cant be bent on

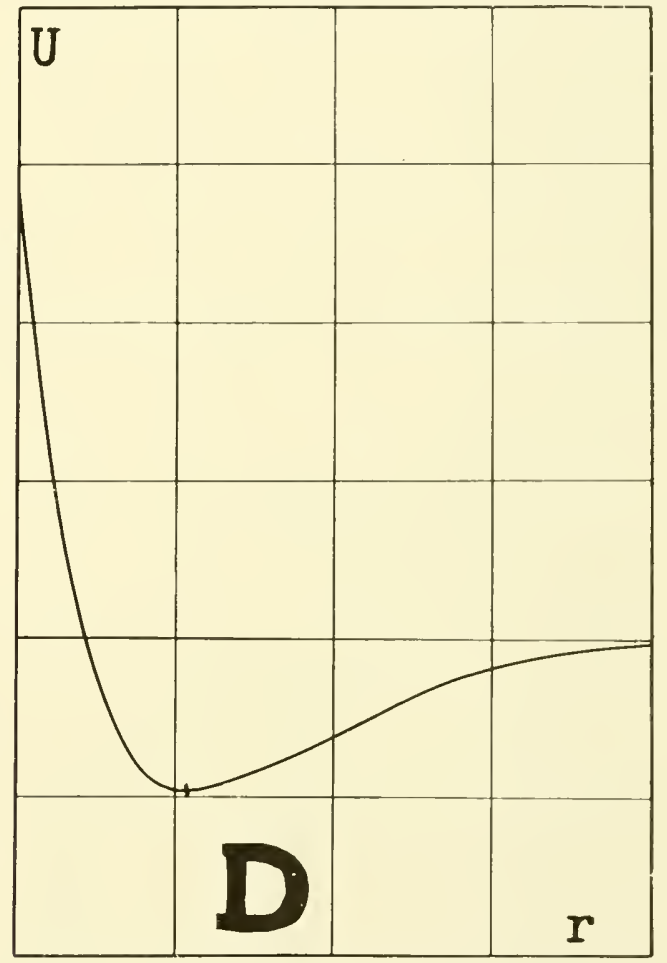

Fig. 1D. Potential function, Ordinates, potential $\mathrm{U}$; alsorissas, distances $r$.

an axis parallel to the long direction of the particles compared with that of bending it along the axis perpendicular to them. such tactoids have been often observed in liring strurtures, the most striking ase being that of the spindle found at eertain stages of mitosis. Pfeiffer was the first to sugerest that this spindle is probably a tactoid, and that the fibers of which it is molmally smpposed to be composed are artefarts formed by the dehrelration action of the fixing medium. The study of tobaceomosale tactoids confirms this sucrestion; in this case, also, fibers are formed which 
follow the lines of orientation of the equally-spaced virus particles.

The theory of tactoids makes it possible to go a long way in the explanation of the mechanism of cell division, for it provides secondary forces affeeting the poles of the tactoids which are due not to any inmediate reaction between these poles, but to the whole field of orientation of the tactoid itself. These forces overcome the difficulty implicit in the earlier crude electrical or diffusion theory of spindle formation because they admit of consiclerable geometrical variation; they do not aet in straight lines but along the flow lines of the long partieles and consequently may follow curved or even sinnous tracks. Not only do long particles suspended in an unoriented medinm tend to form taetoids, but any enclosure of this medium in the tactoid itself takes on a tactoid shape which may be termed a negative tactoid (Fix. 2, B). The poles of the negative tactoid lave a tendency to move apart as the orientation of the tactoid becomes more pronounced, and also tend to move bodily into the equatorial plane of the original tactoid. On the basis of a few rery simple hypotheses, it is therefore possible to give a simple accomnt of the external mechanisms of cell division :

1. That the cell (probably the nucleus) contains protein material which under snitable ionic and chemical conditions aggregates into long particles of dimensions of the order of $1000 \AA \times 100 \hat{\Lambda}$.

2. That structures exist in the cell toward which these particles tend to set themselves at right angles, i.e., cell walls, centrosones, and rentromeres.
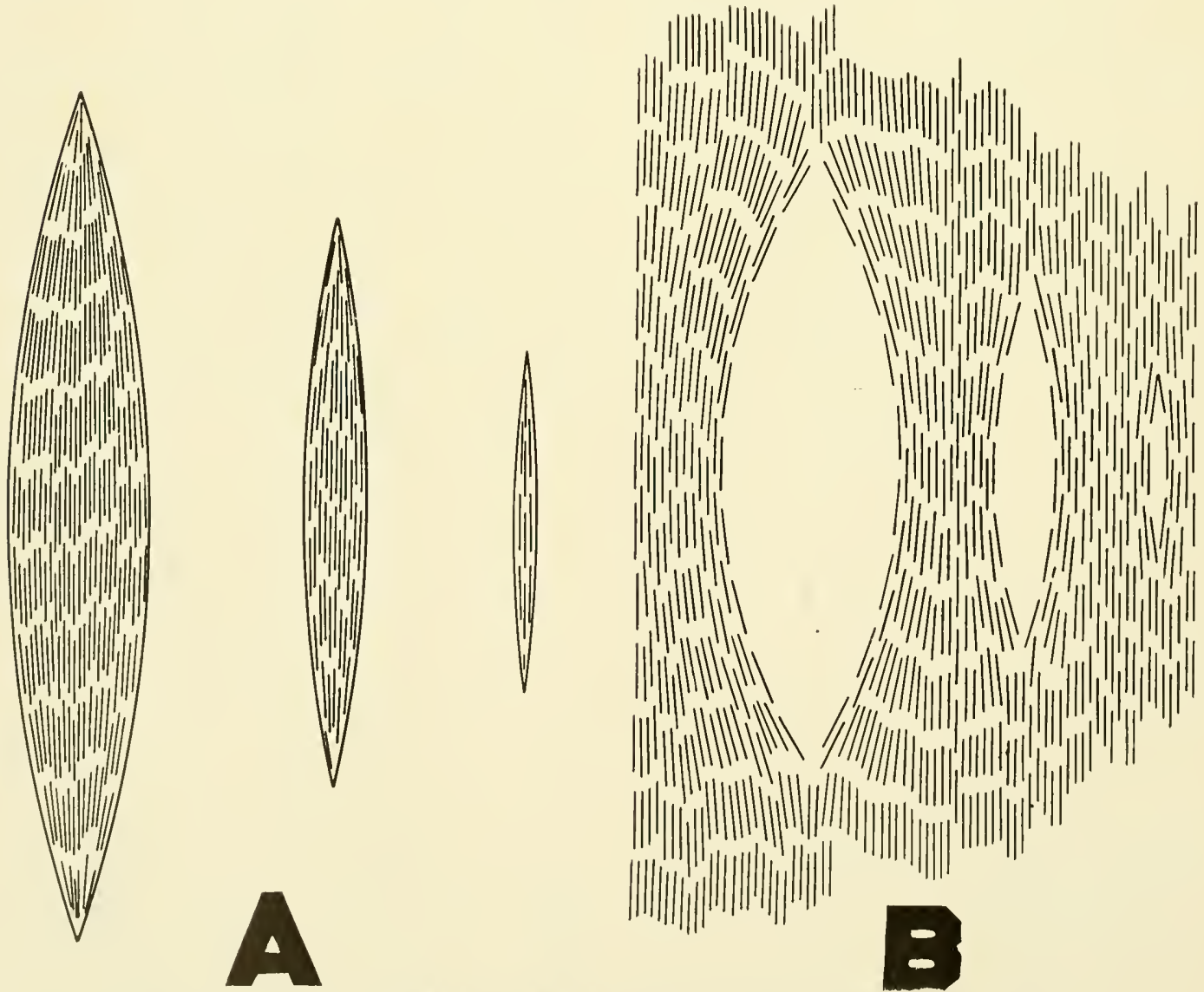

Fra. 2. Tactoids of different sizes. A, positive tartoids; P, negative tactoids. 
3. That the chromosomes in the region near the centromere are capable of liberating material which disagregates the long particles in its immediate vicinity.

4. That there are progressive chemical ehanges of a crelical nature which first tend to lengthen and later to break up these long particles.

The mechanism of cell division would then proceed as follows (Fig. 3). From
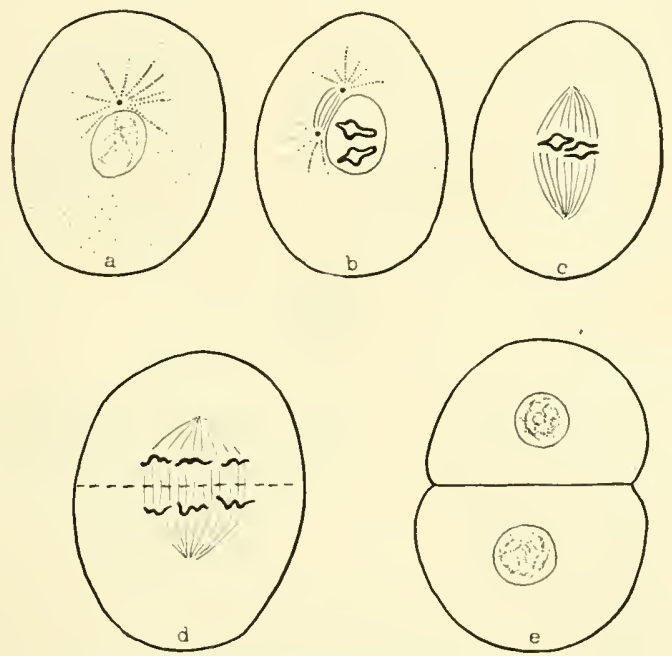

Fig. 3. Mechanism of cell division.

the rentrosome a wave of orientation wonld result first in a physical aster (a). The division of the centrosome, dne to instability in the field of these forces, wonld next lead to the formation of a spindle (b). At the same time, the centromeres having divided, small negative spindles wonld be formed aromid each of them. These negative spindles would be then drawn into the efunatorial plane of orientation parallel to the main spindle (c). In cases where the main spintle is not formed, subsicliary spindles would simply be arranged in parallel. As the elongation of the particle proceeris, both the positive and the negative spindles woukl grow in length, driving the now divided chromosomes farther and farther apart, and leaving an area of parallel oriented material between them (d). Finally, the long particles would break up into short ones and the process wonld pass into the next resting phase (e). The formation of a dirjoling cell wall would seem to be closely linked with the existence of the lone particle field, as it tends to grow perpemdicular to the fiber direction. The evidence for the tanth of this picture is still very scantr. The existence of a positive tactoid is, lowerer, fairly safe, as it is narked in living cells by its birefringence. For the negative tactoid there is much less evidence; some photowraphs do, howerer, seem to show that the remaining fibers at amaphase seem to be located not on the lines joining the chromosomes but in the areas between them, as the existence of negative tactoids would demand. The whole picture at this stage is much too arude and takes no account of the very large variety of methods of division fommd in cells, but it may be a useful starting point for renewed study of the details of these mocesses.

It is possible to extend the application of the idea of long-range forces to cover even more complicated intercellular processes, namely those connected with the pairing and movement of the chromosomes themselves. But here, naturally, explanations are necessarily even more sperulative than in the ease of the spindle mechanism. Chromosomes are known to vary in length by a factor of the order of 20 at various stages of mitosis. In its most extended form in the resting stage or in the salivary gland, the chromosome appears to be in every respect a trpical fibrous motein, micromolecular or perhaps microtactoid, probably composed of alternate protein and nurleoprotein romponents. The character of any structure having a linear arrangement in a solntion will be such that any change, particularly any change on the interface, must canse the structure to lengthen or shorten. If it has, besides, an internal structure of an unstmmetrical kind, this shortening will take the form of spiralization. Therever conditions favor small surfaces, the spirats will be elose, and vice versa.

The interaction of different chromosomes can be at any rate partially accounted for by the long-range forces che to their ionic atmospheres. As has already been said, 
these forces are attractive at long distances even between like particles. The difficulty is to explain why, in meiosis, chromosomes pair and in their pairing come together so as to bring all the corresponding parts into contact. At first sight it seems impossible to postulate a mechanism of any physical character to aceount for this, but a consideration of the mutual energy of configurations may throw some light on it. The chromosomes are known to cousist of alternate segments containing more or less mucleoprotein, the width and oreler of sncression of which is its specific character.
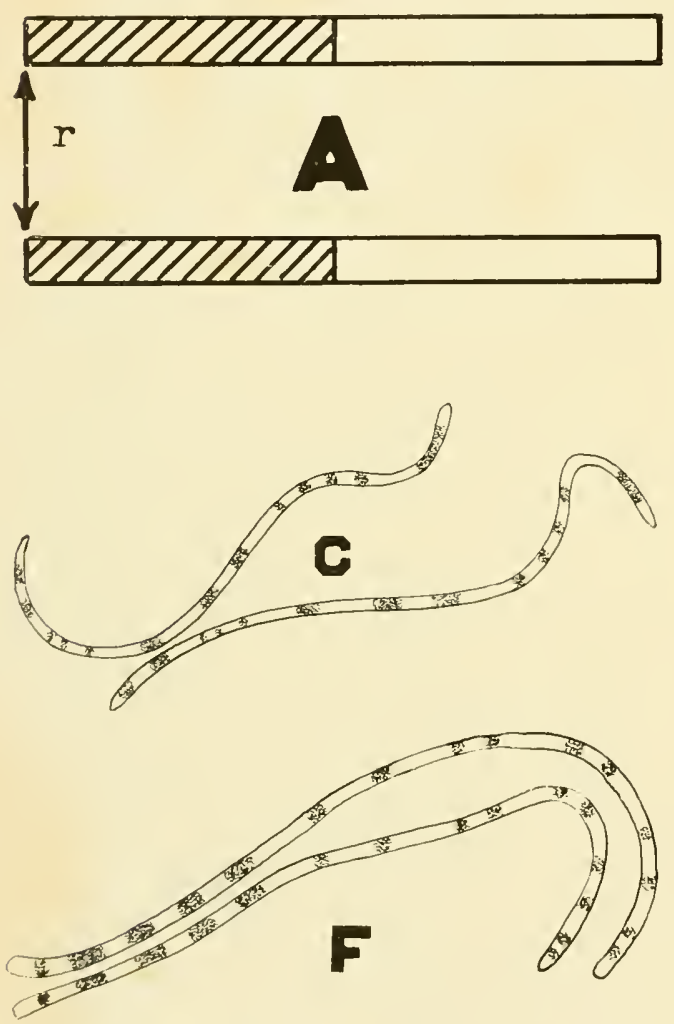

Now the energy of interaction between nudeoprotein parts of chromosomes and nonmucleoprotein parts is bound to be different. It we make the reasonable assmuption that this energy of interaction depends on the products of some character of the parts interacting dirided hy some function of the distance between them, then we have for the energy interaction hetween two nucleoprotein parts the value $-a^{2} f(r)$; for two non-mucleoprotein palts, $-b^{2} / f(r)$; and for a nucleoprotein part and a non-nucleoprotein part $-a b / f(r)$, where $a$ and $b$ stand for a specific coefficient of the num-
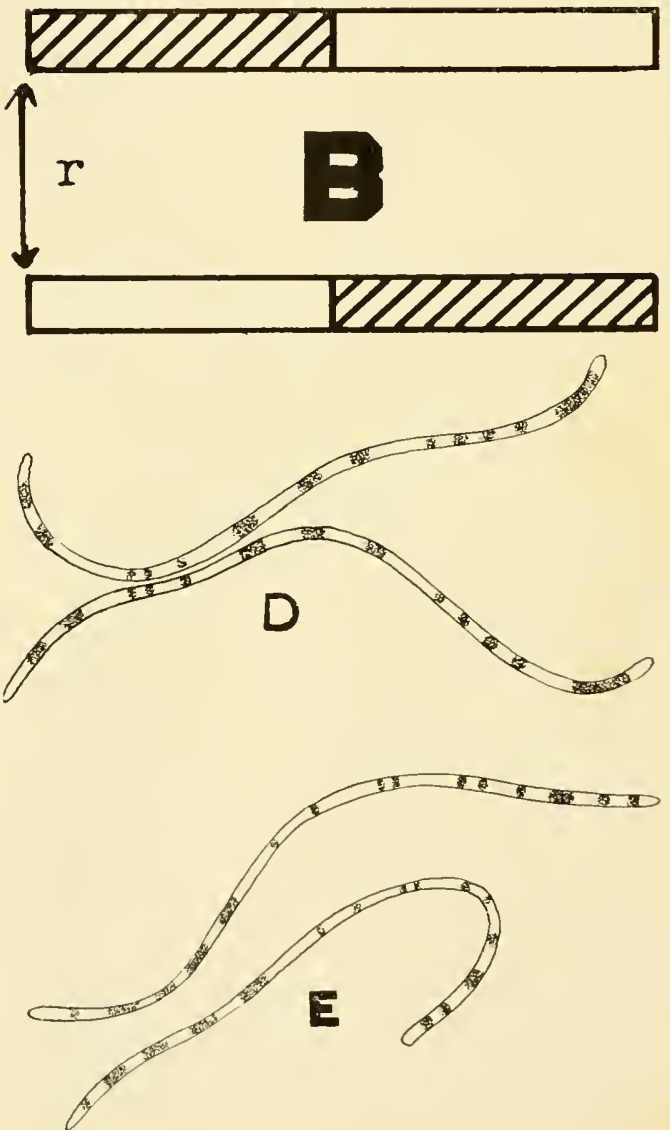

Fifi, f. Diagrams illustrating the approach of chromosomes in such at way that eorresponcling parts join. In Fig. 41 the long distance foree between the similar shided regments at the left is $a^{2} / f(r)$; between the similar mshated parts at the right, $b^{2} f(r)$, where $r$ is the distanee befween the segments. Therefore the total fore between the two uncleoprotein parts of fwo clumosemes is $\left(a^{2}+b^{2}\right) / f(r)$.

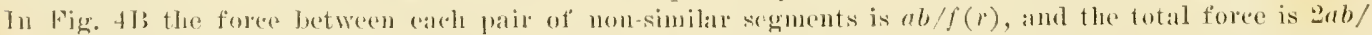

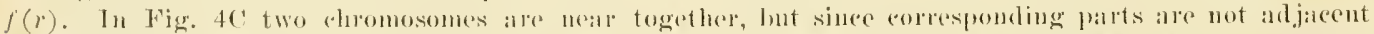

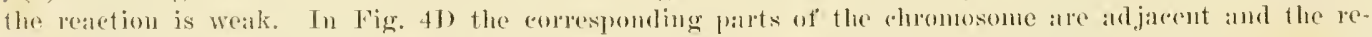
action is strong. Fig. +F shows first stage of approich in which the large nuelei ale eoming togetler. Fig. tF slows detaled anposition of a region of small muelej and other large regions coming together. 
cleoprotein and non-nucleoprotein parts, respectively. Now consider a short element of chromosome containing equal amounts of nucleoprotein and non-nucleoprotein sections (Fig. 4); it will attract a similar section at any distance, but at short range the energy of interaction will be perceptibly different when like and unlike parts come together. In the first case it would be represented by $-\left(a^{2}+b^{2}\right) f(r)$; in the second case, by $-2 a b / f(r)$. Now if $a$ and $b$ are both positive, the energy in the first case will always be absolutely greater than in the second; in other words, the degree of binding will be closer if like fits with like or vice versa. The principle is the same physically as that accounting for the immiscibility of oil and water. Water molecules attract water molecules, and they also attract oil molecules even more than oil molecules attract each other, but the greater attraction between water molecules for each other forces the oil out. Granted this mechanism, the like-to-like approximation of chromosomes becomes the position of lowest energy, but since it is only one of innumerable arrangements, it would be so improbable as not to occur if there were not a further mechanism. The chromosomes as a whole are in movement in the cell fluid, and if two like chromosomes happen to touch at some point where they have no homologous parts, we must assume that the energy of interaction is not sufficient for them to remain long in this position; if, however, the parts are homologous, the moment they touch all the other parts up and down from the point of contact will also be homologous, the process of approximation will spread, and it will be no longer possible for the thermal motion to separate them (Fig. 4, C, D). This may be called the zipper hypothesis of chromosome pairing. There may indeed be a whole series of zipper actions in the pairing of chromosomes. Two ends with any nucleoprotein will tend to line themselves up at some distance apart. Later these will find the appropriate places to enter into close union (Fig. 4, E, F). This explanation will account not only for normal pairing of chromosomes, but for abnormalities, loops, inversions, etc., where the pairing process is interrupted. It fails, however, to give a satisfactory reason why pairing is limited to two identical chromosomes, such as occurs in polyploids. Possibly further interactions occur after the conjugation of the two chromosomes which prevent the process recurring. But speculation as to its nature would seem unwarranted at this stage.

The fundamental question of the molecular structure of the chromosomes must necessarily wait for its full elucidation on the knowledge of protein structure. However, its marked similarity of chemical composition to the viruses of the tobaccomosaic type suggests that it is also a longmoleculed nucleoprotein with internal crystalline structure. This would account for its growth by addition of similar parts of an identical nature at each point. But how and why such an arrangement usually becomes unstable when it has doubled its original size, but does not always become so, as in the salivary gland chromosomes, is not easy to see. It probably depends on the repulsive element of the long-distance forces, but no system even remotely analogous to it has yet been studied.

The suggestions in this paper are put forward with great reserve, on the basis of what is at present quite insufficient evidence. It is not my intention to claim that they are the explanations of these facts, but rather to show that we have in the new physicochemical knowledge a way of providing general explanations for biological phenomena. A closer study of biological material in the light of the newer physical knowledge may give rise to other and more valid and verifiable hypotheses. My main object will have been achieved if I have shown that these methods have some contribution to make and that it would be unwise to ignore them in the attempt to understand cellular mechanisms. 



